\title{
Student perceptions of plagiarism: A study of Vietnam- and New Zealand-educated postgraduate students
}

\author{
By \\ Minh Ngoc Tran
}

A thesis

submitted to Victoria University of Wellington in fulfilment of the requirements for the degree of Doctor of Philosophy 



\begin{abstract}
This study investigated perceptions of plagiarism among Vietnam- and New Zealand-educated postgraduate students in a New Zealand university. Informed by Bourdieu's cultural capital theory, Bandura's social cognitive theory of moral thought and action, and Marginson's theory of student self-formation, various aspects of student backgrounds were explored and analysed to identify and explain factors influencing their perceptions.
\end{abstract}

An explanatory sequential mixed methods research design, qualitative dominant, was employed. The quantitative phase consisted of an online survey with 207 Vietnam- and New Zealand-educated postgraduate students at Victoria University of Wellington. Survey results informed the instrument development and purposeful sampling for the qualitative phase. 12 survey respondents with divergent understandings of plagiarism were selected for participation in a longitudinal series of interviews to seek in-depth information about their understanding and attitudes towards plagiarism, and how their perceptions of plagiarism had developed.

The findings revealed that postgraduate students held a range of different views regarding plagiarism at university. Some of them thought students were responsible for their plagiarism, viewing intentional plagiarism as a moral issue, and unintentional plagiarism as part of the learning process. The others were concerned about university's responsibilities in terms of plagiarism education and management, considering plagiarism as a form of academic cheating, and a scholarly offence. The study found multiple influences on students' perspectives, habits, and expectations regarding plagiarism, affirming the relevance of the underpinning theories. Students from diverse backgrounds possessed distinct sources of embodied cultural capital, including understanding of plagiarism. They developed moral standards through various environments that they interacted within. As they progressed through their doctoral studies, most students showed deepening understanding of plagiarism and the importance of correct practices. They actively developed their own voice in writing and strived to write with integrity. The research advances knowledge about Vietnam- and New Zealand-educated postgraduate students' perceptions of plagiarism, populations that have not been previously studied. It offers an alternative perspective to deficit models regarding plagiarism by international students by contributing rich qualitative evidence showing multiple influences on student perceptions. Findings point to practical implications to help university faculty engage with students' needs and expectations in ways that respect their diverse social and educational backgrounds and generate meaningful and productive outcomes across student groups, thus enhancing equity. 


\section{Acknowledgements}

I would first like to express my deepest gratitude to my supervisors, Associate Professor Stephen Marshall and Dr Linda Hogg for their constant guidance, support, and inspiration throughout my doctoral journey. It has been truly a great privilege and honour for me to work under their supervision. I tremendously appreciate their time, kindness, and patience in reading my various chapter drafts and thesis manuscripts. Their thoughtful suggestions, invaluable advice, and insightful feedback have significantly enhanced the quality of my research. Without their assistance and encouragement, this study could not have been completed.

Thanks to the participants for their contributions and commitment; the associate deans and school managers within faculties of VUW for facilitating the recruitment of survey participants. I am thankful to the examiners for their constructive feedback and valuable suggestions which greatly enhanced my thesis. Thank you for their appreciation of my effort and commitment.

I am grateful to Dr Stephanie Doyle for her support both before and during my PhD. It was during her Research Methods in Education course that I built on my earlier interest in plagiarism. She also organised the PhD cohort group and allowed me to be part of it. My sincere thanks to Dr Michael Johnston for his instructions on quantitative research and for walking me through my quantitative data analysis; Dr Sara Cotteral and Dr Lizzie Towl for various workshops where I engaged in the postgraduate community; Dr Lizzie Towl for running the Thesis Bootcamp 2020, which gave me a chance to make substantial progress on my thesis writing.

Thanks to Vietnam International Education Development (VIED) and VUW for supporting me financially by co-funding the VIED-VUW scholarship; VUW for the research grant that enabled my data collection and overseas conference presentations.

Thank you, the VUW cohort group and PhD students at 3 Waiteata Road for their friendship, which has enriched my international education experience and given me a sense of belonging. Thanks to Hau Trung Ho for his companionship, encouragement, and invaluable support during my studies. Thank you for being present in every up-and-down moment of my doctoral roller coaster and making my journey more meaningful.

Special thanks to my family for inspiring me to follow my dream, encouraging my endeavor, and supporting me along the way. They are the strongest motivation for me to pursue my doctoral degree at VUW. I am indebted to my parents for their unconditional love and moral support; my brother and sisters for their love, care, and encouragement. 


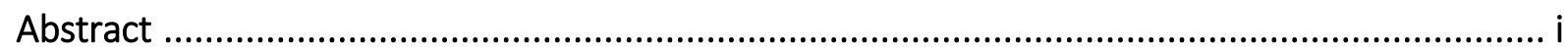

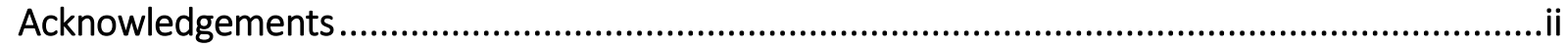

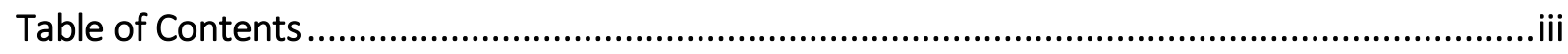

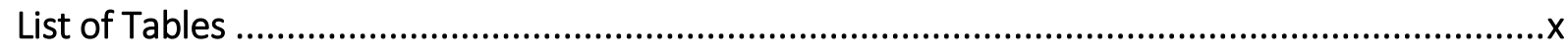

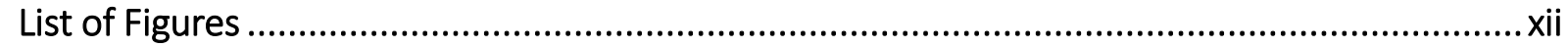

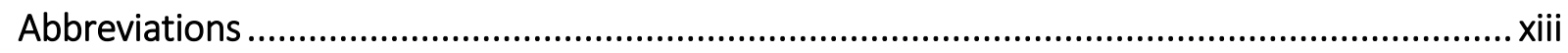

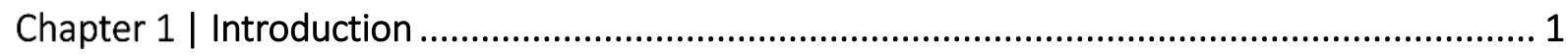

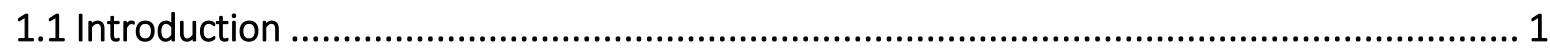

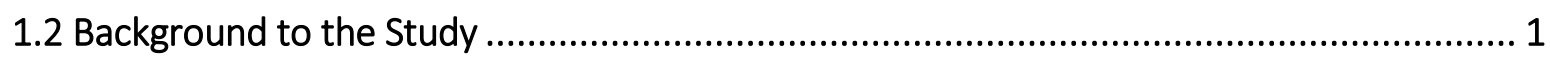

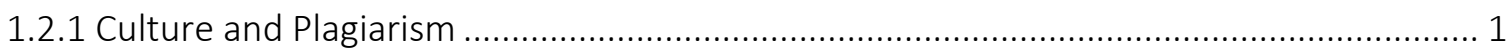

1.2.2 Domestic and International Student Perceptions of Plagiarism ....................................... 3

1.2.3 Alternative Views of Plagiarism by International Students ............................................... 4

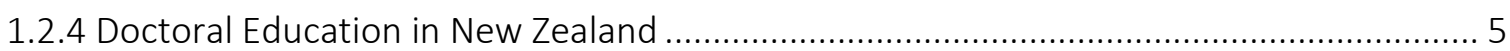

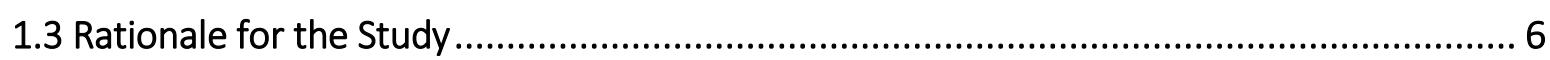

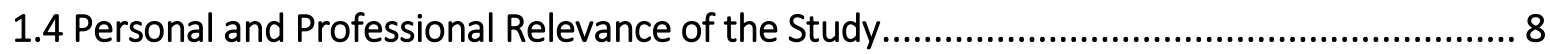

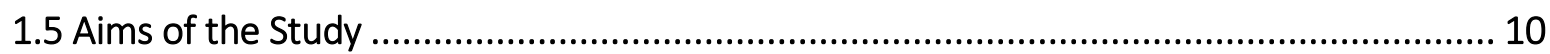

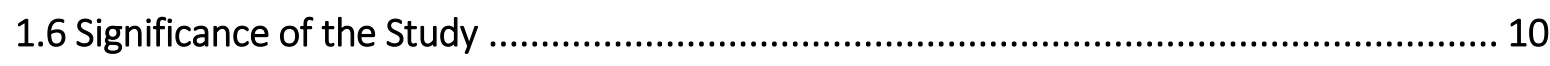

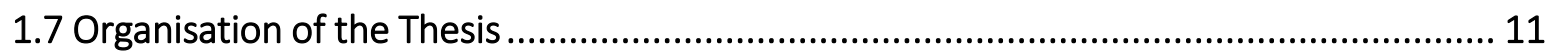

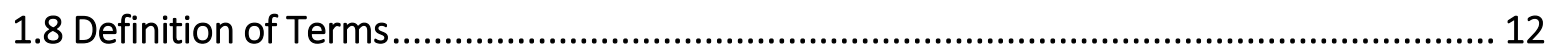

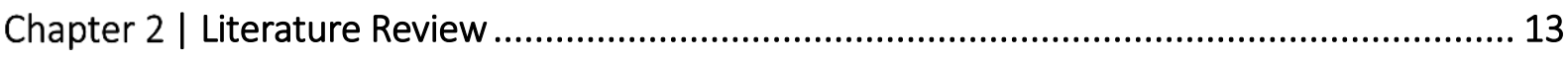

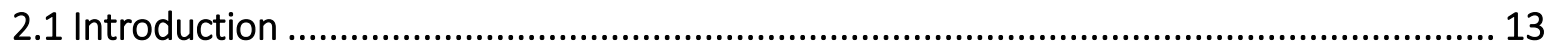

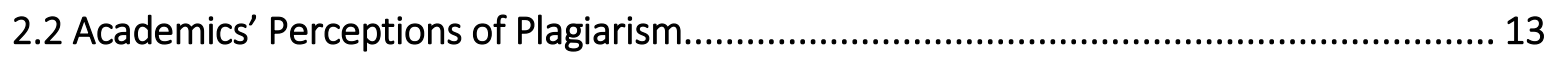

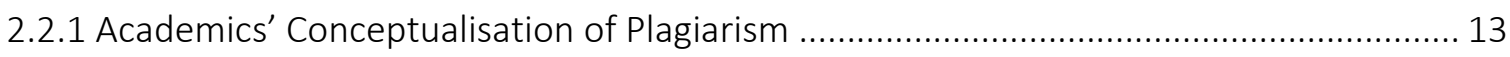

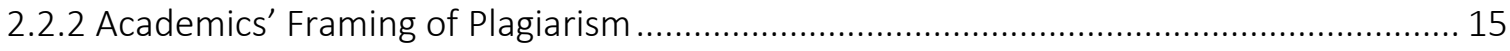

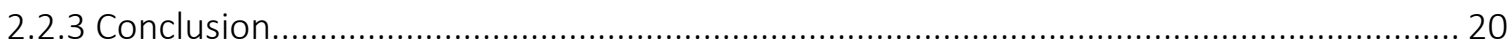

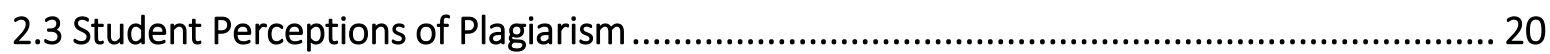

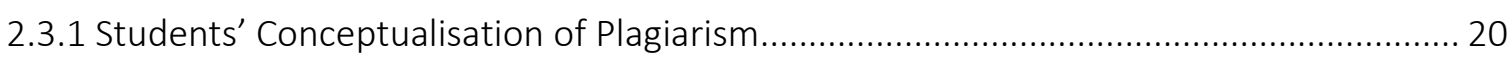

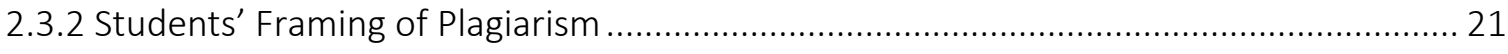

2.4 Variations in ESB and NESB Students' Perceptions of Plagiarism .................................. 22

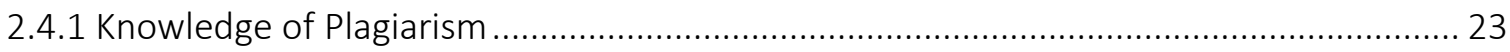

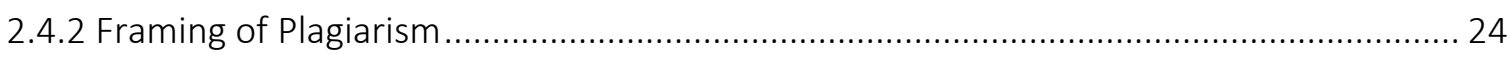

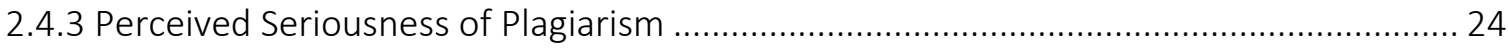




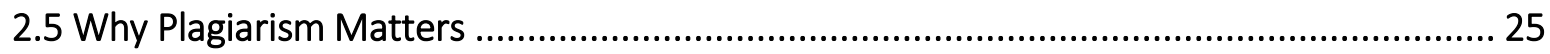

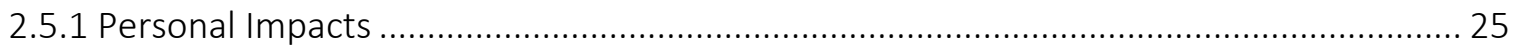

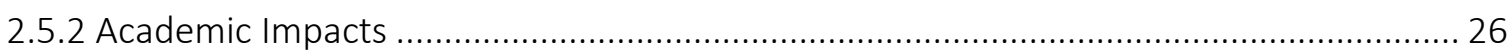

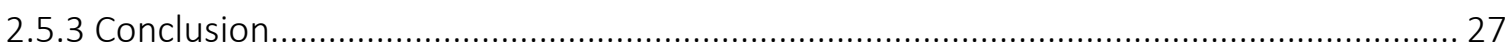

2.6 Factors Associated with Student Perceptions of Plagiarism ........................................ 27

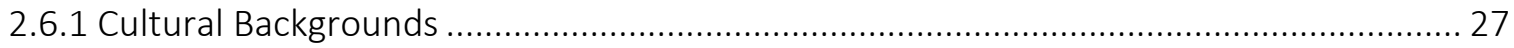

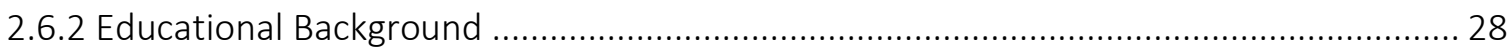

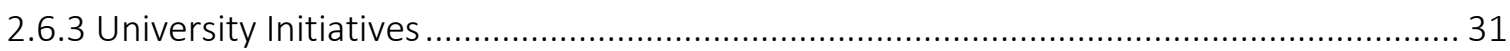

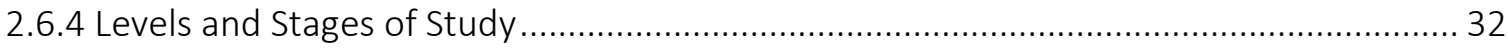

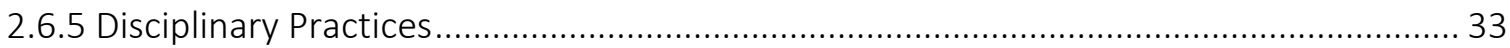

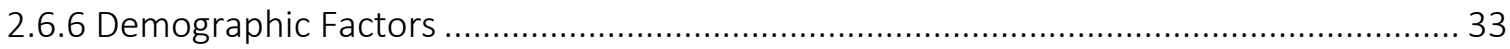

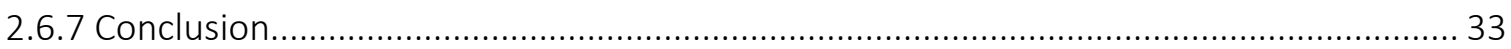

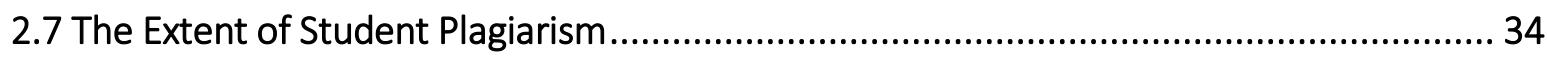

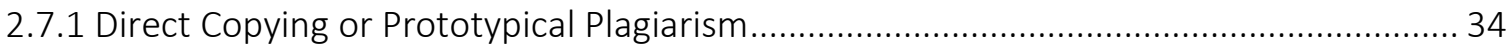

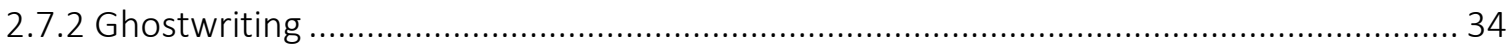

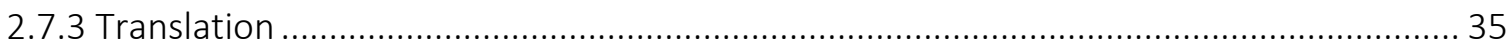

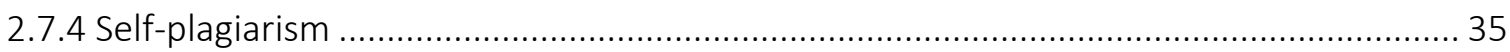

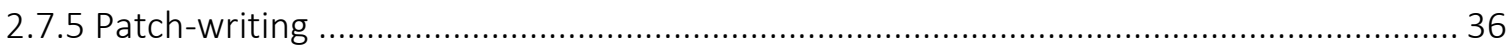

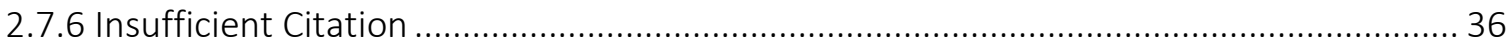

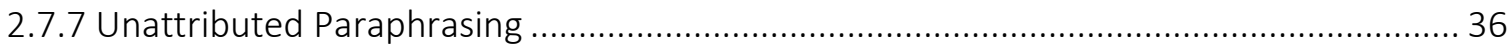

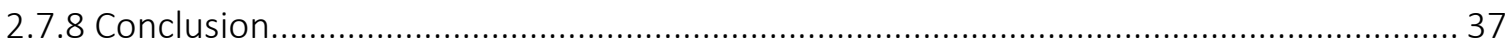

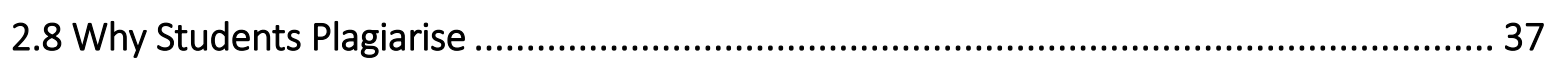

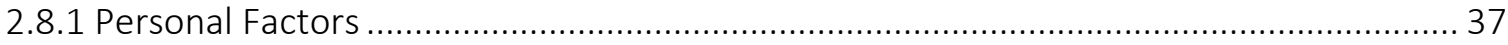

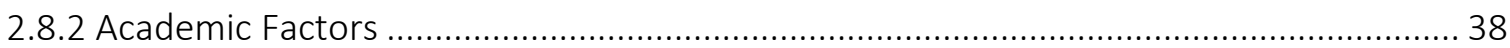

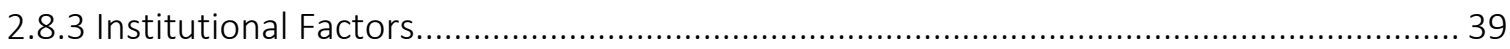

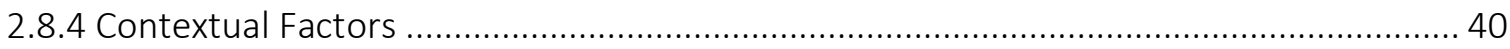

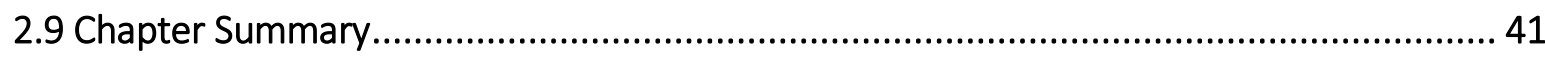

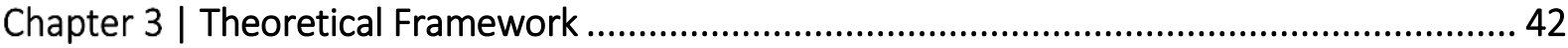

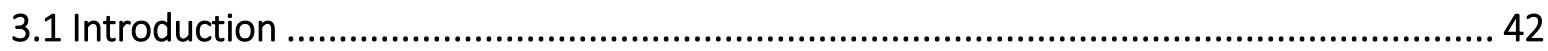

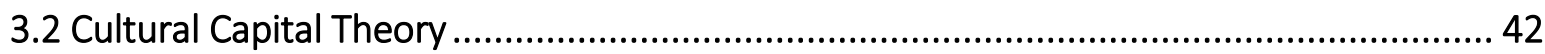

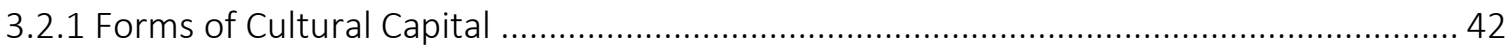

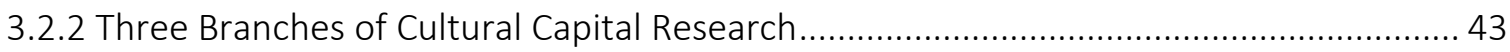

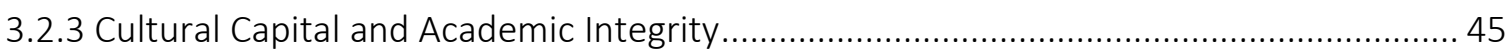


3.2.5 Conclusion

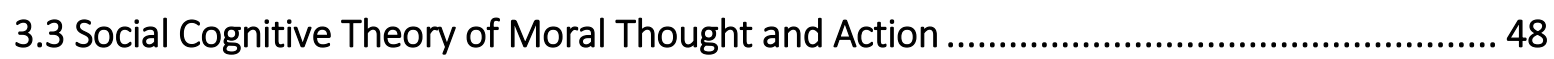

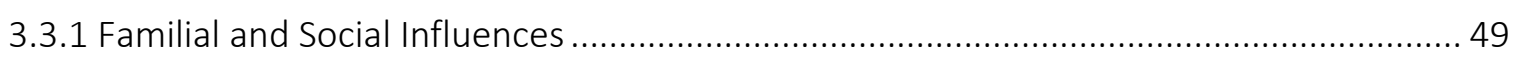

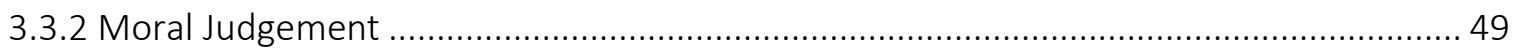

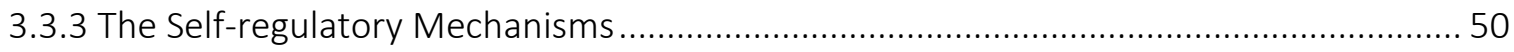

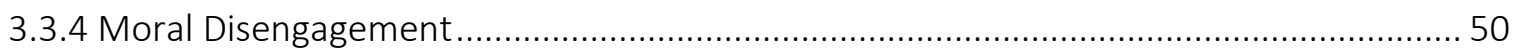

3.3.5 Social Cognitive Theory of Moral Thought and Action in Educational Research ............. 50

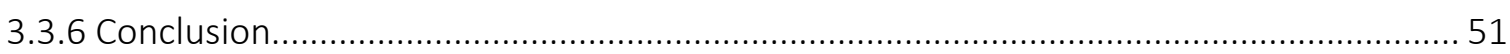

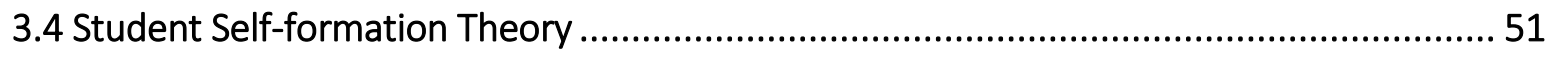

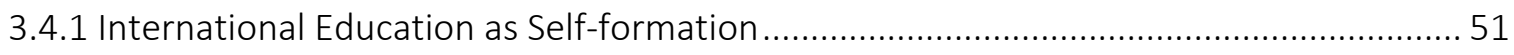

3.4.2 Student Self-formation Theory in Educational Research ............................................... 52

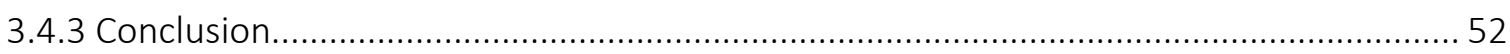

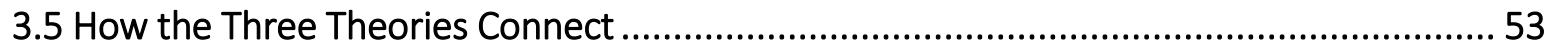

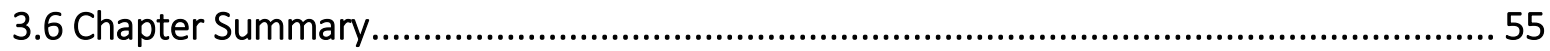

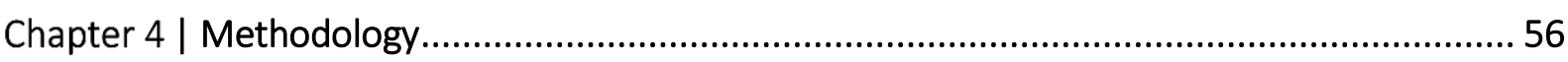

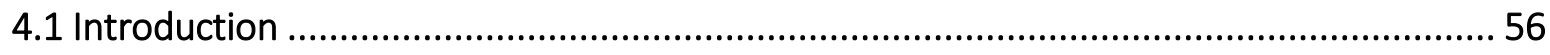

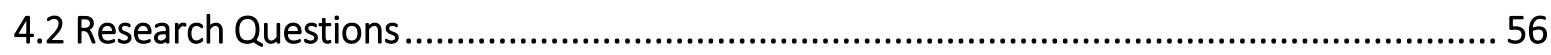

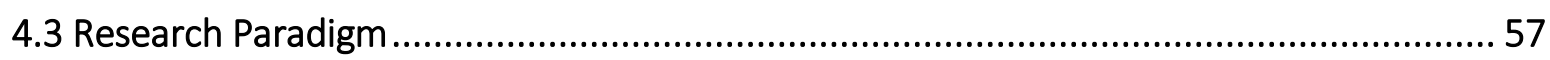

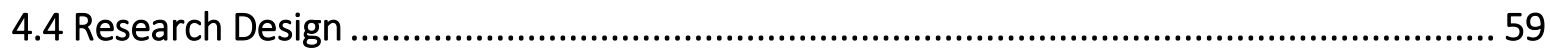

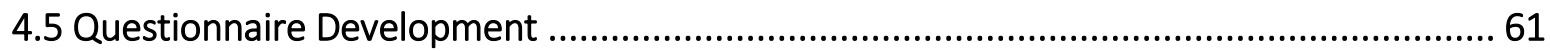

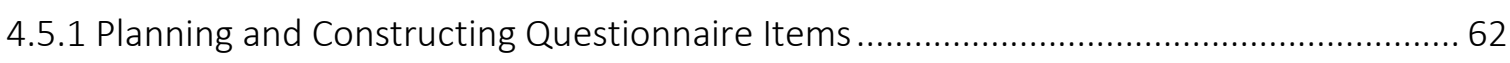

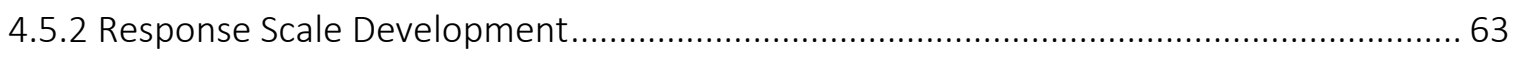

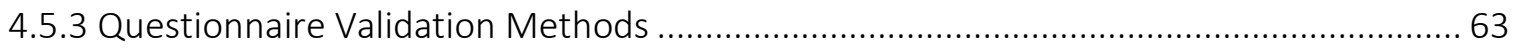

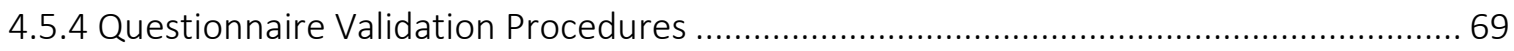

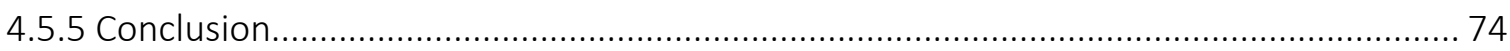

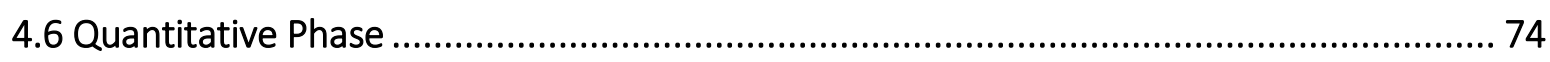

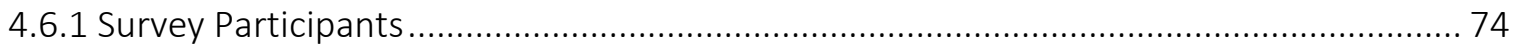

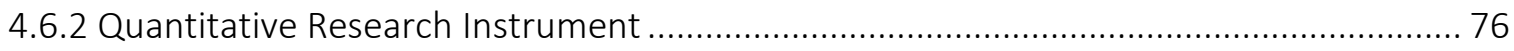

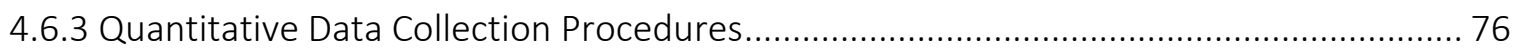

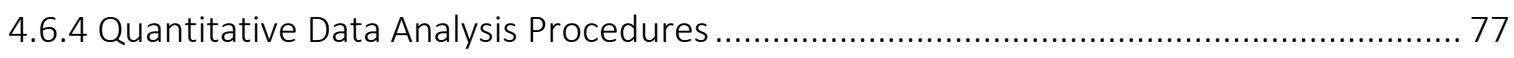

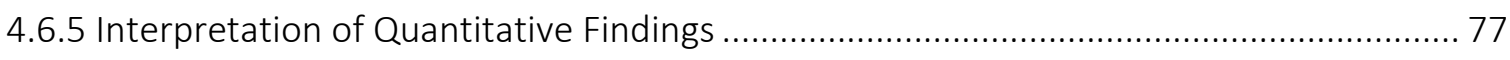

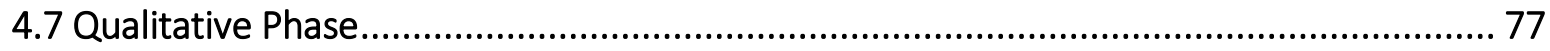




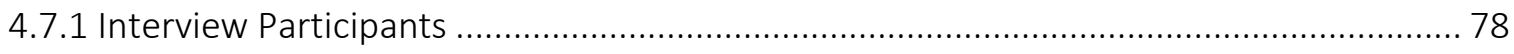

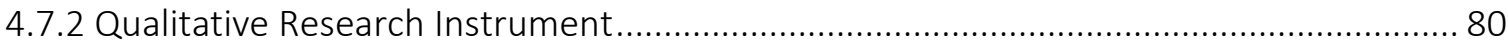

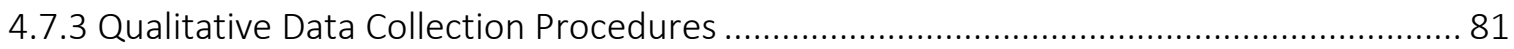

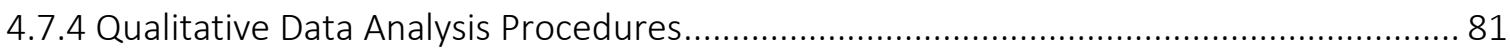

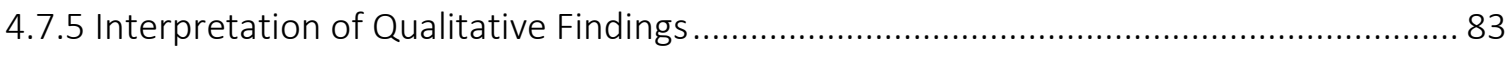

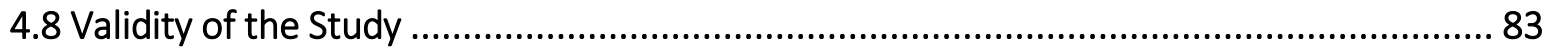

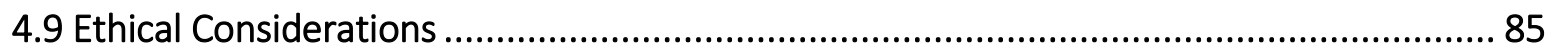

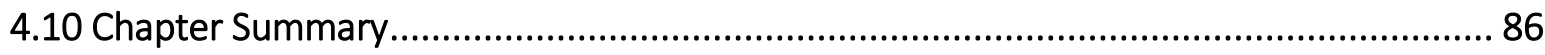

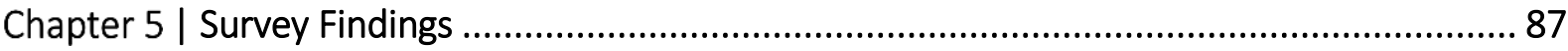

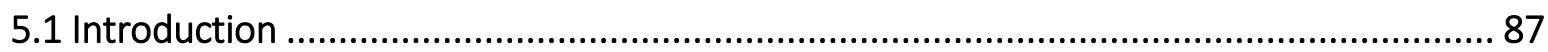

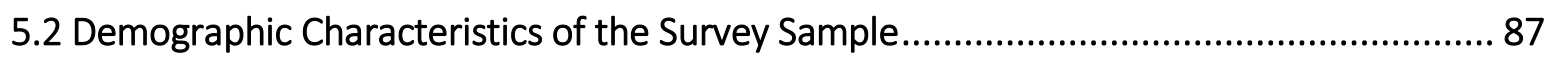

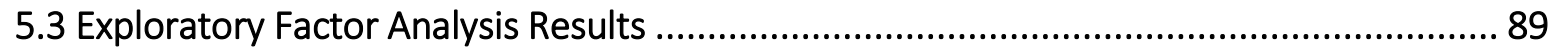

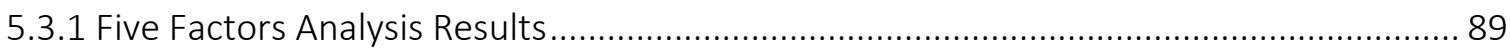

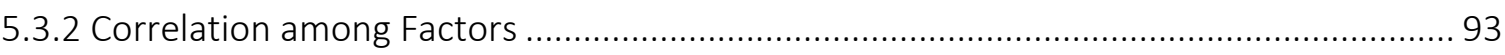

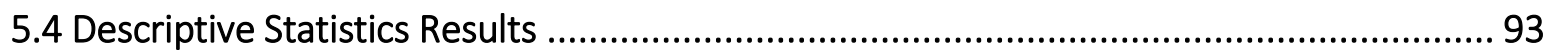

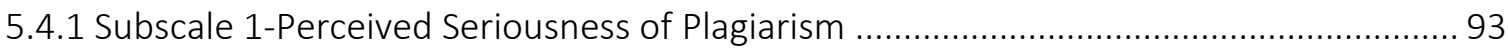

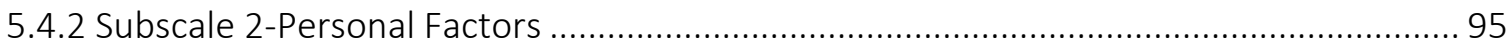

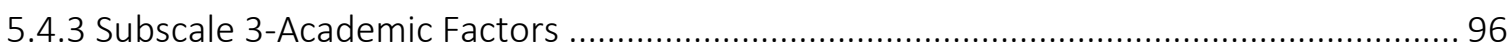

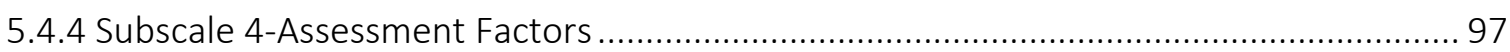

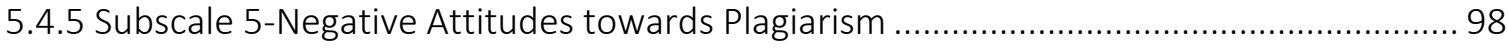

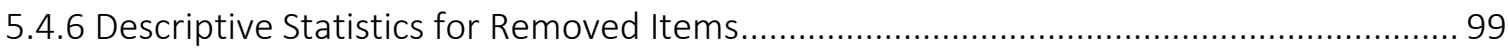

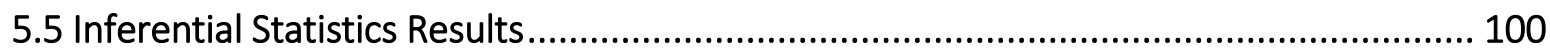

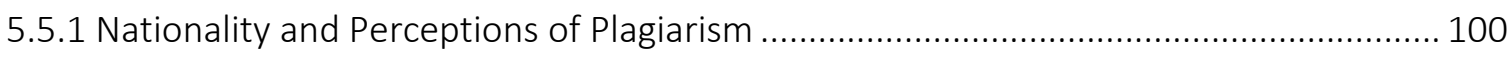

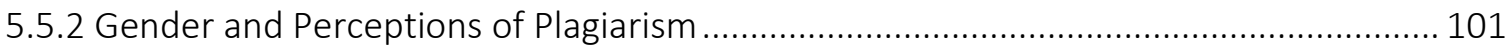

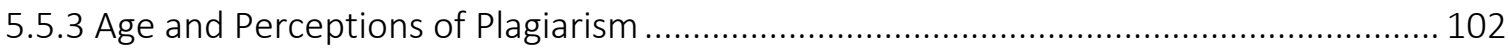

5.5.4 Employment in Teaching Roles and Perceptions of Plagiarism ................................... 103

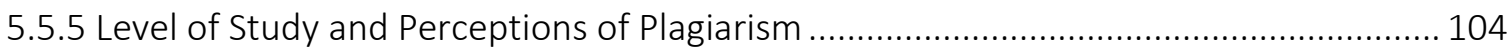

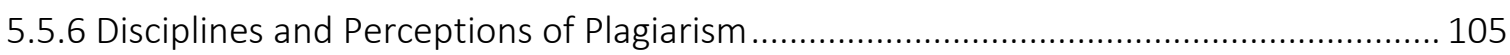

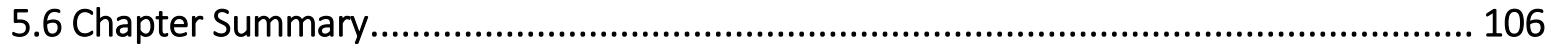

Chapter 6 | Individual Stories of Interview Participants ..................................................... 107

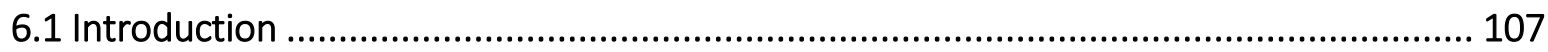

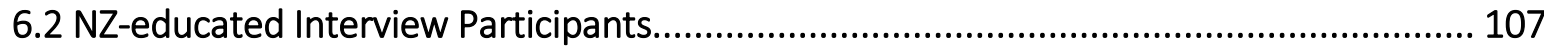

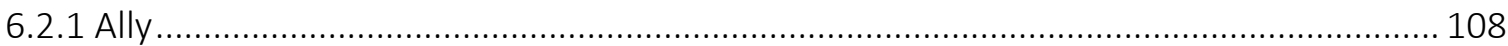




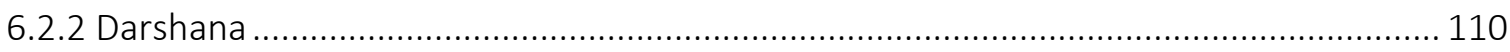

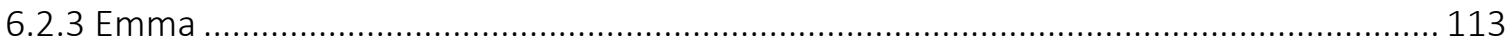

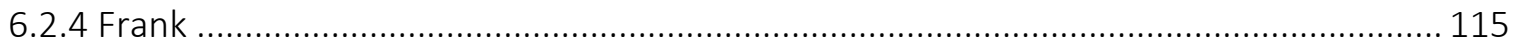

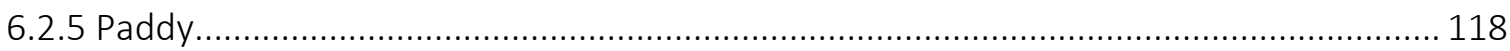

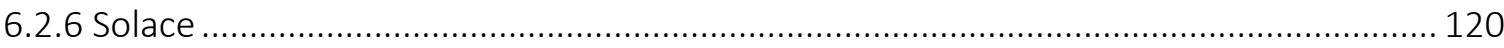

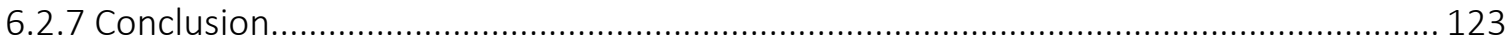

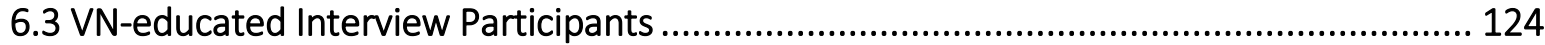

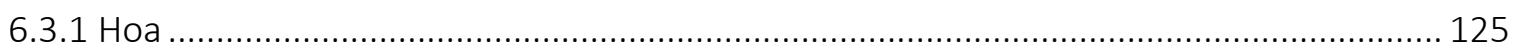

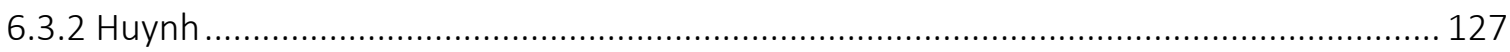

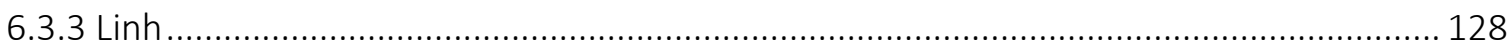

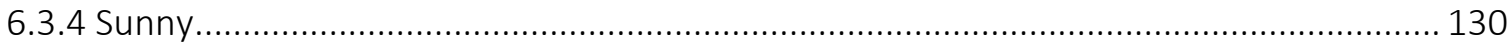

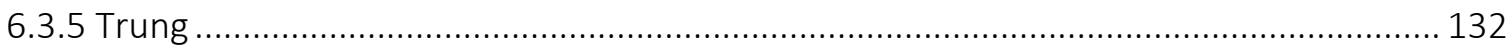

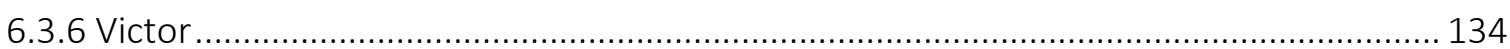

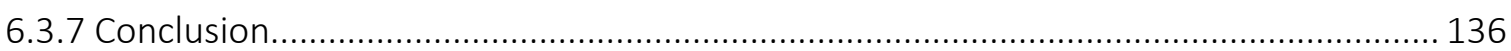

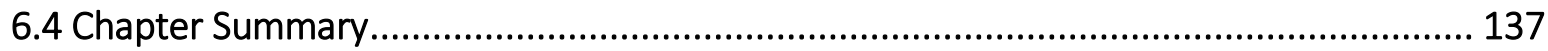

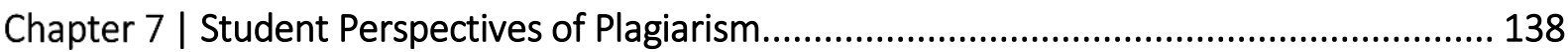

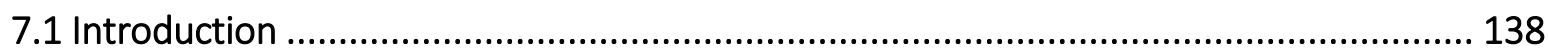

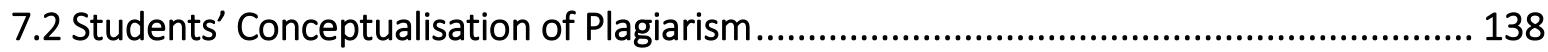

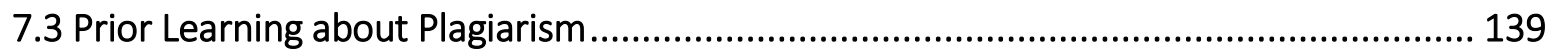

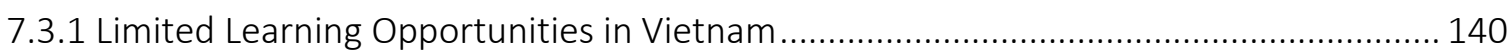

7.3.2 Extended Learning Opportunities in New Zealand or outside Vietnam ........................ 141

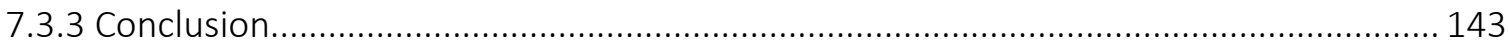

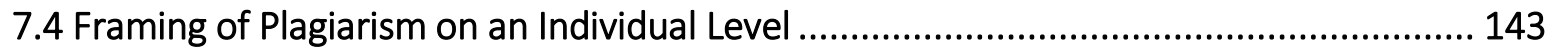

7.4.1 Participants' Perspectives of Plagiarism at University .................................................. 143

7.4.2 Participants' Views of Individual Factors Associated with Student Plagiarism .............. 147

7.4.3 Participants' Views of Individual-Level Outcome of Plagiarism .................................... 153

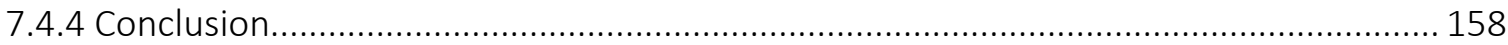

7.5 Framing of Plagiarism on an Organisational Level..................................................... 158

7.5.1 Participants' Perspectives of Plagiarism at University ................................................... 159

7.5.2 Participants' Views of Institutional Factors Associated with Student Plagiarism .......... 160

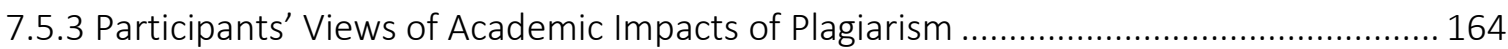

7.5.4 Participants' Suggestions on How to Prevent Student Plagiarism ................................ 167

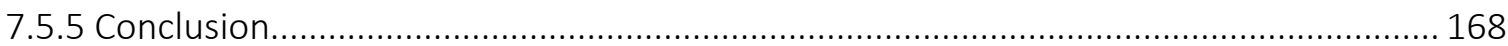




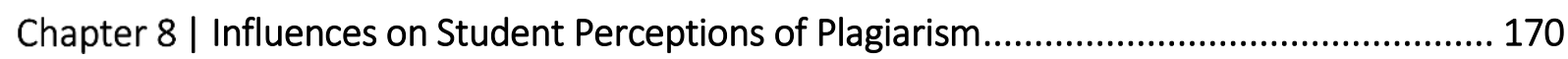

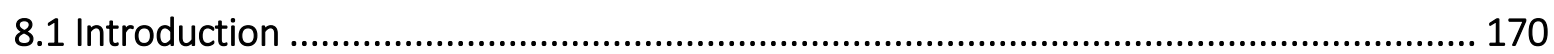

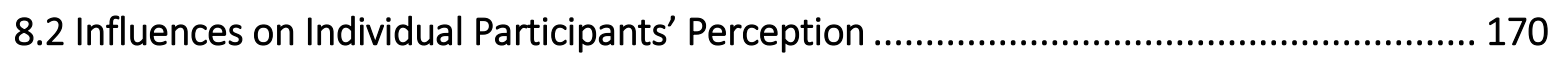

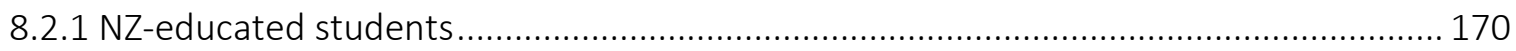

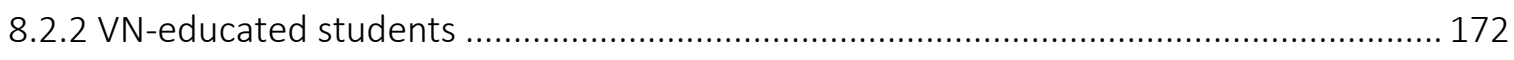

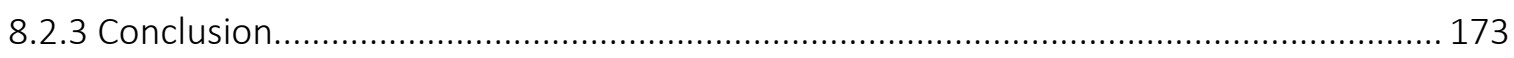

8.3 Influences on Student Perceptions from a Cultural Capital Perspective......................... 174

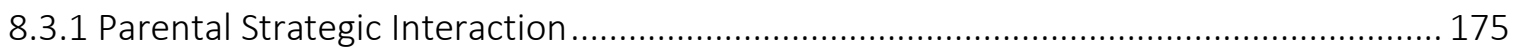

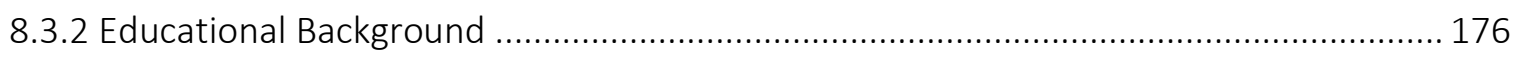

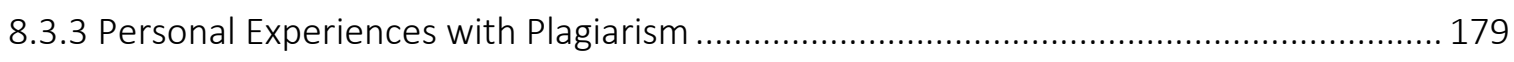

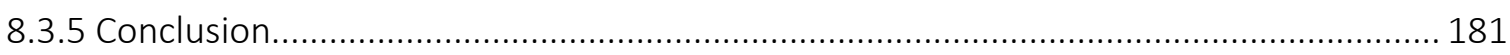

8.4 Influences on Student Perceptions from a Social Cognitive Perspective ........................ 182

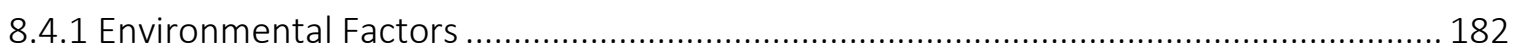

8.4.2 Moral Agency, Self-regulation, and Perceptions of Plagiarism .................................... 191

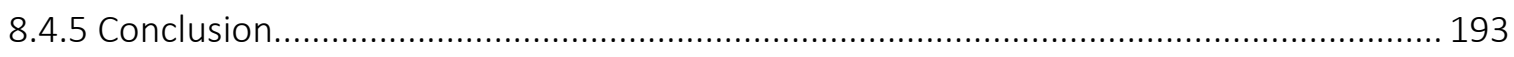

8.5 Influences on Student Perceptions from a Self-formation Perspective .......................... 193

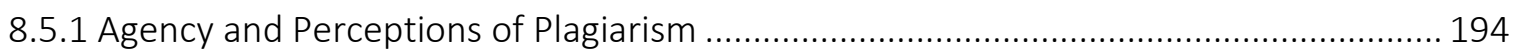

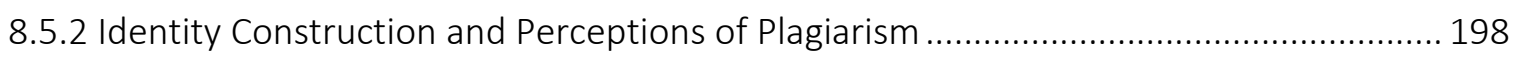

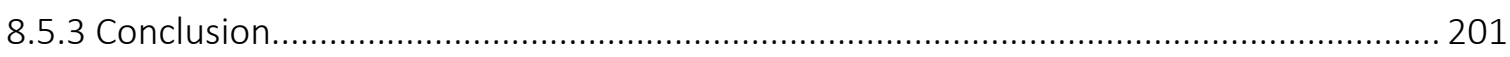

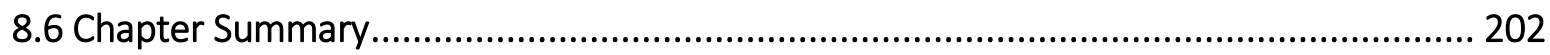

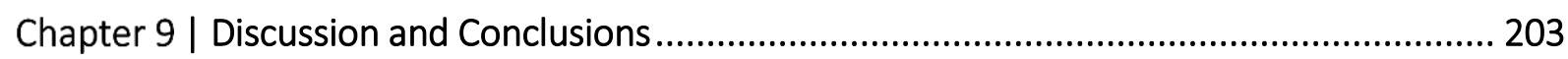

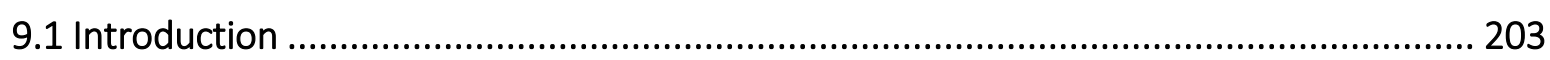

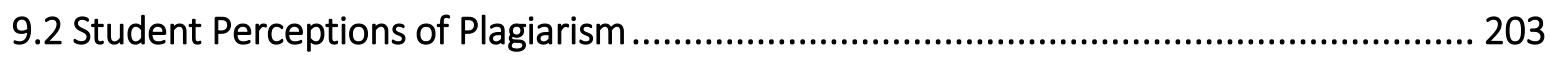

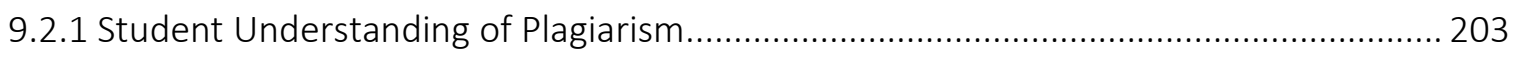

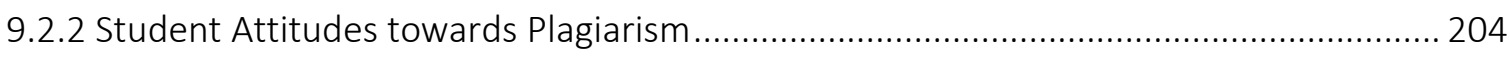

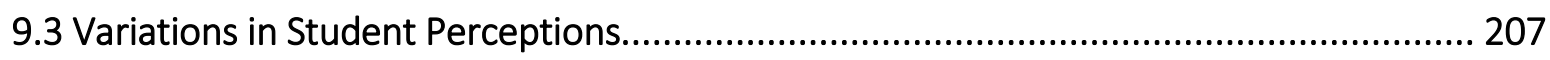

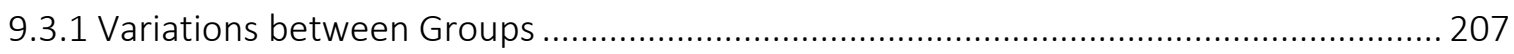

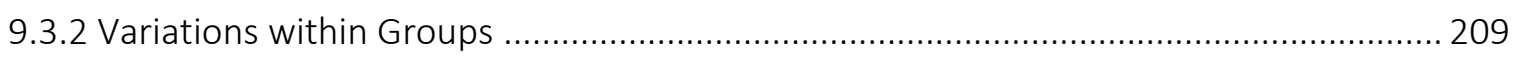

9.4 Theoretical Perspectives of Influences on Student Perceptions.................................. 211

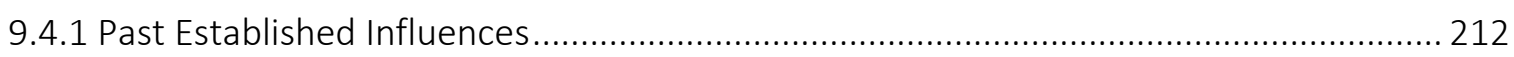

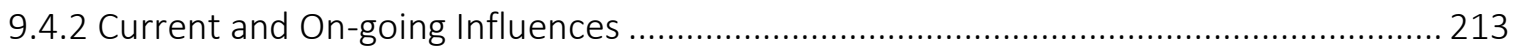

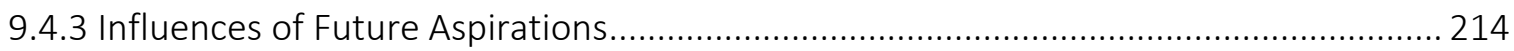




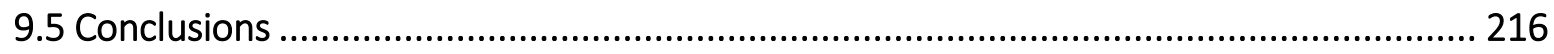

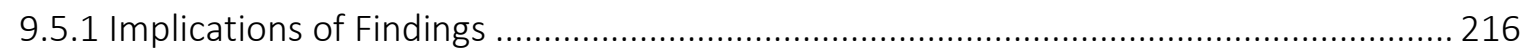

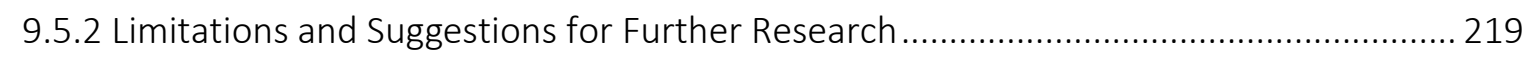

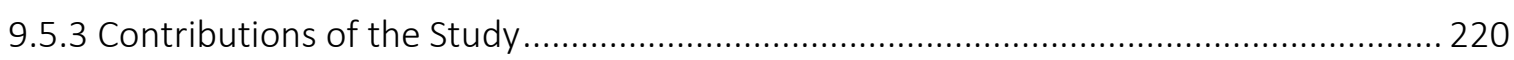

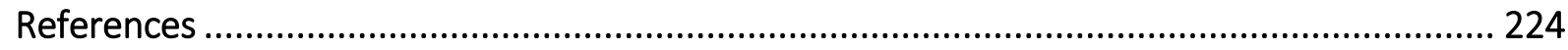

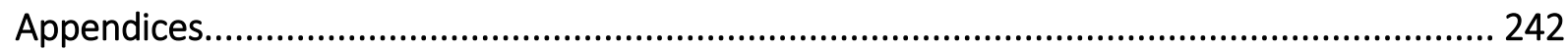

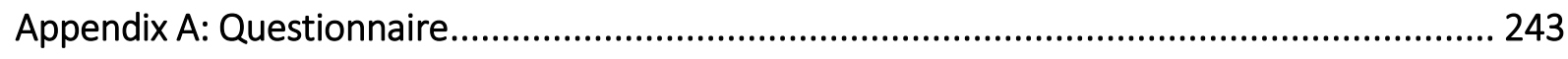

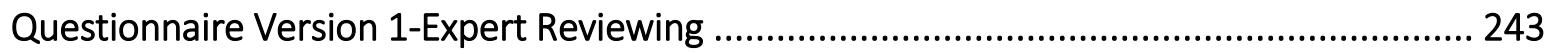

Questionnaire Version 2-Questionnaire Pretesting ...................................................... 245

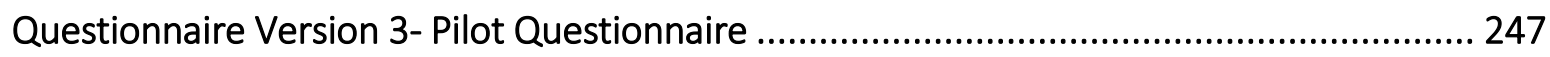

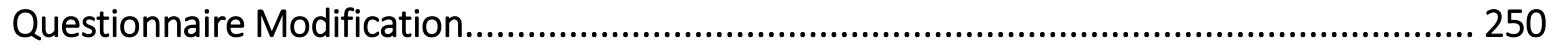

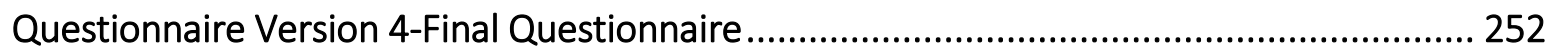

Appendix B: Interview Participants' Survey Responses ...................................................... 256

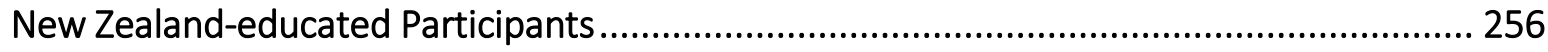

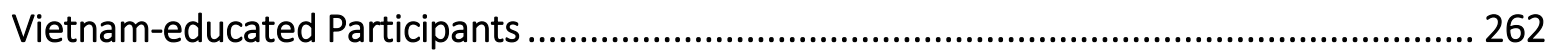

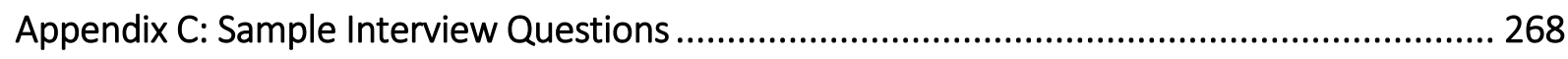

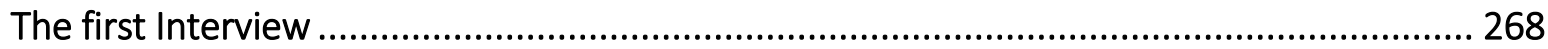

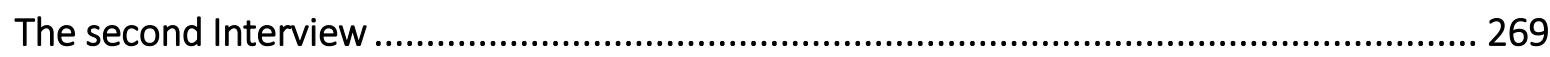

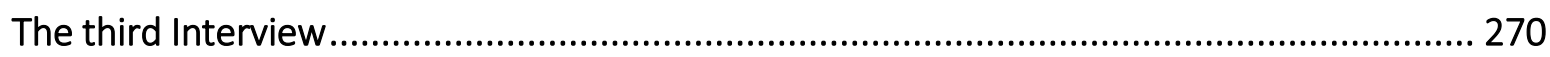

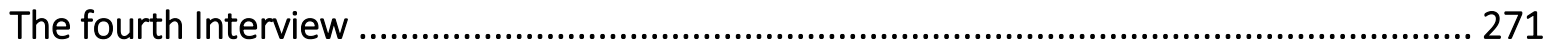

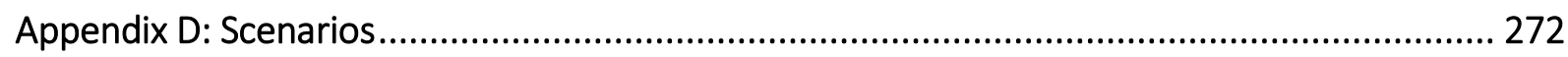

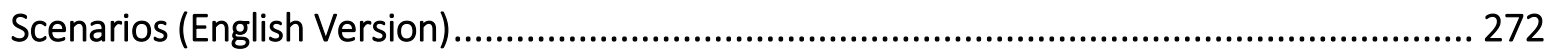

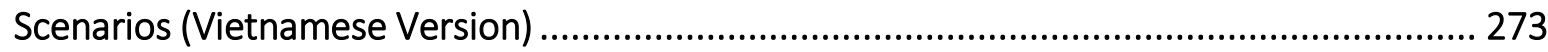

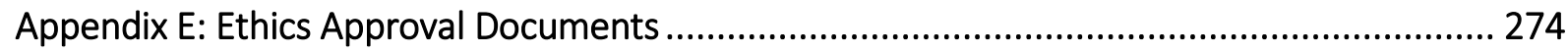

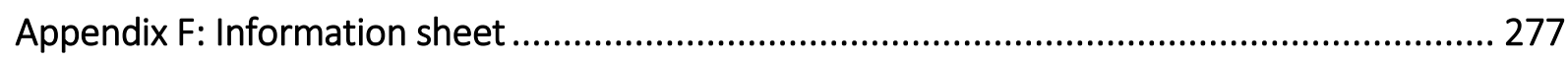

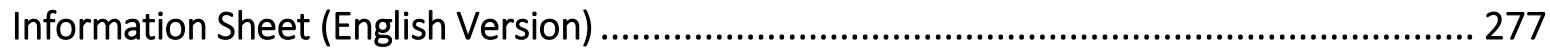

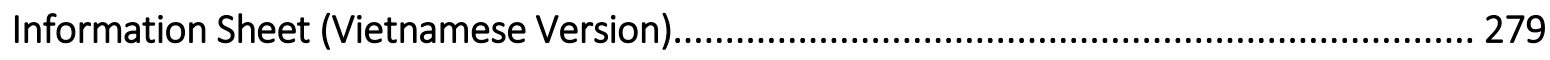

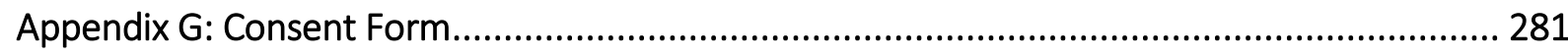

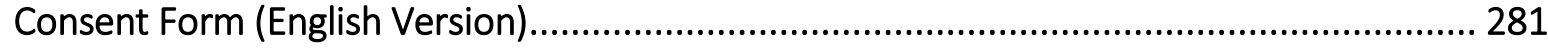

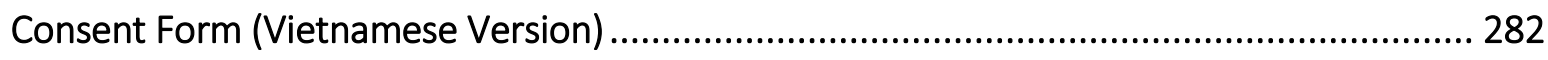

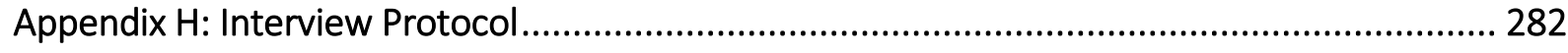

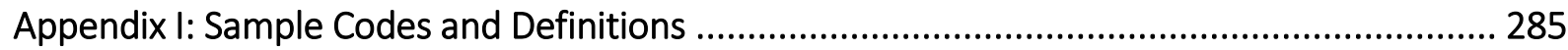




\section{List of Tables}

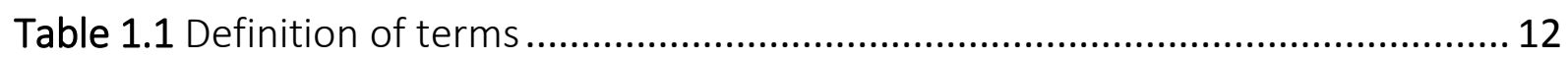

Table 4.1 Students' perceptions of plagiarism questionnaire-version 1 .......................62

Table 4.2 Students' perceptions of plagiarism questionnaire-version 2 .....................69

Table 4.3 Students' perceptions of plagiarism questionnaire-version $3 \ldots \ldots \ldots \ldots \ldots \ldots \ldots . . . .70$

Table 4.4 Students' perceptions of plagiarism questionnaire-version 4 ...................... 73

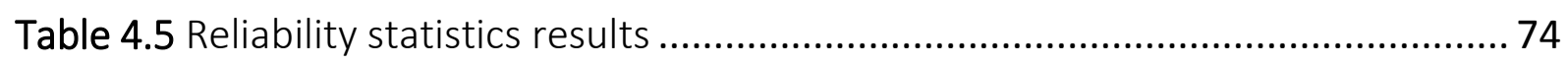

Table 4.6 Demographic characteristics of the survey sample ..................................... 75

Table 4.7 Students' perceptions of plagiarism questionnaire-final version ................... 76

Table 4.8 Demographic characteristics of interviewees ............................................ 79

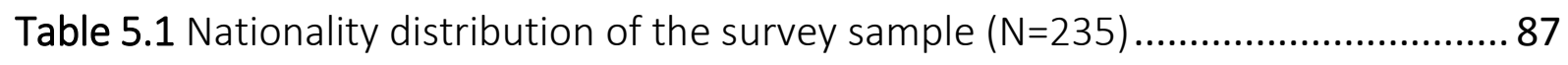

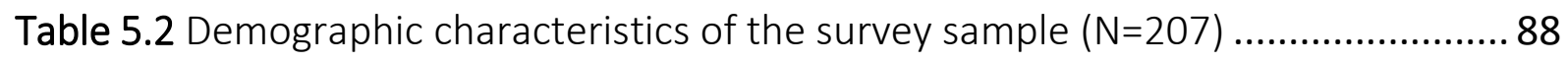

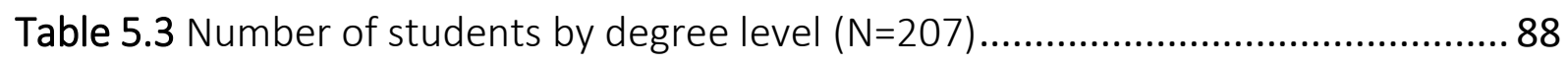

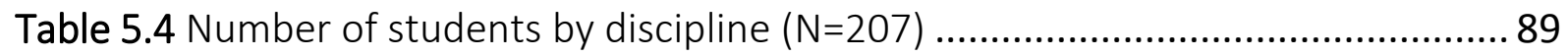

Table 5.5 Pattern matrix extracted using maximum likelihood estimation and oblique rotation (direct oblimin) with a five-factor solution...................................................... 90

Table 5.6 Pattern matrix extracted using maximum likelihood estimation and oblique rotation (direct oblimin) with a five-factor solution.................................................... 91

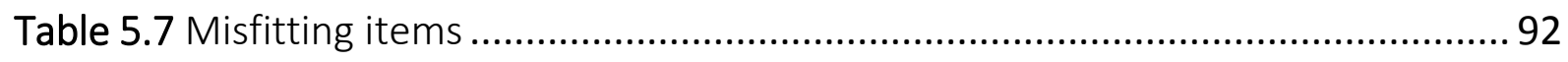

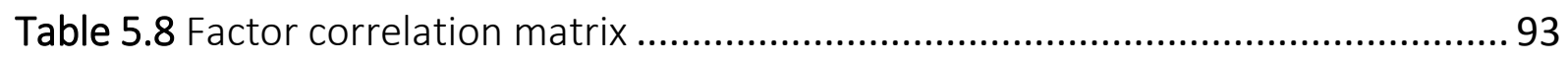

Table 5.9 Descriptive statistics for removed items.................................................... 99

Table 5.10 T-test comparison of VN- and NZ-educated students .............................. 101

Table 5.11 T-test comparison of male and female students ....................................... 102

Table 5.12 One-way ANOVA comparison of age group differences ............................ 102

Table 5.13 T-test comparison of students with and without teaching experience ..... 103 
Table 5.14 T-test comparison of PhD and master's students .................................. 104

Table 5.15 One-way ANOVA comparison of differences between disciplines ............ 105

Table 6.1 Demographic characteristics of NZ-educated interviewees ....................... 107

Table 6.2 NZ-educated interviewees' characteristics ........................................ 123

Table 6.3 Demographic characteristics of VN-educated interviewees ....................... 124

Table 6.4 VN-educated interviewees' characteristics ........................................ 136 


\section{List of Figures}

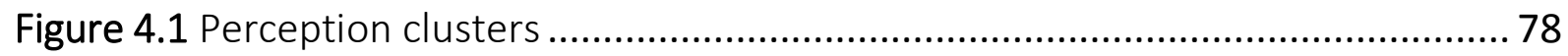

Figure 4.2 Summary of research processes ...................................................... 86

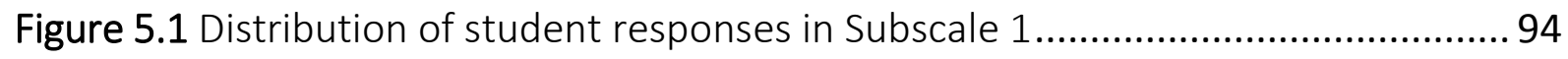

Figure 5.2 Distribution of student responses in Subscale 2 .................................. 95

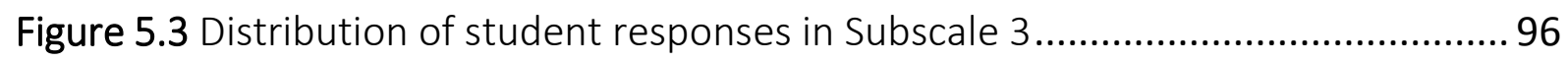

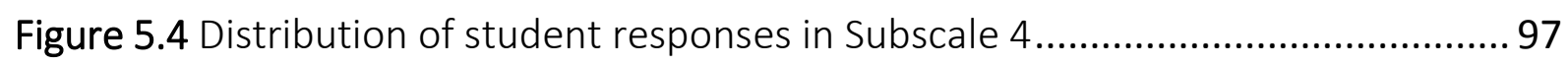

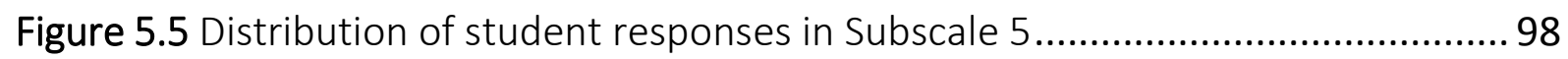

Figure 5.6 Mean plot subscale 1-Perceived seriousness of plagiarism....................... 103

Figure 5.7 Mean plot subscale 5-Negative attitudes towards plagiarism.................. 105

Figure 6.1 NZ-educated students' perceptions of plagiarism ................................ 124

Figure $6.2 \mathrm{VN}$-educated students' perceptions of plagiarism ................................ 137

Figure 7.1 Students' framing of plagiarism on an individual level .......................... 143

Figure 7.2 Students' framing of plagiarism on an organisational level..................... 158 
Abbreviations

\begin{tabular}{|c|c|}
\hline BA & Bachelor of Arts \\
\hline BSc & Bachelor of Science \\
\hline ESB & English speaking backgrounds \\
\hline FHSS & Faculty of Humanities and Social Sciences \\
\hline FoArch & Faculty of Architecture and Design \\
\hline FoEduc & Faculty of Education \\
\hline FoEng & Faculty of Engineering \\
\hline FoHealth & Faculty of Health \\
\hline Folaw & Faculty of Law \\
\hline FoSci & Faculty of Science \\
\hline Hons & Honours \\
\hline Int1 & Interview 1 \\
\hline $\ln 2$ & Interview 2 \\
\hline Int3 & Interview 3 \\
\hline Int4 & Interview 4 \\
\hline MA & Master's \\
\hline NESB & non-English speaking backgrounds \\
\hline NZ & New Zealand \\
\hline PhD & Doctor of Philosophy \\
\hline VBS & Victoria Business School \\
\hline VN & Vietnam \\
\hline VUW & Victoria University of Wellington \\
\hline
\end{tabular}




\section{Chapter 1 | Introduction}

\subsection{Introduction}

This research investigated Vietnam-educated (VN-educated) and New Zealand-educated (NZeducated) postgraduate students' perceptions of plagiarism, informed by Bourdieu's (1977) cultural capital theory, Bandura's (1991) social cognitive theory of moral thought and action, and Marginson's (2014) theory of student self-formation. Section 1.2 presents the background to the study, highlighting debates around cultural perspectives of plagiarism, giving an overview of earlier research on domestic and international student perceptions, underlining alternative views of student plagiarism, and describing the context where the study was conducted. Section 1.3 focuses on the rationale for the study. Also included in the chapter is a detailed description of the relevance of the topic for me personally and professionally, explaining my motivations to conduct a study on plagiarism. The next sections describe the aims and significance of the study. Section 1.7 introduces the organisation of the thesis. The chapter ends with definitions of key terms.

\subsection{Background to the Study}

Managing plagiarism is a significant challenge facing Western institutions, particularly in the context of internationalisation of higher education, because they have an increasing number of international students. Academic writing and plagiarism are complicated for international students, who transfer to an unfamiliar cultural and educational environment (Adhikari, 2018; Hayes \& Introna, 2005; Leask, 2006; Song-Turner, 2008; Tran, 2012), and for whom English is a foreign language (Amsberry, 2009; Bloch, 2012; Marshall \& Garry, 2006; Pecorari \& Petric, 2014; Schmitt, 2005; Tran, 2012). The literature reflects an ongoing examination of whether international students plagiarise more than domestic students and to what extent their understanding of conventions and expectations of academic writing differ.

\subsubsection{Culture and Plagiarism}

Culture is a recurring topic within this debate. In the earliest paper suggesting an association between culture and plagiarism, Zobel and Hamilton (2002) made links between plagiarism and cultural factors, such as students' perceived seriousness of plagiarism and rote-learning habits. Sowden (2005) identified values and practices of multilingual students which conflicted with 
Western values related to plagiarism, for example, Japanese and Chinese practice of communal ownership of knowledge, and Chinese copying and reproducing practices. However, Phan (2006) disputed links between cultural differences, attitudes, and knowledge about plagiarism, asserting that plagiarism was unacceptable in Vietnamese culture and Vietnamese students' memorising practices were unrelated to plagiarism. Liu (2005), a Chinese scholar, reviewed books which showed that plagiarism was inadmissible in his country, further highlighting that reliance on stereotypes of non-Western culture has led to inaccurate ideas about international students. Culture, while clearly important to student preferences and experiences, cannot be regarded as a simple explanation for student plagiarism behaviour.

While not explicitly arguing against influences of culture on how students use source texts, scholars have identified multiple determinants of plagiarism other than simply cultural ones. Park (2003) asserted that international students are at risk of plagiarism due to language difficulties. According to Pecorari (2016), non-English speaking backgrounds (NESB) students normally portrayed and labeled as being deficient in academic English - might engage in patchwriting (see Section 2.7.5) when producing academic work. Studies highlighted various aspects of students' educational backgrounds which may influence their knowledge and experience of plagiarism - educational approaches (Amsberry, 2009), plagiarism education (Bamford \& Sergiou, 2005; Foltýnek et al., 2014; Stappenbelt, 2012; Sutherland-Smith, 2005a), language experiences (e.g., Adhikari, 2018; Bloch, 2012; Divan et al., 2013; Marshall \& Garry, 2006; Park, 2003; Pecorari, 2008, 2016; Schmitt, 2005), academic expectations (Amsberry, 2009; Schmitt, 2005; Stappenbelt, 2012; Sutherland-Smith, 2005b), and assessment practices (Amsberry, 2009; Bennett, 2005; Hayes \& Introna, 2005; Song-Turner, 2008). Others reported that NESB international students might engage in unintentional plagiarism due to limited understanding of it (e.g., Babaii \& Nejadghanbar, 2017; Bamford \& Sergiou, 2005; Foltýnek et al., 2014; Shi, 2004; Stappenbelt, 2012; Sutherland-Smith, 2005a). These studies suggest various factors influencing students' ethical perceptions, habits, and expectations, affirming the need to recognise diverse individual factors present in student groups when addressing plagiarism.

Responding to current debates about culture and plagiarism perceptions, this study investigated VN- and NZ-educated postgraduate students' perceptions of plagiarism, focusing on educational, professional, and disciplinary backgrounds seeking to identify and explain factors impacting upon their perceptions. 


\subsubsection{Domestic and International Student Perceptions of Plagiarism}

A growing body of research has examined problems of plagiarism by international students. Despite variations in research aims, samples, and designs, these studies unpacked the issues and developed a general picture of these subjects.

Previous findings added to debates on stereotypical views of international students concerning plagiarism. Some studies found that non-Western students were slightly more likely to commit plagiarism, but it was also highly prevalent among Western students (Hayes \& Introna, 2005; Marshall \& Garry, 2006; Pecorari, 2003; Song-Turner, 2008; Walker, 2010). However, in two studies, Western students plagiarised more than their non-Western counterparts (Martin, 2012; Maxwell et al., 2006). Some showed that international students demonstrated a good basic understanding of the concept (Egan, 2008; Stappenbelt, 2012). While most students were taught about plagiarism before university (Bamford \& Sergiou, 2005; Sutherland-Smith, 2005b), many reported not having heard about it (Bamford \& Sergiou, 2005; Stappenbelt, 2012). Other studies noted that most international students might not fully understand university policies and/or expectations concerning plagiarism (Ramzan et al., 2012; Stappenbelt, 2012). These findings suggest that international students typically possess fundamental understanding of plagiarism but need instructional support to develop academic knowledge and skills and to engage with sources in more complex and demanding contexts.

Contradictory findings regarding domestic and international student perceptions of plagiarism have been revealed. Researchers showed that various types of plagiarism were viewed less seriously by international students than locals (Hayes \& Introna, 2005; Marshall \& Garry, 2006; Sutherland-Smith, 2005b; Sutton et al., 2014). In two studies, local students performed slightly better than their overseas counterparts in identifying plagiarism in academic work (Green et al., 2006; Stappenbelt, 2012), but others found no significant difference between the two groups (Egan, 2008; Maxwell et al., 2008). Most international students reported limited training on plagiarism-related issues in their home countries (Stappenbelt, 2012; Sutherland-Smith, 2005b), indicating that plagiarism education was not well aligned to their needs.

Together, these studies suggest that substantial issues in student understanding of plagiarism are experienced by all student groups, and responses targeted towards specific groups, such as students from particular cultures, could be more likely to be effective than initiatives aimed at the entire student population as if it was homogeneous. 


\subsubsection{Alternative Views of Plagiarism by International Students}

Contemporary scholarship includes calls for an holistic stance towards plagiarism by international students. The literature suggests focusing beyond cultural influences (Adhikari, 2018; Leask, 2006; Tran, 2013). The most significant recent focus shift is addressing plagiarism by paying attention to individuals' challenges (Adam et al., 2016; Adhikari, 2018; Fatemi \& Saito, 2020; Macdonald \& Carroll, 2006; Pecorari, 2013; Robertson et al., 2000). Findings from recent research also have highlighted the importance of rehabilitative as opposed to punitive approaches in dealing with student plagiarism (Adam et al., 2016; Born, 2003; Fatemi \& Saito, 2020; Green et al., 2006; Leask, 2006; Marshall \& Garry, 2005; Phan, 2006).

Researchers recognise the importance of alternative approaches to plagiarism that go beyond cultural influences. According to Leask (2006), stereotyping Asian students as deficient and more susceptible to plagiarism hinders institutions from effectively dealing with the issue. Adhikari (2018) considers that academics should not focus on how different cultures might define plagiarism and intellectual dishonesty. Discussing international students' adaptation to academic writing, Tran (2013) argues for adopting a more critical perspective of international student academic adaptation that moves away from linguistic and cultural factors.

Plagiarism is positioned by some researchers as a developmental issue rather than a moral one. For example, several consider patch-writing as a transitional stage in academic writing development (Howard, 1993; Pecorari, 2016; Pecorari \& Petric, 2014). Some scholars recognise the potentials of patch-writers in acquiring language, knowledge, and source use skills (Adhikari, 2018; Neville, 2007; Pecorari \& Petric, 2014; Sousa-Silva, 2014). Patch-writers could become good writers if provided appropriate guidelines and support (Pecorari, 2003, 2008). Others suggest focusing on student difficulties rather than dishonesty and intentional factors (Adam et al., 2016; Adhikari, 2018; Fatemi \& Saito, 2020; Macdonald \& Carroll, 2006; Pecorari, 2013; Robertson et al., 2000). Increasingly in contemporary scholarship, researchers highlight the need to realise the complex and multifaceted nature of plagiarism (Adhikari, 2018; Bokosmaty et al., 2019; de Jager \& Brown, 2010; Donnelly, 2013; Evering \& Moorman, 2012; Halupa et al., 2016; Macdonald \& Carroll, 2006; Pecorari, 2016; Sousa-Silva, 2020).

Some researchers promote correctional and educational responses to student plagiarism. They recommend academic institutions to acknowledge students' diverse backgrounds and needs (Adhikari, 2018; Amsberry, 2009; Fatemi \& Saito, 2020; Leask, 2006; Marshall \& Garry, 2005). 
Several suggest remedies that go beyond policing and punishing (Bretag, 2013; Marshall \& Garry, 2005; McCabe \& Stephens, 2006). Researchers recognise the need to inform students about the university's rules and/or expectations concerning plagiarism (Adam et al., 2016; Born, 2003; Fatemi \& Saito, 2020; Green et al., 2006; Leask, 2006; Marshall \& Garry, 2005; Phan, 2006) and provide them with skills to engage with sources (Adam et al., 2016; Adhikari, 2018; Green et al., 2006; Leask, 2006; Marshall \& Garry, 2005; Vardi, 2012; Yeo, 2007).

\subsubsection{Doctoral Education in New Zealand}

The eight New Zealand universities that offer doctoral degrees to domestic and international students include University of Auckland, AUT University, Victoria University of Wellington, University of Otago, Massey University, University of Canterbury, University of Otago, and Lincoln University. These universities have been recognised globally for academic and research standards and performances (New Zealand Education, 2019). They offer both full-time (taking from three to four years) and part-time (taking up to six years) doctoral programmes.

New Zealand higher education institutions attract a large number of international students every year, 61,240 students in 2019, many of whom are doctoral students (Institute of International Education, 2019). Vietnam is the sixth-ranked source country for international students in New Zealand, with 1,270 students commencing their studies in 2019 (Institute of International Education, 2020). International students have several financial aid options while doing a PhD in New Zealand. Firstly, there is no additional international fee for doctoral students. They can bring their families with them and work full-time during their studies. Various scholarship opportunities are offered by the government and universities. Most importantly, doctoral graduates can apply for a three-year post-study work visa.

Doctoral applicants must meet the academic and English-language requirements of each university. Academically, they have to provide academic transcripts for the prerequisite qualification. Their applications are assessed based on their academic records and research backgrounds. Candidates may or may not be required to submit a research proposal, but their research interests must fit the interests of the school to ensure availability of supervision. Students whose English is a second or foreign language are expected to meet English-language requirements which may vary between universities. In most universities, IELTS overall band of 6.5 with no sub-score below 6.0 or TOEFL (iBT) 90 score or above with a minimum of 20 in writing are minimum requirements. 
Victoria University of Wellington (VUW), founded in 1897, is one of the oldest universities in New Zealand. Its three campuses are located in Wellington, the capital city. VUW has been known for its excellent academic and research quality. The university is in the top $2 \%$ of universities globally and nineteen of its subjects are in the top 1\% in the world (Victoria University of Wellington, 2020b). In 2020, VUW was ranked 223rd by QS World University Rankings, with thirteen subjects in the top 100 . The university offers a range of postgraduate programmes including Architecture and Design, Humanities and Social Sciences, Business, Education, Engineering and Computer Science, and Sciences. An increasing number of international students choose VUW as their study destination. The university hosted 3,645 international students in $2019,1,430$ of whom were at postgraduate levels.

Doctoral students at VUW are required to work independently on an original research project with the support and guidance of academic supervisors. They are expected to demonstrate a high level of academic integrity and conduct their research ethically. Each thesis is assessed by an examination committee consisting of an internal, national, and international examiner (New Zealand Education, 2019). Doctoral graduates are expected to be able to carry out independent research, demonstrate critical insights, and make original contributions to their field.

\subsection{Rationale for the Study}

Transitioning to postgraduate studies is a complex and demanding process (Becker et al., 2019; Franken, 2012; Menzies \& Baron, 2014; O'Donnell et al., 2009; Tobbell \& O’Donnell, 2013) in which students are expected not only to gain necessary expertise and capabilities but to contribute to the knowledge base (Abasi \& Graves, 2008; Barnacle, 2005). To meet these expectations, they need to extensively engage in academic writing (Abasi \& Graves, 2008; Pecorari, 2006). This fundamental academic activity, which involves not only expressing their views but responding to others' ideas, is challenging for both domestic and international students (Graff \& Birkenstein, 2006; Houston, 2015). During these processes, the appropriate use of intellectual property is of significant importance (Abasi \& Graves, 2008).

The literature suggests that academic experiences of students transferring to an unfamiliar cultural, social, and academic environment differ from those of their local counterparts. The scholarly journey is tougher and more challenging for international students (Divan et al., 2013; Fatemi \& Saito, 2020; Franken, 2013; Menzies \& Baron, 2014; Schmitt, 2005; Tobbell \& 
O'Donnell, 2013) because of disparities between their educational backgrounds and overseas universities' expectations (Amsberry, 2009; Divan et al., 2013; Franken, 2012). International students may face challenges concerning unfamiliar academic integrity standards (Fatemi \& Saito, 2020; Zimerman, 2012), different assessment methods and criteria (Carroll, 2008; Divan et al., 2013; Song-Turner, 2008), and new academic practices and expectations (Divan et al., 2013; Duff et al., 2006; Sawir et al., 2012; Schmitt, 2005). International students whose English is a second or foreign language are potentially more vulnerable to plagiarism or not understanding overseas universities' expectations related to academic integrity (Fatemi \& Saito, 2020; Marshall \& Garry, 2006; Pecorari, 2016; Schmitt, 2005; Tran, 2012; Zhang, 2016).

Researchers indicated associations between perceptions and behaviours. For example, Babaii and Nejadghanbar (2017) asserted that student attitudes towards source use and their roles as academic writers are related to their subsequent behaviours. Zafarghandi et al. (2012) found that the more severely students perceived plagiarism, the less likely they would commit it. Specifically, as the severity of student perceptions of plagiarism increased, the likelihood of committing plagiarism fell. Similarly, Curtis and colleagues revealed that the more students understood about plagiarism and its seriousness, the lower the rate of plagiarism was (Curtis \& Popal, 2011; Curtis \& Tremayne, 2019; Curtis \& Vardanega, 2016). Employing the theory of reasoned action and planned behaviour to investigate students' motivation and intention to plagiarise, Camara et al. (2017) showed that students who possessed more positive attitudes towards plagiarism were more likely to plagiarise. Others pointed out that unawareness about plagiarism and related issues might contribute to student plagiarism (e.g., Amiri \& Razmjoo, 2016; Babaii \& Nejadghanbar, 2017; Devlin \& Gray, 2007; Pàmies et al., 2020; Selemani et al., 2018). Bandura's (1991) social cognitive theory of moral thought and action also hypothesised that moral thoughts guide moral behaviours.

These studies suggest that investigating student perceptions is essential to the effective management of plagiarism. Examination of how students think about the issue could also assist in developing appropriate instructional materials not only to enhance their understanding of academic integrity but also to successfully prevent plagiarism. 


\subsection{Personal and Professional Relevance of the Study}

My interest in plagiarism began when I was working on my master's degree in Vietnam. During this time, I witnessed several friends being caught plagiarising, resubmitting their theses, or failing to graduate. I felt sorry for them as most plagiarised unknowingly. The interest was subsequently enhanced by my experience of teaching academic writing and supervising undergraduate students' final projects. In these roles, I encountered various instances of student plagiarism. I recall noticing that my students' understanding of plagiarism and academic integrity was limited. Throughout my professional career, I knew some colleagues who submitted low-quality work to predatory journals or copied other people's works. While several were unaware of academic impacts of plagiarism, others simply did not care about it.

As a Vietnamese lecturer, I am concerned about the prevalence of plagiarism and unclear plagiarism policies in numerous institutions across the country although the issue of plagiarism has gained greater prominence in Vietnam recently. I am aware of limited education on plagiarism and related issues at many academic institutions in my home country. While acknowledging an increasing number of international publications by Vietnamese scholars, I understand constraints that may prevent Vietnamese academics from focusing on research, such as limited research resources, high workload, limited understanding of academic writing conventions, and lack of research knowledge and skills. These matters encourage me to investigate how educators in different regions in Vietnam reflect on their knowledge and understanding of plagiarism and academic writing conventions. I am also keen to explore how postgraduate students - emerging researchers - in New Zealand respond to these issues.

My early interest in plagiarism was later heavily influenced by the Research Methods in Education course I took at VUW. The assignments exposed me to an extensive body of literature about this issue. At that time, I realised that the topic was an increasingly important and contentious area in higher education. The course provided me an opportunity to learn about citations and referencing conventions, things that I did not spend much time studying before, which expanded my knowledge and interest in the topic.

My motivation to conduct this study relates to my experience of being educated in two educational systems - Vietnam (non-Western) and New Zealand (Western), realising mismatches between how I was taught in my home country universities and requirements of 
my overseas institution concerning plagiarism. Since starting my studies in New Zealand, I have observed that students at all tertiary levels in the country are publicly informed about the issue of plagiarism, which did not occur at Vietnamese universities where I taught or studied. A section about plagiarism and academic integrity in the doctoral orientation workshop I attended at VUW and being required to submit my assignments via Turnitin reminded me of my Vietnamese friends whose master's theses were found to be partially copied from others' work. I also recalled various instances of plagiarism in my colleagues' and students' writings back in my home country. All these experiences raise questions about the extent to which these problems exist in different educational settings and why.

More recently, my understanding of Bourdieu's (1977) cultural capital theory, Bandura's (1991) social cognitive theory of moral thought and action, and Marginson's (2014) theory of student self-formation has given me new perspectives to engage in this inquiry. These theories provided me new ways to reflect on my current situation as an NESB (non-English speaking backgrounds) international postgraduate student. Personal reflections on my embodied cultural capital regarding knowledge about plagiarism and academic integrity, and problems I encountered as an NESB learner - finding words to express my ideas and learning to integrate sources into my writing encouraged me to explore influences on students' plagiarism perceptions, which might counteract stereotypes of international students related to plagiarism.

My aspirational identity as a scholar motivates me to investigate students' understanding of academic writing conventions so I can appropriately respond to their problems and needs. I hope with the knowledge about plagiarism and academic skills obtained through my doctoral studies at VUW, I can contribute to the academic culture of integrity in my home country institution. Through the study, I seek to provide practical implications for host institutions to help both domestic and international postgraduate students improve their understanding and perspectives of plagiarism which hopefully will make them better writers and academics.

In summary, the ongoing controversy surrounding plagiarism, especially by NESB international students, and reflections on my own experience as a Vietnamese learner and lecturer have inspired me to explore perceptions of plagiarism held by students with diverse educational backgrounds in the same academic setting. 


\subsection{Aims of the Study}

This study primarily aimed to examine influences on plagiarism perceptions among VN- and NZeducated postgraduate students at VUW. For this purpose, I initially identified and examined student perceptions, especially differences between and within these two groups. This was followed by an in-depth exploration of influences on students' perceptions of plagiarism or how they have developed their perceptions.

Specifically, the study sought to answer two main research questions and two research subquestions:

1. How do VN- and NZ-educated postgraduate students perceive plagiarism?

Research sub-question 1: How do VN- and NZ-educated postgraduate students' attitudes and understanding of plagiarism differ between these groups?

Research sub-question 2: How do VN- and NZ-educated postgraduate students' attitudes and understanding of plagiarism differ within these groups?

2. What are the influences on VN- and NZ-educated postgraduate students' perceptions of plagiarism?

The first research question and two research sub-questions were answered using both quantitative and qualitative data. The second question was addressed using qualitative data.

\subsection{Significance of the Study}

This study contributes knowledge about postgraduate students' perceptions of plagiarism, especially Vietnamese and New Zealand students. No previous studies have examined doctoral students' perceptions of plagiarism in international education settings. This mixed-method analysis offers an in-depth exploration of students' shifting perceptions over a period of time. An application of a theoretical framework means that the study provides another perspective that may promote alternative reflections on deficit models of education related to plagiarism by international students. The findings contribute broader contextual information for managing and dealing with student plagiarism. Insight into factors affecting student perceptions of plagiarism will help educational institutions to better respond to their needs. They will inform 
university faculty to develop appropriate interventions to help both international and domestic students regarding scholarly writing conventions and plagiarism.

\subsection{Organisation of the Thesis}

The thesis comprises nine chapters, including this first chapter which introduces the research and provides the background and rationale for the study. I also detail my personal rationale for the research topic, the study's aims and significance, and the overall structure of the thesis.

The second chapter reviews relevant literature on plagiarism, focusing on recent debates, research methods used, and gaps in knowledge. Because of the study's focus, the review explored seven major themes: (1) academics' perceptions of plagiarism; (2) student perceptions of plagiarism; (3) variations in ESB (English speaking backgrounds) and NESB students' perceptions of plagiarism; (4) why plagiarism matters; (5) influences on student plagiarism perceptions; (6) the extent of student plagiarism; and (7) why students plagiarise.

Chapter Three presents the theories underpinning the study including Bourdieu's (1977) cultural capital theory, Bandura's (1991) social cognitive theory of moral thought and action, and Marginson's (2014) theory of student self-formation, setting the framework for exploring and interpreting student plagiarism perceptions and influencing factors. For each theory, I introduce and explain its relevance to the present study.

Chapter Four describes the research design, research questions, and validity and ethical considerations. In this chapter, I provide a detailed description of the development of the survey questionnaire, quantitative data collection and analysis processes, and qualitative research procedures.

Chapter Five presents major findings from the quantitative phase including a description of the survey sample, results from exploratory factor analysis, and descriptive and inferential statistical findings obtained from the online survey.

The next three chapters report results gathered from in-depth interviews. Chapter Six gives an overview of interview participants' familial, professional, and academic backgrounds, and their perspectives of plagiarism. Chapter Seven unpacks in detail my conversations with interview participants. In this chapter, I present results from the analysis in four major themes: students' conceptualisation of plagiarism, prior plagiarism learning, and students' framing of plagiarism 
on an individual and organizational level. In Chapter Eight, I analyse influences on students' perceptions from theoretical perspectives. While findings that support each theory are reported separately, the boundaries between the theories are soft and not mutually exclusive. In other words, the influences might relate to more than one theory and have some overlaps.

The last chapter discusses the key findings and concludes the thesis. In this chapter, I provide practical implications of the study, its limitations, and suggestions for future research. Then, I highlight contributions of the study to the field of plagiarism.

Appendices are included to provide the research instruments, details of ethics approvals, and supplementary information on the analysis.

\subsection{Definition of Terms}

Table 1.1 presents functional definitions of selected terminologies used in the thesis.

Table 1.1 Definition of terms

\begin{tabular}{|c|c|}
\hline Terms & Definition \\
\hline $\begin{array}{l}\text { International } \\
\text { students }\end{array}$ & $\begin{array}{l}\text { International students mean individuals who are studying outside of their } \\
\text { country of residence on a student visa for a degree programme. The definition } \\
\text { excludes permanent residents, immigrants, and refugees. In reviewing previous } \\
\text { studies, I may use the term "overseas students" as synonymous, because it was } \\
\text { used by a particular author. }\end{array}$ \\
\hline Perception & Perception means attitudes towards and understanding of. \\
\hline Plagiarism & $\begin{array}{l}\text { Plagiarism refers to presenting someone else's work as if it were your own, } \\
\text { whether you mean to or not (Victoria University of Wellington, 2020a). }\end{array}$ \\
\hline Plagiarist & A plagiarist means any person who has ever committed plagiarism in any form. \\
\hline VN-educated & $\begin{array}{l}\text { VN-educated is an adjective that refers to a Vietnamese student with at least } \\
\text { one tertiary degree in Vietnam. }\end{array}$ \\
\hline NZ-educated & $\begin{array}{l}\text { NZ-educated is an adjective that describes a New Zealand student with at } \\
\text { least one tertiary degree in New Zealand. }\end{array}$ \\
\hline
\end{tabular}




\section{Chapter 2 | Literature Review}

\subsection{Introduction}

This chapter presents the literature related to the concept of plagiarism. Section 2.2 introduces academics' perceptions of plagiarism, underlining how scholars in the field define plagiarism and how they view the issue. Section 2.3 describes earlier findings on student perceptions of plagiarism, highlighting their conceptualisation and framing of the practice. To establish a context for the study, Section 2.4 briefly introduces recent research on ESB and NESB students' perceptions of plagiarism, highlighting current debates, conflicts in method, and gaps in knowledge that warrant closer investigations. The next section focuses on impacts of plagiarism on both personal and academic levels. Section 2.6 presents factors associated with student perceptions of plagiarism. The two following sections depict the extent of plagiarism and reasons for its occurrence. Section 2.9 summarises key points discussed in the chapter.

\subsection{Academics' Perceptions of Plagiarism}

Plagiarism is a complex issue in terms of how it is defined, what it covers, and how it should be treated. The literature reflects an ongoing debate on the intentional and/or unintentional dichotomies of plagiarism. Recent attention has focused on pedagogical examinations of plagiarism, resulting in more holistic views of the phenomenon. This section describes how plagiarism is conceptualised and perceived within academia over the past few decades.

\subsubsection{Academics' Conceptualisation of Plagiarism}

To date, there has been no general agreement on how to define plagiarism within academia. Every institution, academic, and handbook writer defines the concept in their own terms, in which each covers different and overlapping aspects of scholarly information use. Within this diversity, two dominant ways of defining plagiarism generally either focus on textual features or deceptive intention.

Some researchers define plagiarism as an issue of citation and acknowledgement, showing their objective stance on the issue. Plagiarism can be used to refer to copying words and ideas belonging to someone else and submitting them as one's own without proper attribution (Badke, 2007; Bouville, 2008; Briggs, 2009; Fish \& Hura, 2013; Howard, 2002). The practice may mean improper use of intellectual property (Bloch, 2012; Halupa et al., 2016; Jones, 2011) or 
undocumented uses of work or concepts developed by others (Halupa et al., 2016; Whitley Jr \& Keith-Spiegel, 2012). Plagiarism is also conceptualised as inclusion (Halupa et al., 2016; Hayes \& Introna, 2005; Shi, 2004; Zobel \& Hamilton, 2002) or presentation (Anderson \& Steneck, 2011) of somebody else's work as one's own without appropriate acknowledgement.

Others, in contrast, are more subjective and pay special attention to plagiarists' deceptive intentions, revealing their attitude towards this type of textual misappropriation and/or the plagiarists. For example, Zhang (2016) uses the concept to refer to instances where people pretend someone else's work as their own. Neville (2007) and Smith et al. (2007) define plagiarism as deliberately taking and claiming someone else's work as one's own either explicitly or implicitly. Pecorari and Petric (2014) emphasised that the notion of plagiarism encompasses unconventional and/or inappropriate intertextual relationships that are brought about intentionally. Others described plagiarism as passing off another person's work as one's own, asserting that instead of properly crediting others' contribution to their work, plagiarists act as if they produced the work on their own (Carroll \& Zetterling, 2009; Sousa-Silva, 2014).

Several scholars define plagiarism with reference to intention. Walker and White (2014), while defining intentional plagiarism as deliberate uses of someone else's words and ideas as one's own to cheat, conceptualised unintentional plagiarism as failure to attribute sources properly. Howard (1993), similarly, clearly distinguished patch-writing (see Section 2.7.5) and plagiarism - using someone else's ideas, or language without attribution or submitting too closely paraphrased text with attribution but no quotation marks. Focusing on textual features such as the similarity of the two texts and the absence of other textual features such as quotation marks, Pecorari (2008) defined "textual plagiarism" as unattributed use of words and/or ideas from other sources (p. 4). In contrast, he used the term "prototypical plagiarism" to refer to plagiarism to deceive (p. 4).

Some researchers, however, do not distinguish between unintentional or intentional plagiarism in the way they define it. Therefore, these scholars asserted that passing off someone else's words or ideas as one own is considered plagiarism whether plagiarists were aware of their behaviours or not. For them, plagiarism involves copying and claiming authorship of someone else's work either intentionally or accidentally (Pàmies et al., 2020; Perkins et al., 2018; Selemani et al., 2018; Yeo, 2007). Similarly, plagiarism is characterised as using words, ideas, or 
creative work of others without proper acknowledgement, regardless of their deceptive intentions (Bretag, 2013; Martin, 2016).

Throughout this thesis, the term plagiarism was used to refer to "presenting someone else's work as if it were your own, whether you mean to or not" which is the institutional definition of plagiarism used by VUW (Victoria University of Wellington, 2020a). I chose this definition not only because it is the definition of my current university, but importantly, it offers a number of affordances. Firstly, the definition does not include assumptions about how and why plagiarism occurs but recognises the multiple issues that contribute to the things that students do when undertaking assessments and scholarly work. This not-knowing stance within the definition is appropriate for this study, which explores possible influences on student perceptions of plagiarism. The definition depicts the continuum of plagiarism, from deliberate plagiarism with an attempt to cheat to accidental plagiarism resulting from lack of understanding, allowing me to explore plagiarism in the full sense. The definition was chosen also because, in this study, I explored student understanding of the university's expectation regarding plagiarism and the extent to which their definition was in line with how the university conceptualised it. One constraint of using this broad definition is that it limits the relevance of the study to contexts where plagiarism is defined differently (e.g., more narrowly focused).

\subsubsection{Academics' Framing of Plagiarism}

While many students intentionally copy someone else's works or cut-and-paste from various sources to deceive, others inadvertently plagiarise because of not knowing how to cite properly. This results in contrasting perspectives of plagiarism around whether to consider it as a subject of criticism or a matter of concern. Many researchers examine intentionality and view plagiarism as a moral transgression, an educational fraud, and a scholarly offence, whereas others analyse its process and treat accidental plagiarism as a developmental issue.

\section{Plagiarism as a moral transgression}

Whether or not plagiarism should be considered immoral has been controversial within academia. While some academics perceive plagiarism as immoral, associating it with negative connotations such as literary theft or an immoral act, others argue that plagiarism within and outside educational contexts should be treated differently. 
Scholars have considered deliberate plagiarism as a form of intellectual piracy. Plagiarism is derived from the Latin term for plundering, or kidnapping, and kidnapping others' words is similar to kidnapping a child from their parents (Pecorari \& Petric, 2014; Singh \& Remenyi, 2016; Sutherland-Smith, 2008). Many scholars regard plagiarism as stealing work or ideas belonging to another person (Pecorari \& Petric, 2014; Sousa-Silva, 2020; Valentine, 2006; Whitley Jr \& Keith-Spiegel, 2012; Zhang, 2016). Plagiarism is also positioned as literary theft because of plagiarists' calculating and intentional actions designed to deceive university faculty (Carroll \& Zetterling, 2009; Jones, 2011; Pàmies et al., 2020; Park, 2003; Pecorari \& Petric, 2014; Sousa-Silva, 2020; Sutherland-Smith, 2008).

Educational practitioners hold that plagiarism is against moral standards or principles. Howard (1995) asserted that plagiarism took place when ethics were absent, and recently reiterated that people did not plagiarise if they were ethical (Howard, 2016). Pecorari and Petric (2014) claimed that plagiarism, which involved deliberate cheating behaviours, reflected moral decay. Similarly, Williams (2003) viewed plagiarism as morally inappropriate, calling people who used other sources to make their own work "cunning plagiarists" (p. 4) because he considered that they were aware of their behaviour but worked hard to avoid detection. Some scholars viewed plagiarism as morally unacceptable (Howard, 2016; Sousa-Silva, 2014; Valentine, 2006; Williams, 2003). Plagiarists deceived the readers (Bouville, 2008; Weber-Wulff, 2014) and hurt plagiarised authors (Bouville, 2008). They are also disrespectful because they failed to acknowledge other people's ownership (Davis et al., 2012).

Several scholars, however, contested viewing student inappropriate source use as literary theft. For example, reflecting on differences in the meaning of stolen credit for students and scholars, Grossberg (2009) said that consideration should be given as to whether plagiarising students and academics get what they steal as thieves normally do and whether they mean to take credit associated with the plagiarised work. Senders (2009) emphasised that students rarely care about the words they took from others and would not keep these words for long. These suggest that plagiarism in a legal sense differs in and outside academic settings.

\section{Plagiarism as an educational fraud}

Within educational contexts, plagiarism is consistently classified as a form of academic misconduct. Some viewed it as a violation of academic integrity (Bretag, 2013; Ehrich et al., 2015; Singh \& Remenyi, 2016; Weber-Wulff, 2014) or a breach of academic conventions 
(Pecorari, 2016). Plagiarism is also considered academically and socially blameworthy (East, 2010; Sousa-Silva, 2014). Proposing a framework for managing student plagiarism, Carroll (2016) advocated that plagiarism which involves a high degree of deception (i.e., a substantial part of the work or repeat offending) suggesting that plagiarism matters, should be considered academic misconduct. Analysing plagiarism policies of 18 universities in Australia, the United Kingdom, and the United States of America, Sutherland-Smith (2010) found that all participating universities treated plagiarism as a form of academic misconduct.

Researchers recognise different boundaries between plagiarism and academic cheating. Sutherland-Smith (2008) said that academic cheating embraces plagiarism in its darkest form, highlighting negative connotations associated with the concept such as "intellectual murder", "the worm", "the cardinal sin of academe" and "academic felony" (p. 21). Some researchers view plagiarism as a form of academic cheating (Jereb et al., 2018; Williams, 2003; Zobel \& Hamilton, 2002). Others, in contrast, consider plagiarism a component of academic dishonesty, along with academic cheating, affirming that plagiarism intersects with academic cheating when students knowingly plagiarise to deceive academic faculty and gain an advantage (Bretag, 2013; Howard, 2016; Vehviläinen et al., 2018; Whitley Jr \& Keith-Spiegel, 2012).

Despite belonging to the larger category of academic misconduct, plagiarism is treated separately by scholars, due to its complexity (Bokosmaty et al., 2019; Bretag, 2013; de Jager \& Brown, 2010; Howard, 2007; Macdonald \& Carroll, 2006; Pecorari, 2016; Sousa-Silva, 2020) and its impacts on academia (Bretag, 2013; Maio et al., 2020; Martin, 2016; Yeo \& Chien, 2007).

\section{Plagiarism as a scholarly offence}

It is widely believed that plagiarism is a scholarly offence because it undermines ethical research standards (Pecorari, 2015; Valentine, 2006; Vehviläinen et al., 2018), takes attribution away from original writers (Anderson \& Steneck, 2011; Bouville, 2008; Bruton, 2014; Martin, 2016; Power, 2009), and creates unfairness within academia (Culwin, 2006; Gipp, 2014; Martin, 2016; Weber-Wulff, 2014). Plagiarism also involves "giving a false statement" about contribution (Vehviläinen et al., 2018, p. 3), which may help plagiarists obtain rewards that exceed their ability (Bouville, 2008; Bretag, 2013; Weber-Wulff, 2014).

Some scholars hold the view that plagiarism impacts the quality of academic work. Plagiarism, both intentional and unintentional, damages academic standards (Pecorari, 2003) and 
represents poor scholarship (Balve, 2014; Vardi, 2012). According to Bretag (2013), plagiarism diminishes the value of original scholarly work. Plagiarising students failed to represent themselves as academic writers, although they are expected to make novel contributions to their field (Abasi et al., 2006). Also, plagiarism threatens academic discourse and makes it hard for readers to identify sources (Bouville, 2008; Bruton, 2014; Weber-Wulff, 2014).

The evidence presented in this section suggests that plagiarism grievously damages academic norms and principles, highlighting the need to make students understand why plagiarism matters and how to avoid it, which hopefully enhances institutional academic integrity.

\section{Plagiarism as part of the learning process}

Alternatively, plagiarism is viewed by some scholars as a part of language use or a linguistic phenomenon. These scholars focused on textual features and the occurrence of plagiarism within the process of learning to write, especially in another language. Pecorari (2008) considered plagiarism an undesirable textual feature that can be determined without examining the presence or absence of deceptive intention. In particular, the amount of similar text and lack of other textual features like quotation marks can help to identify plagiarism instances. Students might plagiarise unintentionally because they are influenced by the materials they read and cannot express themselves in their own words (Pecorari, 2016). Similarly, Howard (1993) noted that patch-writing, viewed by scholars as a type of plagiarism, should be treated as a means of language acquisition.

Researchers consider inadvertent plagiarism or patch-writing (see Section 2.7.5) - a concept developed by Howard (1993) - as a transitional stage in academic writing development. Some view it as an interim stage in the path to becoming writers (Introna \& Hayes, 2008; Pecorari, 2003, 2008, 2016; Pecorari \& Petric, 2014). Students who are new to academic culture and have not learnt specific practices and skills would be more likely to make mistakes despite not intending to do so (Adhikari, 2018; Pecorari, 2016; Shi, 2004). Also, novice writers are developing their ability to use sources (Amiri \& Razmjoo, 2016; Howard, 1993; Introna \& Hayes, 2008; Pecorari, 2016). According to Pecorari (2016), most students use sources improperly before learning to do it correctly.

Scholars recognise the potentials of inadvertent plagiarists to acquire knowledge and produce language. Some insisted that plagiarism sometimes results from an effort to produce good 
writing (Briggs, 2009; Introna \& Hayes, 2008; Shi, 2004; Sousa-Silva, 2014). By integrating other people's ideas into their writing, students engage with materials and acquire content knowledge (Introna \& Hayes, 2008; Neville, 2007). Patch-writing facilitates students' source use skills and acquisition of academic phraseology (Introna \& Hayes, 2008; Pecorari \& Petric, 2014).

Academics highlight the need for an alternative view of plagiarism other than a moral concern, proposing strategies to better accommodate student understanding. Several called for treating plagiarism as a developmental issue rather than an issue of ethics (Abasi et al., 2006; Adam et al., 2016; Blum, 2009; Briggs, 2009; Chandrasoma et al., 2004; Gu \& Brooks, 2008; Howard, 2016; Introna \& Hayes, 2008). Some insisted that patch-writers could become competent writers if received proper guidance and support (Briggs, 2009; Introna \& Hayes, 2008; Pecorari, 2003, 2008, 2016). Academics and universities should recognise problems facing students, especially those who come from other academic cultures and contexts (Adam, 2015a; Adhikari, 2018; Amiri \& Razmjoo, 2016; Fatemi \& Saito, 2020; Robertson et al., 2000; Shang, 2019).

Positioning plagiarism as part of the learning process, some researchers maintain that teachers should employ educative rather than punitive approaches. Regulations are intended not only to punish but also to rehabilitate offenders (Macdonald \& Carroll, 2006). Determination of what punishments are imposed should be based on the presence or absence of intention (Carroll, 2016). Students should be explicitly informed about universities' expectations (Carroll, 2008; Phan, 2006). They need support and education more than regulations and punishments (Adhikari, 2018; Badke, 2007; Chandrasoma et al., 2004; Fatemi \& Saito, 2020; Marshall \& Garry, 2005; Sutherland-Smith, 2010; William, 2007). Others suggested that academic institutions should enhance student understanding of academic integrity and intellectual property which helps to promote an academic culture of integrity (Bretag, 2013; McCabe \& Stephens, 2006; Stephens et al., 2007).

Similarly, researchers suggested improving students' academic writing skills (Amiri \& Razmjoo, 2016; Badke, 2007; Briggs, 2009; Pecorari, 2013; Shang, 2019), language ability (Perkins et al., 2018), source use skills (e.g., Adam et al., 2016; Adhikari, 2018; Badke, 2007; Fatemi \& Saito, 2020; Howard, 1993; Pecorari, 2016), and awareness of academic integrity (Belter \& Du Pré, 2009; Blum, 2009; Gullifer \& Tyson, 2010; Sutherland-Smith, 2014) if plagiarism resulted from unawareness or inexperience. Some argued that pedagogical techniques that enhance student understanding of academic conventions are more helpful than focusing on dishonesty and 
intentional factors (Adhikari, 2018; Amiri \& Razmjoo, 2016; Fatemi \& Saito, 2020). However, analysing the policies concerning plagiarism of 18 world-ranked institutions, Sutherland-Smith (2010) found that policies rarely mention reforming or rehabilitating accused plagiarists.

\subsubsection{Conclusion}

The literature suggests that academics view plagiarism either as a subject of criticism or as a matter of concern. These schools of thought highlight debate over how academic institutions, especially higher education institutions, should view and treat student plagiarism. Although deliberate plagiarism is morally and academically wrong, students' ability to incorporate others' words and ideas into their writings can be improved by learning. These sets of ideas inform the study to inquire into how students view plagiarism. Specifically, survey items and interview questions were designed in this study to explore these perspectives.

\subsection{Student Perceptions of Plagiarism}

This section reviews previous findings on student perceptions of plagiarism, focusing on how they defined plagiarism and their perspectives of the practice.

\subsubsection{Students' Conceptualisation of Plagiarism}

Although student plagiarism has increasingly drawn attention from academics worldwide, there has been little evidence relating to how students defined the concept. According to Yeo (2007), researchers may assume that student conceptualisation of plagiarism was similar to academics. While several attempts have been made to explore how undergraduates defined plagiarism (Egan, 2008; Green et al., 2006; Marshall \& Garry, 2006; Stappenbelt, 2012), little is known about postgraduate student conceptualisation of plagiarism (Selemani et al., 2018).

Research suggests that a majority of undergraduate students were unable to define plagiarism appropriately. Amiri and Razmjoo (2016) indicated that many NESB undergraduate participants in their study could not properly define plagiarism. Sutherland-Smith (2005b) revealed that only around $23 \%$ of international undergraduates could provide a definition of plagiarism aligned with the university's definition. Kokkinaki et al. (2015) found that while most undergraduate participants in Cyprus recognised some features of plagiarism such as presenting someone else's work as one's own and without acknowledgement, their definitions failed to capture the nuances of the behaviour. Yeo (2007) reported that only $18 \%$ of his first-year participants 
defined plagiarism with all three elements: copying or using someone else's work, presenting it as one's own, and without acknowledgement. $27 \%$ of them defined it as copying or using others' work as one's own. 43\% of them mentioned copying others' work and without acknowledgement. 12\% failed to define it properly. Many undergraduate students in New Zealand provided confused definitions of plagiarism (Adam, 2015b; Adam et al., 2016) and many Taiwanese undergraduates could only provide simple definitions of it (Chien, 2017).

Studies revealed widespread confusion of undergraduate students in various educational settings. While many undergraduates in Australia showed basic understanding of plagiarism, they misunderstood other cheating behaviours (e.g., collusion) as plagiarism (Gullifer \& Tyson, 2010). Many engineering students in an Australian study only considered deliberate copying as plagiarism (Yeo, 2007). Misconceptions and confusions of students around various aspects of plagiarism were found in New Zealand (Adam et al., 2016), Japan (Rinnert \& Kobayashi, 2005), Cyprus (Kokkinaki et al., 2015), and Malaysia (Ahmad et al., 2012; Smith et al., 2007).

Overall, previous studies indicated a lack of understanding and confusion around plagiarism and its components among many students, both ESB and NESB. Many undergraduate students understood plagiarism vaguely and their conceptualisation of plagiarism was unaligned with their universities' definition of it. These indicated a need to explore how students define plagiarism to ensure that they understand plagiarism the same way as their universities do.

\subsubsection{Students' Framing of Plagiarism}

In the literature, students have demonstrated contrasting perspectives of plagiarism with and without intention. While intentional plagiarism was perceived as a moral and regulatory issue, unintentional plagiarism was considered an unavoidable part of the learning process.

Most students in previous studies described deliberate plagiarism as a moral issue. Some viewed it as a deceitful behaviour (Babaii \& Nejadghanbar, 2017; Shang, 2019; SutherlandSmith, 2008), a dishonest act (Babaii \& Nejadghanbar, 2017; Dawson \& Overfield, 2006; Farahian et al., 2021), or an immoral practice (Bamford \& Sergiou, 2005; Bennett, 2005; Gunnarsson et al., 2014). Others considered it as stealing (Dawson \& Overfield, 2006; Egan, 2008; Farahian et al., 2021; Shang, 2019).

Plagiarism is also perceived by students, both undergraduate and postgraduate, as an act of wrongdoing or a violation of university rules. Through in-depth interviews with 21 
undergraduates in a New Zealand university, Adam et al. (2016) found that many students viewed plagiarism as a violation of university rules. Selemani et al. (2018) reported that all postgraduate students in a university in Malawi considered plagiarism as a serious breach of academic standards. Gullifer and Tyson (2010), similarly, revealed that many undergraduate students in an Australian university considered major copying as inappropriate.

Students may consider plagiarism as a developmental issue or part of the learning process. When being asked to describe plagiarists, over half of the graduate students in Babaii's (2017) study used words such as inexperienced, innocent, uninformed, and immature. Their language suggested that these students thought plagiarism was committed inadvertently rather than from a deliberate attempt to cheat. Most Asian students in Bamford and Sergiou's (2005) study did not view copying from textbooks as cheating. Chinese students in Hu and Lei's (2015) study held the view that plagiarism was understandable and forgivable. Similarly, Sutherland-Smith (2008) reported that many first-year international undergraduate students in Australia believed that unintentional plagiarism should not be considered academic misconduct.

Overall, previous research has offered substantial findings regarding how students perceived plagiarism. However, most studies failed to capture the nuances underlying students' views, suggesting the importance of further and in-depth explorations to provide a more complete understanding and explanation of the issue.

\subsection{Variations in ESB and NESB Students' Perceptions of Plagiarism}

Dissimilarity in perceptions of plagiarism among ESB and NESB students has increasingly drawn attention from researchers with several studies addressing this issue since 2005. Despite providing comprehensive data about the topic, these studies leave a noticeable gap related to what might shape students' perceptions of the issue. Moreover, most studies exploring student perceptions were quantitative using self-report questionnaires (e.g., Bokosmaty et al., 2019; Egan, 2008; Ehrich et al., 2016; Hayes \& Introna, 2005; Javaeed et al., 2019; Maxwell et al., 2008; Ramzan et al., 2012; Stappenbelt, 2012) and scenarios (e.g., Marshall \& Garry, 2006; Maxwell et al., 2008; Sutton et al., 2014). There has been little qualitative analysis to support deeper and more complete understanding of the subject (e.g., Adam, 2015b; Adam et al., 2016; Amiri \& Razmjoo, 2016; Gullifer \& Tyson, 2010). 


\subsubsection{Knowledge of Plagiarism}

While several studies found that ESB students possessed better knowledge of plagiarism than their NESB counterparts, in terms of the concept meaning, its various forms, and the policies around it, other studies presented contradictory findings of these two groups.

It has been revealed that NESB international students demonstrated inadequate understanding of plagiarism and related issues. Most NESB international students possessed unsophisticated understanding of plagiarism (Bamford \& Sergiou, 2005; Robertson et al., 2000) and referencing conventions (Bamford \& Sergiou, 2005; Chen \& Van Ullen, 2011; Sutherland-Smith, 2005a). They were also unaware of their university's policy and expectations concerning plagiarism (Amiri \& Razmjoo, 2016; Ramzan et al., 2012; Stappenbelt, 2012).

In Asian contexts, researchers reported a lack of basic understanding of plagiarism among most students. Many Iranian undergraduate students showed shallow understanding of plagiarism and were unclear about its various forms (Amiri \& Razmjoo, 2016; Babaii \& Nejadghanbar, 2017; Rezanejad \& Rezaei, 2013). And this confusion was evident among many Malaysian undergraduate students (Ahmad et al., 2012; Smith et al., 2007). Others reported inadequate understanding of plagiarism among undergraduates in Pakistan (Javaeed et al., 2019; Ramzan et al., 2012; Rathore et al., 2018), Thailand (Khathayut et al., 2020), Japan (Rinnert \& Kobayashi, 2005), Taiwan (Chien, 2017), and China (Hu \& Lei, 2012, 2015). Limited understanding of plagiarism was also held by postgraduate students in Japan (Rinnert \& Kobayashi, 2005), Iran (Rezanejad \& Rezaei, 2013), Thailand (Puengpipattrakul, 2016), and Pakistan (Ramzan et al., 2012; Rathore et al., 2018). Du (2020) found that most Chinese postgraduate students possessed limited understanding of subtle plagiarism before engaging in a training section about referencing and plagiarism.

ESB students were found to have greater awareness than their NESB counterparts because they performed slightly better in identifying plagiarism in academic work. ESB postgraduate students in Australia, for example, were reported to be better than NESB students in identifying plagiarism (Green et al., 2006). Similarly, ESB students in the USA were found to possess a better awareness of plagiarism and be more attempted to avoid it than Chinese students (Shi, 2004). Gullifer and Tyson (2010), revealed that most domestic students in Australia, both undergraduate and postgraduate, possessed good understanding of plagiarism and around $52 \%$ of them had read the university plagiarism policy. 
Other studies revealed contradictory findings of ESB and NESB students' understanding of the issue. Stappenbelt (2012) found that most overseas students were aware that plagiarism was academically wrong. According to Egan (2008), most international students showed good basic understanding of the concept. Ryan et al. (2009) observed that while most undergraduate and postgraduate students at an Australian university were aware of their university's plagiarism policy, few knew what the policy covered. Two studies reported similar ability to identify plagiarism among international and domestic students (Egan, 2008; Maxwell et al., 2008).

\subsubsection{Framing of Plagiarism}

Research suggests that many NESB international students were not fully aware of moral implications of plagiarism. Some international students in the UK failed to understand moral aspects of plagiarism; specifically, most Asian international students did not view copying from textbooks as cheating (Bamford \& Sergiou, 2005). Most graduate students in an Iranian university described plagiarists as inexperienced, innocent, and uninformed, suggesting that they considered plagiarism more as unintentional behaviour than deliberate attempts to cheat (Babaii \& Nejadghanbar, 2017). Only 35\% of undergraduate students in a Pakistani university viewed plagiarism as unethical (Javaeed et al., 2019) and many Chinese students viewed plagiarism as understandable and forgivable (Hu \& Lei, 2015). Similarly, many NESB international students in an Australian university considered that not plagiarising was primarily to avoid penalties (Sutherland-Smith, 2008).

The literature, in contrast, suggests that most ESB students are more aware of moral aspects of plagiarism than their NESB counterparts. In a cross-cultural comparison study between Japanese and American undergraduate students, Rinnert and Kobayashi (2005) reported that $64 \%$ of the American students considered plagiarism as unethical and most showed greater awareness of the importance of acknowledging sources than their Japanese counterparts. Stappenbelt (2012) reported that while "dishonest" was the most frequent term Australian students used to describe plagiarism (19\%), only $0.6 \%$ of international students viewed the practice as dishonest. $27 \%$ of international students considered plagiarists as inexperienced.

\subsubsection{Perceived Seriousness of Plagiarism}

Contradictory findings regarding students' perceived seriousness of plagiarism were reported. International students viewed several types of plagiarism less seriously than locals (Hayes \& 
Introna, 2005; Marshall \& Garry, 2006; Sutton et al., 2014). In a study of 2500 students from multiple universities in the UK and Australia, Sutton et al. (2014) found that students previously educated in China and Southeast Asia viewed poorly referencing less seriously than those educated in Europe or Australia. Ehrich et al. (2016) revealed that more Chinese students accepted excuses for plagiarism than their Australian counterparts and that Australian students viewed plagiarism more severely than Chinese students.

\subsection{Why Plagiarism Matters}

Plagiarism is taken seriously in higher education to maintain academic integrity. The literature suggests that most students plagiarise without caring about its tremendous impact. Questions have been raised about how to manage plagiarism and make students aware of its seriousness to create a culture of integrity within academic institutions.

\subsubsection{Personal Impacts}

The most immediate impact of plagiarism on plagiarising students is being disciplined. The literature suggests various types of punishment for identified plagiarists depending on the gravity of the offence. Analysing policies concerning plagiarism of 18 world-ranked institutions, Sutherland-Smith (2010) found that all universities stipulated a range of punishment for accused plagiarists. Cheah (2016) said that penalties for plagiarism range from resubmission and counseling (for inadvertent plagiarism) to lowing course grades (for blatant plagiarism). A common punishment for minor unintentional plagiarism at a university in Sweden is to reduce a grade; for serious cases, students are suspended for up to six months (Carroll \& Zetterling, 2009). Other severe penalties include failing a subject (Zobel \& Hamilton, 2002), withdrawal of a title (Sousa-Silva, 2014), and expulsion (Pecorari, 2003, 2008; Zobel \& Hamilton, 2002).

Another significant impact is related to losing learning opportunities. Assignments are designed to facilitate learning which means plagiarising students do not learn what they are expected to learn such as citing and referencing techniques (Howard, 2002, 2007; Weber-Wulff, 2014). According to Carroll (2009), students who plagiarised rejected opportunities for development and improvement. They were awarded degrees without knowing that they had used improper citation and referencing techniques (Pecorari, 2003). Therefore, academic writing becomes more challenging for them as their studies progress (Gullifer \& Tyson, 2010). Participants in 
previous studies also thought plagiarising students did not learn much (Adam et al., 2016; Babaii \& Nejadghanbar, 2017).

Another consequence relates to breaking trust - one of the six fundamental values of academic integrity: honesty, trust, fairness, respect, responsibility, and courage (International Center for Academic Integrity, 2017). Academics who plagiarised would lose the trust of readers (Bouville, 2008) or their teachers (William, 2007). When teachers' trust is betrayed, their relationship with the plagiarising student is ruined and it affects how they treat future student cohorts (William, 2007). Their perceptions of the student's honesty also influence how they respond to him/her and his/her work (William, 2007).

\subsubsection{Academic Impacts}

Plagiarism is believed to be a threat to educational environments because it impairs the integrity of academic processes (e.g., Bretag, 2013; Ehrich et al., 2015; Maio et al., 2020; Singh \& Remenyi, 2016; Weber-Wulff, 2014). Academic integrity is to guarantee that students submitted their work (Kwong et al., 2010) which demonstrates their learning (Carroll, 2008; Howard, 2002). Plagiarising students fail to contribute novel ideas as writers (Abasi et al., 2006). Also, plagiarism damages educational systems (Pecorari, 2016), impairs assessment processes (Yeo \& Chien, 2007), and diminishes the value of higher education (Gunnarsson et al., 2014).

Plagiarism is believed to lessen the meaning or value of the qualification which is supposed to reflect students' attainment and capabilities. Plagiarism challenges the validity of the degree awarded to plagiarising students, raising the question as to whether they are qualified enough (Ehrich et al., 2015; Singh \& Remenyi, 2016). Many participants in Dawson's (2006) study thought students could not show their knowledge through their plagiarised work.

The most important concern is that plagiarism brings undeserved benefits for plagiarists (Bouville, 2008; Gipp, 2014; Pecorari, 2003) while taking attribution and intellectual capital away from original creators (Bouville, 2008; Bretag, 2013; Bruton, 2014; Gipp, 2014; Power, 2009). Therefore, it gives promotion opportunities for falsely qualified people (Weber-Wulff, 2014) by giving them rewards that mismatches their ability (Bretag, 2013; Gipp, 2014; WeberWulff, 2014). Participants from previous studies believed that plagiarism was unfair to original writers (Adam, 2015b; Adam et al., 2016; Babaii \& Nejadghanbar, 2017; Shang, 2019). 


\subsubsection{Conclusion}

The literature suggests various impacts of plagiarism both on plagiarists and academia. In terms of personal impact, plagiarising students would be disciplined, lose development opportunities, and be in worse relationships with lecturers. Academically, plagiarism would offend fairness, threaten educational systems, and make the degrees less meaningful.

\subsection{Factors Associated with Student Perceptions of Plagiarism}

Awareness of limitations of cultural explanations for plagiarism has seen attention shift to an alternative approach focused on understanding the issue of plagiarism beyond purely cultural influences. A large body of literature has investigated other factors associated with student perceptions of plagiarism. Findings from these studies offer different perspectives, ones that challenge deficit models of education regarding plagiarism by international students and highlight the need to examine alternative explanations.

\subsubsection{Cultural Backgrounds}

Whether or not cultural background impacted students' plagiarism perceptions has long been controversial within academia. Researchers identified associations between individualisticcollectivist cultural values and students' perceptions of plagiarism. Sutton et al. (2014) considered that students from collectivist and individualistic cultures possess different understanding of plagiarism. Similarly, Chien (2017) believed that students from collectivist societies might not clearly distinguish between individual and communal property and social relationships are more important in collective-oriented societies.

Scholars highlighted differences in perceptions of plagiarism and textual ownership between Westerners and Easterners. They pointed out influences of communal ownership of knowledge (Chien, 2017; Sowden, 2005), perceived seriousness of plagiarism (Bamford \& Sergiou, 2005; Zobel \& Hamilton, 2002), memorisation practice (Heitman \& Litewka, 2011; Sowden, 2005), and rote learning habits (Leask, 2006; Zobel \& Hamilton, 2002) on multilingual students' perceptions. Students from other cultures are believed to conceptualise and treat plagiarism differently from standards of Western institutions (Bamford \& Sergiou, 2005; Pecorari, 2003; Zimerman, 2012; Zobel \& Hamilton, 2002). Also, students may have distinct cultural beliefs and values that may influence their attitudes towards plagiarism and textual ownership (Amsberry, 
2009; Bamford \& Sergiou, 2005; Fatemi \& Saito, 2020; Gourlay \& Deane, 2012; Pecorari, 2003, 2013; Shi, 2004; Sutton et al., 2014; Zimerman, 2012).

Other scholars contested stereotyping of students from Eastern cultures regarding plagiarism. Phan (2006) disagreed that culture was associated with the prevalence of plagiarism. She asserted that plagiarism was unacceptable in Vietnamese culture and memorisation techniques in Vietnamese educational practices were unrelated to plagiarism. Similarly, while identifying memorisation as a common learning technique in Chinese and Far East educational systems, Liu (2005) insisted that plagiarism was viewed as inappropriate in Chinese cultures. Adhikari (2018) said that institutions should provide students with necessary skills rather than focusing on how different cultures might define intellectual honesty and plagiarism.

Researchers highlighted the need for an holistic stance towards plagiarism by international students. Many emphasised that plagiarism is a complex issue that needs further investigation (Adhikari, 2018; Evering \& Moorman, 2012; Hayes \& Introna, 2005; Macdonald \& Carroll, 2006; Pecorari, 2016). Leask (2006) suggested that when educators stereotype Asian students as more susceptible to plagiarism, this prevents them from responding effectively to the issue. Numerous scholars recommend making plagiarism expectations explicit to students (Adam et al., 2016; Green et al., 2006; Hayes \& Introna, 2005; Leask, 2006; Marshall \& Garry, 2005; Phan, 2006) and providing them with skills to engage with sources (Adam et al., 2016; Adhikari, 2018; Green et al., 2006; Leask, 2006; Marshall \& Garry, 2005; Vardi, 2012; Yeo, 2007), rather than policing and punishing (Adhikari, 2018; Bretag, 2013; Marshall \& Garry, 2005). Others suggest universities respect the diversity of student backgrounds and needs (Amsberry, 2009; Leask, 2006; Marshall \& Garry, 2005). Taking a broader perspective, Vardi (2012) called for rethinking the relationship between referencing ability and plagiarism. He highlighted the power of citation and referencing in reflecting student understanding and engagement with knowledge. While not explicitly discussing plagiarism, Tran (2013), in her book on international students' adaptation to academic writing, argued for adopting a more critical perspective of international students' academic adaptation that moves away from linguistic and cultural factors.

\subsubsection{Educational Background}

Educational background is identified as a major influence on student perceptions. Much of the literature on plagiarism indicates impacts of several aspects of educational histories including 
prior plagiarism education, language competence, academic expectations, and academic approaches including assessment practices on student perceptions of plagiarism.

\section{Plagiarism education}

Researchers suggest that education about plagiarism- related issues varies between countries around the world. Ongoing evidence suggests that international students might be uninformed about plagiarism-related issues before overseas studies. Bamford and Sergiou (2005) revealed that while most Chinese students learnt about plagiarism before coming to the UK, most international students from West Africa and other Asian countries did not know about plagiarism. A majority of international students were uninformed about plagiarism prior to their studies in Australia (Stappenbelt, 2012; Sutherland-Smith, 2005b) and Canada (Shi, 2006). Nguyen and Buckingham (2019) reported that all seven Vietnamese master's students in their study were uninstructed about citation conventions in their undergraduate studies in Vietnam.

Research revealed inadequate instruction on plagiarism and relevant issues at undergraduate levels in Asian contexts, suggesting this was not well aligned to students' needs. For example, Du (2020) indicated a lack of instruction on appropriate referencing in most tertiary institutions in mainland China. Rathore et al. (2018) found that many students in a Pakistani university received inadequate training on plagiarism. Limited plagiarism education was reported in Thai (Khathayut et al., 2020; Puengpipattrakul, 2016), Iranian (Babaii \& Nejadghanbar, 2017; Rezanejad \& Rezaei, 2013), and Japanese (Rinnert \& Kobayashi, 2005) contexts.

While most domestic students in Western countries were taught about plagiarism prior to tertiary education, this was not consistently the case. Stappenbelt (2012) showed that most domestic students in Australia were aware of plagiarism before entering university. In an investigation about teachers' and students' perceptions of academic writing and plagiarism across Europe, around $60 \%$ of the participants reported that training on academic writing and plagiarism was provided, suggesting that such education was neglected in some European countries (Foltýnek et al., 2014).

\section{Language experiences}

Language experience has a substantial impact on student performances, both as learners and writers. Many researchers hold that learners working in a less familiar language are more vulnerable to inadvertent plagiarism. NESB international students may have inadequate English 
proficiency which affected their ability to successfully engage with sources (Amsberry, 2009; Nguyen \& Buckingham, 2019; Pecorari \& Petric, 2014; Schmitt, 2005; Shi, 2004; Tran, 2012). Writing from sources is more demanding for NESB than ESB students (Abasi \& Graves, 2008; Divan et al., 2013; Perkins \& Roe, 2020; Schmitt, 2005; Shi, 2004; Tran, 2012). Tasks requiring integration between reading and writing are doubly difficult for NESB students who possess limited language resources compared to ESB ones (Schmitt, 2005). NESB learners' writing practices might be incompatible with Western norms of intellectual property (Marshall \& Garry, 2006; Park, 2003; Pecorari, 2008). Also, NESB and ESB students received different levels of instruction on academic writings (Du, 2020; Nguyen \& Buckingham, 2019; Pecorari, 2008; Phan, 2006; Rinnert \& Kobayashi, 2005; Stappenbelt, 2012).

\section{Academic expectations}

International students experience more problems adjusting to new academic environments than local students. Mismatches of expectations between home and overseas universities have been recognised as key influences. Some researchers found the plagiarism instruction that international students received earlier was inadequate compared to their overseas universities' demands (Stappenbelt, 2012; Sutherland-Smith, 2005b). Schmitt (2005) pointed out that expectations concerning writing from sources might be demanding for international students. Amsberry (2009) identified differing academic expectations as a major cause of student misunderstanding about plagiarism. According to Duff et al. (2006), it took time for international students to adapt to academic expectations of Western institutions.

\section{Academic practices}

Researchers suggest that educational practices significantly impact students' attitudes towards plagiarism and source use. Their limited exposure to course work might influence their source use skills and how they viewed academic integrity (Hayes \& Introna, 2005; Nguyen \& Buckingham, 2019). Other scholars problematised exam-oriented assessment practice (Bennett, 2005; Hayes \& Introna, 2005; Song-Turner, 2008) and assessments based on written assignments that international students experience in their home countries (Bennett, 2005). Amsberry (2009) asserted that differing educational approaches may influence how students view and understand plagiarism because some educational systems promote copying as a

learning technique. Hayes and Introna (2005) used focus group interviews with 126 
international students in the UK to show that Asian assessment methods which focus on textbook content discouraged critical thinking and expressions of students' ideas.

These studies suggest that educational backgrounds significantly impact students' ability to identify plagiarism and their sense of its significance. The evidence calls for higher education institutions and faculty staff to recognise students' diverse experiences and provide them with appropriate support and instructions to maximise their learning experiences.

\subsubsection{University Initiatives}

The literature evidenced the effectiveness of university initiatives on student views and understanding. These include interventions such as information about plagiarism policies, academic skills training, and instructions on plagiarism and related issues.

Raising student awareness of university plagiarism policies has been shown to improve their understanding of the issue. For example, Brown and Howell (2001) observed that students who received information about plagiarising and how to avoid it perceived plagiarism more seriously than those who did not. The authors postulated a lower rate of plagiarism occurred in this group of students compared to those in the control group. Duff et al. (2006) noticed that plagiarism among international master's students at an Australian university reduced significantly due to an intervention programme, implying that their awareness of plagiarism increased. Both studies highlighted the need to make rules and expectations explicit to students, increasing their opportunities to successfully engage in academic discourses.

The effectiveness of academic skills development on plagiarism perceptions has been proved in previous research. Newton et al. (2014) reported that tertiary students in an Australian university who participated in a skills training programme were better at in-text referencing, paraphrasing, and avoiding plagiarism than those in the control group. Divan et al. (2013) found that plagiarism rates among master's students in a UK university reduced significantly after a writing development programme and that students became more confident in doing assignments; non-UK students showed greater improvement in understanding of plagiarism, academic skills, and confidence level than their UK counterparts. A training section on referencing was found to significantly improve Chinese students' understanding of proper referencing and textual plagiarism (Du, 2020). Similarly, a 13-week course on plagiarism and 
related issues was reported to considerably improve international students' understanding of plagiarism and academic writing skills in an Australian university (Tran, 2012).

Other scholars proved that university's instructions on plagiarism greatly enhanced student understanding of the practice. Perkins and Roe (2020) reported the effectiveness of an Academic English Masterclass in improving Vietnamese students' academic writing and their understanding of academic conventions. Training on plagiarism-related issues could reduce student plagiarism in Taiwanese (Shang, 2019), Vietnamese (Perkins \& Roe, 2020), and the USA (Belter \& Du Pré, 2009) educational contexts. Training workshops on plagiarism also increase student understanding of the issue (Chen \& Van Ullen, 2011; Rathore et al., 2018).

These studies show the potentials of university initiatives in improving student understanding. They indicated that students' academic skills and understanding of academic integrity, especially plagiarism, would improve given appropriate training and instructions.

\subsubsection{Levels and Stages of Study}

Previous studies indicated significant differences in perceptions of plagiarism between undergraduate and postgraduate students. For example, postgraduate students perceived poor referencing slightly more seriously than undergraduate students due to longer exposure to academic writing and greater training in source use (Sutton et al., 2014). Postgraduate students viewed proper citation as more crucial to their work than undergraduate students (Rinnert \& Kobayashi, 2005). These preliminary findings suggest the need to engage students in academic writing conventions early in their studies.

Student perceptions of plagiarism have been shown to change during their studies, indicating an association between academic exposure and understanding improvements. Song-Turner (2008) revealed that international students' awareness of plagiarism increased through their exposure to Australian academic environments. More experienced writers were more conscious of textual identities than those with less writing experience (Abasi et al., 2006). Students in later years of their degree demonstrated better understanding of plagiarism than those transitioning to tertiary study (Hu \& Lei, 2015; Stappenbelt, 2012). 


\subsubsection{Disciplinary Practices}

Research revealed that students from different disciplines hold divergent views of plagiarism. For example, Business students viewed plagiarism less seriously than those who studied Arts and Biological Sciences (Sutton et al., 2014). English Language and Business Studies students were more likely than Mechanical Engineering and Computer Engineering students to consider slack attitudes as causes of plagiarism (Hu \& Lei, 2015). Students majoring in Humanities, Science, and Engineering were reported to understand plagiarism better than those from Arts and Communication faculties (Chen \& Van Ullen, 2011). However, Rinnert and Kobayashi (2005) noted that students majoring in Liberal Arts seemed more aware of plagiarism than those majoring in Science. These observed disciplinary differences suggest a need to realise students' different strengths and challenges to accommodate their distinctive learning needs. The findings also problematised a cross-disciplinary definition of plagiarism.

\subsubsection{Demographic Factors}

Contradictory findings regarding a link between gender and student perception of plagiarism have been presented. Hu and Lei (2015) reported no significant difference between male and female students, but noted gender interacting with disciplinary factors and affecting student views. For example, male Mechanical Engineering and Computer Engineering students agreed more strongly than male students from English Language and Business Studies that plagiarism resulted from pressure. Male respondents were more likely to read policies (Gullifer \& Tyson, 2014), advocated less severe penalties (Yeo, 2007), and were more confident in assignment writing (Smith et al., 2007) than their female counterparts. Female students were more likely to report poor research skills and difficulties in understanding journal articles (Smith et al., 2007). Male students held slightly more tolerant (Bokosmaty et al., 2019) and positive attitudes towards plagiarism than females (Jereb et al., 2018).

Students' professional experiences also significantly impact their perceptions (Leonard et al., 2015). Specifically, as teaching assistants, graders, and proctors, graduate students saw more plagiarism and were aware of how instructors dealt with the issue.

\subsubsection{Conclusion}

The literature provides important insights into factors associated with student perceptions, establishing broader contexts for understanding and managing the issues. Findings from these 
studies call for a shift from persistent associations of international students with plagiarism to accepting their differences and guiding them towards success.

\subsection{The Extent of Student Plagiarism}

Although a category itself within the broader concept of misconduct, plagiarism can be classified into various categories depending on the extent of the incident and its degree of seriousness. Historically, there is no agreement on how to classify plagiarism. Researchers use a variety of classification schemes resulting in many categories that are not mutually exclusive, as plagiarism can have multiple characteristics. From the most basic definition, there are seven types of plagiarism suggested by previous researchers.

\subsubsection{Direct Copying or Prototypical Plagiarism}

Pecorari $(2003,2008,2015)$ defined direct copying or prototypical plagiarism as unattributed use of words and/or ideas from other sources. Considering the amount of unattributed text, Whitley Jr and Keith-Spiegel (2012) conceptualised direct copying as submitting an exactly copied or slightly modified work as one's own.

\subsubsection{Ghostwriting}

Whether ghostwriting - hiring (Bloch, 2012) or paying (Ali \& Alhassan, 2021) another person to produce a text and claiming that as one's own, should be treated as plagiarism is controversial. Martin (2016) viewed this practice as a special form of institutionalised plagiarism, reasoning that it is ghostwriters who are plagiarised because they are under-credited for their writing. Others considered ghostwriting an extreme form of plagiarism because it involves misrepresentation or lying about authorship (Ali \& Alhassan, 2021; Singh \& Remenyi, 2016).

How ghostwriting should be treated is an area of concern. Some scholars said that while ghostwriting is acceptable in some settings (e.g., entertainment), it might be viewed as plagiarism in academic contexts (Bloch, 2012; Martin, 2016; Singh \& Remenyi, 2016; WeberWulff, 2014). Legal services that exist produce writing work for famous people (Singh \& Remenyi, 2016). However, ghostwriting in tertiary studies is undesirable because students are expected to be able to produce original academic work (Weber-Wulff, 2014).

Ghostwriting has become widespread due to its availability. The internet has made it easier and faster for students to buy untraceable papers (Bloch, 2012). The ready availability of 
ghostwriting services makes it hard to manage (Weber-Wulff, 2014). The latest ghostwriting services, ranging from essays to doctoral theses, are undetectable unless instructors are familiar with students' competence and writing styles (Singh \& Remenyi, 2016).

\subsubsection{Translation}

Plagiarism via translation is defined as having an original translated and claiming it as original work without crediting the author (Sousa-Silva, 2014) or converting a text to another language to hide its origin (Dougherty, 2020; Gipp, 2014). In research contexts, translation plagiarism is defined as republishing an academic work from one language to another without crediting original authors. (Dougherty, 2020). Translation is considered a form of plagiarism because the translated work is not original (Weber-Wulff, 2014) and plagiarists fail to acknowledge the contribution of the original writer (Anderson \& Steneck, 2011).

\subsubsection{Self-plagiarism}

Self-plagiarism is systematically classified as a form of plagiarism within both academia and pedagogical settings although the practice itself is contradictory to the generic definition of plagiarism as passing off someone else's work as one's own.

There are several definitions of self-plagiarism within academia. Some defined the concept as partially or completely reuse of one's own writings (Gipp, 2014) or previously published work (Geraldi, 2021) without justification. According to Bretag and Mahmud (2009), self-plagiarism involves reusing $10 \%$ or more of one's own earlier publication without acknowledgement. Selfplagiarism by academics is categorised differently based on the seriousness of the behaviours. Roig (2016) presents four types of self-plagiarism: duplicate publication (submitting a published paper to a different journal), augmented publication (republishing with additional observation), salami publication (generating more than two papers from the same study), and text recycling (re-using a considerable amount of previously published work). Geraldi (2021) categorises selfplagiarism into recycling text, recycling data, recycling representations, and recycling ideas. Bird (2002) differentiates two forms of self-plagiarism: dual (publishing a paper in more than one journal) and redundant publication (creating more than one paper using the same set of data).

It is widely agreed by scholars that self-plagiarism by academics is fraudulent (Bruton, 2014; Geraldi, 2021; Roig, 2016; Zhang, 2016). Although self-plagiarists do not steal others' works, the act of self-plagiarism breaks trust (Bruton, 2014), violates copyright (Bird, 2002; Zhang, 
2016), and creates unnecessary strain on reviewers and editors (Anderson \& Steneck, 2011; Bird, 2002). Self-plagiarism is deceptive, dishonest, and unacceptable (Bruton, 2014), and thus, is considered a form of research/writing malpractice and a type of cheating (Roig, 2016).

In pedagogical contexts, self-plagiarism has a slightly different meaning. For Whitley Jr and Keith-Spiegel (2012), self-plagiarism means handing one paper for credit in more than one course without instructors' permission. Bretag (2013) uses the term self-plagiarism to refer to reusing a previously submitted paper without attributing original work and/or without the teachers' permission. Bloch (2012) conceptualised it as submitting the same paper to more than one class. The practice is also defined as recycling one's own previous assignments or unpublished work (Halupa \& Bolliger, 2013; Halupa \& Bolliger, 2015; Halupa, 2014).

\subsubsection{Patch-writing}

Patch-writing is changing copied texts by deleting some words, altering grammatical structures, or plugging one-for-one synonym substitutes (Howard, 1993). Scholars differ in attitudes to patch-writing, regarding it as either understandable or debatable. Howard (1993) argued that patch-writing was a valuable composition strategy that students use to grasp new concepts and vocabulary. Pecorari (2003) concurred that patch-writing is unintentional plagiarism, so it should not be treated as a "stigmatising error" (p. 342) but as an essential phase of learning to use sources properly. In his later work, he argued that people involved in patch-writing use sources improperly without an intention to cheat (Pecorari, 2016).

\subsubsection{Insufficient Citation}

Another type of plagiarism identified by scholars is related to inadequate citation or insufficient acknowledgement. Sutherland-Smith (2008) indicates that plagiarism constitutes failing to include appropriate acknowledgement or inadequately attributing to other sources. This type of plagiarism, according to Drinan and Gallant (2008), is more commonly committed by novice students who have just been introduced to rules of citation and attribution.

\subsubsection{Unattributed Paraphrasing}

Unattributed paraphrasing means rewriting a piece of text in one's own words without appropriate attribution (Gipp, 2014) or heavily depending on a source for ideas despite utilising few or no words from that source (Whitley Jr \& Keith-Spiegel, 2012). Students who embed 
pieces of unattributed text into their writing are believed to be inexperienced, possess poor study skills, or lack proper understanding of academic expectations (Williams, 2003).

\subsubsection{Conclusion}

There are various forms of plagiarism with different degrees of seriousness. Classifications of plagiarism illustrate the emotional attitudes of some researchers (Whitley Jr \& Keith-Spiegel, 2012) in comparison to more objective stances of others (Bennett, 2005; Pecorari, 2008; Sutherland-Smith, 2008). While some researchers center on qualities of plagiarists (Roig, 2016; Williams, 2003), others focus on textual features and treat plagiarism as a behaviour (Howard, 1993; Pecorari, 2008; Whitley Jr \& Keith-Spiegel, 2012).

\subsection{Why Students Plagiarise}

Reasons for student plagiarism may be classified into personal, academic, institutional, and contextual factors. While intentional plagiarism seems to result from personal motives, academic pressure, time constraint, and personal circumstances, unintentional plagiarism may arise from a lack of knowledge and limited academic skills. Faculty members are partly responsible for student inadmissible appropriate practices because plagiarism is both an ethical and educational issue. Also, several contextual factors may contribute to student plagiarism.

\subsubsection{Personal Factors}

The desire to gain high grades is undoubtedly a frequent motivation for plagiarism. According to Pecorari $(2003,2008,2016)$, people who engaged in prototypical plagiarism with deceptive intent, were stimulated by the wish to obtain unearned academic benefits. Selemani et al. (2018) reported that nearly 90\% of plagiarising students in a university in Malawi wanted high grades. Chien (2017) revealed that all high achieving students in a Taiwanese university who plagiarised said that getting a high grade was their main motivation for plagiarism. Other studies revealed that plagiarism was associated with a desire to obtain high grades (Curtis \& Popal, 2011; Eret \& Ok, 2014; Sousa-Silva, 2014).

Various sources of pressure contributed to student plagiarism. High expectations from lecturers are consistently identified as a reason (Amiri \& Razmjoo, 2016; Babaii \& Nejadghanbar, 2017). Many students plagiarised because of pressure to succeed (Bamford \& Sergiou, 2005; Bennett, 2005; Curtis \& Popal, 2011) or their parents' expectations for children's academic achievement 
(Devlin \& Gray, 2007; Williams, 2003; Zobel \& Hamilton, 2002). Some plagiarised because of peer pressure when they knew that other students passed the assignments by plagiarising (Amiri \& Razmjoo, 2016). The pressure of adapting to new cultural and academic environments (Devlin \& Gray, 2007; Walker, 2009), heavy workload pressure (Egan, 2008; Sutherland-Smith, 2008) or time constraints (Devlin \& Gray, 2007; Egan, 2008; Rinnert \& Kobayashi, 2005; Selemani et al., 2018; Sutherland-Smith, 2008) might also lead students to plagiarise.

Many students plagiarised because of non-academic commitments. Students spend a lot of time on entertainment, sports, and family responsibilities (Park, 2003). Those who were overcommitted to social activities plagiarised when their workload became unmanageable (Zobel \& Hamilton, 2002). Pressure from earning an income also led them to plagiarise (Bennett, 2005; Howard, 2002; Walker, 1998; Williams, 2003; Zobel \& Hamilton, 2002).

\subsubsection{Academic Factors}

Recent evidence suggests that inadequate academic skills may lead to plagiarism. Most Iranian graduate students in Babaii and Nejadghanbar's and Amiri's (2016) study and nearly 85\% of postgraduate students in Selemani's (2018) study plagiarised due to poor academic writing skills. Devlin and Gray (2007) revealed that poor academic skills were a major reason for student plagiarism. Other academic skills found to be associated with student plagiarism included analytical skills (Bennett, 2005), evaluation skills (Bennett, 2005), research skills (Badke, 2007; Chen \& Chou, 2016; Chien, 2017; Zimitat, 2008), and skills to engage with sources (Camara et al., 2017; Gourlay \& Deane, 2012; Walker \& White, 2014).

Academic incompetence may contribute to student plagiarism. According to Williams (2003), academically weak students may be more willing to pass off others' whole work as their own. Students who earned high grades had a significantly lower prevalence of plagiarism than students who were awarded low grades, indicating a negative relationship between academic performance and the prevalence of plagiarism (Curtis \& Popal, 2011; Smith et al., 2007).

Researchers highlighted impacts of language barriers on plagiarism. NESB learners might accidentally include in their writing textual features that might be considered plagiarism in Western cultures (Pecorari \& Petric, 2014; Prochaska, 2001; Shi, 2004; Tran, 2012). They might struggle to find phrases and sentences to express their ideas, which leads them to copy others' words without an intention to cheat (Amsberry, 2009; Shi, 2004; Song-Turner, 2008; Zhang, 
2016). Others indicated that NESB students are more likely to commit plagiarism due to language difficulties (Heitman \& Litewka, 2011; Nguyen \& Buckingham, 2019; Pecorari, 2013, 2016), and more NESB students engaged in severe forms of plagiarism than ESB students (Marshall \& Garry, 2006). Participants in previous studies reported language difficulties as a reason for their plagiarism (Babaii \& Nejadghanbar, 2017; Song-Turner, 2008).

Common reasons for plagiarism reported by previous research include students' unawareness of plagiarism, citation conventions, and university policies. Students might plagiarise due to inadequate understanding of plagiarism (Devlin \& Gray, 2007; Ellery, 2008; Eret \& Ok, 2014; Farahian et al., 2021; Gullifer \& Tyson, 2010; Palmer et al., 2019; Pecorari \& Petric, 2014; Perkins et al., 2018) and what constituted the behaviour (Babaii \& Nejadghanbar, 2017; SongTurner, 2008; Tran, 2012). Plagiarising students might be unaware of citation conventions (Abasi \& Graves, 2008; Adhikari, 2018; Amiri \& Razmjoo, 2016; Bamford \& Sergiou, 2005; Belter \& Du Pré, 2009; Chen \& Chou, 2016; Devlin \& Gray, 2007; Selemani et al., 2018; Walker \& White, 2014). Others plagiarised because of failing to grasp university expectations both about the subject content (Babaii \& Nejadghanbar, 2017; Eret \& Ok, 2014) and plagiarism (Amiri \& Razmjoo, 2016; Ellery, 2008; Gullifer \& Tyson, 2010; Ramzan et al., 2012; Stappenbelt, 2012).

\subsubsection{Institutional Factors}

Limitations in plagiarism policies were believed to contribute to student plagiarism. Some researchers asserted that a lack of deterrence (Babaii \& Nejadghanbar, 2017; Park, 2003; Shang, 2019; Sutherland-Smith, 2008; Zobel \& Hamilton, 2002) or unclear policies would facilitate plagiarism (Babaii \& Nejadghanbar, 2017; Rinnert \& Kobayashi, 2005; SutherlandSmith, 2008; Walker \& White, 2014). Others noted that students are more tempted to plagiarise knowing that they are not punished (Amiri \& Razmjoo, 2016; Bennett, 2005; Eret \& Ok, 2014; Park, 2003; Selemani et al., 2018). Similarly, Devlin and Gray (2007) found that students' perceived seriousness of plagiarism was significantly associated with the prevalence of plagiarism, raising questions about possible links between ideas that students get from lecturers' enforcement practices and their expectation of being caught.

Associations between policy failure and plagiarism prevalence were evidenced in the literature. Bennett (2005) found that variations in intensity with which lecturers enforce plagiarism rules drive students to plagiarise. Most postgraduate students in Babaii's study (2016) thought students were more likely to plagiarise when plagiarism policies were limited. Students were 
more attempted to plagiarise when they knew that their lecturers were lenient (Babaii \& Nejadghanbar, 2017; Selemani et al., 2018; Walker \& White, 2014) or that they would not check student writings for plagiarism (Amiri \& Razmjoo, 2016; Babaii \& Nejadghanbar, 2017; Doan, 2012; Kokkinaki et al., 2015; Selemani et al., 2018). Many academics responded to plagiarism in ways that were unaligned with universities' policies, which may contribute to the issue (Maio et al., 2020; Selemani et al., 2018).

Research suggests that many students plagiarised due to inadequate training on plagiarism and its various forms (Amiri \& Razmjoo, 2016; Babaii \& Nejadghanbar, 2017; Gourlay \& Deane, 2012; Gullifer \& Tyson, 2010; Halupa \& Bolliger, 2015; Zhang, 2016). Insufficient instructions on academic writing (Amsberry, 2009; Chen \& Van Ullen, 2011; Kokkinaki et al., 2015; Rinnert \& Kobayashi, 2005; Schmitt, 2005), how to avoid plagiarism (Halupa \& Bolliger, 2015; Khathayut et al., 2020; Kokkinaki et al., 2015), and plagiarism policies (Brown \& Howell, 2001; Duff et al., 2006; Ellery, 2008) are other factors that exacerbated student plagiarism.

A significant body of research has explored impacts of assessment practices on inappropriate source use. Bennett (2005) found that assessments based on written assignments contributed to plagiarism. Hayes and Introna (2005), pointed out that coursework assessment which international students experienced in their home country contributes to plagiarism more than examinations. Other studies indicated assessment design as a factor that exacerbated student plagiarism (Comas-Forgas \& Sureda-Negre, 2010; Eret \& Ok, 2014; Walker \& White, 2014).

\subsubsection{Contextual Factors}

The literature suggests that students may breach academic integrity principles if opportunities to plagiarise are available. Most students thought plagiarising was an effortless way to pass (Chien, 2017; Comas-Forgas \& Sureda-Negre, 2010; Kokkinaki et al., 2015; Palmer et al., 2019) because it was simpler than doing the work (Chien, 2017; Comas-Forgas \& Sureda-Negre, 2010; Kokkinaki et al., 2015; Palmer et al., 2019). Some researchers suggest that the ease of plagiarism is due to the booming popularity (Marshall \& Garry, 2005; Sutherland-Smith, 2008) and easy accessibility of the internet (Amiri \& Razmjoo, 2016; Curtis \& Vardanega, 2016; Evering \& Moorman, 2012; Hyland, 2011; Kokkinaki et al., 2015; Zhang, 2016). McCabe and Stephens (2006) and Stephens et al. (2007) asserted that the internet did not cause student plagiarism but facilitated and exacerbated the issue. Others pointed out the influences of digital literacy growth on plagiarism (Badke, 2007; Ma et al., 2008; Palmer et al., 2019). 


\subsection{Chapter Summary}

Plagiarism is a controversial and complex practice because not only the concept incorporates many definitions but also the issue could arise from various personal, institutional, and cultural conditions. The literature indicates an attention shift from viewing plagiarism as a moral issue to acknowledging it as part of the learning process, supporting educative approaches to plagiarism management. Research showed that students' conceptualisation of plagiarism was inconsistent with how academics define it. Students' perceptions of plagiarism were found to be influenced by diverse factors, highlighting the need for further investigation of plagiarism to gain more holistic understanding of the issue.

Although scholars have extensively explored student perceptions of plagiarism, qualitative research on postgraduate student perceptions of plagiarism remains limited, especially in Vietnamese and New Zealand contexts. Two studies that explored how students in New Zealand perceived plagiarism both focused on undergraduate students. Studies on plagiarism in Vietnamese contexts mostly emphasised on the prevalence of and reasons for student plagiarism. While there are two studies that explored Vietnamese student perceptions of plagiarism, one study did not state the participants' academic levels and one included Vietnamese students as a sub-group of international students. Most studies have been quantitative and investigations of influences on student perceptions are rare.

These gaps in current knowledge highlight the value of my study which focused on perceptions of plagiarism among VN- and NZ-educated postgraduate students, especially doctoral students, and influences on their perceptions. 


\section{Chapter 3 | Theoretical Framework}

\subsection{Introduction}

This chapter provides an overview of the theories underpinning the study. Section 3.2 focuses on Bourdieu's (1977) theory of cultural capital, highlighting forms of cultural capital, the evolving uses of the theory, how the concept of cultural capital is used in the field of academic integrity, and a critique of the theory. Section 3.3 introduces Bandura's (1991) social cognitive theory of moral thought and action, focusing on the development of moral standards, moral judgement, the self-regulatory mechanism, and moral disengagement. Section 3.4 presents Marginson's (2014) student self-formation theory, which relates to the self-formation of international students, and discusses the applicability of the theory in educational research. Section 3.5 concludes the chapter by summarising how the theories connect.

\subsection{Cultural Capital Theory}

The theory of cultural reproduction and social reproduction was developed by Bourdieu (1973). Through this work, he proposed the concept of cultural capital. Bourdieu (1977) defined cultural capital as "instruments for the appropriation of symbolic wealth socially designed as worthy of being sought and possessed" (p. 488). Bourdieu (1977) asserted that cultural capital maintains social inequality because people from families rich in cultural capital were more likely to earn more cultural capital or be materially successful. Originally, this theory was used as a framework to explain the maintenance of different social classes in Bourdieu's native France.

\subsubsection{Forms of Cultural Capital}

According to Bourdieu (1986), cultural capital takes three forms: embodied, objectified, and institutionalised. Embodied cultural capital is the fundamental state that is connected to the mind and body. In this state, cultural capital is a form of knowledge that settles within individuals such as preferences, skills, social networks, and educational credentials. Embodied cultural capital is accumulated through inculcation and assimilation. Accumulation of embodied capital is a self-improvement process that takes time and requires personal investment. Individuals cannot accumulate cultural capital beyond their capacities.

Embodied cultural capital functions as a symbolic capital that is perceived as legitimate competence. Scarce cultural capital brings material and symbolic profits to its possessor. 
Embodied cultural capital can be acquired unconsciously, depending on the period, society, and social class. Bourdieu (1986) highlights that embodied capital is a constituent part of every person and cannot be transmitted, purchased, or exchanged; children of families with strong cultural capital accumulate capital easily and rapidly through socialisation.

Cultural capital in the objectified state, which may include writings, paintings, and instruments, can be appropriated materially and symbolically. Objectified capital (or its legal ownership) is transmissible. Bourdieu (1986) maintains that the appropriation of objectified cultural capital is dependent on embodied capital that the given agent holds, demonstrating its symbolic power. Accordingly, the process and required time for appropriating this form of capital depend primarily on the cultural capital possessed by the family. Differences in cultural capital decide one's accumulation capacity and the age when transmission and accumulation begin.

Cultural capital in the institutionalised state comprises educational qualifications that represent institutional recognition of individuals' cultural capital, such as the degree that the people own and how society values them through that degree. Bourdieu (1986) considers institutionalised capital as a certificate of cultural competence that provides its owner a standard, persistent, and legally secured cultural value. Because academic qualifications have a conventional and fixed value guaranteed by law, it is argued that a certificate has the same value to all holders. One qualification holder can substitute other qualification holders.

Academic qualifications enable a comparison of any qualification bearers and allow establishing conversion rates between cultural and economic capital, which can be formed by ensuring the monetary value of any academic capital (Bourdieu, 1986). This process, thereby, determines the value of a given qualification holder to other qualification holders. The meaning of academic investment depends on the reversibility degree of the conversion. Also, the scarcity of an academic qualification determines its material and symbolic profits.

\subsubsection{Three Branches of Cultural Capital Research}

No consensus has been reached regarding how to define cultural capital since its introduction (Davies \& Rizk, 2018). For Dumais (2002), cultural capital encompassed linguistic skills and highstatus cultural knowledge and competence. Yosso (2005) understands cultural capital as cultural assets and resources valued by dominant groups. Cultural capital, as defined by Swartz (2012), may include verbal talent, cultural awareness, artistic preferences, knowledge about 
the educational system, and academic credentials. While Schirato (2018) considers cultural capital as assets that a field recognises as valuable and are exchangeable within that field, according to Davies and Rizk (2018), it comprises cultural characteristics rewarded in the educational system. From points of agreement in these definitions, cultural capital could be understood as forms of knowledge, skills, education, and advantages that a person possesses, which arise from and provide continued access to a higher social status.

Cultural capital itself is a durable but generative and evolving concept (Davies \& Rizk, 2018; Lareau \& Weininger, 2003). Davies and Rizk (2018), in their narrative review, identified three generations of its development. In the first generation, the 1970s until the early 1980s, cultural capital was mainly conceptualised as high-brow cultural practices. Scholars of this generation used the concept as a tool to understand and explain disparities in educational outcomes. From the second generation, the late 1980s until the early 2000s, studies that explored the concept split into three broad variants which developed into three branches in the third generation (the late 2000s until now): DiMaggio's high culture, Lareau's concerted cultivation, and Collins's ritual and cultural capital branches. These branches were categorised based on researchers' interpretations of the concept, their focuses, and the methodologies used.

The first and dominant branch includes those who conceptualised cultural capital in relation to elite status cultures or high-brow arts participation and independently of skills and abilities. These scholars employed statistical analysis to investigate educational attainment among different social groups. The leading researcher of this stream was DiMaggio, who employed Bourdieu's cultural capital framework to explore relationships between class status and educational outcomes (Dimaggio, 1982). Over the past few decades, many scholars have followed DiMaggio's model. Noble and Davies (2009) developed indicators of students' cultural capital to explore the relationship between these cultural capital components and variations in higher education participation. Sullivan (2001) examined the effects of children's and parents' cultural capital on students' educational performance, considering cultural activities, cultural knowledge, and language as cultural capital. Others explored influences of cultural capital on first-generation college students' success (Collier \& Morgan, 2008; Dumais \& Ward, 2010).

In contrast, Lareau (2000, 2002), an influential researcher of the second stream, employed qualitative analysis to examine variations of parents' strategies to align their family practices with institutional expectations. Lareau (2002) developed the term "concerted cultivators", 
which characterises middle-class families who are highly involved in their children's education to secure class advantages. Similarly, Lareau and Weininger (2003) advanced the definition of cultural capital by emphasising micro-interactional processes in which individuals (through knowledge, skills, and competence) comply with institutional standards. They considered knowledge and specialised skills, which are potentially monopolistic and rewarded and could be transmitted among generations, as part of individuals' cultural capital. Despite emphasising parental practice and its effect, Lareau also focused on class differences.

The most recent and least developed interpretation of cultural capital was led by Collins (2014), who considered cultural capital as resources that facilitate ritual interactions. Instead of focusing on high-status cultural and family advantages, Collins (2014) emphasised social interaction and confidence. He believed that cultural capital was not only linked to privileged groups and different social groups provided people with different forms of cultural capital.

In summary, the concept of cultural capital has been elaborated and expanded over nearly half a century of its existence. Numerous studies have employed the theory with diverse research designs, samples, and methodologies within these three branches, proving its strength, importance, and usefulness in the educational field.

\subsubsection{Cultural Capital and Academic Integrity}

In the context of academic writing and integrity, recent scholars identified various skills (Howard, 2011; Riazantseva, 2012; Strangfeld, 2019; Yosso, 2005), qualities (Strangfeld, 2019), and abilities (Kang \& Glassman, 2010) that could be considered cultural capital. Accordingly, cultural capital regarding plagiarism encompasses knowledge about plagiarism plus academic skills and understanding of proper citation and referencing. These cultural capital assets are strongly associated with academic success because they help students not only avoid plagiarism but also become successful writers.

Riazantseva (2012) employed the theory of cultural capital to explore the relationship between academic success and second language academic writing and examine factors affecting students' academic literacy. The participants were three immigrant college students in an American university. The findings revealed that academic socialisation skills (as part of individuals' cultural capital) played a crucial role in students' academic success, shown by high academic grades and reputation. Riazantseva (2012) positioned family expectations, 
involvements, and supports for students' academic and professional life as forms of cultural capital that facilitated academic exposure, highlighting the agency of parents. Riazantseva (2012) shared Lareau's $(2000,2002)$ interpretation of cultural capital in that he viewed academic knowledge and skills as part of cultural capital and emphasised parental strategic involvement in students' academic success.

Maintaining that the intentional/unintentional dichotomy fails to capture complex reasons for student plagiarism, Strangfeld (2019) explored, from a cultural capital perspective, impacts of educational histories on students' decision to plagiarise. Participants were 18 undergraduates at an American university, who plagiarised during their studies. Inadequate vocabulary and language skills, poor academic writing skills, and fear of asking questions were revealed as common reasons for student plagiarism, implying historical educational inequalities rooted in individuals' cultural capital. The author concluded that plagiarism resulted from broader educational histories rather than current circumstances. In other words, these inadequacies resulted from earlier academic experiences rather than suddenly emerged when students transitioned to college. Strangfeld (2019) views language ability, academic writing abilities, and abilities to ask for help as important academic capital assets. He insists that these advantages are amassed over time and impact academic preparedness and classroom participation; those whose norms and values align with their institutions are more advantaged than others. In this respect, Strangfeld (2019) paralleled Lareau's interpretation of cultural capital.

While not providing empirical evidence, Howard (2011) specified ways in which cultural capital is transmitted and accumulated in the context of plagiarism, providing a means to understand cultural capital concerning plagiarism. She suggested that knowledge and skills are embodied cultural capital which results in increased self-satisfaction; an academic institution is a primary venue where students attain cultural capital. Lecturers, by assigning writing tasks and giving instructions, transmit embodied cultural capital to students, thus increasing their value as capital holders. Howard (2011), however, is concerned that students may not consider academic writing a way of building personal and intellectual growth (embodied cultural capital), but simply the means for obtaining a grade or a degree (institutionalised cultural capital).

Similarly, Kang and Glassman (2010) from a cultural capital lens, asserted that moral thought or reasoning could be viewed as a form of cultural capital. Specifically, they considered the ability to discuss controversial moral topics as cultural capital, reasoning that advanced moral 
thought developed through both cognitive development and experience became stable quality and was utilised to assist in explaining moral issues. They argued that this form of cultural capital could be gained through education and provide entry to larger social groups.

These scholars offer new ways of understanding and theorising plagiarism which allows deeper investigation of the subject. From these perspectives, plagiarism should not be considered a single concept but is better explored in the context of a specific academic culture. Also, student plagiarism should not be judged based on immediate circumstances surrounding their behaviours but on the basis of the knowledge and skills brought with them transitioning to new academic environments. These studies highlight the agency of parents who are deliberately involved in their children's academic and moral development which facilitate those children's construction of moral standards and awareness.

\subsubsection{A critique of Bourdieu's Cultural Capital Framework}

Despite being proved to be a useful theoretical tool in various fields, cultural capital theory has received considerable critique. The first critique was its lack of personal agency. Lareau and Weininger (2003), while acknowledging the importance of cultural capital theory in Englishlanguage sociology, argued that the use of the theory to predict educational outcomes was inadequate both in terms of the theory's potential and Bourdieu's implication of his concept. These scholars asserted that micro-interactional processes in which people use knowledge, skills, and competence to comply with institutional standards need to be emphasised.

Bourdieu's theory has also been criticised for its deficit view of people from lower classes. Yosso (2005) argued that because the theory has traditionally been used to explain unequal academic outcomes of people from different classes, it implies that lower socio-economic groups lack necessary knowledge, skills, and abilities for social mobility. Yosso's (2005) concept of community cultural wealth has a focus on unacknowledged or unrecognised capital.

\subsubsection{Conclusion}

The evidence presented thus far suggests the value of cultural capital theory in exploring student perceptions of plagiarism in the international contexts of VN- or NZ-educated students. Through examining differences in perceptions of plagiarism between Western (NZ-educated) and nonWestern (VN-educated) students, the study seeks to identify and explain how and why students from diverse educational backgrounds differ in their views and understanding of plagiarism. 
However, instead of emphasising the unequal cultural capital of students from various social backgrounds, this study explored how the diverse cultural capital possessed by students from different professional, educational, and disciplinary backgrounds might influence their plagiarism perceptions. This study also considers parental strategic interaction or parental involvement as a form of cultural capital that partly shaped students' perceptions of the issue. These interpretations of cultural capital are closer to Lareau's (2000, 2002) and Collins' (2014) tradition. In this study, Bourdieu's cultural capital theory informed the development of interview questions to illuminate the development of students' moral standards or influences of embodied cultural capital on their plagiarism perceptions, which was the focus of the qualitative phase.

However, student perception is a complex phenomenon that may be inappropriate to be explained using one single theory. Also, due to the theory's lack of individual agency and its implication of deficit thinking, the researcher might miss other important interactions that influence student perceptions. Therefore, social cognitive theory of moral thought and action (Bandura, 1991) and student self-formation theory (Marginson, 2014) were used as well to thoroughly explore the research problem. The next two sections further explain why these two theories were appropriate complementary frameworks.

\subsection{Social Cognitive Theory of Moral Thought and Action}

The second theoretical lens of the study is social cognitive theory of moral thought and action (Bandura, 1991) which was developed from social cognitive theory (Bandura, 1986). Social cognitive theory examines interactions among environmental factors, personal factors, and human behaviour in knowledge acquisition. According to this theory, a person's knowledge is formed through their socio-historical settings. Adopting a cognitive interactionist perspective to moral phenomena, Bandura (1991) hypothesised that "personal factors in the form of moral thought and affective self-reactions, moral conduct, and environmental factors all operate as interacting determinants that influence each other bidirectionally" (p. 45). On the one hand, individuals' moral perceptions and conduct are influenced by the community that they belong to; social interaction helps individuals form new or further develop moral standards. On the other hand, their moral thoughts guide their moral behaviour and affect both the environment they want to be in and the one they occupy. 


\subsubsection{Familial and Social Influences}

Bandura (1991) acknowledged universal developments of moral standards resulting from biopsychosocial changes associated with aging. Accordingly, increasing personal competencies and growing autonomy change the moral situations that a person must deal with. The broadening social reality, subsequently, alters the sort of moral concerns and social sanctions. Individual moral reasoning changes from concrete to more abstract, individual to institutional, and focus shifts from external regulation to increased autonomy and self-regulation. Children are affected firstly by their immediate caretakers or companions and then wider social systems.

People adopt standards appropriate to social realities and their social roles. Developmental changes in moral judgement and reasoning are not simply a cumulative process but occur through diverse influences. Children adopt new standards rather than simply add to existing ones. During maturation, parents and other adults continuously explain standards of conduct to children, helping them differentiate right/wrong conduct and thus regulate their behaviours. Moral self-sanctions arise from and are influenced by human relations and larger societies.

According to Bandura (1991), individuals establish moral values and standards through various platforms and these standards are fostered by institutional backing. Not only parents, but other adults, peers, and symbolic models impact children's moral perspectives. Standards that children set for judging their behaviour are partly influenced by the ways people around them respond to it. However, people construct their standards through rules that are prescribed, modeled, and taught, rather than absorb moral standards from all influencers.

\subsubsection{Moral Judgement}

In social cognitive theory, moral thinking involves judgement of conduct using multidimensional rules or standards (Bandura, 1991). Reprehensibility of action is normally determined based on factors such as types of transgression, occurrence rates, contexts, situational and personal motivators, impacts of the behaviour, and characteristics of the offenders and/or direct victims. People select several types of information when dealing with moral situations. Children model their parents' rules of conduct in terms of forms and complexity (Bandura, 1991). Individuals develop judgments from diverse social sources while establishing their moral standards; growth of experience and cognitive competence changes moral judgements from unidimensional to multidimensional rules of conduct. 


\subsubsection{The Self-regulatory Mechanisms}

Transgressive conduct is governed by a self-regulatory mechanism, a process through which moral agency is exercised (Bandura, 1991, 2002, 2006). Accordingly, moral conduct is regulated by social sanctions and self-sanctions. In self-control, people behave in ways that bring them satisfaction and respect and refrain from violating moral standards because of social criticism, social consequences, and shame. Moral conduct is regulated through the continuous use of self-reactive influence (Bandura et al., 1996). According to Bandura (1991, 2002, 2006), selfregulatory mechanism operates through three main subfunctions: self-monitoring of conduct, judgement of conduct, and affective self-reaction. In this process, people monitor their moral conduct and situational circumstances, judge it based on standards, and regulate their actions. Those with weak internal standards are more likely to be affected by external influences.

According to social cognitive theory, individuals' self-influence affects their conduct and the environment to which they belong. Conversely, social influences impact self-system by promoting self-regulatory competence development, enforcing moral standards, and assisting moral self-regulation activation or disengagement. Moral behaviours are affected by and interact with moral thought, self-sanctions, and social influences (Bandura, 1991).

\subsubsection{Moral Disengagement}

According to Bandura (1991), moral disengagement is a gradual rather than an instant process. The processes through which people disengage from inhumane conduct are: (1) moral justification (justifying the morality of the behaviour), (2) euphemistic labeling (sanitising language when referring to the conduct), (3) advantageous comparison (comparing the act favourably with another behaviour), (4) displacement of responsibility (avoiding responsibility), (5) diffusion of responsibility (distributing responsibility), (6) disregarding or distorting consequences, (7) dehumanisation (divesting human qualities from recipients of the behaviour), and (8) attribution of blame (considering themselves guiltless).

\subsubsection{Social Cognitive Theory of Moral Thought and Action in Educational Research}

Many applications of social cognitive theory of moral thought and action thus far explain variations in students' perceptions of different forms of academic misconduct. Resurreccion (2012) revealed that faculty, peers, and integrity culture significantly influenced the probability of Filipino students' academic misconduct. Burnett et al. (2016) indicated that students' 
understanding of the wide prevalence of cheating in their school might lead them to perceive cheating as a trivial offence, which increased cheating occurrences. These findings confirmed a bidirectional relationship among environment, moral thinking, and moral behaviours. Kura et al. (2014) revealed that honour codes were negatively related to deviant behaviour. The authors concluded that environmental factors enhanced students' perceptions which reduced their tendency to engage in deviant acts.

\subsubsection{Conclusion}

In this study, Bandura's (1991) theory was used to gain insights into whether beliefs and values of the environment where students live, work, and study affect their understanding of plagiarism, and whether their plagiarism perceptions determine the environment to which they want to belong. The theory provides a framework for understanding how students develop moral standards which may explain differences in their moral judgement and principles and helped to explain how people exercise agency to monitor and regulate their moral behaviours. The theory informed the development of the online survey and interview questions.

\subsection{Student Self-formation Theory}

The third theory that informed the study is self-formation theory. Its key concepts include agency - or "the sum of a person's capacity to act on her/his own behalf" and identity - "what we call ourselves and what others call us" (Marginson, 2014, p. 10). Marginson (2014) regards international education as a self-formation process that involves constructing multiple identities from a student's home country, host country, and other intercultural spaces and engagement. Instead of viewing prior habits, values, and identities as obstacles, he considers that international students obtain essential features for academic achievements from the host country without leaving their home country selves. This process is a pathway to gain cultural capital in which students quickly acquire knowledge and personal sensibilities.

\subsubsection{International Education as Self-formation}

While agentic self-formation applies to students in all higher education programmes, international students' self-formation, which encompasses dramatic changes in compressed time, is more apparent (Marginson, 2014). International education "calls up especially strong agency" because in leaving their homelands, international students are required to respond to new demanding institutional and cultural environments (Marginson, 2014, p. 8); these 
situations are opportunities through which they learn and develop, rather than challenges and obstacles. They encounter greater and more diverse possibilities than their local counterparts.

Marginson (2014) insisted that international students, who constantly collect new academic, institutional, and social attributes, are strong agents navigating their lives rather than deficient learners regarding host country requirements. Their self-formation is obligatory rather than spontaneous or voluntary. The self-formation process varies among students depending on individuals' resources, personal attributes, and social conditions. The process is complicated and reflexive because of multiple elements involved (educational, economic, occupational, familial, cultural, social, and linguistic).

Like all human subjects, international students engage in continuous self-formation in which they manage their self-definition and respond to change (Marginson, 2014). When studying overseas, students exercise agency to attain identity and work hard to achieve their aims. International students have numerous opportunities for academic and personal development and have their own strategies to construct embodied cultural capital within academic settings and develop their aspirational selves in social contexts.

\subsubsection{Student Self-formation Theory in Educational Research}

Since the introduction of Marginson's (2014) theory, many studies have provided evidence that speaks to international students' self-formation without adopting the theory explicitly. For example, Tran (2016) provided empirical evidence that international students were strong selfforming agents who could navigate their lives. Soong et al. (2015) suggested that international thesis students are capable of navigating the transition to re-define themselves and should be treated as active and self-determining agents.

\subsubsection{Conclusion}

Beyond his focus on cross-border students as powerful agents in their trajectories, Marginson (2014) offers a potential lens to research self-formation of domestic students. Although Marginson (2014) found local students' journeys as less compelling than those of their international counterparts because of fewer obvious cultural challenges, domestic students practice agency to obtain intellectual objectives in a scholarly environment that is quite different from that most experienced prior to doctoral studies. Hence, this study may identify NZ-educated students as agents in their self-formation as well. 
Marginson's (2014) theory explains how students engaged in international education construct hybrid identity (between home and host country). His concept of multiple identities allowed me to explore factors affecting $\mathrm{VN}$ - and NZ-educated postgraduate students' perceptions through observing the development of their plagiarism awareness, as an aspect of agentic selfformation. This theory provides a theoretical lens to explain disjunctions between students' aspirational academic identity and how they view plagiarism. It is also useful in illuminating agency variations between $\mathrm{VN}$-and NZ-educated students which may affect their plagiarism perceptions. In this study, Marginson's (2014) theory informed the design of the interview questions to explore students' self-formation which might impact their plagiarism perceptions.

\subsection{How the Three Theories Connect}

Cultural capital theory, social cognitive theory of moral thought and action, and student selfformation theory each offers a different perspective to explore the research questions. Collectively, they all contribute to the development of understanding about the participants' perceptions of plagiarism and how and why they varied. The theories connect through the concepts of agency, development, and social framing, and therefore each makes a unique contribution to potential understanding of influences on doctoral students' perceptions.

The theories denote distinct levels and unique forms of agency. Bourdieu's (1977) cultural capital theory affords individuals little agency because it conceptualises them as victims of class and culture and subject to replication of their parents' status. As Tholen (2015) explains, students' agency was blocked "within existing social conventions, values, and sanctions' ( $p$. 777). According to Bourdieu, students' understanding of plagiarism would be framed by the same environment and conceptions as their parents. However, two strands of cultural capital theory (Collins, 2014; Lareau, 2002) propose distinct forms of agency that promote educational attainment. Lareau's tradition highlights the agency of parents who actively involve themselves in their children's education so they may gain cultural capital or secure class advantages. This means that strategic family practices potentially influence students' perceptions of plagiarism. Collins' tradition emphasises cultural capital developed within different social and educational groups, highlighting that all individuals deliberately acquire cultural capital through social interactions irrespective of their social status. Students from diverse backgrounds would possess distinct sources of embodied cultural capital, including understanding of plagiarism. 
In contrast, Bandura's (1991) social cognitive theory of moral thought and action focuses on bidirectional relationships between personal factors, behaviours, and environmental factors. When applied to plagiarism, this means students constantly develop their understanding and adopt new perspectives through experiencing and in interaction with different environments. Students have some agency in the attitudes to plagiarism and the use of information by others in their environments, which they choose to adopt. They establish new moral standards in new environments to suit their social roles. They adopt standards from those that are prescribed, modelled, and taught within their specific environment rather than absorb standards from all influencers. The theory suggests that student plagiarism perceptions are influenced as much by environmental demands as they are by aspirations and qualities. Individual agency is reflected in how students monitor and regulate their moral conduct, in this case, their actual personal decisions related to avoiding or engaging in plagiarism.

Marginson (2014) considers individuals as agents who actively engage in self-formation, emphasising their capability to act and ways of operating that lead to success. International students, recognise opportunities, deliberately set out their aims, and accomplish them by means of what they bring from their home country in combination with strategic new learning. While international students exercise agency to overcome challenges, developing their aspirational selves, deliberately constructing and reconstructing identities in new academic settings, domestic students enact agency to obtain their intellectual goals in a scholarly context that is different from the one that most of them experienced prior to doctoral studies. Marginson's theory allows for significant development of student perceptions of plagiarism through international education as an aspect of agentic self-formation.

The three theories can be interpreted as placing different emphasis on the influence of the past, present, and the future, in how students' perspectives, habits, and expectations regarding plagiarism are shaped and developed. While Bourdieu emphasised existing academic skills and moral perspectives that students brought into the new environment, Bandura explained bidirectional influences associated with surrounding environments, and Marginson focused on how students develop moral standards while actively becoming the people they want to be and redefining themselves in new academic settings. When applying this to plagiarism, cultural capital theory emphasises past established influences such as parental strategic interaction, early educational experiences on ideas about plagiarism, and individual experiences with 
plagiarism. In contrast, Bandura's social cognitive theory of moral thought and action highlights current and ongoing environmental influences (e.g., disciplinary norms and ideologies, professional roles, and doctoral environments). Self-formation theory focuses on future aspirations, highlighting agency and identity construction. While Bourdieu's theory helps to explain influences from past experiences, Bandura's theory illuminates how students adopt new moral standards to function appropriately within different environments and how they influence these environments. Marginson's theory explains how students deliberately develop moral perspectives to create their future aspirational selves.

In terms of social framing, cultural capital theory involves limited social interaction because it treats individuals as inheriting their family values and beliefs. This means students' perceptions of plagiarism are mainly influenced by their educational histories and how they are parented. Bandura's theory emphasises wider social interaction because, from his perspective, people acquire values and standards with regard to plagiarism and source use in new social environments to suit their roles. Although the self-formation process emphasises individuality rather than group interaction, students develop their aspirational selves in social settings. This means that students' understanding of plagiarism is associated with their agency and identity formation. They flexibly adopt new values and construct a whole new identity in new contexts. Thus, within this study, by employing all three theories, various aspects of student engagement in academic settings could be rigorously interrogated because the theories together allowed a more complete exploration of factors influencing student perceptions of plagiarism.

\subsection{Chapter Summary}

Overall, the three theories were appropriate frameworks for exploring variations in perceptions of students between and within diverse cultural, social, disciplinary, and academic backgrounds. They help to explain intersections between students' identities and moral beliefs related to plagiarism. With distinct features and conceptual foundations, they collectively provide a set of theoretical lenses to illuminate factors influencing student perceptions. 


\section{Chapter 4 | Methodology}

\subsection{Introduction}

This chapter presents rationales and aims for the selected research method and describes in detail the processes of exploring VN- and NZ-educated postgraduate students' perceptions of plagiarism. Section 4.2 introduces the research questions that guided the study. Section 4.3 focuses on the research paradigm. Section 4.4 describes the mixed methods research approach and rationale for choosing the explanatory sequential mixed methods research design. In Section 4.5, I introduce methods and procedures for developing the questionnaire. The two sections following describe the quantitative and qualitative phases. Each section includes an introduction to the research participants, instruments, and procedures for collecting and analysing data. Section 4.8 presents validity strategies. Ethical considerations are described in Section 4.9. The last section concludes the chapter and introduces the next chapters.

\subsection{Research Questions}

The study sought to answer two main research questions. The first question explored perceptions of plagiarism among VN- and NZ-educated postgraduate students at VUW:

1. How do VN- and NZ-educated postgraduate students perceive plagiarism?

Two research sub-questions examined variations in plagiarism perceptions between and within these two groups:

Research sub-question 1: How do VN- and NZ-educated postgraduate students' attitudes and understanding of plagiarism differ between these groups?

This first research sub-question fits the literature on plagiarism that reveals contradictory findings on understanding of plagiarism held by NESB and ESB students (Bamford \& Sergiou, 2005; Doss et al., 2016; Green et al., 2006; Hayes \& Introna, 2005; Marshall \& Garry, 2006; Stappenbelt, 2012; Sutton et al., 2014).

Research sub-question 2: How do VN- and NZ-educated postgraduate students' attitudes and understanding of plagiarism differ within these groups? 
This second research sub-question reflects the understanding from the literature which suggests that students from different disciplines hold different views about what constitutes plagiarism (Borg, 2009; Chen \& Van Ullen, 2011; Hu \& Lei, 2015; Pecorari, 2006; Rinnert \& Kobayashi, 2005; Sutton et al., 2014). It explores the literature that indicates differences in plagiarism perceptions among students at various levels and stages of studies (Abasi et al., 2006; Hu \& Lei, 2015; Song-Turner, 2008; Stappenbelt, 2012; Sutton et al., 2014). Previous studies also indicated associations between demographics and plagiarism perceptions (Gullifer \& Tyson, 2014; Hu \& Lei, 2015; Leonard et al., 2015).

The second research question illuminated influences on student perceptions of plagiarism:

2. What are the influences on VN- and NZ-educated postgraduate students' perceptions of plagiarism?

This question explores and explains variations in plagiarism perceptions held by students from diverse backgrounds, and how they arise. Sociological theory (Bourdieu, 1977) explains differences in embodied cultural capital between these two groups, suggesting the value of further examining how these variations influenced student perceptions. Social cognitive theory of moral thought and action (Bandura, 1991) suggests a variety of environmental factors that may influence moral standards and values. Marginson's (2014) student self-formation theory explains the development of students' understanding through international education as an aspect of agentic self-formation, suggesting the value of exploring the extent to which their self-formation might affect their perceptions of plagiarism.

\subsection{Research Paradigm}

Researchers bring into their inquiry certain philosophical assumptions or stances to guide the study (Creswell, 2018). These include ontology - researchers' view about the nature of reality, epistemology - ways researchers gain knowledge about reality, axiology - researchers' view on value, and methodology - procedures used to obtain knowledge (Creswell, 2018). These stances are applied in research using different paradigms or philosophical worldviews.

Four types of philosophical worldviews that researchers bring to the research process include (1) Postpositivism, (2) Constructivism, (3) Transformative, and (4) Pragmatism (Creswell, 2014; Creswell \& Clark, 2018). Postpositivists believe that effects or outcomes are decided by causes. Their research problems, which are usually experimental, indicate how and why it is necessary 
to determine causes of outcomes. They developed measures to observe objective reality starting with theory. Constructivists, on the contrary, assume that the ways individuals make sense of their living and working experiences vary and are complex. They fundamentally rely on participants' perspectives of the phenomenon under investigation to generate a theory or a pattern of meaning. Transformative researchers focus on important daily social issues, aiming to change the lives of the participants, institutions, and researchers. In transformative research, theoretical perspectives may be integrated with philosophical assumptions underlying the issue being studied. Pragmatists do not see the world as being unitary but are open to diverse methods, worldviews, assumptions, and multiple methods of data collection and analysis. Pragmatic researchers combine different research procedures in ways that best address the research problem and questions (Johnson \& Christensen, 2014).

Regarding ontological perspectives, I believe that students' perceptions and understanding are complicated and thus cannot be sufficiently explored through solely quantitative or qualitative data. Each research approach offers distinctive benefits, unique types of information (numerical or in-depth), and typical values. When the two are mixed, they complement each other and contribute to the overall quality of the study. The value of statistical results about student perceptions of plagiarism could be enhanced by talking to them about influences on their perceptions. It is worth including students from different academic settings and backgrounds because they might perceive plagiarism differently.

Epistemologically, my motivation to conduct the study stems from my own experiences and understanding of plagiarism. Reflections on my positions as a Vietnamese learner and lecturer have encouraged me to investigate differences in plagiarism perceptions held by students from diverse educational backgrounds and academic settings. My experience of being educated in two educational systems and knowledge of factors affecting student perceptions, motivated me to investigate how students developed their perceptions of plagiarism, in a way that might problematise the deficit model of education related to plagiarism by international students.

The pragmatism paradigm was employed in this study because it applies to mixed methods research which is drawn liberally from multiple assumptions (Creswell, 2014; Creswell \& Clark, 2018), thus, enabling multiple methods, worldviews, and data collection and analysis techniques (Creswell, 2014). Also, the pragmatism paradigm allows adopting a pluralistic 
perspective to data collection, so that multiple types of data are identified to best address the research questions (Creswell \& Clark, 2018).

Methodologically, based on the pragmatism paradigm, this study employed both quantitative and qualitative data collection and analysis rather than relying on one single method. Multiple sources of data (quantitative and qualitative) were used to gain both an overview of student perceptions and in-depth information about how their perceptions were constructed.

\subsection{Research Design}

This study employed a mixed-methods research design to investigate student perceptions of plagiarism. Mixed-methods research is defined as an inquiry that involves both quantitative and qualitative data collection (Creswell, 2014; Johnson \& Christensen, 2014) "for the broad purposes of breadth and depth of understanding and corroboration" (Johnson et al., 2007, p. 123). Mixed methods research is not simply collecting multiple types of data (quantitative and qualitative) but integrating and interpreting multiple forms of data to understand the problem under investigation (Creswell, 2015; Creswell \& Clark, 2018).

Mixed-method research design has recently been used widely in educational research because of multiple benefits. It is used when one type of research is insufficient to address the research problem (Creswell, 2008; Creswell \& Clark, 2018). Combining quantitative and qualitative methods enhances the quality of the study because each approach has different strengths and weaknesses (Johnson \& Christensen, 2014). By collecting multiple types of data, mixedmethods research provides deeper understanding of the issue (Creswell, 2014). Integrating multiple sets of data using multiple research methods produces multiple and complementary strengths because each approach provides distinct types of information (Johnson \& Christensen, 2014) and the results are more convincing and powerful (Creswell \& Clark, 2018).

Creswell (2014) proposes four basic mixed methods research designs: (1) convergent parallel design, (2) explanatory sequential design, (3) exploratory sequential design, and (4) embedded design. Explanatory sequential mixed methods design involves using qualitative data to illustrate or further explain quantitative findings (Creswell, 2014; Creswell, 2015; Creswell \& Clark, 2018). After collecting and analysing quantitative data, researchers identify results that need additional explanations (Creswell \& Clark, 2018). Also, drawing on the findings, researchers refine the qualitative research questions and select appropriate participants to 
follow. In this way, the qualitative phase is linked to and dependent on the quantitative results (Creswell \& Clark, 2018).

Two variants of the explanatory sequential mixed methods research are the follow-up explanation model and participant-selection model (Creswell \& Clark, 2018). The first variant uses quantitative findings to identify specific results that need explanations to follow such as statistical differences among groups. This model is used when the researcher wants to expand quantitative results with qualitative data, so they collect in-depth information from participants who can assist in explaining these findings. The participant-selection model, in contrast, is employed to purposefully select participants for the qualitative phase. For example, after an English proficiency test, high and low achievers were selected to take part in in-depth interviews aiming to compare their motivation for learning English (Creswell \& Clark, 2018). This model emphasises qualitative data which is built based on quantitative findings.

Hesse-Biber (2010), who focuses on qualitative approaches to mixed methods practice, identifies two variations of mixed methods research: (1) sequential and (2) parallel designs. In all designs, the qualitative part (QUAL) is the dominant component while the quantitative (qual) study plays a supplementary role. The quan-QUAL sequential mixed methods research design is used when the researchers want to (1) obtain a representative sample, (2) enhance the generalizability of the qualitative findings, (3) inform the purposive sampling for the qualitative phase, (4) define a population of interest, (5) generate new research questions and (6) enhance the validity and reliability of the qualitative findings. The QUAL-quan sequential mixed methods research design is mainly used to check the validity of qualitative findings on a larger population. A concurrent or parallel mixed methods research design may be used to gain a more complete understanding of the issue under investigation, to triangulate the research findings, or to explore divergent findings.

This study employed an explanatory sequential mixed methods research design in which the qualitative phase was the dominant part because the use of qualitative data collection aimed to develop an in-depth understanding of plagiarism perceptions among the VN- and NZeducated postgraduate students at VUW and influences on their perceptions. The purpose of the first phase was to create a foundation to set up the qualitative phase. Because I wanted the choice of participants to offer rich understanding of diverse influences on plagiarism perceptions, I chose people who were different, with divergent views and potential influences. 
The online survey revealed a range of different views held by respondents regarding plagiarism at university, which helped to identify results to explore and elaborate the interview questions. It enabled a divergent sample of participants to be identified, to ensure that diverse cases were fully explored within the qualitative phase. The second phase offers in-depth understanding of how students have developed their perceptions and provides insights into the nuances underlying students' views identified in the first phase.

Explanatory sequential mixed methods research design, employed in this study, has several advantages which make it the most straightforward and suitable approach among the three designs (Creswell, 2014; Creswell \& Clark, 2018). The design is manageable because researchers can collect quantitative and qualitative data separately. That the qualitative phase is designed based on the quantitative phase makes the design an emergent approach. Also, this design helps to develop better and more complete understanding of the research problem. The final report, written separately, is easy for readers to understand and follow.

However, there are some challenges in implementing explanatory sequential mixed methods research design (Creswell, 2014; Creswell \& Clark, 2018). The time for completing the study is longer than purely quantitative or qualitative research because there are two phases of data collection and analysis. The participants need to be available over an extended period. Also, the qualitative phase cannot be fully determined from the beginning but is based on quantitative results. Researchers cannot develop a fixed plan but only a tentative one for the second phase. They need to identify results to follow, interview questions, and participants.

\subsection{Questionnaire Development}

Although there are various measurements of student perceptions of plagiarism, typically little information about the psychometric properties of these measurements is reported in the literature. While comprehensive results about the topic have been presented, information on the psychometrics of instruments used strengthens the validity of the instruments and the reliability of results obtained from their use. Also, no existing instruments are appropriate and appear to be an adequate tool for this study.

This section, comprising four subsections, outlines the process of developing and validating the survey questionnaire and describes its psychometrics. The first two subsections present steps for constructing questionnaire items and choosing the response scale. The next subsection 
gives an overview of methods employed to validate the questionnaire. The questionnaire validation procedure is described in the last subsection.

\subsubsection{Planning and Constructing Questionnaire Items}

The students were firstly inquired about their demographics. Because this study seeks to examine variations in perceptions of plagiarism between and within VN- and NZ-educated postgraduate students, questions about educational experiences were included to allow understanding of how these factors are associated with students' perceptions. Answers to these questions guided the purposeful sampling of diverse participants for follow-up interviews, which was the second phase. Finally, a Plagiarism Perception Scale was included.

The items were constructed by firstly undertaking a thorough literature review focusing on students' perspectives of plagiarism, reasons for student plagiarism, and the extent of student plagiarism. The literature was then transformed into a set of statements to elicit information about these specific themes, resulting in an initial scale consisting of 39 items (Appendix A). The first version of the questionnaire consisted of three sections as shown in Table 4.1.

Table 4.1 Students' perceptions of plagiarism questionnaire-version 1

\begin{tabular}{ll}
\hline Sections and scale & No. of items \\
\hline Section 1: Demographic information & 4 \\
Section 2: Educational background & 3 \\
Section 3: Plagiarism Perception Scale & 39 \\
Perspectives of plagiarism & 11 \\
Perceived seriousness of plagiarism & 10 \\
Factors contributing to student plagiarism & 18 \\
\hline
\end{tabular}

As shown in Table 4.1, the first section included four demographic questions inquiring students about their age, gender, nationality, and teaching employment. The second section comprised three questions about educational backgrounds: high school education, tertiary qualifications (including where these were earned), and current study at VUW. The last section was a Plagiarism Perception Scale covering three domains: (1) perspectives of plagiarism ( $n=11),(2)$ plagiarism perceived seriousness $(n=10)$, and (3) factors contributing to student plagiarism $(n=18)$. The first 11 items were to explore how respondents viewed plagiarism and its impacts or to measure their moral judgement related to plagiarism. The next ten statements described 
different behaviours in which some were plagiarism while others were acceptable; respondents were asked to indicate their level of agreement or disagreement on the seriousness of these behaviours. Specifically, these items were used to assess students' moral disengagement - the tendency to disengage from moral self-control and responsibility that normally regulate their moral behaviours. The last 18 items asked respondents the extent to which they agreed with various personal, academic, and institutional factors for student plagiarism.

\subsubsection{Response Scale Development}

Similarly, a scale was constructed to measure responses. Likert scaling was chosen because it is widely used to measure opinions, beliefs, and attitudes (DeVellis, 2017). Likert scaling offers several benefits that make it the most extensively used answer format in survey research (Babbie, 2017). Likert scaling allows determining the strength of agreement intended by respondents because researchers can calculate the average index score for individual items which reflects respondents' degree of agreement or disagreement with these items. Also, Likert scaling technique indicates differences in intensity among a set of items, thus making it easy for respondents to understand.

With Likert scaling method, the number of response categories can be odd or even depending on the investigator's purposes (DeVellis, 2017). While an odd number of responses allows equivocation or uncertainty, an even number forces respondents to choose one of the two directions. A five-point Likert scale (1-Strongly agree, 2-Somewhat agree, 3-Neither agree nor disagree, 4-Somewhat disagree, and 5- Strongly disagree) was initially chosen to explore the extent to which students agreed or disagreed with statements about plagiarism.

\subsubsection{Questionnaire Validation Methods}

This section starts with an overview of methods used to validate the survey instrument drawn from the literature and informed by the theoretical framework. It is followed by a description of procedures employed to develop and validate the instrument.

The techniques used to validate the questionnaire relate to validity and reliability. These are the two most crucial psychometric properties of a measure (Johnson \& Christensen, 2014) because they enhance the quality of measurements (Babbie, 2017). 


\section{Validity}

Validity is defined as the extent to which a measure reflects the concept it is supposed to measure (Babbie, 2017) or "the correctness or truthfulness of the inferences" drawn from the findings (Johnson \& Christensen, 2014, p. 279). To ensure that the test or instrument measures what it aims to measure and that inferences made from the results are accurate, researchers need validity evidence (Johnson \& Christensen, 2014).

Although the process of collecting validity evidence is never achieved completely, researchers are recommended to gather multiple forms of evidence to support their interpretations (Johnson \& Christensen, 2014). The validity of a measure may be proved through a combination of content validity, face validity, criterion-related validity, and construct validity (Babbie, 2017; Johnson \& Christensen, 2014).

Content validity is the extent or comprehensiveness with which a measure reflects different dimensions of the concept (Babbie, 2017). Assessment of this type of validity can be undertaken by experts in the field of interest (Johnson \& Christensen, 2014). Face validity, the degree to which an indicator appears to expert eyes to be an appropriate measurement of a variable, is the most important criterion for choosing questionnaire items. (Babbie, 2017). For example, to measure political conservatism, each survey item should appear to be related to conservatism. Criterion-related validity or predictive validity is the extent to which an indicator or a scale empirically relates to some external criterion (Babbie, 2017; DeVellis, 2017). For example, the validity of college admission tests is determined by their ability to predict students' academic success in college. However, it is not always easy to find criteria for directly validating scales or measurements (Babbie, 2017). Construct validity is the extent to which the variables are logically related to one another (Babbie, 2017). One technique for establishing this type of validity is factor analysis (DeVellis, 2017; Johnson \& Christensen, 2014; Yong \& Pearce, 2013).

\section{Factor analysis}

Factor analysis can be used for a variety of purposes (DeVellis, 2017; Fabrigar \& Wegener, 2012; Field, 2009; Thompson, 2004; Yong \& Pearce, 2013). Firstly, this statistical method is used to identify underlying constructs among a set of items, which is essential in scale development. Secondly, it is normally used to summarise data into more parsimonious factors that facilitate 
interpretation and subsequent analyses. Thirdly, factor analysis is useful in developing a theory concerning the nature of the construct. Finally, it provides evidence of scores validity.

Two major models of factor analysis are exploratory factor analysis (EFA) and confirmatory factor analysis (CFA). The main difference between the two models is related to the number of factors to retain and correlations between factors (Brown, 2015; Fabrigar \& Wegener, 2012; Thompson, 2004; Yong \& Pearce, 2013). In EFA, researchers have no expectations concerning the number of and relationships among factors. For CFA, however, they already know the number of factors to extract and how the factors are correlated.

Regarding decisions for implementation, researchers need to consider if factor analysis is appropriate for the research question, whether the data set is appropriate for factor analysis, and whether EFA or CFA fits the research purposes (Fabrigar \& Wegener, 2012).

To answer the first question, researchers can look at types of research questions that can be addressed using factor analysis (DeVellis, 2017; Fabrigar \& Wegener, 2012). The most common use of factor analysis is to identify the constructs constituting an area of interest. It provides useful information about scale dimensionality and psychometric properties of measurement items that speak to their appropriateness. For the second question, researchers need to consider properties of both measured variables (Fabrigar \& Wegener, 2012) and sample size (DeVellis, 2017; Fabrigar \& Wegener, 2012; Field, 2009; Yong \& Pearce, 2013).

There are several criteria for the decision of the characteristics of measured variables (Fabrigar \& Wegener, 2012). Firstly, variables must adequately represent the area of interest. Otherwise, the resulting factor model will be difficult to interpret due to irrelevant and distracting variables. Researchers need firstly to define their area of interest, then examine how these variables meet conceptual requirements, and finally, consider the extent to which the variables sample the domain of inquiry. The number of measured variables should also be taken into consideration. Each expected factor should include more than five variables. The final consideration is associated with scale measurement. Only interval level or quasi-interval level scales are appropriate for factor analysis.

Another factor that determines the reliability of factor analysis is the sample size (DeVellis, 2017; Fabrigar \& Wegener, 2012; Field, 2009; Thompson, 2004; Yong \& Pearce, 2013). Larger sample sizes are desirable as they produce more stable factor patterns (DeVellis, 2017) while 
reducing the magnitude of any errors in data analysis (Yong \& Pearce, 2013). However, the absolute number of subjects required also depends on the number of items included and the number of expected factors (DeVellis, 2017; Mundfrom et al., 2005).

There are various guidelines regarding the absolute sample size for factor analysis (Brown, 2015; Fabrigar \& Wegener, 2012; Field, 2009; Thompson, 2004; Yong \& Pearce, 2013). The first rule is related to the number of participants per measured variable. Some scholars recommend a subject-to-variable ratio of at least 5:1 (Yong \& Pearce, 2013). Another technique is using the Kaiser-Meyer-Olkin (KMO) test of sampling adequacy. The KMO statistic can vary from 0 to 1 , and the minimum value for factor analysis to be performed should be $\geq .5$ (Field, 2009; Yong \& Pearce, 2013). When the KMO value is closer to 1 , factor analysis would produce more distinct and reliable factors (Field, 2009). Another common recommendation is for samples of not less than 100 participants (Field, 2009)

Accepting that factor analysis has been proved to be appropriate to the research question and the data set is suitable for factor analysis, researchers then need to decide whether EFA or CFA is more appropriate. This question can be answered by looking at the broad purposes of the two statistical methods. While the purpose of EFA is to explore patterns within the set of variables, CFA aims at confirming hypotheses. Accordingly, EFA is appropriate for developing theory whereas CFA is used to test if the data fits researchers' theoretical expectations (Fabrigar \& Wegener, 2012; Field, 2009; Thompson, 2004; Yong \& Pearce, 2013).

\section{Exploratory Factor Analysis}

Although both EFA and CFA are useful for grouping related variables into meaningful categories, EFA is typically employed as a descriptive or an exploratory technique (Brown, 2015). Traditionally, it is used to identify basic constructs underlying an area of inquiry or to assess constructs when developing measurement instruments (Fabrigar \& Wegener, 2012). EFA is essential earlier in the process of developing scales and validating constructs because it presents valuable information about the psychometric properties of a set of items (Brown, 2015; Fabrigar \& Wegener, 2012; Yong \& Pearce, 2013).

EFA is not a single analysis but involves a sequence of choices. The three most important decisions include which factor extraction method to use, how many factors to retain, and which 
factor rotation method is appropriate (Fabrigar \& Wegener, 2012; Field, 2009; Thompson, 2004; Yong \& Pearce, 2013).

\section{Factor extraction methods}

Factor extraction methods consist of principal component analysis, principal axis factor analysis, alpha factor analysis, maximum likelihood (ML) factor analysis, image factor analysis, and canonical factor analysis. Out of these techniques, ML factor analysis is mostly used. This method allows the computation of model parameter confidence intervals and permits statistical significance testing (Fabrigar \& Wegener, 2012). ML is based on the assumption that the sample is randomly selected and that variables "have a multivariate normal distribution" (Fabrigar \& Wegener, 2012, p. 47). With ML, the results obtained with sample participants can be generalised to a larger population (Field, 2009).

\section{Number of factors to retain}

There are various theories on how to determine an appropriate number of factors to retain (Fabrigar \& Wegener, 2012; Field, 2009; Thompson, 2004). The common methods are related to the Eigenvalue-greater-than-one rule, the Scree test, parallel analysis, the likelihood ratio test statistic, factor stability, and factor interpretability. Because each of these procedures provides different information concerning how many factors to extract, researchers normally employ multiple methods to obtain the best results.

\section{Factor rotation methods}

After an appropriate number of factors has been decided, researchers need to choose a factor rotation method for a better interpretation of extracted factors. Commonly in EFA, most items load highest into the most important factor and have lower loadings on the remaining factors. Factor rotation helps to rotate those factor axes so that all variables load maximally onto one factor only (Field, 2009; Yong \& Pearce, 2013). Two basic rotation methods are orthogonal analytic rotation and oblique analytic rotation (e.g., Brown, 2015; Field, 2009; Thompson, 2004). Orthogonal rotation is used when the factors are supposed to be uncorrelated. Orthogonal rotation consists of varimax, quartimax, and equamax rotation methods in which equamax is a compromise between the first two methods. Oblique rotation (e.g., direct oblimin and promax), is used when factors are expected to be correlated. Direct oblimin is 
recommended as it simplifies the output structure (Fabrigar \& Wegener, 2012; Field, 2009; Thompson, 2004; Yong \& Pearce, 2013).

\section{Interpretation of the results}

Once a factor model has been identified, researchers need to decide which variables constitute each given factor. This can be done by looking at the factor loading - the Pearson correlation between a variable and a given factor - of each variable, which determines the strength of relationships (Field, 2009; Yong \& Pearce, 2013).

For a better interpretation of results, factor analysis experts suggest determining a cut-off value for a factor to be statistically meaningful. Researchers recommend removing items with an absolute loading value lower than .3 (Field, 2009; Yong \& Pearce, 2013). However, these values depend on the magnitude of the sample size. The larger the sample size is, the smaller are the loadings allowed for factors to be significant (Field, 2009; Yong \& Pearce, 2013). In the case of cross-loadings - when an item loads at $\geq .32$ on more than one factor - complex variables can be retained or dropped depending on the study design (Yong \& Pearce, 2013).

\section{Reliability}

After determining the underlying construct within the data set, researchers need to proceed with reliability tests. Reliability refers to the consistency or stability of scores obtained from a test or a questionnaire (Babbie, 2017; Johnson \& Christensen, 2014). If the scores obtained from a measure are reliable, these scores will not change on any occasion.

The reliability of test scores can be determined through various forms of reliability evidence (Johnson \& Christensen, 2014): test-retest reliability - consistency of test scores over time; equivalent-forms reliability - consistency of test scores on different test forms; internal consistency reliability - the extent to which a set of items consistently measure a single construct; and interscorer reliability - the degree of consistency between two or more scorers.

Choices of reliability analysis methods depend on the types of information researchers want to obtain (Johnson \& Christensen, 2014). However, internal consistency measures are commonly used because of their convenience. Internal consistency reliability can be measured by splithalf reliability and coefficient alpha in which coefficient alpha is more widely used (Babbie, 2017; Johnson \& Christensen, 2014). 
Regarding interpreting the output, Johnson and Christensen (2014) suggested a minimum acceptable coefficient alpha of $\geq .70$ for research purposes but noted that the absolute size depends on many other factors. Johnson and Christensen (2014) and Babbie (2017), however, recommend researchers to be careful in interpreting results as the alpha value will increase with more items on the scales which means a large coefficient alpha does not guarantee that the items are internally consistent.

\subsubsection{Questionnaire Validation Procedures}

This section describes strategies to validate the Plagiarism Perception Scale: expert reviewing (content validity), pretesting and piloting (face validity), exploratory factor analysis (Construct validity), and Cronbach's alpha (reliability). EFA results were presented in Chapter Five.

\section{Content validity}

\section{Expert reviewing}

After constructing the questionnaire items, I invited three experts in the Faculty of Education of VUW to review the questionnaire. They were asked to evaluate the extent to which each item was relevant to the research questions and theoretical frameworks. During the process, academically inappropriate wordings were identified (e.g., items 5-Students plagiarise due to desires to gain high grades, 10-Students plagiarise due to language difficulties and 20Plagiarism threatens institutional quality assurance). Some complex concepts were suggested to be simplified to ensure the comprehensibility of questionnaire items. Comments on the order of items were also made. The experts suggested dropping some items and adding some to the other aspects of the questionnaire. This process resulted in a second version of the questionnaire with changes in content, wordings, and order of items, shown in Table 4.2.

Table 4.2 Students' perceptions of plagiarism questionnaire-version 2

\begin{tabular}{ll} 
Sections and scale & No. of items \\
\hline Section 1: Demographic information & 4 \\
\hline Section 2: Educational background & 3 \\
\hline Section 3: Plagiarism Perception Scale & 39 \\
Perspectives of plagiarism & 9 \\
Perceived seriousness of plagiarism & 9 \\
Factors contributing to student plagiarism & 21 \\
\hline
\end{tabular}


Table 4.2 shows that the second version comprised three main sections, as did the original questionnaire. However, the number of items in each subscale changed compared to the first version: perspectives of plagiarism (reduced to 9), perceived seriousness of plagiarism (reduced to 9), and factors contributing to student plagiarism (increased to 21).

\section{Face validity}

Two techniques employed to ensure face validity of the questionnaire were retesting and piloting. Both procedures were conducted with international postgraduate students within VUW who were ineligible for the main study participation.

\section{Pretesting the questionnaire}

Following expert review and revision, I invited ten international postgraduate students at VUW to pretest the second version of the questionnaire to ensure that respondents could understand and answer the questions easily. These students were selected because they were close to the target group in terms of educational experiences but not eligible for participation.

Students were asked to complete the survey thinking aloud with the researcher listening and taking notes. Specifically, they were advised to read the items one by one reporting items that caused them problems. Evaluation criteria included comprehensibility, clarity, and consistency of wording, formatting consistency, and styles. Six students completed the questionnaire in the presence of the researcher and four completed it online.

After obtaining feedback from the students participating in the pretest process, questions that were observed to be confusing and hard to understand were revised. Most modifications were made to wordings and sentence structures. For example, the item "The Internet makes it easy for students to plagiarise" was reworded as "Students plagiarise when they have easy access to electronic materials". There were changes in the format and order of items. No changes in the number of items in each subscale were made (see Table 4.3).

Table 4.3 Students' perceptions of plagiarism questionnaire-version 3

\begin{tabular}{cl}
\hline Subscales & No. of items \\
\hline Perspectives of plagiarism & 9 \\
Perceived seriousness of plagiarism & 9 \\
Factors contributing to student plagiarism & 21 \\
\hline
\end{tabular}




\section{Piloting the questionnaire}

After pretesting version two of the questionnaire, version three, excluding demographics questions, was piloted with 32 international postgraduate students at VUW who volunteered. Participants were recruited from the schools of Education, Linguistics and Applied Language Studies, and Information Management. They did not belong to the target groups (VN- and NZeducated students) and were approached through one receptive course coordinator (not my supervisors) and a snowball approach starting with direct contacts with other PhD students.

These students were invited to complete the questionnaire distributed through Qualtrics (like the actual survey) as an anonymous survey. The process was to explore the questionnaire feasibility and the accessibility of language. Specifically, the process aimed to determine if questionnaire items were consistent, appropriate, and clearly understood by respondents. It also aimed to identify potential problems in data collection and analysis. The information gained from this process was used to further refine the questionnaire and make necessary changes to the actual data collection and analysis procedure.

With the number of responses received $(n=32)$, the focus of the analysis was to examine the clarity and accessibility of language rather than to determine the psychometric properties of the questionnaire. In other words, the pilot study analysis aimed to explore how well the respondents understood the questionnaire items and identify problematic items.

Firstly, descriptive statistics were performed to explore the distributions of responses in each of the 39 items. The process revealed six items that mostly received extreme response options (five out of five points on the Likert scale). For example, 25 out of 32 students strongly disagreed with item 18-It is not a serious problem if you hire a writer to produce a text that you subsequently submit as your own work. The same number of respondents strongly disagreed with the idea that it was no big deal if you submit exactly copied work as your own without acknowledgement. Results suggested that these items need close examination as to whether they represented misunderstanding or exaggeration from the respondents.

Secondly, Spearman's Correlation was used to explore correlations within the data set. The process was to confirm if the expected structures were reasonable and if the students consistently answered the survey. It also aimed at identifying items that were confusing to students. Results demonstrated that most items, which were anticipated to be correlated, were 
found to have monotonic relationships with each other, indicating that they were consistently answered. For instance, items 14-Students plagiarise because they are confused about plagiarism and 31-Students' poor understanding of citing and referencing leads them to plagiarise, both of which demonstrated how knowledge about plagiarism contributed to plagiarism, were found to be positively correlated with each other $\left(r_{s}=.469, p=.007\right)$.

However, some examples here, which I expected to be related, appeared to have no significant correlations, suggesting that some concepts might not be fully understood by respondents. Three items, 2-Plagiarism happens when students are learning to write, 8-Plagiarism is common in the work of novice writers, and 26-Students' poor understanding of how to write academically causes plagiarism, which described the relationship between students' writing ability and plagiarism. While there was a positive correlation between two pairs of items 2-8 ( $\mathrm{rs}=.495$, $\mathrm{p}=.004)$ and 8-26 ( $\mathrm{rs}=.370, \mathrm{p}=.037)$, the correlation coefficient value of .229 suggested no correlation between items 2 and 26. These items were revised following the suggestions made by the experts.

\section{Questionnaire modification}

Because pilot study analysis indicated some concepts that might not be fully understood by respondents, these items were reworded to simplify and make them more concise and simpler. Modifications of sentence structure were also made for clarity. (see Appendix A)

Six items that mostly received extreme responses were considered for rewording or removal: Three out of these six items which appeared to be leading or obviously right or wrong to respondents as judged by experts were removed (items 18, 29, and 34). The ones that sounded neutral as judged by experts were reworded (items 6, 25, and 37).

The pilot study data analysis resulted in the selection of 37 items for the actual survey. These items covered three main domains: perspectives of plagiarism $(n=11)$, perceived seriousness of plagiarism $(n=6)$, and factors contributing to student plagiarism $(n=20)$. The items were worded both negatively (11 items) and positively ( 26 items) to prevent response bias. The order of items was randomized in Table 4.4 below. 
Table 4.4 Students' perceptions of plagiarism questionnaire-version 4

\begin{tabular}{|c|c|c|}
\hline Sections and scale & No. of items & Placement of items in the questionnaire \\
\hline Section 1: Demographic information & 4 & \\
\hline Section 2: Educational background & 3 & \\
\hline Section 3: Plagiarism Perception Scale & 37 & \\
\hline Perspectives of plagiarism & 11 & $1,6,8,11,17,20,22,30,31,32,37$ \\
\hline Perceived seriousness of plagiarism & 6 & $2,7,13,19,26,34$ \\
\hline Factors contributing to student plagiarism & 20 & \\
\hline Personal factors & 5 & $9,12,25,29,36$ \\
\hline Academic factors & 7 & $3,5,14,18,23,27,33$ \\
\hline Institutional factors & 8 & $4,10,15,16,21,24,28,35$ \\
\hline
\end{tabular}

Because a large number of students provided midpoint responses for many items in the pilot study, the five-point Likert Scale was changed into a six-point Likert Scale in which 1=Strongly agree, 2=Agree, 3=Slightly agree, 4=Slightly disagree, 5=Disagree, and 6=Strongly disagree. This scale was used to ensure that participants would not provide neutral responses and to encourage them to express a level of agreement or disagreement on the statements provided.

\section{Construct validity}

EFA is appropriate to the current study which utilised a newly developed instrument. It was performed to identify relationships among variables, explore the psychometric properties of the data set, and reduce the data set into fewer variable groups for better interpretation. The most important reason was to obtain validity evidence for the questionnaire.

EFA was conducted with the data obtained from the main survey. A total of 235 students completed this survey. The results of EFA were reported in Chapter 5: Survey findings.

\section{Reliability}

Cronbach's Alpha was computed to assess the reliability of the Plagiarism Perception Scale and subscales. The overall alpha for the scale with 29 items was .73, well within the range expected for a reliable instrument. Table 4.5 describes the alpha values for the five subscales. 
Table 4.5 Reliability statistics results

\begin{tabular}{lcc}
\hline \multicolumn{1}{c}{ Subscale } & Cronbach's Alpha & N of Items \\
\hline Perceived seriousness of plagiarism (1) & .69 & 8 \\
Personal factors (2) & .70 & 5 \\
Academic factors (3) & .70 & 6 \\
Assessment factors (4) & .59 & 3 \\
Negative attitudes towards plagiarism (5) & .68 & 7 \\
\hline
\end{tabular}

In Table 4.5, the alpha values for subscales 2 and 3 were .70. The alpha values were 69 for Subscale 1 (eight items), .59 for Subscale 4 (three items), and .68 for Subscale 5 (seven items).

\subsubsection{Conclusion}

This section has outlined how the questionnaire was developed and validated. Having now undertaken the processes described, the psychometric properties of the questionnaire were established. In other words, these processes provide assurance of the questionnaire's validity and reliability for the chosen population.

\subsection{Quantitative Phase}

This section outlines procedures for collecting and analysing quantitative data. It describes the survey participants, techniques used for recruiting participants, and the survey instrument.

\subsubsection{Survey Participants}

\section{Survey participant recruitment}

Survey participants were approached mainly through emails. First, I contacted associate deans of research from different faculties of VUW to seek their approval for the survey to go to their postgraduate student community. When the deans approved the request, they asked their school manager to circulate the invitation email to their students. Only VN-and NZ-educated students were invited to complete the questionnaire.

Many other strategies were employed to draw students' attention. Firstly, I asked VUW's postgraduate student association to place an advertisement about the study in their newsletter. A paper advertisement was posted on the notice boards around the university's campuses. An electronic advertisement was posted to several student Facebook groups. Then 
I went to one class which included a number of Vietnamese and New Zealand postgraduate students to talk to them about the study and invite them to participate. Also, a snowballing approach which started with both direct contacts with other postgraduate students and survey respondents was employed.

\section{Survey participant descriptions}

Participants for the online survey were 235 postgraduate students currently studying at VUW. Because I was looking for VN- and NZ-educated postgraduate students, responses that did not fit into the specified inclusion criteria (e.g., by international students from other countries) were excluded from the main data analysis. Incomplete cases were also removed. The final sample consisted of 207 postgraduate students (72 VN-educated and 135 NZ-educated students), shown in Table 4.6.

Table 4.6 Demographic characteristics of the survey sample

\begin{tabular}{llll}
\hline & & Frequency & Percent \\
Nationality & New Zealander & 135 & 65.2 \\
& Vietnamese & 72 & 34.8 \\
\hline Gender & Female & 138 & 66.7 \\
\cline { 2 - 3 } & Male & 65 & 31.4 \\
\hline Age & Gon-binary & 3 & 1.4 \\
& 24-younger & 1 & 0.5 \\
\hline & $25-34$ & 56 & 27.1 \\
& $35-44$ & 84 & 40.6 \\
& $45-o l d e r$ & 47 & 22.7 \\
\hline Teaching employment & Have not been employed as a teacher/ tutor & 54 & 9.7 \\
\hline & Have been employed as a teacher/ tutor & 153 & 26.1 \\
\hline
\end{tabular}

As illustrated in Table 4.6, the sample included four gender groups: male (31.4\%), female (66.7\%), non-binary (1.4\%), and genderqueer (0.5\%). Respondents were classified into four age groups: younger than 24 (27.1\%); 25 to 34 (40.6\%); 35 to 44 (22.7\%); older than $44(9.7 \%)$. 73.9\% of the respondents had been teaching or tutoring before their postgraduate studies. The remaining $26.1 \%$ had never been employed as a teacher or tutor. 


\subsubsection{Quantitative Research Instrument}

In the quantitative phase, an online questionnaire, which was constructed drawing on relevant literature, was used. Table 4.7 describes its final version with three sections (see Section 4.5 for information about how the questionnaire was developed and validated).

Table 4.7 Students' perceptions of plagiarism questionnaire-final version

\begin{tabular}{lc}
\hline Sections and scale & No. of items \\
\hline Section 1: Demographic information & 4 \\
\hline Section 2: Educational background & 3 \\
\hline Section 3: Plagiarism Perception Scale & 29 \\
Perceived seriousness of plagiarism & 8 \\
Personal factors & 5 \\
Academic factors & 6 \\
Assessment factors & 3 \\
Negative attitudes towards plagiarism & 7 \\
\hline
\end{tabular}

As shown in Table 4.7, the first section of the questionnaire included four demographic questions. The second section comprised three questions about educational background.

The third section was a Plagiarism Perception Scale consisting of five subscales: Perceived seriousness of plagiarism ( $n=8)$, Personal factors $(n=5)$, Academic factors $(n=6)$, Assessment factors $(n=3)$, and Negative attitudes towards plagiarism $(n=7)$. The first subscale presented different degrees of plagiarism. Subscales 2, 3, and 4 described factors that may lead to student plagiarism. The last subscale included statements showing negative attitudes towards plagiarism.

\subsubsection{Quantitative Data Collection Procedures}

In the first phase, an online questionnaire (in English) was constructed using Qualtrics survey software. An online survey was chosen because it allows the researcher to create, distribute, and analyze the data quickly (Sue \& Ritter, 2011). Also, it is convenient for respondents (Sue \& Ritter, 2011) and reaches a large number of respondents easily (Creswell, 2008).

Before launching the survey, a pilot testing of the questionnaire, "a procedure in which a researcher makes changes in an instrument based on feedback from a small number of individuals who complete and evaluate the instrument" (Creswell, 2008, p. 390), was carried 
out to explore whether the survey obtained the expected results. The procedure aims to increase the reliability, validity, and practicability of the instrument (Cohen et al., 2011).

The survey was administered following a three-step procedure proposed by Creswell (2008): (1) sending the survey to potential respondents, (2) sending a reminder to non-respondents after four weeks, and (3) sending another link to non-respondents, after two weeks.

\subsubsection{Quantitative Data Analysis Procedures}

For quantitative data analysis, SPSS 26 (Statistical Package for Social Sciences) was used. The analysis included four steps. Firstly, EFA was run to explore underlying constructs related to students' perceptions of plagiarism. Then, descriptive statistics were performed to summarise respondents' demographic and educational backgrounds and distributions of their responses on five subscales. Finally, independent-samples T-tests and one-way analysis of variance (ANOVA) were performed to explore relationships between student demographics, educational backgrounds, and their perceptions of plagiarism. (See Chapter Five: Survey findings)

\subsubsection{Interpretation of Quantitative Findings}

The interpretation focuses on four main areas: (1) respondents' demographics; (2) results of EFA which depicted the underlying constructs related to student perceptions of plagiarism; (3) descriptive statistics of five subscales identified from the EFA gives an overview of student plagiarism perceptions, and (4) results from inferential statistics which detail relationships between students' demographics and educational backgrounds and their perceptions. Findings from this phase answered the first research question and two research sub-questions. They informed the instrument development and purposeful sampling of the qualitative phase.

\subsection{Qualitative Phase}

This section firstly details procedures for recruiting interview participants. Descriptions of interview participants and qualitative research instruments are then provided. It also describes qualitative data collection and analysis procedures. 


\subsubsection{Interview Participants}

\section{Recruitment of interview participant}

Survey respondents were invited to leave their contact information if they were willing to take part in the interviews. 117 students (47 PhD and 70 master's) expressed their interest. A twostep cluster analysis was performed with the students who volunteered using five measurement variables from factor analysis as input variables. One main focus during selection was on volunteering participants' responses to the five subscales: (1) Perceived seriousness of plagiarism; (2) Personal factors; (3) Academic factors; (4) Assessment factors; and (5) Negative attitudes towards plagiarism, interview participants were grouped into five distinct perception clusters. Figure 4.1 illustrates the size, feature, and importance of each cluster.

Figure 4.1 Perception clusters

\begin{tabular}{|c|c|c|c|c|c|}
\hline & & & \multicolumn{3}{|c|}{ Input (Predictor) Importance } \\
\hline & & & & $\square 1.0 \square 0.8 \square$ & $\begin{array}{llll}0.6 & 0.4 & 0.2 & 0.0\end{array}$ \\
\hline Cluster & 1 & 2 & 3 & 4 & 5 \\
\hline Sizes & \begin{tabular}{|l|l}
$6.2 \%$ \\
$(19)$
\end{tabular} & \begin{tabular}{|r}
$14.5 \%$ \\
$(17)$
\end{tabular} & \begin{tabular}{|l|l|} 
& \\
& \\
& $(23.1 \%$
\end{tabular} & \begin{tabular}{|r|r|} 
& $23.9 \%$ \\
$(28)$
\end{tabular} & $\begin{array}{r}22.2 \% \\
(26)\end{array}$ \\
\hline Inputs & $\begin{array}{c}\text { Negative attitudes } \\
\text { towards plagiarism } \\
-1.04\end{array}$ & $\begin{array}{c}\text { Negative attitudes } \\
\text { towards plagiarism } \\
-2.22\end{array}$ & $\begin{array}{c}\text { Negative attitudes } \\
\text { towards plagiarism } \\
0.98\end{array}$ & $\begin{array}{c}\text { Negative attitudes } \\
\text { towards plagiarism } \\
1.30\end{array}$ & $\begin{array}{c}\text { Negative attitudes } \\
\text { towards plagiarism } \\
0.30\end{array}$ \\
\hline & $\begin{array}{c}\text { Academic factors } \\
-1.25\end{array}$ & $\begin{array}{c}\text { Academic factors } \\
1.40\end{array}$ & $\begin{array}{c}\text { Academic factors } \\
-1.25\end{array}$ & $\begin{array}{c}\text { Academic factors } \\
0.69\end{array}$ & $\begin{array}{c}\text { Academic factors } \\
0.24\end{array}$ \\
\hline & $\begin{array}{c}\text { Perceived seriousness } \\
\text { of plagiarism } \\
1.26\end{array}$ & $\begin{array}{c}\text { Perceived seriousness } \\
\text { of plagiarism } \\
1.91\end{array}$ & $\begin{array}{c}\text { Perceived seriousness } \\
\text { of plagiarism } \\
-0.73\end{array}$ & $\begin{array}{c}\text { Perceived seriousness } \\
\text { of plagiarism } \\
0.27\end{array}$ & $\begin{array}{c}\text { Perceived seriousness } \\
\text { of plagiarism } \\
-1.41\end{array}$ \\
\hline & $\begin{array}{c}\text { Assessment factors } \\
1.13\end{array}$ & $\begin{array}{c}\text { Assessment factors } \\
0.97\end{array}$ & $\begin{array}{c}\text { Assessment factors } \\
-0.89\end{array}$ & $\begin{array}{c}\text { Assessment factors } \\
1.51\end{array}$ & $\begin{array}{c}\text { Assessment factors } \\
-1.64\end{array}$ \\
\hline & $\begin{array}{c}\text { Personal factors } \\
-1.29\end{array}$ & $\begin{array}{c}\text { Personal factors } \\
0.72\end{array}$ & $\begin{array}{c}\text { Personal factors } \\
-0.63\end{array}$ & $\begin{array}{c}\text { Personal factors } \\
1.51\end{array}$ & $\begin{array}{l}\text { Personal factors } \\
-0.38\end{array}$ \\
\hline
\end{tabular}

As shown in Figure 4.1, Negative attitudes towards plagiarism is the most important and Personal factors is the least important variable to the formation of the clusters. The largest cluster consisted of 28 students and the smallest comprised 17 students. One to three students were chosen from each cluster depending on the size of the clusters and students' availability. The other main consideration in the selection process was volunteering participants' demographic backgrounds (e.g., age, gender, area of study, educational background, and stages of their study). The purpose of the sampling techniques was to provide a cross-section 
of the population. I prioritised PhD students because it was more manageable for them to take part in all four interviews (master's students completed their studies within a very short timeframe). Twelve students were selected as potential participants and three were considered back-up participants. Three (two New Zealand and one Vietnamese) of them then declined to participate because of other commitments. I then moved on to contact three students on the back-up list and they all agreed to take part.

The final sample consisted of twelve students: three from Cluster 1 (Emma, Huynh, Paddy), three from Cluster 2 (Darshana, Linh, Victor), two from Cluster 3 (Sunny, Trung), three from Cluster 4 (Ally, Frank, Hoa), and one from Cluster 5 (Solace). The next section presents participants' demographic information and the cluster each of them belonged to. Interview participants' survey responses are provided in Appendix B.

\section{Descriptions of interview participants}

Twelve students with divergent backgrounds and understanding of plagiarism participated in the interviews. These students came from five faculties of VUW: Faculty of Humanities and Social Sciences (FHSS); Faculty of Science (FoSci); Faculty of Engineering and Computer Science (FoEng), Victoria Business School (VBS), and Faculty of Education (FoEduc). Table 4.8 summarises their demographics and the perception cluster each belonged to.

Table 4.8 Demographic characteristics of interviewees

\begin{tabular}{llllll}
\hline Pseudonym & Nationality & Gender & Faculty & Teaching experience & Cluster \\
Ally & New Zealander & Female & FHSS & Teacher, tutor & 4 \\
Darshana & New Zealander & Female & FoSci & Tutor, a small amount of lecturing & 2 \\
Emma & New Zealander & Female & FoSci & Tutor & 1 \\
Frank & New Zealander & Male & FHSS & Tutor (3 years) & 4 \\
Paddy & New Zealander & Male & FoSci & Tutor, TA, a small amount of lecturing & 1 \\
Solace & New Zealander & Male & FoEng & Tutor (5 years), a small amount of lecturing & 5 \\
\hline Hoa & Vietnamese & Female & VBS & Lecturer & 4 \\
Huynh & Vietnamese & Female & FoEd & Lecturer & 1 \\
Linh & Vietnamese & Female & FHSS & Lecturer, tutor & 2 \\
Sunny & Vietnamese & Female & FoEd & Lecturer & 3 \\
Trung & Vietnamese & Male & FoEd & Lecturer \\
Victor & Vietnamese & Male & FoEd & Lecturer & 3 \\
\hline
\end{tabular}


As illustrated in Table 4.8, six participants were New Zealander and six were Vietnamese. Four students come from FoEduc, three from FoSci, three from FHSS, one from FoEng, and one came from VBS. There were seven female and five male students.

\subsubsection{Qualitative Research Instrument}

After the analysis of the survey data, in-depth interviews, which involve "face-to-face, repeated interaction between the researcher and his/her informant(s)" (Kumar, 2008, p. 160) were conducted with the selected volunteer students. This type of interview can lead to in-depth and accurate information because mutual understanding between researchers and informants is established and strengthened through repeated contact (Kumar, 2008).

The purpose of the interviews was to enhance survey data by getting more and deeper information about influences on their perceptions. Interview questions were informed by the theoretical frameworks and survey results. To explore influences of cultural capital on students' perceptions, questions about their familial backgrounds were included. Information about professional, disciplinary, and doctoral experiences was obtained to understand impacts of environmental factors on students' perceptions. Students' self-formation was explored by examining how they constructed their academic identities and responded to challenges during their doctoral studies. Students were also asked about their motivation for doctoral studies, academic goals, aspirational identities, and how they attain their goals.

The study involved four interview rounds. Each interview lasted approximately one hour and included opening questions about students' current learning, scenario questions, and followup questions. Discussion topics were addressed within four interviews according to how each interview was going. The first three interview rounds were conducted from September to October 2018. The last interview was carried out from May to June 2019.

The first interview was to get to know students' familial and educational backgrounds, their writing process, and their views on academic literature. Students were also asked about their prior learning about plagiarism. This interview aimed to establish mutual trust before moving to questions about students' perceptions of plagiarism. In the second interview, a couple of weeks after the first, depending on interviewees' availability, students were inquired about their perspectives of plagiarism. Scenarios, which were framed from the same culture as the interviewees (e.g., using the Vietnamese name/university for Vietnamese interviewees), were 
used to contextualise follow-up questions about plagiarism. In the third interview, conducted a couple of weeks from the second interview, students were asked to give more information about their perspectives of plagiarism and understanding of plagiarism policies at VUW. In the final interview, carried out six to eight months after the third interview, issues discussed in previous interviews were revisited to explore changes in students' perceptions. This interview also focused on students' self-formation and identity to understand how these factors affected their perceptions. I shared with the interviewees the findings from the quantitative phase and the first three interviews to get their feedback.

\subsubsection{Qualitative Data Collection Procedures}

Interviews with open-ended questions were conducted in English with NZ-educated participants. Vietnamese was used to interview VN-educated students to obtain deeper and more accurate data. I also wanted to ensure that I understood exactly what the participants said, and they understood what I asked them.

All interview transcripts were sent back to interviewees for feedback. The students were invited to review the documents, add, change, and justify the information that they had given. They were also asked if they wanted to pick out anything from the final report. The transcriptions were sent to the interviewees twice, after the first three interview rounds and the last interview round. All participants agreed that the information presented in the transcripts accurately reflected their views. Participants' profiles, which were constructed based on interview data were also sent back to them for review. Two students requested minor changes to the wordings of their profiles, which were duly made.

\subsubsection{Qualitative Data Analysis Procedures}

Qualitative data from interviews were analysed using Nvivo12. A combination of inductive and deductive coding approaches was employed. Inductive coding method involves generating codes directly from examining the data (Johnson \& Christensen, 2014). Deductive coding, in contrast, means establishing pre-existing codes prior to data collection, based on previous research or theories (Johnson \& Christensen, 2014). However, using deductive coding, the researchers might miss important ideas or perspectives that have not been identified in the literature. Apart from focusing on the research questions and theoretical frameworks, I looked for new themes or ideas that emerged from the data, things that I did not expect to hear, to 
compare them with what I was looking for, and see how they addressed the research questions. The analysis started with inductive coding to ensure that the themes derived from the data were captured and not lost due to an emphasis on expected themes. Examples of deductive codes are perceived seriousness, literary theft, and embodied cultural capital.

All interview materials were transcribed but only data collected from VN-educated participants were translated from Vietnamese into English. Because the translation might affect the nuances of meaning, I analysed data from VN-educated participants in the source language and then translated themes and categories into English. I also made sure that my supervisors knew whether a quote was a translation of the interviewees' words or a direct quote so that they could provide appropriate support.

Thematic analysis was utilised to analyze the interview data (Braun \& Clarke, 2006). This approach involves six following phases. The first step involved familiarising myself with the data. I went back to the transcripts, read, and reread them thoroughly to have a general sense of the data. For each transcript, I paid special attention to the words or phrases used frequently. While reading, I made notes on my initial impressions of the data and asked myself if the students said something that implied or conveyed their ideas/thinking about plagiarism.

The second step was generating initial codes. Once specific ideas were identified, I assigned code labels to sentences or paragraphs that contained those ideas. The process continued until code labels were provided for each entire transcript. Simultaneously, similar or related codes were grouped into broader categories and subcategories. The same process was conducted with all transcripts. As I worked through these transcripts, I generated new codes/categories or modified the existing ones. The coding process started with transcripts of one VN-educated student's interviews and one NZ-educated student's interviews to develop the coding scheme. The process was repeated with the transcripts of the other ten interviewees. A list of sample codes is provided in Appendix I.

The third step was searching for themes. I looked through the list of generated codes, identified patterns of the data, and clustered codes into themes. Themes were generated either inductively from the interview data or deductively from the theories or literature. Some codes became themes themselves while the others were collated to form themes. 
The fourth step involved reviewing and refining themes. I revisited the themes identified in Step 3, making sure that labels or themes captured associated extracts and accurately represented the data. I also considered splitting themes that were too broad, combining those that were too narrow, and moving codes around the identified themes. For example, the themes that spoke to student perceptions of plagiarism were categorised into personal (what students need to be responsible for) and organisational (the practice of the university) levels.

The fifth step was naming and defining themes. I generated a clear and succinct definition for each theme. Themes were defined in ways that best described the data and answered the main research questions and two research sub-questions.

The final step was producing the report. I wrote up the findings chapters and chose actual quotes or extracts to use. I made sure that I provided sufficient evidence from the data to contextualise my arguments but maintained an appropriate balance between the participants' voice and my interpretation. I tried to structure the findings chapters logically and coherently to make sense to readers and best answer the research questions.

\subsubsection{Interpretation of Qualitative Findings}

The research findings were structured into three chapters. Chapter Six provides a detailed description of the participants' backgrounds and features of their plagiarism perspectives. Chapter Seven chapter reports the themes coming out from the analysis. The chapter also includes an interpretation of how qualitative data helped to explain quantitative results. In other words, here I explained quantitative results using the qualitative findings. In this chapter, I highlighted alignments and contradictions between the qualitative themes and survey results. Chapter Eight describes influences on student perceptions drawing on the theories underpinning the study. Interpretation of findings in these three chapters sheds light on the two research questions, including two research sub-questions.

\subsection{Validity of the Study}

Employing a mixed-methods research design, I needed to ensure the validity of both quantitative and qualitative components. For quantitative research, validity refers to "the correctness or truthfulness of the inferences that are made from the results of the study" (Johnson \& Christensen, 2014, p. 279). It consists of face validity, criterion-related validity, 
construct validity, and content validity (Babbie, 2017; Cohen et al., 2011). Various procedures were carried to ensure the validity of the questionnaire. (See Section 4.5.4)

Qualitative validity is usually referred to as trustworthiness which means that qualitative research is "plausible", "credible", "trustworthy", and "defensible" (Johnson \& Christensen, 2014 , p. 299). Educational methodologists suggest several strategies to maximise the validity of the qualitative phase including collecting data through multiple methods such as surveys and interviews (Creswell, 2014), establishing sequential validity (Creswell, 2014), self-reflecting on potential personal biases (Johnson \& Christensen, 2014), and member checking or "taking the final report or specific descriptions or themes back to the participants and determining whether these participants feel that they are accurate" (Creswell, 2014, p. 201). Creswell (2014) suggests that the more experiences the researchers have with participants, the more accurate and valid the findings are. Also, the researcher can "move back and forth" between participants' subjective insider and researcher's objective outsider viewpoints to produce "fully informed descriptions and explanations" (Johnson \& Christensen, 2014, p. 309).

Several strategies were employed to maximise the validity of interview data. Firstly, data were collected through both quantitative and qualitative approaches. Secondly, the second phase was designed purposely based on the first phase to establish sequential validity. The first phase aimed at exploring student perceptions of plagiarism while the second emphasised the construction of such perceptions. Thirdly, to ensure the accuracy of research findings, transcripts were sent back to the interviewees to get their confirmation before the analysis. Specifically, interviewees were asked whether they wanted to justify, add, or pick out anything from the transcripts. In the last interview, I shared the findings from the survey and the first three interviews with interviewees to get their opinions and feedback. Participants' profiles, constructed based on interview data, were sent back to them to ensure that they were happy and comfortable with my framing of their lives and thoughts. I spent extended time with participants by interviewing each of them four times in six months. Finally, as a VN-educated and postgraduate student, I was both an insider and an outsider of the study. I was aware of and critically reflected on my potential biases that might impact the study process and conclusions when collecting and interpreting data. My position as a doctoral student also allowed me to approach potential participants in an ethical way, to build rapport with them, and to bring my insider knowledge to the interpretation of the interview data. Next, after 
developing the initial codebook, my supervisors and I coded a sample of transcripts independently. After the first coding, disagreements among the three coders were reexamined by going back to the transcripts. As coders, we collectively looked at the transcripts and coding schemes together to get consistent analysis.

\subsection{Ethical Considerations}

Considerations of research ethics are an essential part of all research studies (Johnson \& Christensen, 2014). Three ethics approvals were obtained from the VUW Human Ethics Committee before data collection for (1) the pilot study, (2) the quantitative phase, and (3) the qualitative phase (see Appendix E).

Students' decision to take part in the study was a choice and if they chose to participate, they had the right to withdraw at any time. These and other rights were communicated through an invitation letter sent to participants prior to data collection. Before the first interview, each interviewee was asked to sign a written informed consent form that explained their ethical rights and key facts about the study.

Interview participants were assured that the information they shared would remain confidential and I was the only person who knew who they were and what data they provided. They were assured of the non-traceability of the information by being given a pseudonym. In the interviews, students were not asked to disclose information about specific examples of plagiarism they or other students had undertaken in their interviews. The main reason was that this study focused on how students viewed plagiarism and the development of their perceptions but not the prevalence of student plagiarism. Also, the ethics committee at VUW did not allow asking participants to disclose significant plagiarism that they have committed. Participants' identifiable characteristics were omitted from the final reports so that their answers could not be traced back to them.

Also, compensation for participants, which was a token of recognition of their investment of time and effort, was considered. Survey respondents could enter a draw for one of ten \$20 supermarket vouchers. Each interview participant was given four supermarket vouchers with a total value of $\$ 80$ (a $\$ 20$ voucher per interview) in appreciation of their participation. 


\subsection{Chapter Summary}

This chapter has outlined the rationale for the mixed-methods research design employed in the study. It provides detailed descriptions of the research questions, research paradigm, and techniques used to ensure the validity and reliability of the study. Also included in the chapter are procedures for collecting and analysing quantitative and qualitative data. Figure 4.2 summarises two phases of data collection and analysis in sequence.

Figure 4.2 Summary of research processes

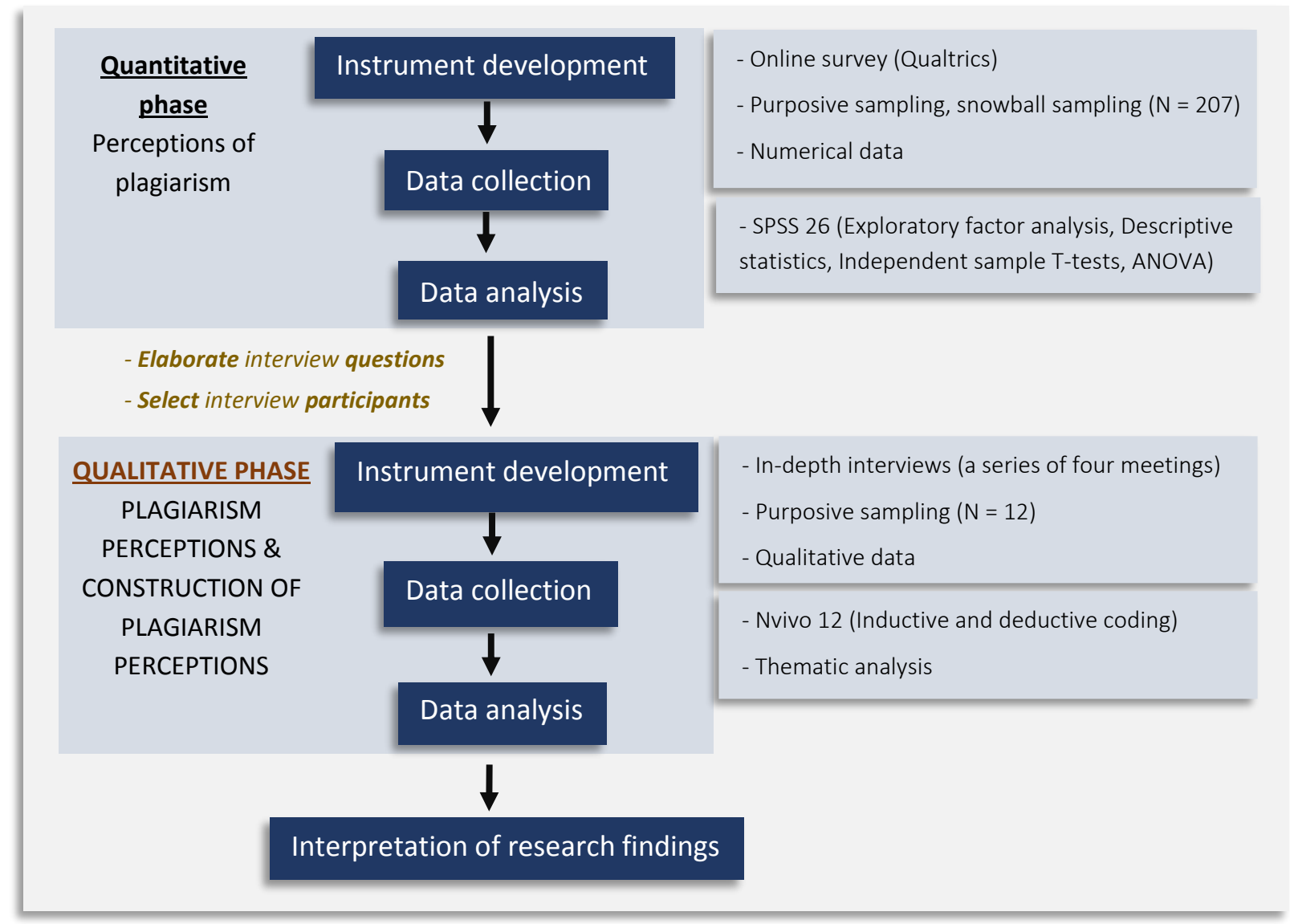

The next chapters present the findings of the study. Specifically, Chapter Five focuses on quantitative findings; Chapters Six, Seven, and Eight describe qualitative results. 


\section{Chapter 5 | Survey Findings}

\subsection{Introduction}

This study examined similarities and variations in plagiarism perceptions between and within the two groups of VN- and NZ-educated postgraduate students at VUW. This chapter presents major findings derived from statistical analyses of survey data and comprises four sections. Section 5.2 describes the respondents' demographics. Section 5.3 presents exploratory factor analysis results, demonstrating underlying constructs related to students' perceptions of plagiarism. The next section focuses on descriptive statistics of the five subscales. Section 5.5 reports results from the independent-samples T-tests and one-way ANOVAs, detailing relationships between students' demographics and educational backgrounds and their perceptions of plagiarism. These four sections together answer one main research question: How do VN- and NZ-educated postgraduate students perceive plagiarism? And two research sub-questions: (1) How do VN- and NZ-educated postgraduate students' attitudes and understanding of plagiarism differ between these groups? and (2) How do VN-and NZ-educated postgraduate students' attitudes and understanding of plagiarism differ within these groups?

\subsection{Demographic Characteristics of the Survey Sample}

The online survey was completed by a total of 235 postgraduate students at VUW. Table 5.1 presents the nationality distribution of survey participants.

Table 5.1 Nationality distribution of the survey sample $(N=235)$

\begin{tabular}{lll} 
& Frequency & Percent \\
\hline New Zealander & 135 & 57.4 \\
Vietnamese & 72 & 30.6 \\
Other & 28 & 11.9 \\
Total & 235 & 100.0 \\
\hline
\end{tabular}

As illustrated in Table 5.1, a majority of respondents were New Zealanders (57.4\%) and $30.6 \%$ of them were Vietnamese. A small number of respondents (11.9\%) came from other countries. Because the study focused on VN- and NZ-educated postgraduate students', responses that did not fit into this specified inclusion criterion were excluded from the main analyses. However, the full data set $(\mathrm{N}=235)$ was used for factor analysis as it produced more stable pattern structures. Descriptive and inferential statistics results reported in later sections were associated with the sample of VN- and NZ-educated students ( $N=207)$. 
Respondents were asked to indicate their nationality, age, gender, and teaching employment. Distributions of students' responses to these questions were provided in Table 5.2.

Table 5.2 Demographic characteristics of the survey sample $(N=207)$

\begin{tabular}{llcc}
\hline & & Frequency & Percent \\
\hline \multirow{2}{*}{ Nationality } & New Zealander & 135 & 65.2 \\
& Vietnamese & 72 & 34.8 \\
\hline Gender & Female & 138 & 66.7 \\
& Male & 65 & 31.4 \\
& Non-binary & 3 & 1.4 \\
& Genderqueer & 1 & 0.5 \\
\hline Age & $24-y o u n g e r$ & 56 & 27.1 \\
& $25-34$ & 84 & 40.6 \\
& $35-44$ & 47 & 22.7 \\
& $45-o l d e r$ & 20 & 9.7 \\
\hline Teaching employment & Have been employed as a teacher/tutor & 54 & 26.1 \\
& Have not been employed as a teacher/ tutor & 153 & 73.9 \\
\hline
\end{tabular}

Table 5.2 shows that $65.2 \%$ of respondents were New Zealander and $34.8 \%$ of them were Vietnamese. The sample included four gender groups: female (66.7\%); male (31.4\%); nonbinary (1.4\%); and genderqueer (0.5\%). They were classified into 4 age groups: 24 years old or younger (27.1\%); 25 to 34 (40.6\%); 35 to 44 (22.7\%); and 45 years old and older (9.7\%). $73.9 \%$ of them had been employed as a teacher/tutor and $26.1 \%$ had no teaching experiences.

Students were inquired about their high school education, tertiary qualifications and where they were earned, and current studies. 100\% of VN-educated participants attended high school in Vietnam. Six out of 135 NZ-educated students went to high school in other countries. Table 5.3 describes the distribution of respondents concerning types of degrees.

Table 5.3 Number of students by degree level $(N=207)$

\begin{tabular}{lrr}
\hline Types of degree & Frequency & Percent \\
\hline PhD & 100 & 48.3 \\
Masters & 95 & 45.9 \\
BA with Honours & 7 & 3.4 \\
PG diploma & 3 & 1.4 \\
Rather not say & 2 & 1.0
\end{tabular}

$48.3 \%$ of respondents were PhD students and $45.9 \%$ were master's students. BA with Honours students comprised $3.4 \%$ and postgraduate diploma students accounted for $1.4 \%$. Two 
students (1\%) did not indicate their level of study. The respondents came from eight faculties of VUW. Table 5.4 below illustrates the distribution of students by discipline.

Table 5.4 Number of students by discipline $(N=207)$

\begin{tabular}{lrr}
\hline Faculty & Frequency & Percent \\
\hline FHSS & 61 & 29.5 \\
VBS & 50 & 24.2 \\
FoSci & 42 & 20.3 \\
FoEduc & 33 & 15.9 \\
Faculty of Architecture and Design (FoArch) & 5 & 2.4 \\
FoEng & 5 & 2.4 \\
Faculty of Law (FoLaw) & 3 & 1.4 \\
Faculty of Health (FoHealth) & 1 & 0.5 \\
Rather not say & 7 & 3.4
\end{tabular}

Table 5.4 shows that most of the respondents came from FHSS (29.5\%), VBS (24.2\%), FoSci (20.3\%), and FoEduc (15.9\%). The other respondents were studying in FoArch (2.4\%), FoEng (2.4\%), FoLaw (1.4\%), and FoHealth (0.5\%). The remaining 3.4\% did not answer this question.

\subsection{Exploratory Factor Analysis Results}

Before the main analyses, EFA was performed to determine the underlying constructs of the data set. Before EFA, two items were reverse-scored so that items loaded on the same factor had the same sign of factor loadings. This section presents the results of the analysis. Multiple factor analyses (principal component analysis, principal axis factoring, and ML factor analysis with varimax and oblimin rotation) were performed with all 37 items to determine the stability of the factor structure. The overall factor structure was stable across different extraction and rotation methods and the factors were interpretable, providing support for its validity and robustness. The next section reports results of $\mathrm{ML}$ factor analysis using an oblique factor rotation. Oblique factor rotation was chosen because it allowed factors to be correlated.

\subsubsection{Five Factors Analysis Results}

The initial KMO statistic was 0.712 and Bartlett's Test of Sphericity was significant $(\chi 2=2150.50$, $\mathrm{df}=666, \mathrm{p}<.001$ ), indicating that the sample was sufficient for factor analysis. Initial eigenvalues and proportions of variance were examined to determine the appropriate number of factors to retain. EFA identified 12 factors with eigenvalues greater than .1 (explaining $61.52 \%$ of the variance). The Scree Plot suggested that a five-factor solution would best fit the data. The 
diagonals of the anti-image correlation, the KMO measure of sampling adequacy for individual variables, were all above .5. Also, there were at least five items in each factor. The analysis revealed three cross-loading items: items 27, 30 and 20. Five items (italicised in Table 5.5), did not load significantly (factor loadings below .3) on any factors.

Table 5.5 Pattern matrix extracted using maximum likelihood estimation and oblique rotation (direct oblimin) with a five-factor solution

\begin{tabular}{|c|c|c|c|c|c|}
\hline \multirow[b]{2}{*}{ Items } & \multicolumn{5}{|c|}{ Factor loadings } \\
\hline & 1 & 2 & 3 & 4 & 5 \\
\hline 2. It is no big deal if you submit slightly modified work as your own without proper citation. & .57 & & & & \\
\hline $\begin{array}{l}\text { 7. Heavily depending on an original source for ideas without citation is no big deal if you use few } \\
\text { or no words from that source. }\end{array}$ & .56 & & & & \\
\hline 16. Students are more likely to plagiarise written assignments than presentations. & .51 & & & & \\
\hline $\begin{array}{l}\text { 13. In an assignment, it is fine to include some texts if you delete some words, alter grammatical } \\
\text { structures, or substitute synonyms. }\end{array}$ & .44 & & & & \\
\hline $32 *$. Plagiarism is academically wrong. & -.41 & & & & \\
\hline 34. It is not a serious problem if you acknowledge the original sources insufficiently. & .35 & & & & \\
\hline 31. Plagiarism helps students do well in later life. & .32 & & & & \\
\hline
\end{tabular}

26. Submitting exactly copied work as your own without appropriate acknowledgement is not a serious problem.

35. Students plagiarise when assessments test understanding of textbook materials.

19. It is fine to submit the same assignment to more than one class.

29. Students plagiarise because they want to pass courses. 70

9. Students plagiarise because of pressure to succeed. $\quad .60$

12. Students plagiarise because they want high grades.

36. Students plagiarise when they are under academic workload pressure. $\quad .56$

25*. Time constraints have no influence on student plagiarism.

4. Students plagiarise when lecturers set the same assignments year after year.

18. Students' poor understanding of how to write academically leads to plagiarism.

3. Students' poor understanding of citing and referencing leads them to plagiarise. -.62

14. Students plagiarise because they can't tell what is or isn't plagiarism.

5. Plagiarism is more common in the work of beginner writers.

23. Plagiarism happens when students are learning to write.

24. Students plagiarise when there are no policies about plagiarism.

10. Students don't plagiarise when assignments are interesting.

33. Students who are very fluent in their use of language don't plagiarise. $\quad .46$

28. Students don't plagiarise when assignments are personalised. $\quad .42$

27. Academically weak students are more likely to plagiarise. $\quad-.37 \quad .37$

15. Students don't plagiarise when there is a high chance of being caught.

$\begin{array}{lr}\text { 17. Plagiarism is deceitful. } & .70\end{array}$

22. Plagiarism is stealing. $\quad .49$

1. Plagiarism damages the meaning of a degree. $\quad .48$

30. Plagiarism worsens teacher-student relationships. $\quad .34 \quad .47$

6. Students who plagiarise learn less. $\quad .43$

20. A good person doesn't plagiarise. $\quad .31 .41$

11. Plagiarism threatens the reputation of the university. $\quad .41$

21. Students plagiarise when they have easy access to electronic materials. $\quad .34$

8. Plagiarism is unethical. $\quad .33$

37. Students who plagiarise are penalised by the university.

\begin{tabular}{|c|c|c|c|c|c|}
\hline Eigenvalue & 4.586 & 3.923 & 2.351 & 1.960 & 1.58 \\
\hline$\%$ of variance (38.926) & 12.4 & 10.1 & 6.4 & 5.3 & 4.3 \\
\hline
\end{tabular}

Note: $*$ indicates items that were reverse scored for EFA 
As the results were usable with related items loaded into the same factors, the five-factor analysis was repeated with these low-loading and crossed-loading items removed from the initial pool of items one at a time. Considerations for removing items were based not only on loading strength but also on item wordings, i.e., items that were different in meaning from other items in the subscale. After multiple analysis, 29 items were retained. The KMO statistics was 0.733 and Bartlett's Test of Sphericity was significant ( $\chi 2=1572.60, d f=406, p<.001)$ with these 29 items. There were at least three items loaded into each factor (Table 5.6).

Table 5.6 Pattern matrix extracted using maximum likelihood estimation and oblique rotation (direct oblimin) with a five-factor solution

\begin{tabular}{|c|c|c|c|c|c|}
\hline \multirow[b]{2}{*}{ Items } & \multicolumn{5}{|c|}{ Factor loadings } \\
\hline & 1 & 2 & 3 & 4 & 5 \\
\hline \multicolumn{6}{|l|}{ Perceived seriousness of plagiarism } \\
\hline 2. It is no big deal if you submit slightly modified work as your own without proper citation. & .59 & & & & \\
\hline $32 *$. Plagiarism is academically wrong. & .52 & & & & \\
\hline $\begin{array}{l}\text { 7. Heavily depending on an original source for ideas without citation is no big deal if you use } \\
\text { few or no words from that source. }\end{array}$ & .45 & & & & \\
\hline 31. Plagiarism helps students do well in later life. & .43 & & & & \\
\hline 19. It is fine to submit the same assignment to more than one class. & .42 & & & & \\
\hline $\begin{array}{l}\text { 26. Submitting exactly copied work as your own without appropriate acknowledgement is } \\
\text { not a serious problem. }\end{array}$ & .39 & & & & \\
\hline $\begin{array}{l}\text { 13. In an assignment, it is fine to include some texts if you delete some words, alter } \\
\text { grammatical structures, or substitute synonyms. }\end{array}$ & .37 & & & & \\
\hline 34. It is not a serious problem if you acknowledge the original sources insufficiently. & .36 & & & & \\
\hline \multicolumn{6}{|l|}{ Personal factors } \\
\hline 29. Students plagiarise because they want to pass courses. & & .70 & & & \\
\hline 9. Students plagiarise because of pressure to succeed. & & .59 & & & \\
\hline 36. Students plagiarise when they are under academic workload pressure. & & .59 & & & \\
\hline 12. Students plagiarise because they want high grades. & & .56 & & & \\
\hline 25*. Time constraints have no influence on student plagiarism. & & .34 & & & \\
\hline \multicolumn{6}{|l|}{ Academic factors } \\
\hline 3. Students' poor understanding of citation and referencing conventions leads them to plagiar & rise. & & -.63 & & \\
\hline 18. Students' poor understanding of how to write academically leads to plagiarism. & & & -.62 & & \\
\hline 14. Students plagiarise because they can't tell what is or isn't plagiarism. & & & -.57 & & \\
\hline 5. Plagiarism is more common in the work of beginner writers. & & & -.49 & & \\
\hline 23. Plagiarism happens when students are learning to write. & & & -.49 & & \\
\hline 27. Academically weak students are more likely to plagiarise. & & & -.36 & & \\
\hline \multicolumn{6}{|l|}{ Assessment factors } \\
\hline 10. Students don't plagiarise when assignments are interesting. & & & & .71 & \\
\hline 28. Students don't plagiarise when assignments are personalised. & & & & .50 & \\
\hline 15. Students don't plagiarise when there is a high chance of being caught. & & & & .37 & \\
\hline \multicolumn{6}{|l|}{ Negative attitudes towards plagiarism } \\
\hline 17. Plagiarism is deceitful. & & & & & .69 \\
\hline 22. Plagiarism is stealing. & & & & & .47 \\
\hline 1. Plagiarism damages the meaning of a degree. & & & & & .47 \\
\hline 20. A good person doesn't plagiarise. & & & & & .43 \\
\hline 30. Plagiarism worsens teacher-student relationships. & & .37 & & & .41 \\
\hline 6. Students who plagiarise learn less. & & & & & .41 \\
\hline 11. Plagiarism threatens the reputation of the university. & & & & & .35 \\
\hline Eigenvalue & 4.116 & 3.288 & 2.298 & 1.739 & 1.331 \\
\hline Percent of total variance accounted for by each factor & 14.2 & 11.3 & 7.9 & 6.0 & 4.6 \\
\hline Alpha value & .69 & .70 & .70 & .59 & .68 \\
\hline
\end{tabular}


The Plagiarism Perception scale consisted of five factors, accounting for $44 \%$ of the variance. Factor 1 (Perceived seriousness of plagiarism) accounted for $14.2 \%$ of the variance and included eight items representing different degrees of plagiarism. The highest loading item was It is no big deal if you submit slightly modified work as your own without proper citation (0.59).

Factor 2 (Personal factors) consisted of four items describing personal factors for student plagiarism, accounting for $11.3 \%$ of the variance. Students plagiarise because they want to pass courses (0.70), Students plagiarise when they are under academic workload pressure (0.59), and Students plagiarise because of pressure to succeed (0.59) were the highest loading items.

Factor 3 (Academic factors) accounted for $7.9 \%$ of the variance and comprised six items involving academic skills associated with student plagiarism. Three highest loading items were Students' poor understanding of citation and referencing conventions leads them to plagiarise (-0.63), Students' poor understanding of how to write academically leads to plagiarism (-0.62), and Students plagiarise because they can't tell what is or isn't plagiarism (-0.57).

Factor 4, which described assessment factors that may contribute to student plagiarism, accounted for $6 \%$ of the variance. It included three items: Students don't plagiarise when assignments are interesting (factor loading of 0.71), Students don't plagiarise when assignments are personalised (0.50), and Students don't plagiarise when there is a high chance of being caught (0.37). The factor was named Assessment factors.

Factor 5 included six items reflecting negative attitudes towards plagiarism and accounted for $4.6 \%$ of the variance. The item with the highest factor loading was Plagiarism is deceitful (factor loading of 0.69). This factor was named Negative attitudes towards plagiarism.

Eight items failed to load significantly (items 4, 8, 16, 21, 24, 33, 35, 37), with factor loadings below $\leq 3$, on any of these five factors, and these are presented in Table 5.7.

Table 5.7 Misfitting items

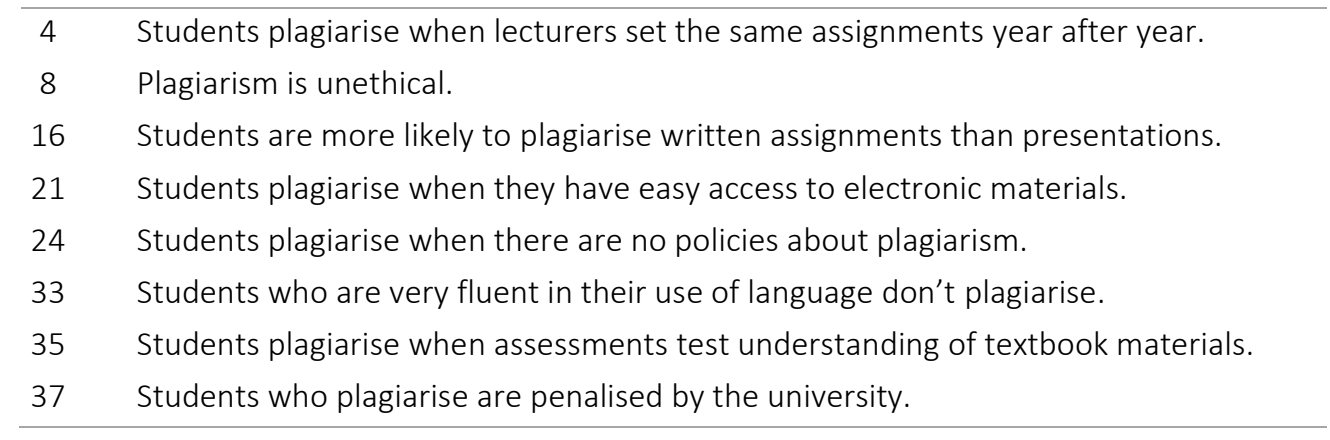




\subsubsection{Correlation among Factors}

Correlations of above .3 , representing the shared variance of approximately $\geq 10 \%$, were considered meaningful. Correlations obtained from factor analysis revealed both negative and positive correlations among five factors as illustrated in Table 5.8 below.

Table 5.8 Factor correlation matrix

\begin{tabular}{lrrrrr}
\hline Factor & $\begin{array}{c}\text { Perceived } \\
\text { seriousness of } \\
\text { plagiarism (1) }\end{array}$ & $\begin{array}{c}\text { Personal } \\
\text { factors (2) }\end{array}$ & $\begin{array}{c}\text { Academic } \\
\text { factors (3) }\end{array}$ & $\begin{array}{c}\text { Assessment } \\
\text { factors (4) }\end{array}$ & $\begin{array}{r}\text { Negative attitudes } \\
\text { towards plagiarism } \\
(5)\end{array}$ \\
\hline 1 & 1.000 & .085 & .052 & -.297 & .291 \\
2 & & 1.000 & -.126 & .161 & .128 \\
3 & & & 1.000 & -.108 & .066 \\
4 & & & & 1.000 & .050 \\
5 & & & & & 1.000
\end{tabular}

Table 5.8 shows no strong correlations between the factors. There was a weak negative correlation between factors 1 and 4 ( $\left.r_{s}=.-297\right)$, suggesting that students who viewed plagiarism as a serious offence would slightly agree that plagiarism resulted from assessment factors. Factor 1-Perceived seriousness of plagiarism was weakly positively correlated with Factor 5Negative attitudes towards plagiarism $\left(r_{s}=.291\right)$ representing that students who viewed plagiarism seriously would possess negative attitudes towards the practice.

\subsection{Descriptive Statistics Results}

This section describes the distribution of students' responses to each survey item. Results are presented in relation to five subscales identified from EFA. Each item is illustrated by a graph with frequency distribution and standard error bar showing the standard deviation of the data set. The distribution of responses for removed items was also provided.

\subsubsection{Subscale 1-Perceived Seriousness of Plagiarism}

This subscale includes eight items in which six items represented degrees of plagiarism: 1-direct copying or prototypical plagiarism, 3-unattributed paraphrasing, 5-self-plagiarism, 6-direct copying or prototypical plagiarism, 7-patch-writing, and 8-insufficient citation. While the respondents perceived plagiarism as a serious offense, their perceived seriousness for each 
type of plagiarism varied. Figure 5.1 presents the distribution of students' responses and standard error for each item.

Figure 5.1 Distribution of student responses in Subscale 1

1. It is no big deal if you submit slightly modified work as your own without proper citation.

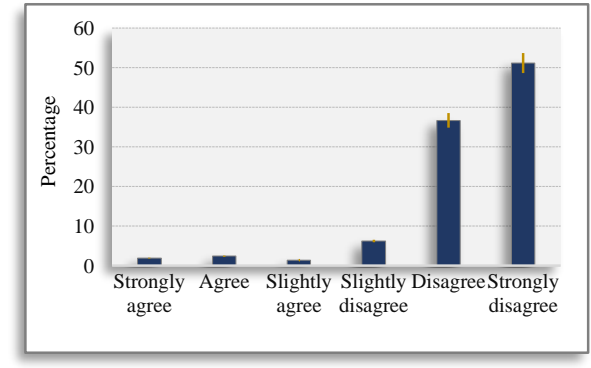

2. Plagiarism is academically wrong.

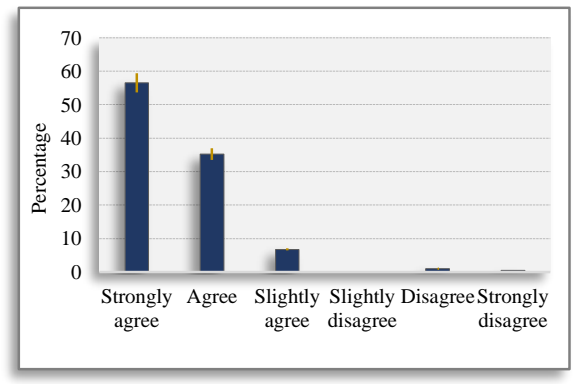

3. Heavily depending on an original source for ideas without citation is no big deal if you use few or no words from that source.

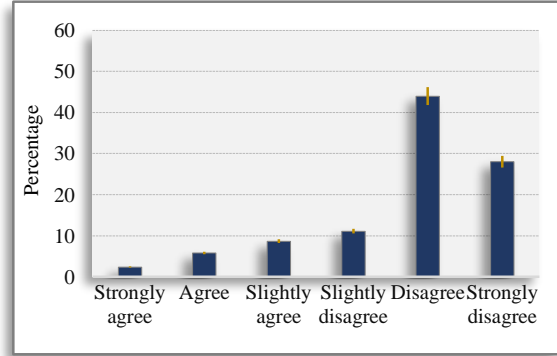

4. Plagiarism helps students do well in later life.

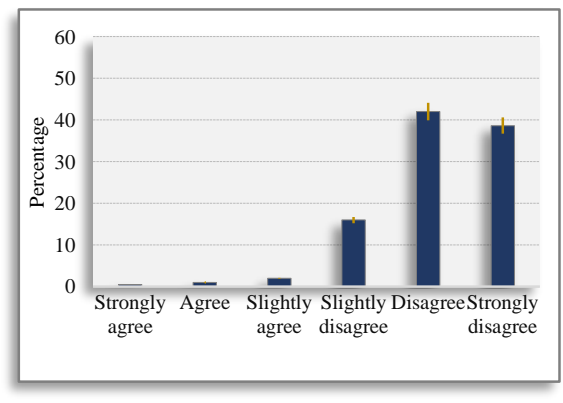

5. It is fine to submit the same assignment to more than one class.

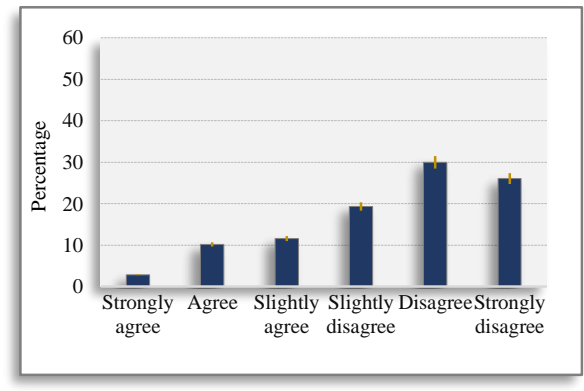

6. Submitting exactly copied work as your own without appropriate acknowledgement is not a serious problem.

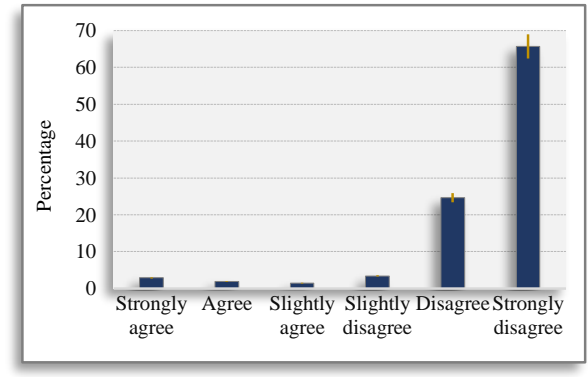

7. In an assignment, it is fine to include some texts if you delete some words, alter grammatical structures, or substitute synonyms.

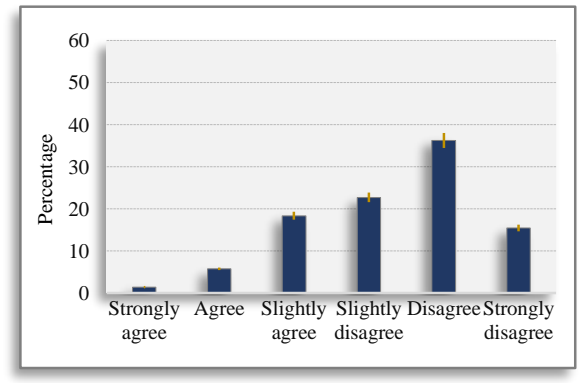

8. It is not a serious problem if you acknowledge the original sources insufficiently.

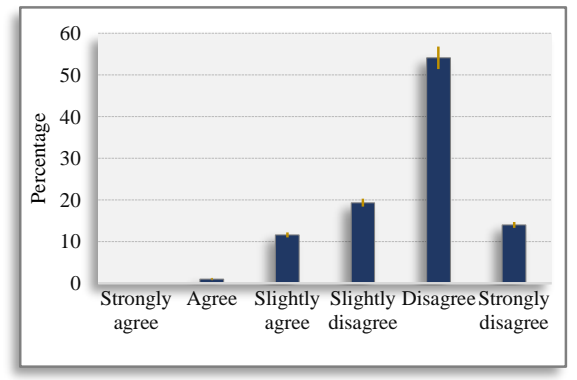

Figure 5.1 shows that respondents tended to strongly disagree or disagree with items representing degrees of plagiarism. For example, over 51\% of them strongly disagreed and approximately $37 \%$ disagreed that it was no big deal if you submit slightly modified work as 
your own without proper citation. Almost $70 \%$ of them strongly disagreed and disagreed that "It is not a serious problem if you acknowledge the original sources insufficiently" (Item 8). Nearly $44 \%, 30 \%$, and $36 \%$ of respondents disagreed with items 3, 5, and 7 respectively.

Students' perceived seriousness of plagiarism could be supported by their answers to item 2Plagiarism is academically wrong and item 4-Plagiarism helps students do well in later life. As illustrated in Figure 5.1, most respondents (nearly 60\%) strongly agreed and agreed (over 35\%) that plagiarism was academically wrong. On the contrary, $45 \%$ of them strongly disagreed and $40 \%$ disagreed that plagiarism helped students do well in later life.

\subsubsection{Subscale 2-Personal Factors}

The second subscale comprised five items which described personal factors that contributed to student plagiarism. Figure 5.2 illustrates the distribution of students' responses with standard error for each item.

Figure 5.2 Distribution of student responses in Subscale 2

1. Students plagiarise because they want to pass courses.

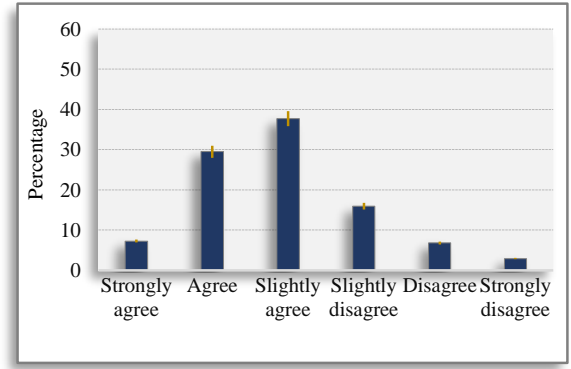

2. Students plagiarise because of pressure to succeed.

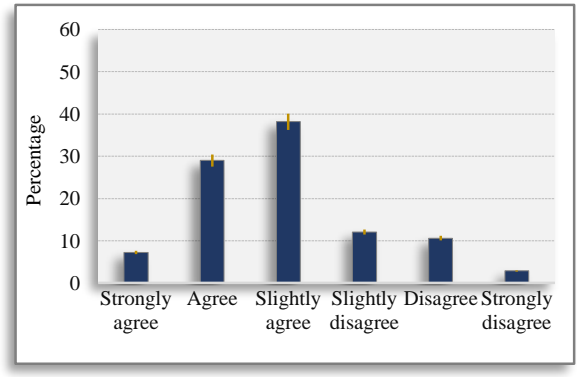

4. Students plagiarise because they want high grades.

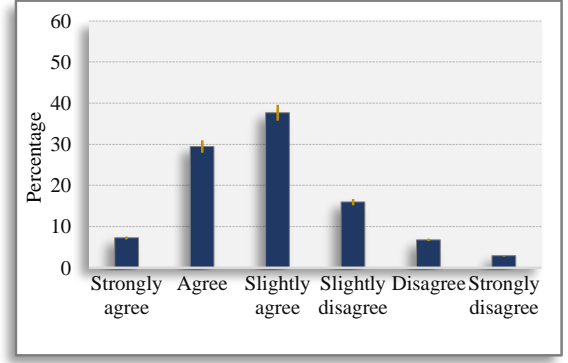

5. Time constraints have no influence on student plagiarism.

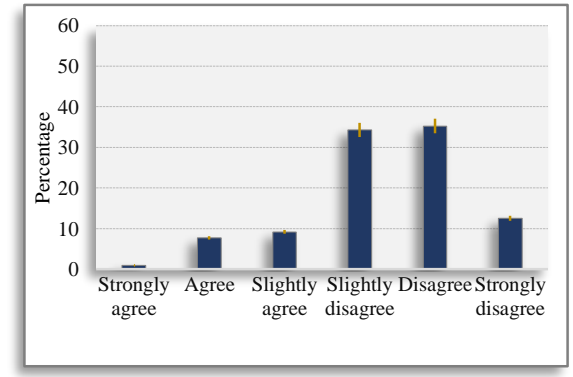

3. Students plagiarise when they are under academic workload pressure.

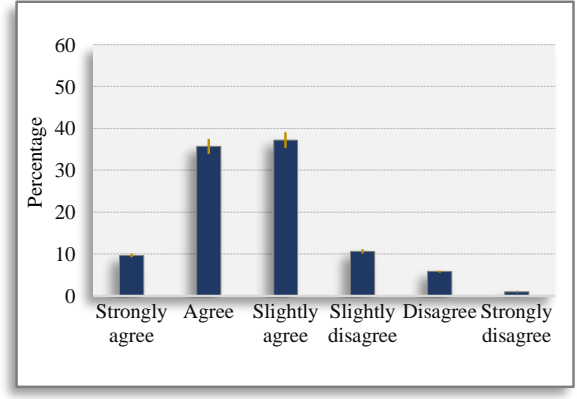


Generally, the respondents agreed that plagiarism resulted from personal factors. Most of them agreed (30\%) or slightly agreed (40\%) with the item Students plagiarise because they want to pass courses. Almost $30 \%$ of them agreed and nearly $40 \%$ slightly agreed that students plagiarised because of pressure to succeed. Similar results were found for the items Students plagiarise when they are under academic workload pressure and Students plagiarise because they want high grades. Almost 35\% of them slightly disagreed and nearly $40 \%$ disagreed with the statement Time constraints have no influence on student plagiarism.

\subsubsection{Subscale 3-Academic Factors}

Subscale 3-Academic factors consisted of six items about academic factors associated with student plagiarism. The distribution of students' responses and standard error for each item is illustrated in Figure 5.3.

Figure 5.3 Distribution of student responses in Subscale 3

1. Students' poor understanding of citation and referencing conventions leads them to plagiarise.

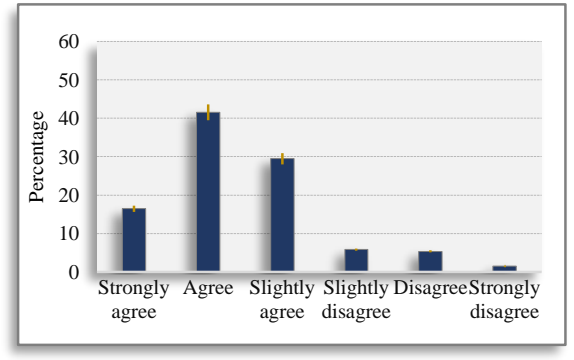

2. Students' poor understanding of how to write academically leads to plagiarism.

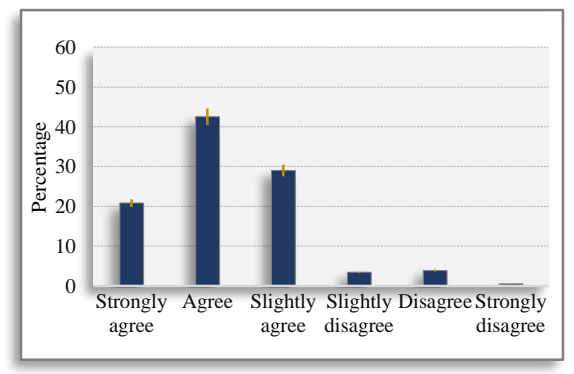

3. Students plagiarise because they can't tell what is or isn't plagiarism.

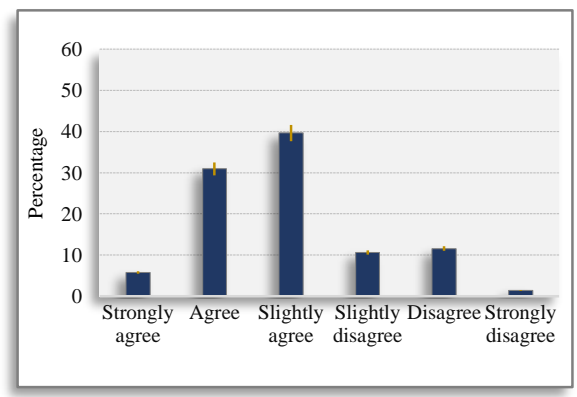

4. Plagiarism is more common in the work of beginner writers.

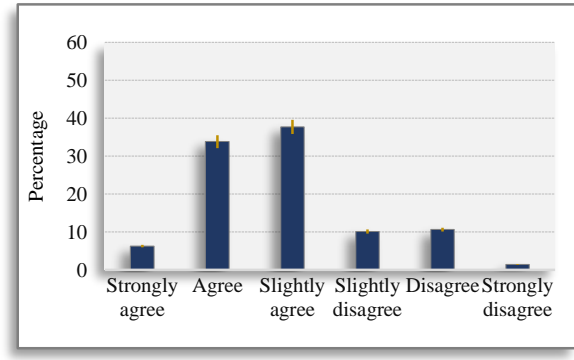

5. Plagiarism happens when students are learning to write.

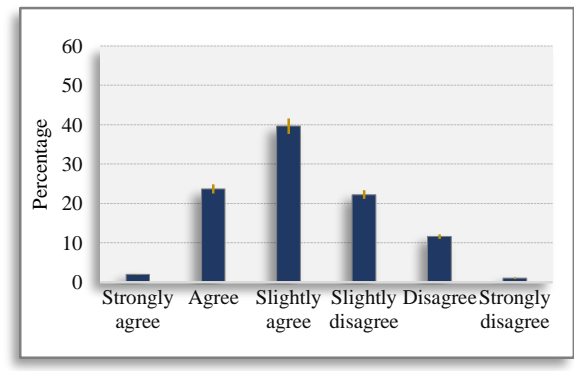

6. Academically weak students are more likely to plagiarise.

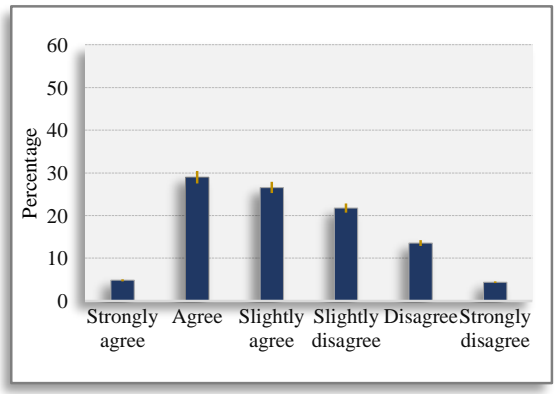


Figure 5.3 shows that respondents tended to agree on academic factors that might contribute to student plagiarism. For instance, over $40 \%$ of them agreed and nearly $30 \%$ slightly agreed that "Students' poor understanding of citation and referencing conventions leads them to plagiarise". An approximately similar number of respondents agreed and slightly agreed with Item 2-Students' poor understanding of how to write academically leads to plagiarism and Item 3-Students plagiarise because they can't tell what is or isn't plagiarism. Around $40 \%$ of them expressed slight agreement with items 5-Plagiarism happens when students are learning to write, and 4-Plagiarism is more common in the work of beginner writers. $22 \%$ of respondents slightly disagreed and over $13 \%$ of them disagreed with Item 6-Academically weak students are more likely to plagiarise.

\subsubsection{Subscale 4-Assessment Factors}

Subscale 4 with three items indicated that plagiarism resulted from assessment factors. Figure 5.4 illustrates the distribution of students' responses and standard error for each item.

Figure 5.4 Distribution of student responses in Subscale 4

1. Students don't plagiarise when assignments are interesting.

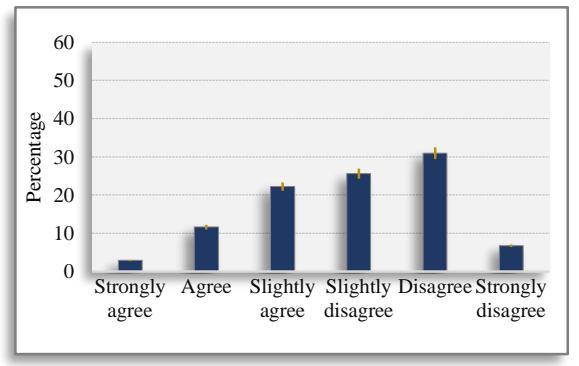

3. Students don't plagiarise when there is a high chance of being caught.

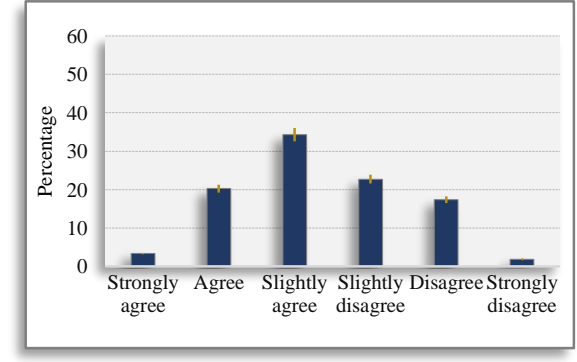

2. Students don't plagiarise when assignments are personalised.

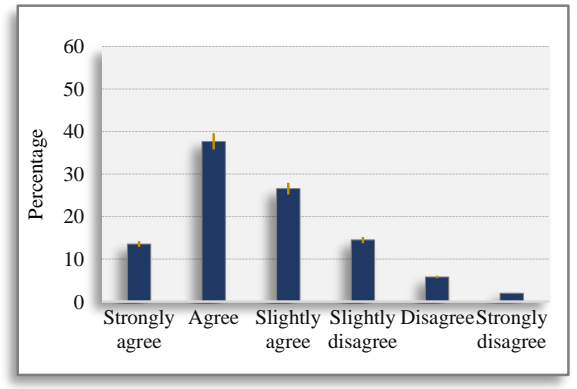

As illustrated in Figure 5.4, students responded differently to the items on this subscale. For example, nearly $40 \%$ of respondents agreed and over $25 \%$ slightly agreed that "Students don't plagiarise when assignments are personalised" (Item 2). With Item 3-Students don't plagiarise when there is a high chance of being caught, more than $34 \%$ of respondents slightly agreed and around 20\% agreed. Item 1-Students don't plagiarise when assignments are interesting 
received more disagree responses than the other two with more than $22 \%$ of respondents disagreed and more than $25 \%$ slightly disagreed.

\subsubsection{Subscale 5-Negative Attitudes towards Plagiarism}

The last subscale comprised seven items which all presents negative attitudes towards plagiarism. Figure 5.5 illustrates the distribution of students' responses.

Figure 5.5 Distribution of student responses in Subscale 5

1. Plagiarism is deceitful.

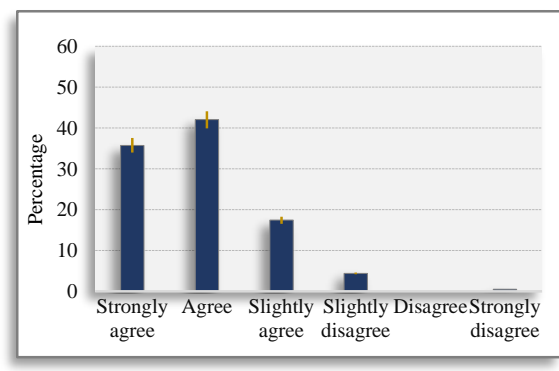

2. Plagiarism is stealing.

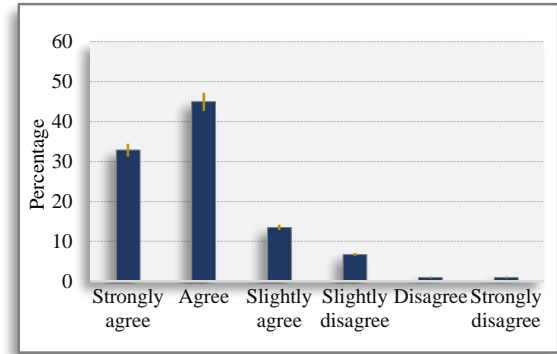

3. Plagiarism damages the meaning of a degree

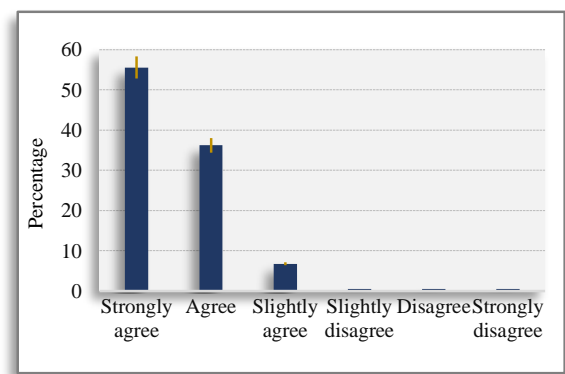

5. Plagiarism worsens teacher-student relationships.

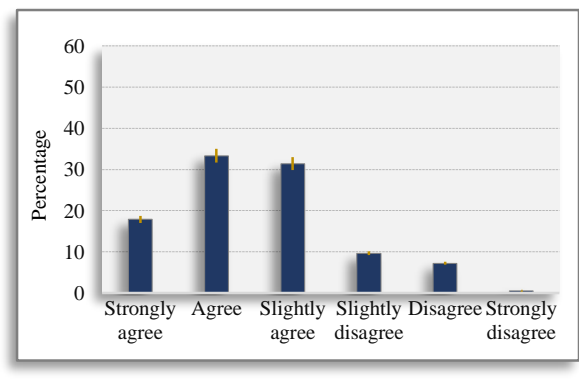

6. Students who plagiarise learn less.

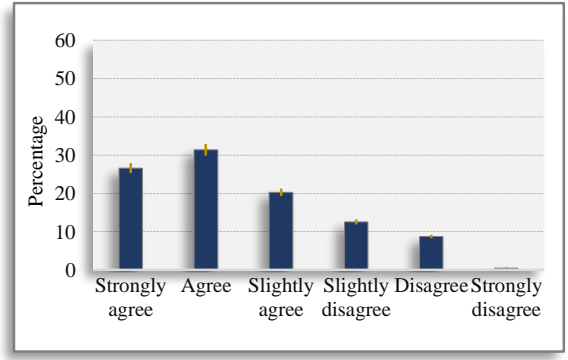

7. Plagiarism threatens the reputation of the university.

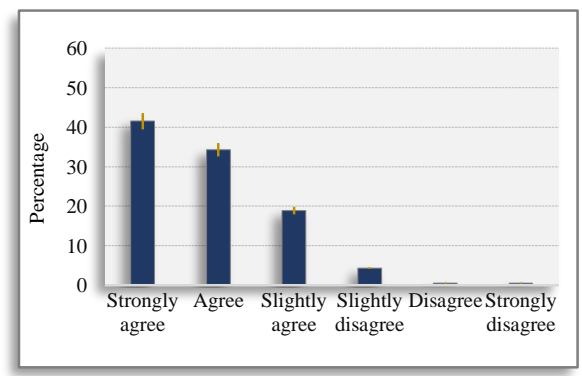

4. A good person doesn't plagiarise.

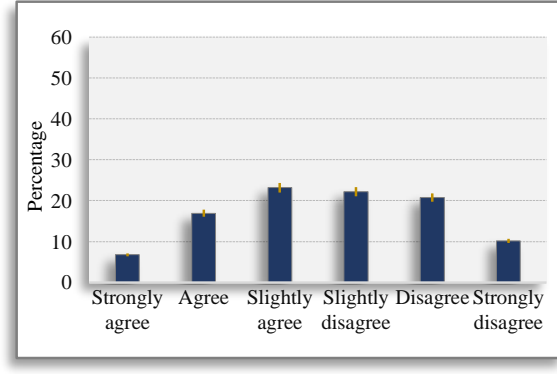


Figure 5.5 shows that the respondents tended to hold negative attitudes towards plagiarism. Item 3-Plagiarism damages the meaning of a degree received the most strongly agreed option (56\%). With the next two items, Plagiarism is deceitful, and Plagiarism is stealing, $42 \%$ and nearly $44 \%$ of respondents disagreed respectively. The number of students who agreed and disagreed with Item 4-A good person doesn't plagiarise was balanced. Respondents tended to agree that plagiarism threatened the reputation of the university with over $41 \%$ strongly agreed and nearly $35 \%$ agreed. Around $65 \%$ of respondents agreed and slightly agreed with item 5Plagiarism worsens teacher-student relationships. The item that received the least agreed responses (around 31\%) was item 6-Students who plagiarise learn less. Nearly 95\% of the respondents agreed that plagiarism threatened the reputation of the university.

\subsubsection{Descriptive Statistics for Removed Items}

As described in Section 5.3.1, eight items failed to load significantly (factor loadings below $\leq 3$ ) on any of the five factors. Descriptive statistics for removed items are presented in Table 5.9.

Table 5.9 Descriptive statistics for removed items

\begin{tabular}{|c|c|c|c|c|c|c|}
\hline & $\begin{array}{c}\text { Strongly } \\
\text { agree }\end{array}$ & Agree & $\begin{array}{c}\text { Slightly } \\
\text { agree }\end{array}$ & $\begin{array}{l}\text { Slightly } \\
\text { disagree }\end{array}$ & Disagree & $\begin{array}{l}\text { Strongly } \\
\text { disagree }\end{array}$ \\
\hline \multicolumn{7}{|c|}{ 4. Students plagiarise when lecturers set the } \\
\hline same assignments year after year. & 2.9 & 24.6 & 37.7 & 13.5 & 19.3 & 1.9 \\
\hline 8. Plagiarism is unethical. & 54.6 & 36.7 & 4.8 & 0.0 & 2.4 & 1.4 \\
\hline \multicolumn{7}{|c|}{ 16. Students are more likely to plagiarise written } \\
\hline assignments than presentations. & 9.2 & 28.5 & 24.6 & 15.9 & 18.8 & 2.9 \\
\hline \multicolumn{7}{|c|}{ 21. Students plagiarise when they have easy } \\
\hline access to electronic materials. & 2.9 & 20.3 & 36.7 & 21.3 & 11.6 & 7.2 \\
\hline \multicolumn{7}{|c|}{ 24. Students plagiarise when there are no } \\
\hline policies about plagiarism. & 16.9 & 37.7 & 19.8 & 12.6 & 10.1 & 2.9 \\
\hline \multicolumn{7}{|c|}{ 33. Students who are very fluent in their use of } \\
\hline language don't plagiarise. & 1.0 & 7.7 & 9.2 & 34.3 & 35.3 & 12.6 \\
\hline \multicolumn{7}{|c|}{ 35. Students plagiarise when assessments test } \\
\hline understanding of textbook materials. & 56.5 & 35.3 & 6.8 & 0.0 & 1.0 & 0.4 \\
\hline \multicolumn{7}{|c|}{ 37. Students who plagiarise are penalised by the } \\
\hline university. & 2.4 & 9.2 & 19.3 & 25.1 & 30.0 & 14.0 \\
\hline
\end{tabular}

As illustrated in Table 5.9, the item that received the most agreed options was item 8Plagiarism was unethical, with $91 \%$ of the students strongly agreed and agreed. $65.2 \%$ of 
respondents agreed with Item 4-Students plagiarise when lecturers set the same assignments year after year. Around $62 \%$ of respondents agreed with Item 16-Students are more likely to plagiarise written assignments than presentations. Nearly $60 \%$ of them agreed with Item 21 Students plagiarise when they have easy access to electronic materials received. With the next item-Students plagiarise when there are no policies about plagiarism, over $74 \%$ of respondents strongly agreed to slightly agreed. $98.6 \%$ of the respondents strongly agreed, agreed, and slightly agreed with Item 35-Students plagiarise when assessments test understanding of textbook materials. Over $69 \%$ of the students strongly disagreed to slightly disagreed that those who plagiarised were penalised by the university. The item that received the least agreed options was Item 33-Students who are very fluent in their use of language do not plagiarise, with $8,7 \%$ of respondents strongly agreed and agreed, suggesting that most respondents did not consider low language proficiency as a reason for student plagiarism.

\subsection{Inferential Statistics Results}

Inferential statistics were performed to explore variations in plagiarism perceptions among VNand NZ-educated postgraduate students. The analysis began with four independent samples Ttests to determine if there were statistically significant differences in perceptions between students who were (1) VN- and NZ-educated, (2) male and female, (3) PhD and master's students, and (4) with and without teaching experiences. For all t-tests, the Levene's tests for homogeneity of variances indicated that variances were equal across two groups in all subscales, ( $p$ values >.05). Therefore, t-test results associated with the criterion "Equal variances assumed" were reported.

Next, a one-way ANOVA was employed to compare the means of four faculty groups: FHSS, VBS, FoSci, and FoEduc. Another one-way ANOVA was used to compare the means of four age groups: 24-younger, 25-34, 35-44, and 45-older. Because the number of students answering each demographic and educational question was different, the population ( $n$ ) in the following analyses varied and represented the number of students answering each question.

\subsubsection{Nationality and Perceptions of Plagiarism}

An independent-samples t-test was conducted to compare VN- and NZ-educated postgraduate students' perceptions of plagiarism, shown in Table 5.10. 
Table 5.10 T-test comparison of VN- and NZ-educated students

\begin{tabular}{|c|c|c|c|c|c|c|c|}
\hline & Nationality & $\mathrm{n}$ & M & SD & $\mathrm{t}$ & df & $p$ \\
\hline \multirow[t]{2}{*}{ 1. Perceived seriousness of plagiarism } & NZ-educated & 135 & .4666 & 1.62739 & 3.982 & 205 & $.000 * *$ \\
\hline & VN-educated & 72 & -.4646 & 1.55482 & & & \\
\hline \multirow[t]{2}{*}{ 2. Personal factors } & NZ-educated & 135 & -.1117 & 1.86944 & -.691 & 205 & .491 \\
\hline & VN-educated & 72 & .0815 & 2.00503 & & & \\
\hline \multirow[t]{2}{*}{ 3. Academic factors } & NZ-educated & 135 & .2425 & 1.47166 & 2.777 & 205 & $.006^{* *}$ \\
\hline & VN-educated & 72 & -.3592 & 1.50932 & & & \\
\hline \multirow[t]{2}{*}{ 4. Assessment factors } & NZ-educated & 135 & .2979 & 2.11261 & 2.532 & 205 & $.012^{*}$ \\
\hline & VN-educated & 72 & -.5222 & 2.40846 & & & \\
\hline \multirow{2}{*}{$\begin{array}{l}\text { 5. Negative attitudes towards } \\
\text { plagiarism }\end{array}$} & NZ-educated & 135 & -.0221 & 1.64591 & -.688 & 205 & .492 \\
\hline & VN-educated & 72 & .1361 & 1.43099 & & & \\
\hline
\end{tabular}

Note: M=Mean, SD=Standard Deviation, *Significant at .05 level, **Significant at .01 level

Table 5.10 shows no significant difference between VN- and NZ-educated students in subscales 2 and 5, suggesting that both groups considered that plagiarism resulted from personal factors and they had negative attitudes towards plagiarism.

There was a significant difference in subscale 1-Perceived seriousness of plagiarism $(t(205)=$ $3.982, p<.05)$, with NZ-educated $(M=.4666, S D=1.62739)$ viewed plagiarism more seriously than their VN-educated counterparts $(M=-.4646, S D=1.55482)$.

A significant difference $(\mathrm{t}(205)=2.777, \mathrm{p}<.05)$ in subscale 3 - Academic factors suggests that VN-educated students $(M=-.3592, S D=1.50932)$ were more likely than NZ-educated students $(M=.2425, S D=1.47166)$ to perceive that plagiarism resulted from limited academic skills and the lack of knowledge about plagiarism.

Another significant difference was found in subscale $4,(t(205)=3.982, p<.05)$, indicating that VN-educated students $(M=-.5222, S D=2.40846)$ agreed more strongly than NZ-educated students $(M=.2979, S D=2.11261)$ that plagiarism resulted from assessment factors.

\subsubsection{Gender and Perceptions of Plagiarism}

The means of responses from the gender groups on five subscales are compared in Table 5.11. With only three non-binary students and one genderqueer student, the comparison was conducted with males and females, who accounted for most of the sample. 
Table 5.11 T-test comparison of male and female students

\begin{tabular}{|c|c|c|c|c|c|c|c|}
\hline & Gender & $n$ & M & SD & $\mathrm{t}$ & df & $p$ \\
\hline \multirow[t]{2}{*}{ 1. Perceived seriousness of plagiarism } & Male & 65 & .2873 & 1.69891 & -.986 & 201 & .325 \\
\hline & Female & 138 & .0441 & 1.61072 & & & \\
\hline \multirow[t]{2}{*}{ 2. Personal factors } & Male & 65 & -.3527 & 1.90523 & 1.618 & 201 & .107 \\
\hline & Female & 138 & .1116 & 1.90774 & & & \\
\hline \multirow[t]{2}{*}{ 3. Academic factors } & Male & 65 & .1283 & 1.33251 & -.563 & 201 & .574 \\
\hline & Female & 138 & -.0003 & 1.59832 & & & \\
\hline \multirow[t]{2}{*}{ 4. Assessment factors } & Male & 65 & .0998 & 2.25761 & -.345 & 201 & .730 \\
\hline & Female & 138 & -.0183 & 2.27988 & & & \\
\hline \multirow[t]{2}{*}{ 5. Negative attitudes towards plagiarism } & Male & 65 & -.4206 & 1.48109 & 2.826 & 201 & $.005^{* *}$ \\
\hline & Female & 138 & .2384 & 1.58190 & & & \\
\hline
\end{tabular}

Note: $\mathrm{M}=$ Mean, SD=Standard Deviation, *Significant at .05 level, **Significant at .01 level

Table 5.11 shows no significant differences between males and females in subscales 1, 2, 3, and 4, suggesting that the two groups were not different significantly in their perceived seriousness of plagiarism and their views on determinants of student plagiarism.

In subscale 5- Negative attitudes towards plagiarism, female students $(M=.2384, S D=1.58)$ viewed plagiarism more negatively than male students $(M=-.4206, \mathrm{SD}=1.48)$.

\subsubsection{Age and Perceptions of Plagiarism}

The means of responses from four age groups (younger than 24, 25 to 34,35 to 44 , and older than 44) are compared in Table 5.12.

Table 5.12 One-way ANOVA comparison of age group differences

\begin{tabular}{|c|c|c|c|c|c|c|}
\hline & & $\begin{array}{l}\text { Sum of } \\
\text { Squares }\end{array}$ & df & $\begin{array}{l}\text { Mean } \\
\text { Square }\end{array}$ & $\mathrm{F}$ & Sig. \\
\hline \multirow[t]{2}{*}{ 1. Perceived seriousness of plagiarism } & Between Groups & 24.784 & 3 & 8.261 & 3.092 & $.028 *$ \\
\hline & Within Groups & 542.459 & 203 & 2.672 & & \\
\hline \multirow[t]{2}{*}{ 2. Personal factors } & Between Groups & 1.504 & 3 & .501 & .135 & .939 \\
\hline & Within Groups & 753.983 & 203 & 3.714 & & \\
\hline \multirow[t]{2}{*}{ 3. Academic factors } & Between Groups & 9.936 & 3 & 3.312 & 1.465 & .225 \\
\hline & Within Groups & 459.025 & 203 & 2.261 & & \\
\hline \multirow[t]{2}{*}{ 4. Assessment factors } & Between Groups & 33.532 & 3 & 11.177 & 2.251 & .084 \\
\hline & Within Groups & 1007.949 & 203 & 4.965 & & \\
\hline \multirow[t]{2}{*}{ 5. Negative attitudes towards plagiarism } & Between Groups & 7.361 & 3 & 2.454 & .992 & .398 \\
\hline & Within Groups & 502.212 & 203 & 2.474 & & \\
\hline
\end{tabular}

Note: *Significant at .05 level, **Significant at .01 level 
Table 5.12 shows no significant differences in perceptions of plagiarism between age groups ( $p$ values $>.06$ ) for subscales 2, 3, 4, and 5. However, in subscale 1-Perceived seriousness of plagiarism, the means were statistically different $(F(3)=3.092, p<0.05)$. The mean plot in Figure 5.6 illustrates how the mean varied between different groups.

Figure 5.6 Mean plot subscale 1-Perceived seriousness of plagiarism

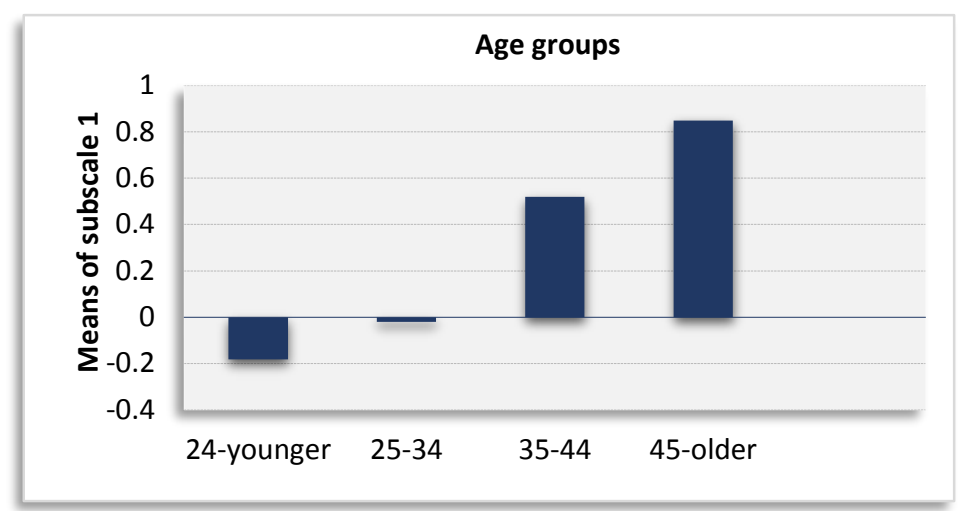

Figure 5.6 shows that students who were older than $44(M=.8493, S D=1.74546)$ viewed plagiarism more seriously than those who were younger than $24(M=-.1824, S D=1.45322)$.

\subsubsection{Employment in Teaching Roles and Perceptions of Plagiarism}

The means of responses from students who had been employed as a teacher or tutor and those who had never engaged in teaching jobs were compared in Table 5.13.

Table 5.13 T-test comparison of students with and without teaching experience

\begin{tabular}{|c|c|c|c|c|c|c|c|}
\hline & $\begin{array}{c}\text { Teaching } \\
\text { employment }\end{array}$ & $\mathrm{n}$ & $M$ & SD & $t$ & $d f$ & $p$ \\
\hline \multirow[t]{2}{*}{ 1. Perceived seriousness of plagiarism } & Yes & 153 & .1836 & 1.67628 & -.596 & 205 & .552 \\
\hline & No & 54 & .0267 & 1.62035 & & & \\
\hline \multirow[t]{2}{*}{ 2. Personal factors } & Yes & 153 & -.1573 & 1.95166 & 1.430 & 205 & .154 \\
\hline & No & 54 & .2750 & 1.78602 & & & \\
\hline \multirow[t]{2}{*}{ 3. Academic factors } & Yes & 153 & -.0963 & 1.58474 & 2.095 & 205 & $.037^{*}$ \\
\hline & No & 54 & .4001 & 1.20840 & & & \\
\hline \multirow[t]{2}{*}{ 4. Assessment factors } & Yes & 153 & .0618 & 2.32109 & -.529 & 205 & .598 \\
\hline & No & 54 & -.1267 & 2.04280 & & & \\
\hline \multirow[t]{2}{*}{ 5. Negative attitudes towards plagiarism } & Yes & 153 & .0473 & 1.55466 & -.220 & 205 & .826 \\
\hline & No & 54 & -.0077 & 1.63726 & & & \\
\hline
\end{tabular}

Note: *Significant at .05 level, ${ }^{* *}$ Significant at .01 level 
Table 5.13 shows no significant differences between the two groups in subscales 1, 2, 4, and 5 . There was a statistically significant difference $(t(205)=2.095, p<.05)$ between students with teaching experience $(M=-.0963, S D=1.58474)$ and those without $(M=.4001, S D=1.20840)$ in Subscale 3, indicating that students with teaching experience were more likely than those without teaching experiences to perceive academic factors as causes of student plagiarism.

\subsubsection{Level of Study and Perceptions of Plagiarism}

The means of responses from master's and PhD students were compared in Table 5.14.

Table 5.14 T-test comparison of PhD and master's students

\begin{tabular}{|c|c|c|c|c|c|c|c|}
\hline & $\begin{array}{l}\text { Level of } \\
\text { study }\end{array}$ & $n$ & $M$ & SD & $\mathrm{t}$ & $d f$ & $p$ \\
\hline \multirow[t]{2}{*}{ 1. Perceived seriousness of plagiarism } & Master & 95 & -.1243 & 1.58200 & -2.276 & 193 & $.024^{*}$ \\
\hline & $\mathrm{PhD}$ & 100 & .4176 & 1.73431 & & & \\
\hline \multirow[t]{2}{*}{ 2. Personal factors } & Master & 95 & -.0598 & 1.97946 & -.050 & 193 & .960 \\
\hline & $\mathrm{PhD}$ & 100 & -.0461 & 1.89263 & & & \\
\hline \multirow[t]{2}{*}{ 3. Academic factors } & Master & 95 & .0930 & 1.46130 & 1.029 & 193 & .305 \\
\hline & $\mathrm{PhD}$ & 100 & -.1257 & 1.50354 & & & \\
\hline \multirow[t]{2}{*}{ 4. Assessment factors } & Master & 95 & -.3876 & 2.17117 & -2.554 & 193 & $.011^{*}$ \\
\hline & $\mathrm{PhD}$ & 100 & .4326 & 2.30554 & & & \\
\hline \multirow[t]{2}{*}{ 5. Negative attitudes towards plagiarism } & Master & 95 & .0613 & 1.56009 & .175 & 193 & .862 \\
\hline & PhD & 100 & .0219 & 1.58960 & & & \\
\hline
\end{tabular}

Note: $M=$ Mean, SD=Standard Deviation, *Significant at .05 level, **Significant at .01 level

Table 5.14 shows a statistically significant difference in Subscale 1-Perceived seriousness of plagiarism, $(\mathrm{t}(193)=-2.276, \mathrm{p}<.05)$, with $\mathrm{PhD}$ students $(\mathrm{M}=.4176, \mathrm{SD}=1.73431)$ viewed plagiarism more seriously than master's students $(M=-.1243, S D=1.58200)$. Another significant difference $(t(193)=-2.554, p<.05)$, was found in subscale 4-Assessment factors, with master's students $(M=-.3876, S D=2.17117)$ being more likely than PhD students $(M=.4326$, $\mathrm{SD}=2.30554)$ to consider features of assessment as causes of plagiarism. There were no significant differences between the two groups in subscales 2,3 , and 5 . 


\subsubsection{Disciplines and Perceptions of Plagiarism}

Because fewer students came from FoArch $(n=5)$, FoEng $(n=5)$, FoLaw $(n=3)$, and FoHealth $(n=1)$ these groups were excluded from mean comparisons. Table 5.15 shows a comparison of the means of responses from FHSS, VBS, FoSci, and FoEduc.

Table 5.15 One-way ANOVA comparison of differences between disciplines

\begin{tabular}{|c|c|c|c|c|c|c|}
\hline & & $\begin{array}{l}\text { Sum of } \\
\text { Squares }\end{array}$ & $d f$ & $\begin{array}{l}\text { Mean } \\
\text { Square }\end{array}$ & $F$ & Sig. \\
\hline \multirow[t]{2}{*}{ 1. Perceived seriousness of plagiarism } & Between Groups & 12.525 & 3 & 4.175 & 1.533 & .208 \\
\hline & Within Groups & 482.023 & 177 & 2.723 & & \\
\hline \multirow[t]{2}{*}{ 2. Personal factor } & Between Groups & 8.141 & 3 & 2.714 & .698 & .554 \\
\hline & Within Groups & 687.906 & 177 & 3.886 & & \\
\hline \multirow[t]{2}{*}{ 3. Academic factors } & Between Groups & 16.629 & 3 & 5.543 & 2.490 & .062 \\
\hline & Within Groups & 393.983 & 177 & 2.226 & & \\
\hline \multirow[t]{2}{*}{ 4. Assessment factors } & Between Groups & 18.466 & 3 & 6.155 & 1.217 & .305 \\
\hline & Within Groups & 894.910 & 177 & 5.056 & & \\
\hline \multirow[t]{2}{*}{ 5. Negative attitudes towards plagiarism } & Between Groups & 29.555 & 3 & 9.852 & 4.184 & $.007^{* *}$ \\
\hline & Within Groups & 416.796 & 177 & 2.355 & & \\
\hline
\end{tabular}

Note: *Significant at .05 level, **Significant at .01 level

Table 5.15 shows that the one-way ANOVA comparisons were not significant ( $p$ values $>.06$ ) for subscales 1, 2, 3, and 4. In subscale 5-Negative attitudes towards plagiarism, the means of the four groups were statistically different $(F(3)=4.184, p<0.01)$. Therefore, the mean plot was detected to examine the mean-variance.

Figure 5.7 Mean plot subscale 5-Negative attitudes towards plagiarism

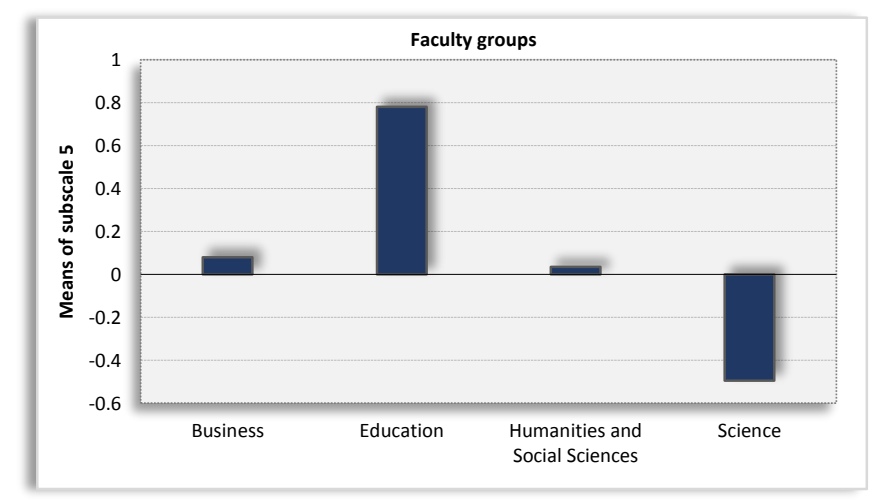


Figure 5.7 shows a clear difference in the mean of students from FoEduc and FoSci. Post-hoc analyses using Tukey's HSD indicated a significant difference between Education students $(M=$ $.7807, S D=1.39881)$ and Science students $(M=.-4937, S D=1.57467)$, suggesting Science students possessed more negative attitudes towards plagiarism than Education students.

\subsection{Chapter Summary}

This chapter described major findings obtained from the online survey. EFA identified five dimensions of students' perceptions: (1) Perceived seriousness of plagiarism; (2) Personal factors; (3) Academic factors; (4) Assessment factors; and (5) Negative attitudes towards plagiarism. While most students perceived plagiarism as a serious offence, NZ-educated students viewed plagiarism more seriously than their VN-educated counterparts. The students agreed that plagiarism resulted from personal factors and expressed negative attitudes towards the practice. The VN-educated students, however, tended to agree more strongly than their NZ-educated counterparts that plagiarism resulted from academic and assessment factors. Student perceptions were found to be associated with demographic characteristics such as age, gender, disciplines, levels of study, and teaching experience. 


\section{Chapter 6 | Individual Stories of Interview Participants}

\subsection{Introduction}

Based on the survey results, twelve PhD students (six New Zealand and six Vietnamese) with divergent backgrounds and understanding of plagiarism were invited to take part in four followup interviews. Specifically, those with typified distinct perspectives were selected. These students were also chosen on the basis of their educational histories, disciplines, age, gender, and stages of their study. This recruitment technique was designed to ensure sample diversity and coverage of a full range of views and experiences.

This chapter firstly outlines participants' backgrounds focusing on information they provided about themselves, their family, academic and educational experiences, professional identity, and doctoral studies. Participants' plagiarism perceptions are presented, highlighting individuals' different views. Findings from NZ-educated participants are provided first, followed by those of VN-educated students, identifying similarities and differences within these two groups. All names are pseudonyms chosen by interview participants.

\subsection{NZ-educated Interview Participants}

This section describes six NZ-educated participants, who were at varying stages of their PhD studies. Darshana, Paddy, and Solace were in their twenties. Ally, Emma, and Frank were in their thirties. Emma and Paddy were working on their thesis drafts. Darshana and Paddy were writing their findings chapters. Ally had finished data collection, and Frank was looking for research participants. Table 6.1 summarises participants' demographics.

Table 6.1 Demographic characteristics of NZ-educated interviewees

\begin{tabular}{lllll}
\hline Pseudonym & Gender & Faculty & Tertiary qualifications & Teaching experience \\
\hline Ally & Female & FHSS & $\begin{array}{l}\text { BA (Hons) and MA (overseas), } \\
\text { MA (NZ) }\end{array}$ & Teacher, tutor \\
\hline Darshana & Female & FoSci & BA and BSc (Hons) (NZ) & Tutor, a small amount of lecturing \\
\hline Emma & Female & FoSci & BA and BSc (Hons) (NZ) & Tutor \\
\hline Frank & Male & FHSS & BMus Hons and BA (Hons) (NZ) & Tutor (3 years) \\
\hline Paddy & Male & FoSci & BA and MSc (NZ) & Tutor, TA, a small amount of lecturing \\
\hline Solace & Male & FoEng & BA (Hons) (NZ) & Tutor (5 years), a small amount of lecturing
\end{tabular}


As shown in Table 6.1, the ratio of female to male was 3:3. This represents an oversampling of male students as female students made up over $63 \%$ of the survey participants. Darshana, Emma, and Paddy studied in FoSci. Ally and Frank were from FHSS. Solace studied in FoEng. The distribution closely matched the survey population where most NZ-educated participants came from FoSci and FHSS. Two students had completed a master's degree before commencing PhD studies. All students gained tertiary qualifications in NZ except Ally who earned one of her degrees in Europe. All participants had tutoring (teaching assistant) experiences. Darshana, Paddy, and Solace had done lecturing and Ally had been a teacher. None was employed fulltime at the time the study was conducted.

\subsubsection{Ally}

\section{Ally's profile}

Ally, a PhD student in FHSS, describes herself as being sociable and friendly. She has a particular passion for travelling and has been to many countries around the world. She spent time in Western Asia when she was young and lived in Southeast Europe for a while. Ally enjoys reading fiction, cookbooks, and also online news and information.

Both of Ally's parents have pursued language-based careers. Her mother is an English teacher and an applied linguist who has a Diploma in TESOL (Teaching English to Speakers of Other Languages). She never advised Ally to undertake postgraduate studies but supported her decision. Ally's father, who passed away several years before, was a journalist. Her family often talks about words and language in her household.

Ally gained her undergraduate education in Europe and undertook her earlier postgraduate studies in NZ. Before that, she was a teacher for several years in East Asia. She has tutored in her faculty but is not currently teaching. She is a research assistant for a large linguistics research project in her faculty.

Ally is passionate about research, especially doctoral research. In the first interview, she shared: "In undergraduate, it's a mixture of exams and essays. I always enjoy essays and feel fine with exams, but I don't remember anything that I studied for an exam. It's kind of a pointless way of gaining knowledge, whereas if you research a topic, you're actually learning about it [...] you're also able to contribute to the topic." For Ally, a PhD is a good measure of individuals' selfmotivation, ability to cope with completion pressure, and time management skills. She loves 
being able to work at her own pace, setting her own goals, and achieving them. She feels quite privileged and lucky but responsible as a scholarship holder. She feels the responsibility of studying at a higher level. Ally comments that her academic writing ability is quite high. Before her PhD, she felt confident in structuring a thesis.

Although Ally loves research, she is reluctant to carry on the academic path. She does not want to be an academic or a lecturer. However, she would like to continue researching after her PhD. She wants a PhD with practical but not just academic applications. She hopes to contribute to her field and expects a professional role that would make a difference to society. Ally has one overseas conference paper and one published journal article from her research.

Regarding embodied cultural capital, both Ally's parents have careers involving language - the field that she pursues. She is a second-generation college student who has excellent writing and research skills. She holds rich cultural, intercultural, social, and professional knowledge and experiences through learning, working, and living around the world. Ally built her embodied cultural capital through reading, both for her research and more widely for pleasure. In terms of objectified cultural capital, she has an in-press journal article from her PhD research. Her institutionalised cultural capital includes her BA and MA degrees.

Ally's perception of plagiarism - Plagiarism is not the worst offence in the world Ally perceived plagiarism at different levels of academic study differently. At higher levels such as $\mathrm{PhD}$, she thought plagiarism was unethical because students were expected to produce original knowledge. She argued that people should be given credit only for their energy and effort. She thought postgraduate students should have enough knowledge to not plagiarise.

Conversely, Ally was compassionate when talking about undergraduate plagiarism, showing her sympathy for their mistakes. She stated that identifying undergraduates' plagiarism as deceitful was harsh because "a lot of stuff at first-year could be mistakes, they just don't know". She believed that students could plagiarise for various reasons:

I don't think you can put it black and white. You know, you can't have the same answer, one person may be lazy, the next person might be under a lot of pressure, the next might have no idea what they're supposed to be doing. (Ally, Int2)

For Ally, if students attempted to do the work and tried not to plagiarise, she appreciated their effort despite their making errors. She thought teachers needed to teach students what was or 
was not plagiarism, why they should not plagiarise, and the consequences of plagiarism. She considered that most undergraduates possessed inadequate skills to avoid plagiarism:

It turns out that lots of people coming to university have got absolutely no referencing skills. So, I think sometimes they plagiarise without kind of meaning to. (Ally, Int2)

Ally thought plagiarism was unrelated to personal traits and was not the most serious offence in the world:

A person could do bad things for all sorts of reasons. [...] Just even at whatever level, l'd never like to say a person is either good or bad because of one thing that they do, especially something that a lot of the time won't actually harm anyone. (Ally, Int2)

Ally indicated multiple adverse effects of plagiarism. She believed plagiarism would threaten students learning because they did not think about or interact with the materials. If students plagiarised through their degree, she thought their academic qualifications became meaningless and they could not fulfil their future professional or academic roles:

If the students want to do a much harder paper or carry on academically, then it will [be hard], because they haven't actually gone through that process of thinking. (Ally, Int2)

Ally was on the highest point of the teleological scale viewing plagiarism as immoral and unethical but also dependent on specific contextual features. She assessed plagiarism based on its consequences rather than plagiarists' motives. Compared to other participants, she was more tolerant in that she understood undergraduates' need for further academic skills and the pressure that they felt, saying that "deceitful" was a strong word to describe their plagiarism. She thought faculty members played a crucial role in managing and reducing plagiarism.

\subsubsection{Darshana}

\section{Darshana's profile}

Darshana identifies herself as a sociable, outgoing, and nice person. As undertaking her PhD, she took part in various activities of the postgraduate students' association. She likes meeting people, going to a range of talks about different topics, learning lots of new things, and growing. She has traveled extensively around Asia, going to villages, talking to local people, and seeing real poverty which made her appreciate life in NZ. Darshana has been to Europe. She has an appreciation of different cultures. She likes to follow rules and be a good person. 
Darshana's parents, who both finished undergraduate studies, have been focused on her educational success since her high school. They are strict about studying hard, getting good marks, and having a good work ethic. They chose academic subjects for her alongside her "passion" courses. They had plans for her after her undergraduate studies but let her decide her path when realising that she would not enjoy her life unless she did what she liked.

Having received her BA degree at VUW, Darshana completed her BSc Hons degree. She has tutored and become a senior tutor in her faculty. Darshana is unsure about her future career. She does not know if she wants to become a lecturer. She likes teaching, but she finds research expectations challenging. Post-PhD, she may either find a job or take a break because she has gone straight from school to postgraduate studies with no break.

Darshana is pursuing a PhD in FoSci because those subjects appealed to her the most at that time and she was awarded a scholarship. About doctoral studies, she says, "I'm proud to be a doctoral student. [...] Especially for me, since I did undergrad at the same university, I feel like more responsibility to uphold the reputation of the university and make sure I'm doing things right and being responsible. Because possibly from other students, I have a bit more respect and so with that, I have more responsibility" (Darshana, Int1). Through her PhD, Darshana wants to improve her research and academic skills. She feels her academic writing abilities have room for improvement. She understands that writing is a long process, but if she has enough time and works hard, she can produce great work.

The cultural capital that Darshana possesses is primarily embodied and institutionalised. She grew up in a well-educated family who focused on academic skills. Having two tertiaryeducated parents gives her more advantages - having someone already there and giving her advice. She accumulates embodied cultural capital through attending talks and participating in social and academic activities. Darshana's travel experiences also enhance her cultural capital. Her institutionalised cultural capital comprises her tertiary qualifications.

\section{Darshana's perception of plagiarism - Plagiarism is unjustifiable}

Darshana considered plagiarism as contrary to academia, which is about knowledge, finding new things, and forming ideas. In the second interview, she said, "it [academia] can't come from a place of any kind of deception or stealing. Otherwise, it's not a good foundation". Darshana viewed plagiarism as stealing and deceitful regardless of any intent: 
I think no matter what the reasons are, even if they didn't know, even if they didn't mean to plagiarise, it's still unethical, because it's wrongfully taking someone's idea and not attributing it to them. (Darshana, Int3)

Darshana considered plagiarism a self-regulatory issue, about compliance with obligations and requirements from the university. She saw plagiarism as related to work ethics because she thought "most plagiarising students know what they're doing, and they just hope that they don't get caught. They're trying to be sneaky about it". Darshana said that if students encountered difficulties, they should access available help and support:

If they're in a Western university and have to do all assignments in English. It's definitely more difficult, that's not a question. So, they would be more tempted to, like, cheat or copy. But again, there's a lot of help, like the student learning. (Darshana, Int3)

Darshana found improper referencing serious because "you just gotta be very clear about things and make sure that it never seems like your idea if it's not". She asserted that every plagiarist should be punished regardless of any intent:

If someone plagiarised and they didn't mean to or didn't know, I would feel a little bit sorry for them, but they should still get the same consequences because you have to kind of set an example. You can't treat different people differently. (Darshana, Int4)

Darshana said that the university should care about plagiarism because of the quality of education and its scholarly side - "rigorous research practices" and "knowing the correct way to write something". She considered experiences and skills as more important than a grade or qualification. When students plagiarised, Darshana thought their degree was pointless and plagiarism would adversely affect non-plagiarising students:

It's about your whole learning experiences and the skills you've learnt that you're gonna take with you. And if you got through by plagiarising and copying other people's ideas, the degree is not meaningful for me. And plagiarism kind of undermines everyone else that has done everything correctly. (Darshana, Int2)

Darshana was concerned that students who plagiarised might be unqualified for future careers because they were used to stealing ideas. She said she would never think of plagiarising because "I just imagine if it was my work and someone used it and said that it was his/her, I would be so upset and angry." (Darshana, Int3) 
In contrast to the teleological stance taken by Ally, Darshana considered plagiarism as unethical independent of any circumstances and consequences. While acknowledging different factors leading to plagiarism, she found plagiarism unjustifiable and academically and ethically wrong. From a deontological standpoint, she considered plagiarism a violation of rules or standards. She was unforgiving to plagiarism, maintaining that students had options to avoid plagiarism.

\subsubsection{Emma}

\section{Emma's profile}

Emma describes herself as being empathetic, stubborn, and disciplined. She is perseverant, humorous, and creative as well. She loves reading about her field, medical history, and the history of psychology. She likes fantasy and TV shows. Emma has no inspirational role models but is determined to define her success in life in her own terms.

After high school, Emma obtained three diplomas in Psychology, Business, and Adult Education and Training, hoping to get a job in these fields. She gained a few qualifications that were not registered within the NZQA (New Zealand Qualifications Authority) system. Subsequently, she realised that these were not the right fields for her, so she came back to university and got a degree. She has since obtained a BSc Hons and a BA. Emma held diverse jobs in various domains including administration, research, and business. She has also tutored in her faculty.

Emma's father, who works in the construction sector, has no tertiary qualifications. Her mother has some tertiary qualifications and works in the business sector. Emma's parents have no aspirations for her studies and work. They think she should decide her own life. From her mother, Emma learns that she can make choices no matter what she does, and she has the option to quit if things get too hard.

Emma is a third-year PhD student in FoSci. She wants to have an opportunity to explore indepth an area of research, which she felt would be unachievable within the 12 months of a master's programme. The biggest driving factor in Emma's life is her health. During her undergraduate years, she was diagnosed with a fatal illness and never thought she would live long. So, she wanted to make the most of the opportunities that she has in her remaining time. In the first interview, she talked about her PhD goals: "Publications would be nice, and being able to put something into the field, into literature, make searchable items on google, leave my mark somewhere. That's something I definitely want to achieve and hopefully will do so. More 
skills ultimately, becoming a better writer, a better researcher, and a better experimentalist". She says that what drives her to complete her doctoral studies is being capable of pulling together a cohesive narrative about her research.

Emma is passionate about her research area and wants to become a researcher. She hopes to help people with what she learnt. She has gained amazing project management, research, and critiquing skills which makes her confident in future occupational roles. Post PhD, she does not want to pursue a postdoctoral position but hopes to find a paid job outside of academia. As a doctoral student, Emma has written a book chapter and a journal article. She has also presented at a conference in NZ.

Emma's cultural capital assets include knowledge and the skill sets developed through her work and studies. She spent a lot of time studying and achieved several diplomas and qualifications. Her mother is a well-educated woman and has positively influenced Emma's life goals. Emma is enthusiastic about research and is aware of knowledge production. She wants to contribute to her field and has been working hard for that goal. Her objectified cultural capital includes her published work and conference paper. Regarding institutionalised capital, she possesses two bachelor's degrees and various diplomas.

\section{Emma's perception of plagiarism - Plagiarism is against my personal value}

Emma had been a victim of plagiarism, some fellow students plagiarised her assignment without her consent, and she found it insulting. She has a strong personal value around academic credit - its functions and meaning. Therefore, she perceives plagiarism as stealing, which means passing off someone else's hard work as one's own.

Emma's direct experience of plagiarism resulted in her strong feelings about it. For her, plagiarism, major or minor, entailed taking the credit away from original creators:

That's stealing, that's faking it. That's not doing the work yourself, that's not acknowledging who comes before you but advancing on it. (Emma, Int2)

Apart from viewing plagiarists as thieves who attempted to cheat, Emma saw them as "arrogant", thinking that they could get away with their plagiarism. Emma believed that the responsibility of plagiarism was on the students who decided to plagiarise despite their tutors, 
teaching assistants, and lecturers telling them that plagiarism was wrong. However, she disputed a link between plagiarism and personal characteristics:

It's more about the opportunity, education, awareness, and policies. I think it's more of an environmental and behavioural type thing rather than a laid-back personality, or lazy, or an immoral personality. (Emma, Int2)

Emma emphasised credit and the recognition of authorship. This was particularly relevant for academics who received little financial benefit for publishing. She was concerned that plagiarism would create unfairness, saying that although people with the same degree applying for the same job might be seen as equivalent if they had plagiarised, they were incomparable:

When [plagiarists] go for the same job that I'm going for, then how are we equivalent? I have a very different skill set to them; I can probably write better, work harder, and think more critically than they can, but we're still seen on paper as equivalent. (Emma, Int2)

Plagiarism, according to her, diminished the value of education because plagiarising students were neither genuinely critically thinking, nor using their brain, or processing and synthesising information, but regurgitating or using someone else's ideas. She emphasised that though students who plagiarised might pass courses and get good grades, they were unsuccessful, and plagiarism falsified their situation and knowledge. She asserted that students who plagiarised and thought they succeeded were lying to themselves.

Emma holds a strong deontological moral outlook. She views plagiarism at any level as immoral, unacceptable, and unfair. While she has a very strong view of plagiarism saying that it was against her personal values, she did not consider there was a link between plagiarism and personality. Through participating in the publication process, she understands the contexts underlying academic work, insisting that attribution and authorship were critical to research publications. Emma thought plagiarism undercut students' learning opportunities because plagiarising students did not think critically or process information at the same level as nonplagiarising ones. For her, plagiarism was primarily student plagiarists' responsibility.

\subsubsection{Frank}

\section{Frank's profile}

Frank, who says that he is older than other PhD students working in the same area, possesses extensive knowledge and experience in different fields. He has two BA degrees from VUW. 
Frank held various jobs during his undergraduate studies. Later, he completed one year of a two-year master's program, developing his interest in the research method. He has tutored and worked as a research assistant within VUW. He has co-authored a journal article while doing research assistant work.

Frank considers himself a reflexive person. He spends much time contemplating things and is compelled by the notion of the inner self. His focus is the philosophy of social science, political and Eastern philosophy. He is interested in the integration and relationship between Eastern and Western thinking, spirituality, and social science.

Frank enjoys playing music and travelling. He reads intellectual books (philosophy and social sciences) for hours every day. What he reads for personal interest and his PhD is similar. He is motivated by people whom he reads, and the idea of producing original knowledge.

Frank's father, who passed away when Frank was a little child, had no tertiary education. His mother obtained professional training and worked in public health in a managerial role for many years. She understands little about what he does or why he does it. She is neither concerned nor interested in Frank's studies and work.

Frank wants to become an educator, cultivating critical and reflective thinking in students. As a PhD student, he feels responsible to produce quality scholarship. He considers himself a lifelong learner. Post-PhD, he wants to continue with research-related work, to pursue either academic work or post-doctoral studies.

Frank is pursuing a PhD in FHSS because of his passion for social science. He focuses on the link between natural and social sciences. He thinks by doing a PhD, he can grapple with larger topics and more complex questions. In the first interview, he stated that: "When I became incredibly passionate about research, methodology, and ideas of producing knowledge, it was something that I couldn't not pursue and couldn't not continue to pursue". Frank believes that he is a competent academic writer, saying that when he writes, there is an aesthetic element to writing and using references. Additionally, he is meticulous in his note-taking from reading.

Frank holds all three forms of cultural capital. He has interdisciplinary interests and he often reads intellectual books, demonstrating good research and writing skills. Despite not receiving support from his family, Frank is persevering and dedicated to fulfilling his life goal. He builds 
his objectified cultural capital through co-authoring published research. His institutionalised cultural capital comprises his academic degrees.

\section{Frank's perception of plagiarism - An holistic view of plagiarism}

Frank believes that plagiarism is undesirable and contrary to good scholarship. He emphasised the values of truthfulness and the production of genuine scholarship within educational environments. He remarked that those who were committed to "ensure a robust level of scholarship and academic work" would not plagiarise:

There's a degree of integrity or being honest about your work. And hopefully, ideally, it would lead to the generation of new innovative ideas. If you take plagiarism seriously, you're potentially gonna be compelled to come up with your original ideas. (Frank, Int4)

When people plagiarised, Frank would suspect their scholarship and the quality of their academic product. He thought people should face consequences for plagiarising:

The circumstances don't force someone to plagiarise. So, I think if she does make that decision at some point to just copy another's essay, then if she was pulled up on it, there should be some types of repercussions for that. (Frank, Int3)

However, he would not judge plagiarists if he did not know them personally. He did not consider a relationship between plagiarism and someone's personal characteristics.

I always want to know what the reason was for doing it, rather than just assuming that someone is a bad person or something like that. I don't necessarily see a strong link between plagiarism and someone being bad. (Frank, Int4)

Although Frank considered undergraduate plagiarism as unacceptable, he maintained that students come to university to learn and it made no sense to pursue a degree having known everything. He argued that part of the learning process should include an explicit discussion or presentation on what plagiarism was and what constituted it. For him, although the universities covered correct practice regarding plagiarism, citations, and referencing techniques, it did not guarantee that all students acquired that knowledge at the same level.

While not explicitly talking about plagiarism, Frank said that students encountered multiple challenges outside universities (e.g., their personal lives) which might affect their academic performance. So, he thought students needed professionals whom they could consult for help 
because many did not quite understand course requirements or university expectations and at the same time fail to get assistance from the university:

Perhaps just a very kind of basic non-understanding of the content or what is required. And the availability of people to help, listen, or something. Or kind of on the slip side of it, a student is not confident in asking for help or things like that. (Frank, Int4)

Plagiarism, for Frank, would diminish the value of a degree and undermine higher education. If student plagiarism was not detected and addressed, he worried that it would promote deceptive behaviours which he considered negative.

Holding a teleological view about plagiarism, Frank never judges other people's mistakes hastily but considers circumstances behind behaviours. He highlights the production of knowledge in academia and considers plagiarism as countering good scholarship. He distinguishes student and academic plagiarism, asserting that reasons for and impacts of plagiarism in the two contexts are different.

\subsubsection{Paddy}

Paddy's profile

Paddy is a PhD student in FoSci. He enjoys reading fantasy, science fiction books, and stories. He perceives himself as being reasonably compassionate. Paddy learnt from his mother not to be afraid to speak up, be confident, and voice his opinion. When people say something he disagrees with, he tries to consider where that comes from, emotionally and intellectually. From his father, Paddy understood the value of both hard work and rest.

Paddy is the first member of the family to pursue higher education. His father, who comes from a working-class family, obtained private training but not tertiary education. His mother did not go to university. Paddy said that his parents are encouraging and supportive without knowing what they support, because of having no university experience. Though they increasingly see the importance of education and are proud of what he did, they want him to get a job and earn money rather than pursuing postgraduate studies.

Paddy identifies himself as somebody who thinks things through, which he considers a result of education. He views his PhD as consistent with a general pattern of what he has achieved or a habit of continuing what he is doing and trying to get good at it. In the second interview, he 
said, "You kind of push through all the other years you've done beforehand to get to the point where you're seen as being able to add something to the knowledge base and it's very cool. The learning relationships that you own become a lot less one-sided, and a lot more even, in that you find things, and come up with ideas that your supervisors genuinely enjoy. [...] And you discuss, rather than just you're a learner and they're teachers."

Paddy completed his undergraduate and previous postgraduate degrees from VUW. He has tutored and was a teaching assistant in his faculty. Through his PhD, Paddy wants to achieve a critical understanding of the literature. He hopes to be able to explain complex things to a range of people, including those who have no idea of the field or those who are familiar with his study, to be able to target his explanation. Paddy had two published papers and one in-review paper. After earning a PhD, he would love to do research or continue with a postdoctoral position.

Paddy possesses three forms of cultural capital. His embodied cultural capital includes his professional knowledge and competence. Despite coming from a working-class family, Paddy is motivated to excel in life. He builds on his research skills and experience through writing up journal articles. Paddy studied hard and obtained various qualifications.

\section{Paddy's perception of plagiarism - A strength-based approach to plagiarism}

Paddy viewed intentional plagiarism as immoral and "reasonably grievous", especially at PhD level and higher. He considered consciously crediting others' work as one's own as deceitful. For Paddy, plagiarism was opposed to knowledge contribution, the primary element of academia. He thought people's time and effort should be recognised. For Paddy, the quality of work is the real measure of success and the most important outcome, not the grade:

The grade to me is with some noise, I guess. I think the quality of the work is success. The grade isn't the outcome; it's the measure of the outcome. (Paddy, Int2)

Paddy's understanding of undergraduate plagiarism was that sometimes there was confusion about rules. He emphasised that many first-year students knew little about citation and referencing because they did not study that at high school. Thus, he was hesitant to identify their plagiarism as immoral:

I hesitate around the moralising of it. I do understand that there are lots of different reasons that people might accidentally plagiarise or not understand, while they shouldn't in many ways. (Paddy, Int2) 
However, Paddy believed that undergraduate plagiarism was undesirable because it hinders students' learning and development:

They don't really have to come up with their own ideas and work with them, so their level of processing is much shallower. I don't think they're really familiar with the materials to the same degree as if they didn't plagiarise. (Paddy, Int2)

Identifying himself as an educator, Paddy promoted a strength-based approach to plagiarism, focusing on positive aspects of learning and promoting students' self-determination to learn:

An important part of that [learning process] is understanding the purpose of why we reference. Because it's a good practice, it helps you think, as well as it's sort of required for making sure that people's ideas are appropriately labeled, so that they can benefit from those ideas. (Paddy, Int4)

Once students understood why they needed to cite, Paddy believed that they would be less likely to plagiarise, their writing would be much better, and they would present an argument rather than copy and paste from materials that they found. He emphasised that basic teaching about the benefits of citing and referencing should be done as early as possible:

That kind of stuff should be presented upfront early on, at the start of classes, especially in the first or second year, maybe even before university, teaching the basics of why citing and referencing is a good way to go about writing. (Paddy, Int3)

Paddy holds a teleological standpoint of plagiarism maintaining that its seriousness was dependent on academic levels. He considered himself an educator and emphasised lecturers' responsibilities in teaching and supporting student learning. He was in favor of a strength-based approach, integrating teaching about plagiarism and the benefits of correct practice.

\subsubsection{Solace}

\section{Solace's profile}

Solace graduated with a BA from FoEng, then earned a postgraduate diploma. He has tutored at VUW for several years. He finds supporting students and seeing them improve interesting and satisfying. He puts in much effort to make sure his students learn what they need to learn by writing extra course materials and helping them after hours.

Solace is a passionate person, but he gets distracted easily. When he runs into difficulties or getting interested in other things, he deprioritises his PhD. He enjoys playing sports, especially 
badminton. He relaxes mostly on the computer, watching TV series or playing games. He mainly reads scientific papers and sometimes reads articles online. He loves travelling and has been to Australia and several Asian countries.

Solace's mom completed a professional training course and has been a nurse her entire life. His father earned a university equivalent qualification while working as an intern. Solace's parents constantly encourage their children to do well at school. Solace's sister has two higher education qualifications and his brother finished undergraduate studies.

Many people have inspired Solace. His father encourages him to overcome challenges in life. One of his lecturers inspires him to study, be engaged in his field, and be a better teacher and lecturer. His mom influenced him by being a very sympathetic woman. When things go wrong, or someone does bad things, she believes that there are two sides of the story, and "you could not judge somebody just based on just something, you've got to know the whole story". She always looks for reasons behind behaviours.

Solace is doing his PhD in FoEng because of his academic interests. In the second interview, he talked about how a PhD student is different from an undergraduate: "As an undergraduate, you know something about some subjects, or know something about this broad subject. Whereas with doctoral studies, it's sort of like an entry into the academic world. You're able to research an area. So, I feel like I'm earning a qualification to do research in a particular area". His PhD goals relate to doing satisfactory research, not just getting the qualification. Post PhD, Solace hopes to gain a postdoctoral and then a lecturing position.

Solace's cultural capital assets are primarily embodied and institutionalised. Although his parents are not tertiary educated, they encourage their children to learn. Regarding institutionalised capital, Solace possesses a BA degree and a postgraduate certificate.

\section{Solace's perception of plagiarism - Plagiarism is a morally grey area}

Solace viewed plagiarism as a morally "grey area", where something morally and ethically acceptable in some contexts might be counted as plagiarism:

There are situations where it's acceptable to take other people's work, slightly modify it, and submit it as your own. Because the slight modification is your contribution and it doesn't matter where it comes from exactly or what it is. It's just the slight modification that you've made contributes to the whole work being your own. (Solace, Int2) 
Solace saw a "fine line" where it was hard to have "an ironclad rule" on plagiarism. He thought the circumstances underlying people behaviours were important:

You can't have an ironclad rule, where if somebody has plagiarised at any degree, he's suspended for 6 months. If you link it to something like the court system. It's not the fact that you committed a crime, you get a set punishment. It always depends on all the circumstances where you committed it. (Solace, Int4)

Therefore, Solace felt hesitant to associate someone's moral qualities and their misconduct because people might get into situations where they had no other choice. And he thought plagiarism does not mean they were bad people:

I know lots of good people that plagiarise, I know lots of good morally, ethically, upstanding people that have plagiarised, and in some cases, it's unintentional, it's been done because of their particular circumstances. (Solace, Int2)

Solace believed looking at or using others' work was how people learnt. However, an important part of the learning process was to acknowledge that they did that which he found many students did not understand. He thought they were unaware of the importance of crediting other authors for their time and effort.

However, he considered academics' plagiarism unethical because it involved taking and passing them off someone else's ideas as their own. He thought by doing that people took away attribution that should be given to original creators.

If you're copying an image, for example, make sure that you actually give people an idea of where that image came from, and if you've got it from the internet, make sure at least you're giving a URL for the original image and who created that image. (Solace, Int2)

Solace saw plagiarism as a hindrance to students' growth because they did not present their ideas. He felt unsure if they could come up with their ideas or provided the same level of work as if they did not plagiarise. Therefore, he thought institutions needed to ensure that students were qualified enough to graduate, otherwise, it would diminish the value of the degree. He thought the university was responsible for informing and guiding students:

If you deny education from somebody because of a misunderstanding, a mishap, or an incident that could be rationally explained, I don't think the university has done the job. That's the job of the university to inform and guide students. (Solace, Int3) 
Solace looked at plagiarism from a teleological point of view. He was concerned about the credit stolen from original creators. While viewing plagiarism as immoral, he identified the "fine line" between plagiarism and not plagiarism, arguing that sanctions on plagiarism should be dependent on circumstances. He thought some undergraduates were unaware that they plagiarised. However, he worried that the quality of education would be undermined when students plagiarised, insisting that the university played a key role in plagiarism education.

\subsubsection{Conclusion}

All six NZ-educated students possess rich cultural capital in various forms. Ally, Darshana, and Emma all have at least one parent who attended higher education. While Paddy, Frank, and Solace came from working-class families, they cultivated cultural capital through their work and studies. All participants are experienced tutors. Darshana, Paddy, and Solace had lectured, and Ally had been a teacher. Ally and Frank had worked as research assistants. Five students pursued a PhD because of their passion for research. Most students produced publishable research papers during their $\mathrm{PhD}$. They consider doctoral studies as a chance to excel themselves and accumulate academic skills. Table 6.2 summarises students' characteristics.

Table 6.2 NZ-educated interviewees' characteristics

\begin{tabular}{|c|c|c|c|c|}
\hline Pseudonym & $\begin{array}{l}\text { Tertiary } \\
\text { qualifications }\end{array}$ & $\begin{array}{l}\text { Second generation } \\
\text { university students }\end{array}$ & Research outputs & $\begin{array}{l}\text { Professional } \\
\text { experiences }\end{array}$ \\
\hline Ally & $\begin{array}{l}\text { Overseas BA, } \\
\text { MA }\end{array}$ & $\begin{array}{l}\text { Both parents have } \\
\text { tertiary degrees }\end{array}$ & $\begin{array}{l}\text { An in-press journal article, } \\
\text { conference papers }\end{array}$ & $\begin{array}{l}\text { Teaching, tutoring, } \\
\text { being a research } \\
\text { assistant }\end{array}$ \\
\hline Darshana & BA, BSc Hons & $\begin{array}{l}\text { Both parents have } \\
\text { tertiary degrees. Father } \\
\text { has an honour degree }\end{array}$ & & Tutoring, lecturing \\
\hline Emma & $\begin{array}{l}\text { BA, BSc Hons, } \\
\text { undergraduate } \\
\text { diplomas }\end{array}$ & $\begin{array}{l}\text { Mother has a tertiary } \\
\text { degree }\end{array}$ & $\begin{array}{l}\text { A book chapter, a } \\
\text { published journal article, } \\
\text { conference papers }\end{array}$ & $\begin{array}{l}\text { Administrator, } \\
\text { research assistant, } \\
\text { tutor, business sector }\end{array}$ \\
\hline Frank & $\begin{array}{l}\text { BMus Hons, } \\
\text { BA Hons }\end{array}$ & $\begin{array}{l}\text { Parents have no tertiary } \\
\text { education }\end{array}$ & $\begin{array}{l}\text { One published journal } \\
\text { article }\end{array}$ & $\begin{array}{l}\text { Tutoring, being a } \\
\text { research assistant }\end{array}$ \\
\hline Paddy & $\begin{array}{l}\text { BA, MSc, } \\
\text { postgraduate } \\
\text { certificate }\end{array}$ & $\begin{array}{l}\text { Parents have no tertiary } \\
\text { education }\end{array}$ & $\begin{array}{l}\text { Two published and one in } \\
\text { press journal articles, } \\
\text { conference papers }\end{array}$ & Tutoring, lecturing \\
\hline Solace & BA, Hons & $\begin{array}{l}\text { Parents have no tertiary } \\
\text { education }\end{array}$ & $\begin{array}{l}\text { One published journal } \\
\text { article }\end{array}$ & Tutoring, lecturing \\
\hline
\end{tabular}


Four participants adopted a teleological view on plagiarism, maintaining that its seriousness was dependent on the consequences. These students were reluctant to judge undergraduate plagiarism as being immoral. Darshana and Emma, however, believed that plagiarism was wrong regardless of the outcome or plagiarists' motives. Most students looked at plagiarism both from the perspective of an educator and a researcher, viewing it as a moral and an academic issue. They emphasised how plagiarism damaged good scholarship - a basic element of academia. Figure 6.1 depicts students' stances on plagiarism in relation to their NZ peers.

Figure 6.1 NZ-educated students' perceptions of plagiarism

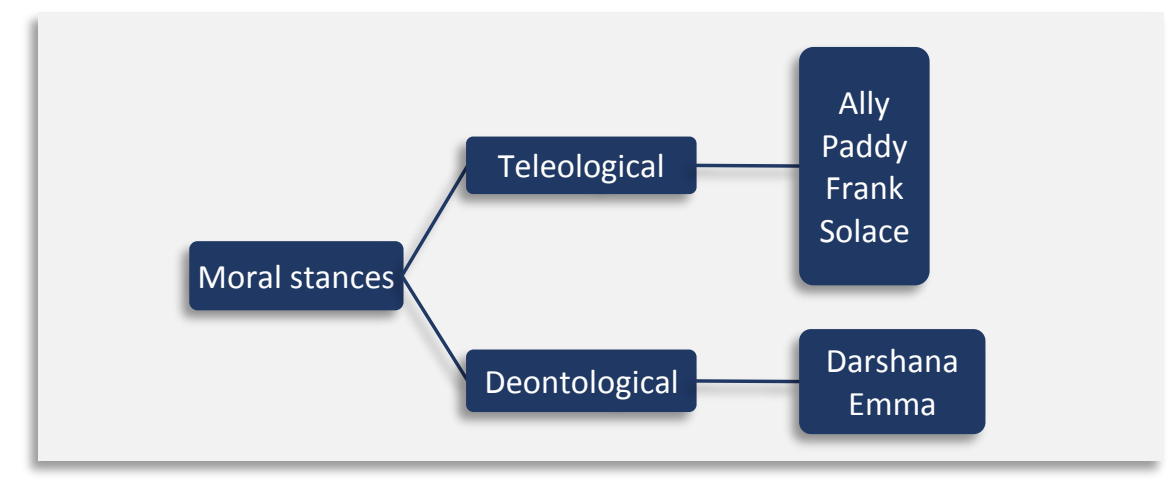

\subsection{VN-educated Interview Participants}

All six VN-educated participants had finished collecting data by the last interview. Hoa, Huynh, Victor were second-year students. Linh and Trung were in their fourth year. Sunny had been at VUW for nearly three years. Hoa, who was in her twenties, was the youngest. Linh, Sunny, Trung, and Huynh were in their thirties. Victor was in his early forties. Table 6.3 summarises their demographics.

Table 6.3 Demographic characteristics of VN-educated interviewees

\begin{tabular}{lllll} 
Pseudonym & Gender & Faculty & Tertiary qualifications & Teaching experience \\
\hline Hoa & Female & VBS & BA (VN), MA (overseas) & Lecturer \\
\hline Huynh & Female & FoEd & BA (VN), MA (overseas), MA (VN) & Lecturer \\
\hline Linh & Female & FHSS & BA (VN), MA (overseas) & Lecturer, tutor \\
\hline Sunny & Female & FoEd & BA, MA (VN) & Lecturer \\
\hline Trung & Male & FoEd & BA, MA (VN) & Lecturer \\
\hline Victor & Male & FoEd & BA (VN), MA (overseas) & Lecturer \\
\hline
\end{tabular}


Table 6.3 shows that there were four female and two male students. The distribution was consistent with the female-to-male ratio of 7:3 in the quantitative phase. Four students were studying within FoEduc, one within FHSS, and one from VBS. All students completed undergraduate studies in Vietnam and were full-time lecturers there. Four completed previous postgraduate studies in Western universities and two gained their MA in their home country.

\subsubsection{Hoa}

\section{Hoa's profile}

Hoa grew up in a well-educated family. Her father is a professor and her mother has an MA degree. Hoa's brother finished his undergraduate studies in Vietnam. While her parents expect a lot from her brother, they have little expectations for Hoa because she is female. They want her to live a normal life, obtain a job, and get married, rather than to gain postgraduate degrees. They hope she could pursue a lecturing career which they find suitable for females.

Hoa perceives herself as being sociable, patient, and reluctant to change. Hoa tries her best under any circumstances but would not pressure herself to achieve beyond her capacity. She has no role models but admires some people in her life because of their worldview.

Hoa obtained her undergraduate degree in Vietnam. Shortly after graduation, she worked for a Vietnamese university, mainly as a teaching assistant and lecturer for in-service programmes. She then completed her MA overseas. Hoa is doing a PhD in VBS because of her job requirement, not a passion. She thinks having a PhD makes her a more confident lecturer.

Hoa possesses two forms of cultural capital. Her embodied cultural capital consists of experiences, competence, and skills developed while studying abroad. She comes from a welleducated family with her parents both holding postgraduate qualifications and her father working in academia. Her institutionalised capital includes her academic qualifications.

Hoa's perception of plagiarism - Plagiarism is not as serious as murder.

Hoa viewed plagiarism as academic robbery and considered plagiarism at research levels as unacceptable. She asserted that the term plagiarism sounded serious. She would be ashamed if other people called her a plagiarist because it would mean she was stealing. However, she did not think plagiarism was as bad or deceptive as other violent crimes: 
Too bad for me means doing immoral things. Plagiarism is unethical, but it's not too bad in a certain way, like murder or something. As for deception, it's a bit. (Hoa, Int2)

Hoa thought the seriousness of plagiarism varied depending on the magnitude of the behaviour and plagiarists' academic level. For example, stealing a whole paragraph or essay was more severe than copying a simple or unimportant sentence. Similarly, plagiarism by PhD students was more serious and less excusable than undergraduate plagiarism.

The more they study, the more they should find plagiarism serious. There should be no excuses for plagiarism such as being accidental, not knowing, or not being taught. They have all been instructed at that level [PhD]. (Hoa, Int4)

Hoa said that knowing many instances of plagiarism of doctorates reported in the media gave students the impression that qualified people still plagiarised, leading them to view plagiarism as less serious than it was. She viewed plagiarism as an instructional problem that resulted from a lack of education. She thought adults needed to set an example:

Because they see older people plagiarise. For example, in Vietnam, people keep telling their children not to cross the street over the red light, but they keep doing it. So, the children just follow it. Adults haven't set an example. (Hoa, Int3)

Hoa believes that plagiarism may affect education quality and plagiarising students would form a bad habit in multiple settings outside academic environments. She thought when students graduated by plagiarising, their degrees would be meaningless because they gained less knowledge than expected. She was concerned about their limited skills and competence to complete required work:

Students don't have the skillset. They're not capable of doing the work as expected. They could plagiarise only at that time. Later, there's no one for them to copy. (Hoa, Int3)

Hoa holds a teleological stance towards plagiarism, viewing it as less serious than violent crimes. She considered plagiarism at research levels immoral and was concerned about its impacts on students. She asserted that plagiarism mostly resulted from a lack of education. 


\subsubsection{Huynh}

Huynh's profile

Huynh is a full-time lecturer in Vietnam. She is doing a PhD in Education mainly because it is a requirement for her job. She also wants a change in life and the environment after a long time working at university. During her PhD, Huynh expects to update her knowledge, improve her research ability, and learn about the people, lifestyle, and culture in NZ. However, she finds her doctoral studies a huge responsibility because of the scholarship she was awarded.

Huynh's siblings all have tertiary qualifications, which is her parents' expectation. Huynh is the first family member to pursue a doctorate. She describes herself as a friendly and helpful person. She is persistent and determined as well. Although she likes social activities, she sees herself as a profound person. She enjoys travelling and has been to many countries.

After finishing her undergraduate studies, she worked for a Vietnamese university. Shortly after that, she gained her master's degree overseas. Upon return to Vietnam, she worked at her previous university and followed by the completion of her second MA. She was a lecturer of English for a long time before coming to NZ. Huynh's purpose for learning is to gain knowledge, help others, and make herself confident. She wants to contribute to her Vietnamese university after finishing her doctoral studies.

Huynh possesses both embodied and institutionalised cultural capital. She grew up in a family with all siblings having a tertiary qualification. She has overseas study experiences and is an experienced lecturer. Huynh has a BA and two MA degrees.

\section{Huynh's perception of plagiarism - Conscientious people would not plagiarise}

Huynh views plagiarism as "robbery" where students passed off someone else's work as their own to get high scores. She considered that when plagiarising, students deceived their teachers, themselves, and their families. She asserted that conscientious people would behave well in any situation. While she thought people with conscience and proper direction would feel guilty for their behaviour and the undeserved outcome, she found making ethical judgements difficult because morally good people may plagiarise for various reasons. 
At a high level such as doctoral level, Huynh thought students were responsible for their behaviour and work. At undergraduate or high school levels, she believed that the responsibility lies with the institution because they need to teach students what was right or wrong:

Teachers must raise students' awareness of plagiarism. Students need to learn before they have experience. The roles of schools and teachers are very important. (Huynh, Int2)

If plagiarism was not detected, Huynh was concerned that students would get used to it. She thought plagiarism would affect plagiarists, their prestige, and how others looked at them. She said that plagiarism was unfair for non-plagiarising students:

While a hardworking student only received 8 points (equal to an A), another student copied from an academic and got 10 points (equal to an $A^{+}$) for their writing. (Huynh, Int4)

Despite considering that plagiarism might result from insufficient knowledge, Huynh took a deontological view of plagiarism, affirming that students had to follow the rules set by the university. She believed that conscientious people would not plagiarise.

\subsubsection{Linh}

\section{Linh's profile}

Linh is a PhD student from the FHSS. She describes herself as an active and sociable person and a confident public speaker. She has no specific goals in life other than gaining expertise and professional success. She wants recognition of her capacity and contribution rather than promotion or a high-status position. She described herself in the first interview: "I don't try to be over-positive and I'm never too negative to affect other people's emotions. At work, I want justice but understand that everything is relative, and absolute justice never exists. I don't want to be too extreme about things, insisting that everything is clearly white or black."

Linh's father, who is her first English teacher, has an in-service tertiary qualification in English. Her mother did not go to university. Linh's parents oriented her towards becoming a lecturer of English from her very young age and supported her to pursue an MA programme. Linh's younger sister obtained her undergraduate degree at a Western university.

Linh obtained her BA in Vietnam, then worked as an English teacher for several years before pursuing her MA at a Western university. After graduation, she returned to her previous 
university. She is a passionate and dedicated teacher who invests much of her time to hold students' attention and interest. She has been a tutor and research assistant within VUW.

Linh feels part of the academic community at VUW. During her enrolment, she engaged in various research and academic activities. She attends most talks, lectures, and seminars in her faculty. She loves networking with scholars in her field. She likes doing research but does not think about it as a lifetime career. After graduation, Linh wants to work in her field. She would love to get jobs in other universities or countries if she could.

Through her PhD, Linh learnt more about research and her area of interest. While she thinks doctoral students must contribute original knowledge, she finds it hard to find something novel or make her own mark. She wants to graduate with the best result she can achieve. Linh has presented at conferences in and outside NZ and is working on a paper about her PhD project.

Linh's embodied cultural capital assets comprise her English learnt from her father. She also got overseas study experiences. These are advantages compared to other students who speak English as a foreign language. Her institutionalised cultural capital includes her tertiary degrees.

\section{Linh's perception of plagiarism - Education plays a crucial role}

Plagiarism either in or outside academia was unacceptable in Linh's view. She would feel uncomfortable if people plagiarised her work, saying that she could not do that with anyone else. Linh affirmed that plagiarism was serious because it was equal to stealing someone else's intellectual product. She explained that no matter how the person modified or reworded the work, the ideas belonged to original authors who needed to be credited:

It's the same as stealing someone else's bike. Even if you reformed and painted it differently, it belongs to other people. You cannot make it yours. (Linh, Int2)

At a doctoral or research level, Linh considered plagiarism a calculated moral behaviour of an intellectual person. For her, plagiarism would devalue the degree, which was a measure of students' progress, skills, and capabilities:

A degree shows your progress, knowledge, skills, and experiences. If you copied from someone else's, that degree means nothing (Linh, Int2).

Linh asserted that plagiarism was unjustifiable because "mature" students - "who are 18 or over" should understand that blatantly taking someone else's work was wrong. They could not 
say that they did not understand the rules. However, when students were conscious about crediting other people, but did it improperly due to limited knowledge, she found it excusable:

Students know they need to cite, but their improper citation makes people misunderstand that they plagiarised intentionally. I mean, sometimes they don't mean to plagiarise but just don't know how to cite correctly. (Linh, Int2)

While considering plagiarism as unacceptable in academia, Linh would not judge people's personality by the offence they committed:

To judge whether someone is a good person, there are many other aspects. I mean when people do something bad, it doesn't mean that they're completely bad. (Linh, Int2)

Linh holds a teleological stance on plagiarism, perceiving it as immoral and unacceptable. While considering blatant or deliberate plagiarism for her was unjustifiable, she found insufficient and incorrect citations understandable. She thought judging people by their plagiarism was difficult.

\subsubsection{Sunny}

\section{Sunny's profile}

Sunny's parents have no tertiary qualifications. They set no goals for their children but always support their decisions. Sunny learnt a lot from them about working hard and making efforts because she has seen them starting from nothing, but overcoming obstacles, and being successful in life. She learnt that, with effort, she will succeed in whatever she does. Her parents were happy when she pursued her PhD, although they never said loudly.

Sunny gained her BA at a Vietnamese university. She taught in a private university for a while before moving to a public university. Around that time, she worked part-time for a language center. Later, she pursued her MA degree in Vietnam. Sunny is a motivated and dedicated lecturer, who always wants to renew herself, innovate, and update her knowledge.

Sunny comments that she is a simple but reliable person. She is unambitious, but she has desires. When she has defined a goal, she will try her best and take it seriously. Since childhood, Sunny has lived independently and was not affected by her parents' expectations. She loves cooking and listening to music. She enjoys reading memoirs of successful people. She loves to try local cuisines when travelling, seeing it as a way to learn about other cultures. 
Sunny is doing her PhD in the FoEd because she thinks it will advance her research expertise and make her more confident in her lecturing career. Through her PhD, she hopes to develop professional knowledge and research skills and learn new teaching techniques for her future lectures. She believes that having an overseas PhD will give her more opportunities and respect. She explains that in Vietnamese culture, the more qualifications people earn, the more opportunities they will have. Sunny does not feel much passionate about research but feels more motivated to do a PhD abroad, compared to a PhD in her homeland. She finds many new things to learn. Sunny enjoys her doctoral studies in a relaxed and comfortable environment.

Sunny's cultural capital is mainly embodied and institutionalised. Regarding embodied cultural capital, she has professional knowledge and skills. Although she grew up in a working-class family, she has desires and tries hard in her life. Sunny is experienced and motivated to learn. In terms of institutionalised cultural capital, she earned one BA and one MA degree.

\section{Sunny's perception of plagiarism - We need to show them why plagiarism is wrong}

Sunny viewed plagiarism as stealing because, for her, intelligence was an important source of property. Once people committed it, she thought they disrespected themselves and others as academic writers. She said that although people modified a copied text, it was basically someone else's work, not theirs.

Considering the qualification as a product, Sunny emphasised that the process of creating that product was more important. When students plagiarised, she thought the qualification did not reflect their ability because genuine study meant following the rules. She was concerned that plagiarism would form a dishonest practice - claiming someone else's work as their own.

However, Sunny believed that when plagiarising, students might still learn how to use other people's work to support their ideas. She viewed it as a way of gaining knowledge and improving academic writing skills:

Although they took someone else's ideas without giving appropriate citations, they know how to use materials to support their work. At least at that point, they might have learnt the author's writing. It's input. They're acquiring knowledge too. (Sunny, Int2)

Linh thought the role of an academic institution was not just telling students not to plagiarise: 
They need to know how to avoid such errors. We should provide them the tools. In many Vietnamese universities, there's no systematic education on plagiarism. (Sunny, Int2)

Sunny said that plagiarism education had not been thoroughly emphasised at the institution where she worked. Therefore, it did not create an impact on students' awareness:

We did not emphasise or touch students' consciousness. [...] Plagiarism is morally wrong because it's stealing. It's unacceptable because they don't respect the writers and themselves as academic writers. (Sunny, Int2)

Sunny holds a teleological view of plagiarism. She was concerned about its impacts on student learning, the qualifications they earned, and their later lives. From the perspective of an educator, she realised gaps in plagiarism education at her Vietnamese university.

\subsubsection{Trung}

Trung's profile

Trung is doing a PhD in Education. He admires successful people who are respected by their colleagues and communities. He looks up to those who have broad political and disciplinary knowledge. Pursuing lifelong learning is important in his life. He studies abroad to expand his expertise and apply advanced international knowledge to teach Vietnamese students. He is passionate about research and wishes to contribute to his field. After his PhD, he hopes to pursue a postdoctoral position or work in international environments to gain more experience.

Reading is one of Trung's biggest passions. He enjoys reading academic and intellectual books, seeing it as a way to broaden knowledge and discover new things. He likes collecting books. Trung loves travelling and learning about different cultures. He has travelled to many countries in Asia and Europe. He also watches movies and reads online news.

Although Trung's parents are not tertiary educated, they understand the value of education and encourage him to learn. They told him that education would make him respected and give him a position in society. They want him to learn to the best of his ability. They were happy and supported him mentally and financially when he decided to pursue a PhD.

Trung obtained both his BA and MA degrees at the same university in Vietnam. He worked as a lecturer for many years before commencing his $\mathrm{PhD}$. Before that, he worked in a foreign language center. During his PhD, Trung had done several conference presentations in and 
outside NZ. He already published a journal article and was working on another paper, both were from his PhD research.

As a doctoral student, Trung feels proud, because, in his Vietnamese department, few people are offered scholarships and study overseas. At VUW, he enjoys attending talks, seminars, lectures, and workshops. He volunteered in various activities within VUW. In his office, he meets doctoral students from other countries and learns about their research, cultures, and academic issues in their countries. Besides that, Trung regularly meets other PhD students with the same interests, to share about their studies, progress, and challenges. For him, all these experiences, which he considers advantages of studying overseas, enrich his experience and expertise. His PhD goals are to accumulate professional knowledge and experience, improve his research skills, contribute to his field, and achieve satisfying results.

Trung cultivates embodied cultural capital by taking part in academic activities. His capital assets included his tertiary qualifications. His conference papers and published journal article show his endeavors, hard efforts, and commitment to doctoral studies. Trung is passionate about research and considered himself a life-long learner. He sets clear academic goals and tries his best to achieve them. He is enthusiastic and perseverant. Although his parents did not attend university, they understand the value of education and always encourage him to learn.

Trung's perception of plagiarism - Plagiarism is against the production of knowledge

Trung considered plagiarism as academically wrong and countering the production of knowledge which is fundamental in academia. However, he did not view undergraduate plagiarists as immoral, but considered their plagiarism as a lack of understanding about that area. He saw no link between plagiarism and a person's personality.:

A good person with insufficient knowledge of plagiarism still violates and makes mistakes. It's not only a moral issue but also an educational one. (Trung, Int2)

Trung asserted that although Vietnamese students might not be fully aware of plagiarism, its forms, and seriousness, most understood that copying someone else's work was wrong. He thought educators were responsible for educating students about plagiarism-related aspects and providing them with tools to avoid it. Lecturers needed to make sure that students all had the same level of understanding. By doing that, equity in education could be assured: 
Some students know [about plagiarism], some may not. We need to judge it on a case by case basis. For example, in a competition between a fish and a monkey, if we ask them to climb trees, the monkey will win. (Trung, Int2)

Trung said that the lack of specific regulations about plagiarism and tools to detect it created a gap for those who deliberately plagiarised. Trung believed that plagiarism arose from a lack of self-awareness, where students did not realise the severity of their behaviour:

Plagiarism results from students' unconsciousness. Maybe they know that action is wrong, but they're not aware of its importance. (Trung, Int4)

Trung maintained that plagiarism would affect the reputation and academic products of a university. If research students plagiarise, it would negatively influence their scholarship. Undergraduate student plagiarists would not think or learn much. Then the qualification that students gained, which was supposed to measure and classify their progress and achievement, could not do its basic job. He thought plagiarism created unfairness:

They got high scores without making much effort while other students worked hard to achieve the same score. Then they're equal. So, the score cannot show anything. It's (the degree) no longer meaningful because it equates everything. (Trung, Int2)

Trung possesses a teleological stance on plagiarism. He viewed plagiarism as an academic issue because plagiarists did not contribute to new knowledge. He did not see plagiarism as related to personality but as temporary mistakes resulting from lack of knowledge. He believes that institutions should educate students about plagiarism and its seriousness.

\subsubsection{Victor}

Victor's profile

While Victor's parents are teachers, they put no pressure on his studies and work but let him make his decisions and support his choices. Victor's father taught him English when he was young. Victor's brother works in international affairs.

Victor has been to many European countries. He enjoys reading non-fiction books and listening to music. He loves travelling, learning about people, their lives, and their cultures. He considers himself to be critical and, in some situations, strict with himself and others. 
Victor obtained a BA degree in Vietnam majoring in English. Before starting his MA degree in a Western country, he had attended professional courses in teaching methodology. He had worked in various sectors, but his main job was lecturing. Before coming to NZ, he was a fulltime lecturer in Vietnam. Victor preferred working in the business sector.

Victor is doing a PhD in Education. He wants a doctoral degree to prove his competence at a high level. He wants to get new experiences, meet his job requirements, and update his expertise. Victor values the knowledge gained through his PhD more than the qualification. He does not feel proud of being a doctoral student but sees it as a chance to develop himself and a necessary milestone in the development process.

Regarding embodied cultural capital, Victor comes from a well-educated family with his parents being teachers. He traveled a lot and his work experience is diverse. His institutionalised cultural capital consisted of his tertiary qualifications.

\section{Victor's perception of plagiarism - Plagiarism is stealing}

Victor views plagiarism as stealing because plagiarists claimed someone else's work as their own. For him, stealing involved not just physical but intangible objects. Plagiarising students deceived their teachers and falsified their knowledge and competence. He considers plagiarism in any circumstances as equally severe which meant it did not matter who the person was:

It's stealing. A president who plagiarises is like a plagiarising student. Plagiarism in any context is the same. It doesn't matter if it's in or outside academia. (Victor, Int2)

However, Victor said that deciding if a person was morally good or bad by their plagiarism was difficult because some people might be socially and morally good outside academia. For student plagiarism, he believed that it was important to find out the reasons behind that, who the students were, and their backgrounds. After that, he would decide on how to handle it. He did not judge if the student was a bad person or not from just reading his/her work.

Victor believed that plagiarism would negatively affect how people looked at the person and their work. He asserted that plagiarism would promote laziness and create a bad habit where students found copying anyone else's work acceptable, both in and outside academic settings:

It might make them lazy. Instead of thinking about how to do the work; they google how other people have done it. They do nothing new, things like that. (Victor, Int2) 
Victor adopted a deontological view on plagiarism. He considered plagiarism as immoral, confirming that plagiarism was deceitful and that it would develop into a bad habit.

\subsubsection{Conclusion}

While most VN-educated students own embodied and institutionalised cultural capital, the forms of cultural capital varied among them. Hoa, Linh, and Victor's parents held tertiary qualifications. Five students are experienced lecturers; Hoa, also a lecturer, had less teaching experience. Linh has worked as a tutor and research assistant at VUW. Four obtained MA degrees overseas. Two students (Linh and Trung) pursued doctoral studies because of their passions for research and had published or completed publishable work during their PhD. The other four students pursued a PhD as a requirement for their lecturing job. All students show their engagement in doctoral studies. Table 6.4 presents participants' characteristics.

Table 6.4 VN-educated interviewees' characteristics

\begin{tabular}{|c|c|c|c|c|}
\hline Pseudonym & $\begin{array}{l}\text { Tertiary } \\
\text { qualifications }\end{array}$ & $\begin{array}{l}\text { Second generation } \\
\text { university students }\end{array}$ & Research outputs & $\begin{array}{l}\text { Professional } \\
\text { experiences }\end{array}$ \\
\hline Hoa & BA, overseas MA & $\begin{array}{l}\text { Both parents have } \\
\text { postgraduate degrees }\end{array}$ & & Lecturing \\
\hline Huynh & $\begin{array}{l}\text { BA, overseas and } \\
\text { domestic MA }\end{array}$ & Not stated & & Lecturing \\
\hline Linh & BA, overseas MA & $\begin{array}{l}\text { Father has a tertiary } \\
\text { degree }\end{array}$ & $\begin{array}{l}\text { An in-progress journal } \\
\text { article, two conference } \\
\text { papers }\end{array}$ & $\begin{array}{l}\text { Lecturing, being a } \\
\text { research assistant, } \\
\text { tutoring }\end{array}$ \\
\hline Sunny & BA, overseas MA & $\begin{array}{l}\text { Parents have no } \\
\text { tertiary education }\end{array}$ & & Lecturing \\
\hline Trung & BA, MA & $\begin{array}{l}\text { Parents have no } \\
\text { tertiary education }\end{array}$ & $\begin{array}{l}\text { A published journal } \\
\text { article, an in-progress } \\
\text { journal article, three } \\
\text { conference papers }\end{array}$ & Lecturing \\
\hline Victor & BA, overseas MA & $\begin{array}{l}\text { Both parents have } \\
\text { tertiary degrees }\end{array}$ & & Lecturing \\
\hline
\end{tabular}

Four VN-educated participants hold teleological stances to plagiarism, focusing on impacts and consequences of the behaviour. Two (Huynh and Victor) adopt a deontological view of it. Most students identified themselves as educators, talking about plagiarism at the learning level, considering it as a violation of rules and an institutional issue. Two students (Linh and Trung) 
mentioned scholarly aspects of plagiarism, viewing it from the standpoint of a researcher. Figure 6.2 illustrates students' perspectives from a teleological and deontological scale.

Figure 6.2 VN-educated students' perceptions of plagiarism

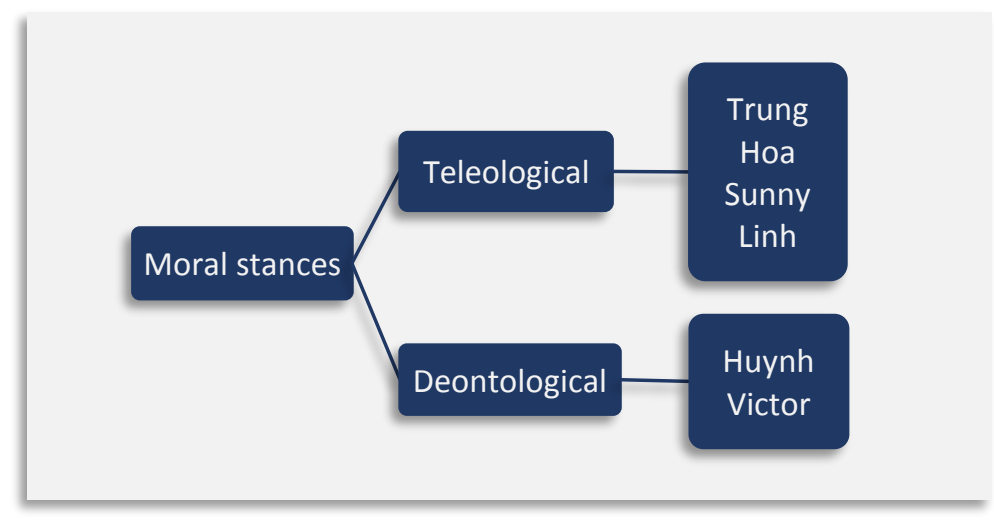

\subsection{Chapter Summary}

This chapter has described interview participants' backgrounds and perceptions of plagiarism. Most VN- and NZ-educated students hold rich cultural capital. While all VN-educated students had full-time employment in Vietnam, no NZ-educated students worked full time. All NZeducated students had tutoring experiences whereas all VN-educated students had been lecturers before commencing their PhD. Many participants grew up in highly educated families. Four VN-educated students enrolled in doctoral studies because it was a job requirement, whereas most NZ-educated students were driven by their passion for research. More NZeducated than VN-educated students produced publications during PhD enrolment.

All students perceived plagiarism as immoral and unacceptable in educational settings. While the NZ-educated students considered plagiarism from a scholarly and educational standpoint, most VN-educated students adopted an educational view of plagiarism. These VN-educated students mentioned problems in plagiarism education in their homeland. All NZ-educated and two VN-educated students (Linh and Trung) focused on underlying aspects of plagiarism and how it threatened academia. Two students in each group took a deontological view on plagiarism, considering it as wrong regardless of repercussions or motives. The other students possessed teleological stances on plagiarism, paying more attention to the consequences.

The next chapter outlines key themes emerging from the interview data. 


\section{Chapter 7 | Student Perspectives of Plagiarism}

\subsection{Introduction}

This chapter presents interview participants' understanding of plagiarism, setting the scene for a detailed analysis of influences on their perceptions in the next chapter. Section 7.2 outlines student conceptualisation of plagiarism. Section 7.3 describes their prior plagiarism education, comparing education opportunities offered in different educational contexts. The next sections focus on student perspectives of plagiarism, indicating alignment and contradiction between qualitative themes and survey results. Section 7.4 summarises students' individual-level framing of plagiarism, their beliefs about personal causes and outcomes of plagiarism. Section 7.5 depicts their perspectives of plagiarism on an organisational level, featuring institutional factors, academic impacts, and suggested plagiarism-prevention strategies. Section 7.6 sums up the main points and introduces the next chapter.

\subsection{Students' Conceptualisation of Plagiarism}

For this research, the term plagiarism was used to refer to "presenting someone else's work as if it was your own, whether you mean to or not" which was the institutional definition used by VUW (Victoria University of Wellington, 2020a). This section reports findings on how interview participants defined plagiarism, examining the degree to which their conceptualisation was in line with the definition of plagiarism from the university perspective. This was also to ensure that the researcher and participants shared an understanding of what plagiarism meant.

Most interviewees defined plagiarism as presenting somebody else's words or ideas as one's own either intentionally or unintentionally. A typical response was:

I define plagiarism as taking somebody else's words or ideas and writing them as if they were your own, without citing or referencing the person whose ideas were written or work they were. Whether it's intentional or unintentional, it's plagiarism. (Ally, Int2)

Plagiarism from students' perspectives included work taken from various sources. For example, Victor considered presenting others' work as one's own as plagiarism regardless of who owned the work. Plagiarism, in Emma's view, was copying work from either a published paper or a friend's assignment. For Hoa, copying ideas from colleagues' work-in-progress paper was also 
a form of plagiarism. Darshana, Emma, Hoa, Solace, Trung, and Victor said that plagiarism included reusing one's own previously submitted work.

For several students (Emma, Solace, and Trung), plagiarism encompassed broader aspects outside academic settings. They emphasised that plagiarism was not merely involved words and ideas but broader creative work such as images, ideas, programmes, or artistic creations.

Overall, interview participants understood plagiarism as an appropriation of words or ideas either advertently or inadvertently, which is aligned with the operational definition of the study or the definition of plagiarism currently used by VUW. Several students added other aspects to their definitions as illustrated in Table 7.1.

Table 7.1 Students' conceptualisation of plagiarism

\begin{tabular}{|c|c|c|c|c|c|c|c|}
\hline $\begin{array}{l}\text { Plagiarism } \\
\text { aspects }\end{array}$ & $\begin{array}{l}\text { Copying } \\
\text { words }\end{array}$ & $\begin{array}{l}\text { Copying } \\
\text { ideas }\end{array}$ & $\begin{array}{c}\text { Copying other } \\
\text { intellectual } \\
\text { products }\end{array}$ & $\begin{array}{l}\text { Presenting } \\
\text { as one } \\
\text { own }\end{array}$ & $\begin{array}{l}\text { Without } \\
\text { citation }\end{array}$ & $\begin{array}{l}\text { Either with } \\
\text { or without } \\
\text { intention }\end{array}$ & $\begin{array}{l}\text { Regardless } \\
\text { of who owns } \\
\text { the sources }\end{array}$ \\
\hline Ally & $\checkmark$ & $\checkmark$ & & $\checkmark$ & $\checkmark$ & $\checkmark$ & \\
\hline Darshana & $\checkmark$ & $\checkmark$ & & $\checkmark$ & $\checkmark$ & $\checkmark$ & \\
\hline Emma & $\checkmark$ & $\checkmark$ & $\checkmark$ & $\checkmark$ & $\checkmark$ & $\checkmark$ & $\checkmark$ \\
\hline Frank & $\checkmark$ & $\checkmark$ & & $\checkmark$ & $\checkmark$ & $\checkmark$ & \\
\hline Paddy & $\checkmark$ & $\checkmark$ & & $\checkmark$ & $\checkmark$ & $\checkmark$ & \\
\hline Solace & $\checkmark$ & $\checkmark$ & $\checkmark$ & $\checkmark$ & $\checkmark$ & $\checkmark$ & \\
\hline Hoa & $\checkmark$ & $\checkmark$ & & $\checkmark$ & $\checkmark$ & $\checkmark$ & $\checkmark$ \\
\hline Huynh & $\checkmark$ & $\checkmark$ & $\checkmark$ & $\checkmark$ & $\checkmark$ & $\checkmark$ & \\
\hline Linh & $\checkmark$ & $\checkmark$ & & $\checkmark$ & $\checkmark$ & $\checkmark$ & \\
\hline Sunny & $\checkmark$ & $\checkmark$ & & $\checkmark$ & $\checkmark$ & $\checkmark$ & \\
\hline Trung & $\checkmark$ & $\checkmark$ & $\checkmark$ & $\checkmark$ & $\checkmark$ & $\checkmark$ & \\
\hline Victor & $\checkmark$ & $\checkmark$ & $\checkmark$ & $\checkmark$ & $\checkmark$ & $\checkmark$ & $\checkmark$ \\
\hline
\end{tabular}

As shown in Table 7.1, six out of twelve students adopted quite similar definitions of plagiarism. Five expanded their definition by including copied work in broader contexts besides academic settings. Three asserted that copying was plagiarism regardless of who owns the sources.

\subsection{Prior Learning about Plagiarism}

Interviewed participants reported different levels of plagiarism education prior to doctoral studies. While all NZ-educated participants were taught explicitly about plagiarism early in undergraduate levels, most VN-educated students received insufficient instructions about 
plagiarism in their undergraduate and master's studies. Exceptions were found with those who undertook master's degrees overseas.

\subsubsection{Limited Learning Opportunities in Vietnam}

For most VN-educated students, plagiarism education for undergraduates in Vietnam was not formally integrated into the curriculum; lecturers spent most of their lecture time explaining course materials rather than showing students how to engage with sources, what plagiarism was, or how to avoid it. As undergraduates, Hoa and Sunny possessed only basic knowledge about plagiarism. What their lecturers told them was not to copy anyone else's work. They found it hard to recall how they were instructed about plagiarism. Sunny, who gained all her tertiary degrees in Vietnam, described her understanding of plagiarism as being "vague":

It was vague then. Because there was no emphasis from the university, I don't have much impression now. As I remember, there was a small section in a course. [...] I simply quoted whenever I used other sources. (Sunny, Int1)

According to Trung, the issue of plagiarism was raised in his classes but had never been presented as a necessity. Another said that what she knew at that time was to cite whenever using others' words or ideas. Apart from that, she understood little about plagiarism:

I didn't understand what constituted plagiarism. I knew I needed to cite the sources that I used. I always put the authors' names when using their full text. I didn't understand in which situations I needed a quote and what would be considered plagiarism. (Linh, Int1)

According to three students (Hoa, Huynh, and Linh), plagiarism education was delivered to a specific group of students but not the whole undergraduate population. Typically, it was considered more important for thesis students. Hoa was taught about plagiarism-related issues when she started her undergraduate thesis:

Before I did my thesis, my faculty organised a writing workshop including a section about plagiarism. Few students in my class were thesis students. (Hoa, Int1)

Teaching about plagiarism was inconsistent among Vietnamese lecturers. While the instruction was considered the responsibility of academic writing lecturers, only English-majored students completed this course. In that respect, students might miss learning opportunities if their lecturers neglected such instructions. For example, Sunny said: 
Because it's related to writing, lecturers who taught essays or academic writing would tell students about it. So, it depended on those people. If they guided students, they would have an opportunity to learn. Otherwise, students could not. (Sunny, Int1)

Education about plagiarism was not provided at some universities. In the first interview, Victor, a VN-educated student who completed his undergraduate education years ago, said "As I remember, no lecturers mentioned that we had to be careful about plagiarism."

At the master's level, plagiarism education was given a bit more emphasis but remained insufficient, as Trung said:

I was taught how to cite and paraphrase. These are ways to avoid plagiarism I remember. Generally, they [the lecturers] talked about that but did not emphasise. (Trung, Int1)

Three students (Hoa, Trung, and Victor) were unaware of their previous universities' policies of plagiarism. While Trung did not know any plagiarism policies during his undergraduate and postgraduate studies in Vietnam, he was not sure if there were any policies implemented later because he completed his studies nearly ten years ago. Similarly, Hoa did not hear of the policy until her final year of university:

I did not know if there was a policy or not. It was not until I started my thesis and met my supervisor that I got told about plagiarism. There was no formal education about it. I think the policy was not publicly informed to students. (Hoa, Int1)

Hoa, Huynh, Linh, and Sunny highlighted the role of supervisors in raising postgraduate student awareness and understanding because these students spent most of the time working with supervisors. They thought if supervisors stressed the seriousness of plagiarism, students would be serious about it, otherwise, students would not care much. However, Sunny reflected that plagiarism education to master's students was given little attention in her previous university.

\subsubsection{Extended Learning Opportunities in New Zealand or outside Vietnam}

In contrast to VN-educated students, all NZ-educated participants were taught about plagiarism early in their undergraduate years through multiple channels and platforms. Instructions were integrated into orientations, tutorials, and course outlines. In comparison to their VN-educated counterparts, who reported not having strong memories about how they were taught, those students described their experiences in detail and vividly. 
Education about plagiarism was offered regularly throughout students' entire programmes in NZ universities. Solace, who gained all his tertiary qualifications at VUW, emphasised that plagiarism education was inserted at the start of every lecture he attended, focusing on what plagiarism was, how and why students should avoid it. Darshana and Paddy were informed about plagiarism in their first year, during the orientations.

I think, one of those workshops that I went to in the first year during the orientation. They made it very clear [...] what plagiarism is, you can't just copy what people say and pretend that it's your own, which is not okay. (Darshana, Int1)

We were told that there's this thing called referencing, you need to do it and if you don't, you're cheating and presenting things that aren't yours. So, you may be kicked out of the university. (Paddy, Int1)

VN-educated students who obtained their previous postgraduate degrees outside Vietnam had a chance to learn about plagiarism during their studies overseas. What they found different from their home country universities was that elsewhere, teaching about the issue was given more attention and delivered through multiple channels and platforms:

In the orientation, I learnt that plagiarism was serious, and it was an academic-related issue or things like that. In the academic writing class, the lecturer talked about it again, like what plagiarism was, why and how to avoid it. (Hoa, Int1)

They talked about it in the orientation and at the beginning of every course. We submitted our assignments through Turnitin too. (Linh, Int1)

There were talks or short courses where people reminded me that in academic writing, you have to write this and that way to avoid plagiarism. (Victor, Int1)

In some universities, students were required to demonstrate a certain level of understanding about plagiarism before commencing their studies. For example, Huynh was required to pass a test about plagiarism before enrolling in her master's programme:

The university offered an orientation about plagiarism at the start of each trimester. Then there was a short test with around 40 questions. (Huynh, Int1)

All Vietnamese students who studied outside Vietnam previously became aware of the seriousness of plagiarism and its academic impacts when studying in other countries. 


\subsubsection{Conclusion}

VN- and NZ-educated students possessed dissimilar plagiarism education opportunities before starting their PhD. While plagiarism instructions were not emphasised at undergraduate levels in Vietnam, training and policies were paid special attention in Western and NZ institutions. NZeducated students reported that both university administrations and faculty members were involved in plagiarism education. The efficiency of the procedures was reflected in how students recalled their learning. While VN-educated students, who studied overseas, and NZeducated students described in detail their prior learning experience, other VN-educated students found it hard to recall how they were taught previously about the issue.

\subsection{Framing of Plagiarism on an Individual Level}

On an individual level, interview participants believed that plagiarism was directly linked to people's moral reasoning, self-awareness, and knowledge. They thought plagiarising students were fully responsible for their misconduct, which would conversely negatively impact their learning, future moral behaviours, relationship with faculty members, and prestige. Figure 7.1 summarises the main themes that emerged from the analysis.

Figure 7.1 Students' framing of plagiarism on an individual level

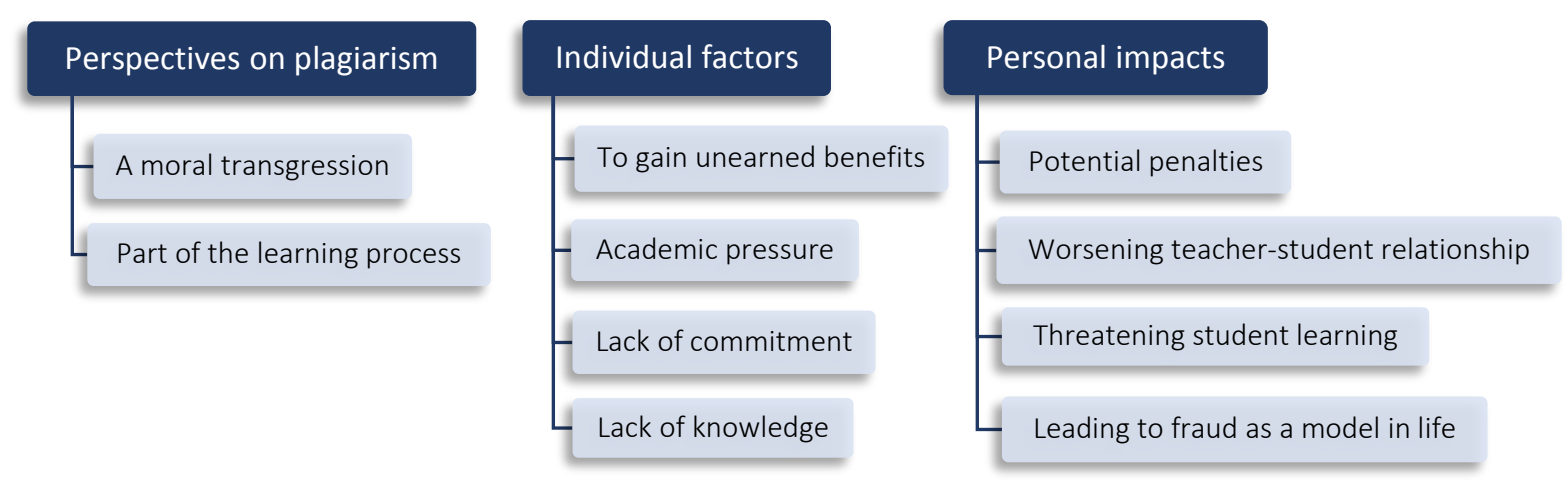

\subsubsection{Participants' Perspectives of Plagiarism at University}

Interviewees perceived plagiarism from diverse standpoints, including ethical concerns and professional empathy. Those who took an ethical stance perceived it as unacceptable and inexcusable, insisting that plagiarism was unaligned with moral standards or principles. Those who took the second viewpoint understood undergraduate challenges and learning situations, maintaining that plagiarism was not necessarily negative. 


\section{Plagiarism as a moral transgression}

Most interview participants viewed plagiarism as immoral and associated it with negative connotations such as stealing and deception, in line with the survey results where most respondents agreed that plagiarism was stealing and deceitful. Interview data provided deeper explanations for reasons and nuances underlying students' moral standpoints.

Most students viewed plagiarism as serious as other types of larceny. They thought by plagiarising, individuals tried to claim others' thoughts as their own instead of acknowledging them. For Trung, plagiarism was stealing because plagiarists used someone else's work without permission. Hoa considered plagiarism as robbery, but in academic contexts. Darshana viewed it as theft without reference to intentions, contexts, or circumstances. Emma saw plagiarism as regurgitating intellectual labour, reasoning that people's thoughts or ideas were as important as physical items they created, either a car or an artwork. Victor viewed appropriating either word, ideas, or physical objects as stealing:

Taking something (either tangible or intangible) belonging to other people without permission is stealing. Claiming an idea or a piece of writing created by someone else as their own means appropriating their energy and attribution. (Victor, Int2)

All participants viewed plagiarism as deceptive, underlining that plagiarising students fooled original authors, teaching staff, readers, and themselves that they submitted their own work. They also regarded it as being dishonest about authorship. One stated:

You're lying or saying that your thoughts are xyz when you explicitly read xyz written by somebody else. You're trying to say that you had thoughts on whatever it is, that you've got authority on it when you have not. (Emma, Int2)

While being concerned about moral aspects of the act of plagiarism itself, most participants (Ally, Emma, Frank, Hoa, Linh, Trung, and Victor) disputed associating plagiarism with personal ethical values. This provided more contextual details for why survey respondents disagreeing that a good person did not plagiarise. Ally and Linh thought plagiarism did not show much about someone's ethics because many factors could affect people. Emma considered plagiarism as an environmental and behavioural matter rather than indicative of a laid-back or immoral personality, stating that plagiarism was closely linked to opportunity, education, awareness, and policies. Ally, Frank, Trung, and Victor found judging people by plagiarism difficult. 
I always want to know what the reason was for doing it, rather than just assuming that someone is a bad person or something like that. I don't necessarily see a strong link between plagiarism and someone being bad, you know, that moral type of aspect. It's not such an easy link to make at all. (Frank, Int4)

I don't think all people who plagiarise are bad. For me, it comes down to the level of education. Undergraduate students, particularly first year, I don't think every single person who plagiarised would be a bad person. (Ally, Int4)

Several argued against moral aspects of plagiarism or specified contexts where plagiarism should not be treated as immoral. Most viewed undergraduates' plagiarism, where there was confusion around what might or might not be counted as plagiarism, as understandable:

If it's a first-year student, who doesn't really know what they're doing and, you know, they're not quite sure how to reference, or they're just really not used to university life, the students should be showed what they need to do and what they've done wrong. (Ally, Int4)

There's plagiarism that comes from maybe a lack of understanding. (Paddy, Int2)

Three students - Ally, Paddy, and Trung - argued that undergraduate plagiarism might not be fraudulent. Ally thought "deceitful" was a strong word to describe first-year student plagiarism. Trung said that in teaching contexts where student understanding of plagiarism was limited, he was reluctant to identify their plagiarism as stealing:

While undergraduate thesis students are instructed about plagiarism, the others are mostly confused about the rules, how to quote, and how to integrate people's ideas. It leads them to plagiarise without meaning to. (Trung, Int2)

Some students put that plagiarism might not mean ideas were taken away from original authors. However, when people copied someone's work and published it before the author, it would be stealing. One said:

If somebody was about to publish something, you took that idea, published it before them, and got all the attributions, that would be stealing. Taking somebody's existing idea and attributing it to your own, I wouldn't quite say it's stealing. It's close. It's a similar term. (Solace, Int2)

Considering contexts and intention factors of plagiarism, Frank, Hoa, Linh, Paddy, Sunny, and Trung disputed considering accidental plagiarism as immoral. Understanding reasons behind inadvertent plagiarism, including forgetting to keep track of reading notes, they were hesitant 
to decide on moral values underpinning someone's behaviour. Others did not consider plagiarism resulted from a lack of knowledge as deceptive:

If people deliberately plagiarise and hide it, it's immoral. If it's unintentional, it isn't a moral issue. Many students may have not been taught about it and may not understand the complexity of the issue. (Sunny, Int4)

People may plagiarise accidentally. Then, they're still good people, they just don't know about plagiarism. Plagiarism does not necessarily mean that they're bad. (Hoa, Int2)

Similarly, Linh stated that while deliberate plagiarism was a sophisticated stealing behaviour, insufficient citations should not be considered stealing. She believed that although students referenced improperly, they were conscious that they had to acknowledge other people's contributions to their work and did make efforts to do so.

\section{Plagiarism as part of the learning process}

Some participants (Frank, Solace, Paddy, Sunny, and Trung) regarded accidental plagiarism as an unavoidable part of the learning process, thinking that university was a place for learning and improving oneself. They believed that students need to learn before they have experience and education basically aimed at providing students with skills, knowledge, and expertise; if students were already competent, there was no reason to pursue tertiary education:

It's necessary to keep in mind that students are there to learn. They don't come to university knowing everything. There's no point going through a degree if they know everything. (Frank, Int2)

Linh, Paddy, Hoa, Solace, Sunny, and Trung asserted that educators could not expect students to be perfect and plagiarism, referencing, and citation were complex to many students. Sunny insisted that not many students understood plagiarism-related aspects systematically. For Frank, covering correct practice related to plagiarism, citations, and referencing did not mean that all students gained knowledge to a similar standard. Solace had seen students failing to achieve basic understanding and plagiarising as an option:

I know students who have fallen behind in their understanding. In some cases, they aren't taught well in the courses. And that forces them to plagiarise because it's the only way they know to pass the course. (Solace, Int2) 
Several participants (Linh, Paddy, Sunny, and Trung) considered plagiarism a transitional stage in the path to becoming a writer, which was aligned with survey results where respondents agreed that plagiarism happened when students were learning to write and it was more common in the work of beginner writers. They thought beginners made more errors because of not having grasped referencing and citation conventions or they could not fully realise complex aspects related to plagiarism such as what was counted as "common knowledge". For Linh, beginners might have low academic ethics which led to mistaken belief and behaviour or their lack of understanding might make other people think they plagiarised:

Novice writers would be more likely to make mistakes, or they may not understand referencing conventions. As a result, others may think they plagiarise. (Linh, Int2)

Two students viewed plagiarism as a way of acquiring knowledge. Sunny thought despite failing to credit authors' contribution to their work, plagiarising students knew how to use other people's work to support their ideas; they could develop their writing skills. Similarly, Solace argued that looking at or taking information from different sources was basically where and how people learnt, and academic work was created in the same way but with citations:

A lot of students don't look at others' work. When you plagiarise, you're looking at other people's work in order to solve the problem. Looking at or taking other people's work and using it as their own is sort of a fundamental concept in how you learn. (Solace, Int2)

\subsubsection{Participants' Views of Individual Factors Associated with Student Plagiarism}

When asked about reasons for student plagiarism, the participants indicated factors for both intentional and unintentional plagiarism. Reasons for intentional plagiarism included personal motives, academic pressures, and reluctance to work. Unintentional plagiarism was believed to arise from a lack of knowledge and skills.

Plagiarism results from a desire to gain unearned benefits

Most participants believed that students were tempted to plagiarise due to unearned benefits they received if not caught. The first benefit was getting a passing mark. Interview participants' opinions echoed the survey finding where respondents agreed that many students plagiarised to pass courses. Most thought plagiarising helped students to pass requirements without effort. Some said that passing was the sole hope of students when they could not convey their views. 
Most survey respondents agreed that students plagiarised because they wanted high grades. Interview participants insisted that competent students still plagiarised to obtain their desired scores. Solace talked about one of his achievement-addicted students who copied some answers in the test (that he could not complete) to get a perfect score:

I know of one student in particular who couldn't do the last part of an assignment which got him from an A-to an At, and he copied his friend's code for the last part, so all the rest was his own work. He knew how to do it, but he wasn't able to implement it, and so he ended up copying his friend's code in order to get that last bit of a grade. (Solace, Int2)

Frank, Linh, and Paddy observed that student plagiarists might not want a grade but course completion. By plagiarising, students could finish their work without engaging with the material and those who were reluctant to complete a task would copy online resources. Linh recalled a student who just wanted to submit something:

It's not because they want high grades, but they're too lazy. I have a student who only needs to get assignments done. So, she handed in everything she found. (Linh, Int3)

Others (Frank, Hoa, Linh, Sunny, and Victor) highlighted that plagiarising students might seek recognition. They believed that sometimes plagiarists wanted to be respected for unique ideas. One distinctive response was:

Some are ambitious but incompetent. They wish to be seen as coming up with a novel idea but cannot think of any. So, they copy someone else's paper and deliberately turn it into their work. (Linh, Int4)

Victor said that students might choose plagiarism to avoid losing face. He said that students might want to show their friends and lecturers that they were competent learners.

\section{Plagiarism results from academic pressure on students}

Interview participants indicated a range of pressures contributed to plagiarism, matching those observed in the quantitative study (respondents agreed that plagiarism resulted from personal factors). Both VN- and NZ-educated students said that having many things going on at the same time might lead to intentional plagiarism. In their views, the more work students had to complete in a period, the more likely they would plagiarise. 
NZ-educated students highlighted external influences from friends, lecturers, and universities. For example, Frank pointed out that there might be peer pressure - to not fail or to get a high mark - which he called the competitive nature of academic work. For Emma, the pressure could be higher expectations from lecturers for senior students.

VN-educated participants said that pressure might include parental and academic expectations. They thought Vietnamese education put a lot of emphasis on achievement. Linh and Victor asserted that for Asian students, especially Vietnamese students, the pressure on students to obtain good grades was heavy. Similarly, Trung underlined that Vietnamese students had to study irrelevant courses with many forms of assessments:

In my experience, students need to take many unrelated courses (e.g., Philosophy, Political Economy, and Psychology). The workload is heavy, with too many forms of assessment: tests, assignments, presentations, and written exams. (Trung, Int2)

Most VN- and NZ-educated participants thought students were more likely to plagiarise when they were behind schedule, especially when they had poor time management skills. This result supported the quantitative result where most respondents disagreed with the idea that time constraints did not influence student plagiarism.

They take ideas from other papers so that they don't have to read. Because they cannot come up with anything new within that period, they start looking for similar papers to pick up something here and there. (Linh, Int2)

If you've got a limited amount of time and you've got other pressures and whatnot and the option is there, that can cause people to sort of like it's ok if I just copy a little bit of this or get this to get me started. (Solace, Int2)

Similarly, Darshana, Sunny, and Trung believed that disorganised students left things to the last minute and plagiarised as a result because time constraints limited students' ability to think about assignments or to invest mental effort. Trung said that master's students in Vietnam were given a short period of time to do courses and thesis, which might lead them to plagiarise.

Several (Darshana, Emma, Frank, Paddy, Trung, and Victor) mentioned the pressure students might face transitioning to Western institutions including new expectations, different teaching approaches, unfamiliar assessment types, and language barriers. They thought international 
students would meet a double layer of difficulty compared to domestic students because of having to deal with both new content and expectations:

Learning and adapting to a new environment and knowing what's acceptable and unacceptable would be a challenge itself. And doing the content as well. So, doing the actual coursework that you need to learn, as well as knowing the rules or guidelines. (Emma, Int3)

Darshana, while mentioning the extra layer of difficulty in terms of language barriers, suggested that many students plagiarised instead of putting in extra efforts:

It's like so much extra work to get to the same standard as someone like me who was born in New Zealand and speaks English as the first language. So, it's so much harder for some people to get the same standard, but for some people instead of putting in all the effort, it's so much harder to get, they would just plagiarise. (Darshana, Int4)

Three VN-educated students (Hoa, Trung, and Victor) stated that doing assignments in English would be challenging for those whose English was a foreign language in terms of both time and effort. For example, one asserted:

Writing in English takes many times as long as in Vietnamese, including moving back and forth between the two languages when processing ideas, choosing the right words, adjusting writing styles, and correcting grammatical and spelling mistakes. (Trung, Int3)

The NZ-educated students believed that international students might be particularly vulnerable to not understanding requirements because of differences in teaching and learning approaches between their home and host country. Paddy said:

Even a multiple-choice question or something that requires them to apply and reason with the knowledge they have learnt [...] they look at the question and say they don't have all the information to do that, because it isn't written down as the answers in the textbook or isn't said directly in the lecture. It's the case. It's not simply rote learning. (Paddy, Int3)

Ally and Frank asserted that plagiarism might result from variations in what would be counted as plagiarism and not plagiarism. They maintained that students from different educational systems might not identify plagiarism in the same way. 
Plagiarism results from a lack of commitment

For several participants, plagiarism was associated with student motivation, engagement, and commitment. They thought students who were motivated by qualifications rather than knowledge were more likely to plagiarise:

For those who know it's wrong and still do it, I think they're not really taking the education system seriously because maybe they just want to get the degree. (Darshana, Int1)

Some people probably don't want to be at university. They don't enjoy writing or the course. And they just want to get it done. Maybe they're more likely to plagiarise. (Ally, Int4)

Similarly, Frank and Trung believed that uncommitted students might not be inclined to invest time and energy into the topic. They thought some students were not interested in their studies and did not see the values of learning and acquiring knowledge.

\section{Plagiarism results from a lack of knowledge}

Most interview participants believed that sometimes students plagiarised without knowing what they were wrong. This is consistent with the survey result where most survey participants agreed that students plagiarised because they could not tell what was or was not plagiarism. Many interviewees thought a good person with inadequate knowledge of plagiarism might plagiarise accidentally. Overall, more VN-educated than NZ-educated participants held this view, matching the survey finding that $\mathrm{VN}$-educated students were more likely to perceive a lack of knowledge and skills as causes of plagiarism than NZ students.

Many of them would think if they don't take a word, sentence, or paragraph from others, then it's fine. And they think if they have the idea, and they read papers that have the same idea, then it's because they have similar ideas rather than they copy from others. (Linh, Int3)

Some forms of plagiarism are not necessarily deceitful but probably more unintentional, and [...] there's a confusion around the rules. (Paddy, Int2)

Some participants thought plagiarism resulted from self-awareness and students who were conscious about possession of knowledge would not plagiarise. Trung stated that sometimes students were unaware of the seriousness of plagiarism. Similarly, Solace said: 
They don't understand how big of an issue it is to make sure things are cited properly or if they get an image that's available for fair use and they don't understand that you still need to cite fair use images (Solace, Int2).

Most participants identified students' poor understanding of how to reference as a reason for accidental plagiarism, echoing the survey result where most respondents agreed that student poor understanding of citation and referencing conventions led to plagiarism. One said:

If you aren't academically like well-read, like you don't understand the format of how to cite, where citations go in or the structure of writing where you cite after you state a sentence or an idea from a particular person then it can lead to more plagiarism, especially accidentally plagiarism. (Solace, Int2)

Several students agreed that plagiarism was associated with academic writing competence which was aligned with the survey result where respondents agreed that student poor understanding of academic writing led to plagiarism. Many considered that students who were unfamiliar with academic writing, which encompassed not just vocabulary, but also citing and referencing, might plagiarise unintentionally.

In contrast, other students (Hoa, Frank, Linh, Paddy, Solace, Sunny, and Trung) argued that those who wanted to plagiarise would do so regardless of their academic writing competence. They stated that some people could write well and still plagiarised.

It's not just common with beginners. People who have been studying or writing for a long time still make mistakes. If they want to do it, they're gonna do it. (Sunny, Int2)

I think people can write well and still plagiarise. (Frank, Int2)

I don't think experienced people don't plagiarise. In fact, these people can do it more sneakily and professionally. And plagiarism in academia is not rare. (Linh, Int2)

Similarly, Paddy said that people who were good at writing might be better at plagiarising in sneaky ways. In contrast, Solace considered that people who had been in academia for a long time might still struggle with writing and referencing and thus plagiarise accidentally. 


\subsubsection{Participants' Views of Individual-Level Outcome of Plagiarism}

Interviewees indicated both immediate and long-term repercussions of plagiarism. Short-term consequences included immediate penalties, social judgement, and poor student-lecturer relationships. In the long run, plagiarism would impact student learning and future behaviours.

\section{Potential penalties}

The participants indicated disciplinary actions they believed to be appropriate for plagiarism, ranging from warnings, point reduction, failing a course, to expulsion. They emphasised that penalties would depend on the policies of each institution or country. If plagiarism resulted from ignorance, Ally, Darshana, Emma, Sunny, Solace, and Trung thought students needed warnings to realise their mistaken behaviour. Said Darshana:

The lecturers or course coordinators should sit down with her and have a proper talk about it, which would hopefully be enough, she wouldn't do it again. (Darshana, Int3)

With intentional plagiarism, the participants believed that sanctions should be imposed. Many believed that discipline was to prevent students from repeating their mistakes in other courses. However, if students contributed to the assignment, they should be marked for the part which was their own work. If they could redo the assignment, the highest grade for this second chance should be lower than if they completed it in the first place. Frank believed that student plagiarists should take responsibility for their behaviour and should not be marked as if they completed the assignments on their own:

To me, to be too lenient is to kind of encourage undesirable behaviours like a pattern or whatever. The circumstances don't force someone to plagiarise. So, I think if she does make that decision at some point to just copy another's essay, then if she was pulled up on it, there should be some types of repercussions for that. (Frank, Int3)

Most participants thought harsh punishments were suitable for serious violations. Those who had been taught about plagiarism and referencing but plagiarised blatantly were believed to deserve harsh punishments. For Solace, if students plagiarised intentionally, they should not get a passing grade for that assignment. Linh suggested that those who copied a major part of their assignment should get a zero grade. For severe intentional plagiarism, Sunny thought the results should be dismissed. Paddy said that for major plagiarism in important courses, students needed to retake the course and their future work should be checked: 
She has to retake that course if it's essential to her degree. And she's now under watch because she's known for plagiarising. So, you know, you check her future work and make sure that she does not plagiarise. (Paddy, Int3)

For repeated plagiarism, many participants said that students should not be allowed to take the course. If students were caught plagiarising in multiple courses, most participants thought expulsion should be imposed. For example, one said:

If it was something that a student did over and over and over again, perhaps that would justify expulsion, but I don't think I've ever heard of anyone being expelled for plagiarism, especially not at the undergraduate level. (Frank, Int3)

VN-educated participants would be extremely careful when disciplining student plagiarists. They thought lecturers could punish students only when the policies had been previously informed, confirming that the situations were complex in Vietnamese contexts:

In football, all players must know the rules before the game. We can't wait until they make mistakes to catch, explain, and punish them. It's unfair. It's very complicated in Vietnamese contexts, where there are no clear plagiarism policies. (Trung, Int3)

Similarly, Huynh, Linh, Trung, and Victor thought the lack of consistent policies made it hard for lecturers to address plagiarism. Lecturers could not punish students according to policies in Western institutions.

\section{Plagiarism worsens the teacher-student relationship}

Most participants maintained that plagiarism negatively affected lecturer-student relationships in many aspects. The finding was aligned with the survey result where most respondents agreed that plagiarism worsened teacher-student relationships. The first impact was a break of trust. One typical response was:

They trust that their students are good and doing the work properly. If people are copying and trying to say it's their own, it's kind of disrespectful, almost to the lecturer and the whole uni, because it's like they don't care enough to put in the effort and do their own work, they just go and steal people's ideas. (Darshana, Int2)

If Huynh found out that her well-performing students repeatedly plagiarised, she would lose faith in them. She thought not being able to catch plagiarism was bad for her image as well. Emma and Linh thought intentional plagiarism would negatively affect how they viewed the 
students. Although Linh would try to be patient, she envisaged plagiarising students thought she knew nothing about their behaviour:

I felt like they thought I didn't know what they were doing. But I would tell them gently that they shouldn't have done that or asked them where they took the information. If they continued to do so, it would affect how I thought about them. (Linh, Int2)

Paddy would feel upset and disappointed because students failed to understand and meet his expectations and disrespected his energy devoted to teaching them:

It's frustrating and you feel sad, you feel your efforts in teaching them are undervalued, cos' they haven't engaged with their work as deeply as you like, haven't put in as much effort as you like, and haven't seen the value of really trying to do the work. They've tried to get away with someone else's work. It makes you feel stunted and a bit mad. (Paddy, Int2)

Most participants affirmed that impacts of plagiarism would depend on intent levels. For example, while Sunny would think differently about those who had been taught about plagiarism but plagiarised intentionally, she thought accidental plagiarism would not affect the relationship at all. For her, catching plagiarism would be a chance to assess student knowledge to retrain or give them extra support.

\section{Plagiarism entails social consequences}

Many participants believed that plagiarism affected not only plagiarising students' attitudes and behaviours but also how other people looked at them and their work. Most VN-educated students emphasised the social effects of plagiarism. Victor stated that plagiarists would lose the trust of the wider community and plagiarism could negatively impact their position and lives. Hoa thought students would lose prestige and trust from others if their plagiarism was discovered. While Linh viewed plagiarists as being unreliable, she believed that student plagiarism would have less impact than academic plagiarism:

They will create a bad impression on other people. I think it's difficult for people in academia to accept those behaviours. So, if someone is caught plagiarising, it takes them a lot of time to be able to return to the position they used to occupy. (Linh, Int4)

Hoa believed that the social effects of plagiarism would depend on who looked at it. While some would judge plagiarised work, others would lose trust in plagiarising students: 
Easygoing people will not care much about it. They only think students were wrong at that time. But some may think students are bad because of their plagiarism. And people will not trust these students in whatever situations. (Hoa, Int4)

NZ-educated students, however, expressed their personal views of plagiarists. They thought plagiarism, if intentional, would make him question plagiarising students' scholarship and the quality of their academic work. Emma insisted that plagiarism would lessen her respect for the person's work and opinions although she could not speak for other people:

If I learned that my classmate was plagiarising, I wouldn't respect their work and views. But that's because I have such a strong view of it. Whether my students would care, I don't know. It depends on people's view and their educational system. (Emma, Int4)

Solace said that the magnitude of the effect would depend on specific intent levels. If students intentionally and maliciously plagiarised, he believed it would change what people thought about them. But if they plagiarised unintentionally, he thought it would change nothing.

\section{Plagiarism threatens student learning}

Most students believed that plagiarism diminished student learning opportunities, consistent with the survey result where most survey respondents agreed that plagiarising students would learn less. While NZ-educated students emphasised creativity and critical thinking skills, VNeducated students were mostly concerned about content knowledge loss. For example, Emma affirmed that when plagiarising, students did not progress through essential learning processes:

We take up courses, we take up papers, and we do assignments to learn. Part of that learning is being able to critique and think in your own words. That's not plagiarising. Like you've got to be able to put it into your own words, or at least cite the people, or give credit to the people that came up with the original ideas. (Emma, Int4)

Solace and Paddy were concerned about whether plagiarising students invested in their work the same way as when they completed it themselves. They said that plagiarism would affect their evaluation of student ability:

If a student plagiarised, you're unsure whether they're able to come up with ideas of their own, or whether they provided the same level of work as if they didn't. (Solace, Int4) 
Several participants believed that later in their life confronting a harder task, plagiarising students would find it challenging. Ally explained that students did not go through the process of thinking, whereas Darshana stated that they had been used to stealing other people's ideas. Hoa and Trung thought students who plagiarised did not interact with materials or spend as much time thinking about or working with the topic at the same level as non-plagiarising students. On the contrary, Linh believed that students who learnt and read a lot might plagiarise for various reasons although those who plagiarised repeatedly would acquire less knowledge.

\section{Plagiarism leads to fraud as a model of life}

Many participants were concerned about impacts of plagiarism on student subsequent practice if plagiarism was not handled. They worried that plagiarism might encourage deception, which they considered negative. Others said that plagiarism promoted a slack attitude:

If they think that's ok and get away with it, whatever job they're in, they might just kind of have flow-on effects from not being strict about these aspects, maybe when they have to write a proper report or something, they just don't reference properly. (Darshana, Int3)

Many students - Hoa, Huynh, Emma, Paddy, Sunny, and Victor - believed that students might develop a deceptive habit in their future lives - claiming someone else's work as their own which they found unfavorable.

I think if they're getting away with it, it might motivate people to be more dishonest in other areas, possibly. (Ally, Int4)

If that's done at an undergraduate level and not prevented then it exacerbates when people are becoming researchers themselves, then going into the workforce, and claiming people's ideas to be their own which is inappropriate, stealing, and lying. (Emma, Int3)

They will do it for the second, third, and fourth time. The degree will be higher. Deception is built up in them, not just in academia. (Hoa, Int3)

Other students feared that if students were not advised that they were wrong, they would keep plagiarising either in or outside academic environments:

Like, they feel it's not a big deal to deceive or take something from others. Or they think others are doing the same. (Hoa, Int3) 
Once people had that intention, it would probably become a habit or a systematic thought. When there's something to think about, the first thing people will do is going online to see if anyone talks about it, and they may use others' products. (Linh, Int4)

Similarly, Sunny believed that plagiarism formed a copying habit and that habit created personality which she referred to as an unhealthy lifestyle.

\subsubsection{Conclusion}

While viewing deliberate plagiarism as a moral and self-regulatory issue, interview participants considered accidental plagiarism part of the learning process. They indicated a range of factors contributing to intentional plagiarism including personalities, lack of self-awareness, and academic pressure. Most were concerned that plagiarism would lessen learning opportunities, lead to unhealthy habits both in and outside academic environments, and affect teacherstudent relationships. While most VN-educated students thought plagiarism affected wider communities' willingness to trust plagiarists, NZ-educated students believed that plagiarism created a bad impression about plagiarists and their future products.

\subsection{Framing of Plagiarism on an Organisational Level}

On an organisational level, interviewees were concerned about university's responsibilities in terms of plagiarism education and management. They viewed plagiarism as a form of academic cheating and scholarly offence. Many believed that plagiarism resulted from institutional failures and would diminish the value of tertiary education and the resulting degree. They were concerned about its impacts on academia both in terms of rigorousness and fairness. Figure 7.2 summarises the major themes.

Figure 7.2 Students' framing of plagiarism on an organisational level
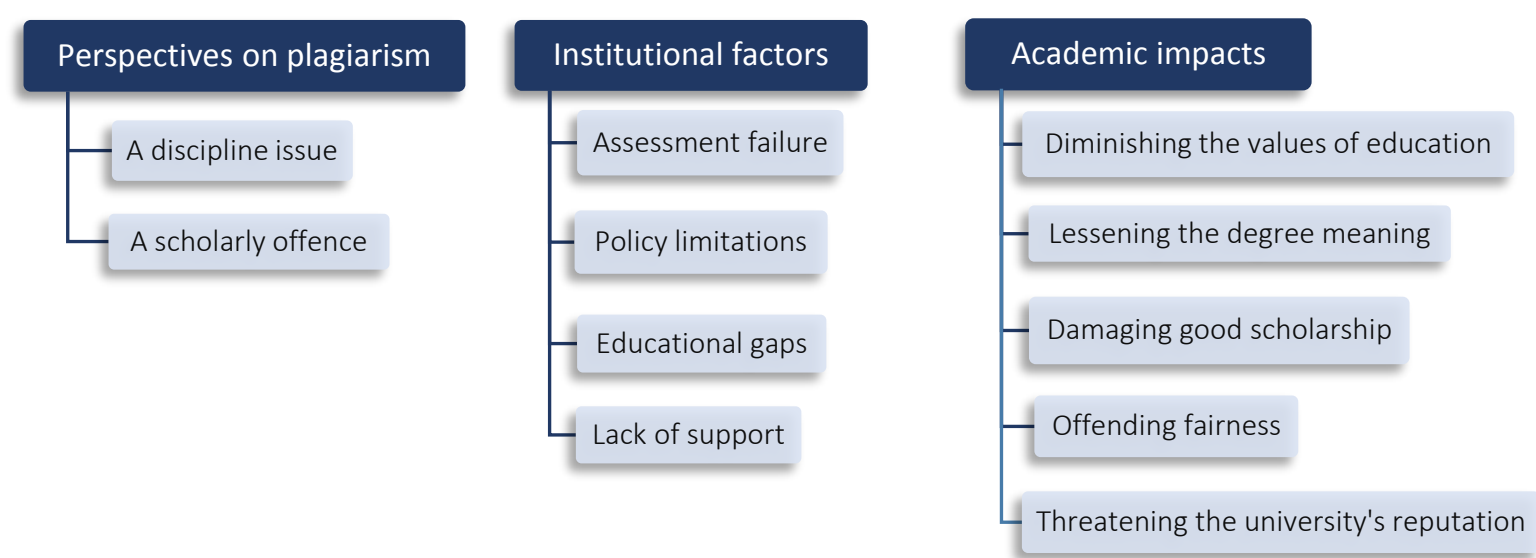


\subsubsection{Participants' Perspectives of Plagiarism at University}

Interview participants considered plagiarism both in learning and researching contexts. From the first domain, they treated plagiarism as a violation of institutional obligations. From the second domain, they viewed plagiarism as contrary to principles or expectations of academia.

\section{Plagiarism as a discipline issue}

Most participants (Ally, Darshana, Emma, Frank, Hoa, Linh, Sunny, Paddy, and Trung) perceived plagiarism as a breach of university obligations. Their comments supported and explained the survey finding where most respondents agreed that plagiarism was academically wrong. Interviewees noted that most plagiarists were aware of their behaviour and the consequences.

I think when people come to university, they really need to get a very clear idea from the outset. It's a regulatory issue in that the regulations have to be followed. (Ally, Int4)

Mostly, I'm gonna say it's the students who are responsible. The ones that are doing it despite the information, despite tutors, TAs, and lecturers saying don't do it. (Emma, Int2)

Many people understand it well but still plagiarise. I mean, people understand that something is wrong doesn't mean that they will not do it. (Linh, Int3)

Many believed that in the case of plagiarism with intentional deception, students did not take regulations seriously and they knew exactly what they did but concealed their behaviour and hoped not to be caught. Darshana and Hoa said about such students:

They're trying to be sneaky about it or they use a friend's assignment and then just change something, or paraphrase but don't use a citation. (Darshana, Int2)

They know they're not allowed to plagiarise but they're too lazy to do the work. They copy from someone else and modify it so that they will not be caught. (Hoa, Int2)

Others considered deliberate plagiarism as a choice which meant plagiarising students were aware that they broke the rules. Frank asserted that a combination of factors might increase the chance but did not force someone to plagiarise. Darshana and Emma maintained that students could avoid plagiarism. Sunny and Hoa stated that student plagiarists knew that they were plagiarising but did not want to complete the work by themselves. 


\section{Plagiarism as a scholarly offence}

All NZ-educated and two VN-educated students (Linh and Trung) believed that plagiarism was against knowledge contribution and thus unacceptable in academia. Darshana argued that in an academic environment, there was no room for any deceptive acts including plagiarism:

Academia is about knowledge, finding out new things, and forming ideas. That can't come from a place of any kind of deception or stealing. Otherwise, it's not a good foundation. It has to come from a place like you use other people's ideas and say that you use them. (Darshana, Int2)

Frank explained that reflexivity, which was essential in academic work, was absent when people plagiarised because plagiarism demonstrated a non-reflective approach.

Perhaps, it comes back to the value of truthfulness, that type of thing, much more underlying implication for society. And then within the university, the production of genuine scholarship is important. (Frank, Int3)

Some said that by plagiarising, students appropriated other people's contributions to the area. They thought plagiarism hindered original contributions to knowledge, which was an integral part of academic work:

You come up with an original idea, some original products or, you know, thoughts or something like that. And all a sudden, someone else is taking that and presenting it as their own, and all that work, that sweet, that effort that you put into creating that has been taken away. (Solace, Int3)

It's academically wrong because, in academia, the original contribution is important. Copying from someone else's isn't original. (Trung, Int2)

It contradicts some of what I consider to be fundamental aspects of the academy and research, and that type of thing, and the production of knowledge. (Frank, Int4)

Trung thought academic integrity would make student work and degree more valuable. He believed that research students needed to develop their own voice as opposed to plagiarism.

\subsubsection{Participants' Views of Institutional Factors Associated with Student Plagiarism}

Most participants - Ally, Darshana, Emma, Huynh, Linh, Paddy, Solace, Sunny, and Trung underlined the function of higher education institutions in preparing students to be qualified employees or academics. They thought the process should include training about plagiarism 
because children did not go to school knowing everything. However, they observed that sometimes universities inadvertently created opportunities for student plagiarism.

\section{Plagiarism results from the assessment process}

Frank, Linh, Solace, Sunny, and Trung said that plagiarism happened in part as a result of gaps in the assessment system. The assessment procedure might create opportunities for plagiarism when teachers failed to state their content or plagiarism requirements. Trung exemplified how the open exam format, popular in Vietnam, exacerbated plagiarism:

In subjects like philosophy or essay writing, students could use materials during tests or exams. But no lecturers explained how they should use the materials, whether they could copy exactly from the documents, or had to paraphrase and quote them. The university facilitates plagiarism by having no clear regulations or explanations. (Trung, Int3)

Some students highlighted the role of assignments in arousing student interest and stimulating them to invest time in their work, giving explanations why survey respondents agreed that students did not plagiarise when assignments were interesting and personalised. For Linh, assigning tasks that students got a sense of what they were about to write would reduce their tendency to copy. Ally, Darshana, and Hoa, however, disagreed with impacts of interest levels on plagiarism. They considered that plagiarism was related to awareness or what students thought to be important but not the assignment itself.

\section{Plagiarism results from detection failure}

Half of the survey respondents agreed that students did not plagiarise when there was a high chance of being caught. Across the interviews, both VN- and NZ-educated students - Emma, Frank, Hoa, Linh, Paddy, Solace, and Trung - stressed the role of detection systems. Ally said:

If one of your tutors is talking a lot about plagiarism and not doing it, and it would be more likely to get caught in this class, you definitely won't do it in that class. (Ally, Int2)

While agreeing that the chance of being caught might impact student decision to plagiarise, Solace was concerned about lecturers' willingness and readiness to check for plagiarism:

When there's a high chance of being caught, and the students know it, there's a huge disincentive to plagiarise. The problem is that it's dependent on how much effort the marker or examiner is going to put into it. (Solace, Int2) 
Plagiarism results from policy limitations

Another factor contributing to plagiarism according to most participants was policy limitations. According to Frank, the lack of a plagiarism policy was undesirable because students might take advantage of it when they were under pressure. Emma, Hoa, and Linh said that even when plagiarism was detected, some would continue plagiarising if they knew that there was no sanction or punishment to be imposed. Hoa, for example, commented:

If teachers warned students, they would be afraid. But if teachers said nothing, or students knew that other students could get away with it, they would do it. (Hoa, Int2)

All VN-educated students drew attention to policy limitations in their Vietnamese institutions, stating that Vietnamese students plagiarised because of not being informed of policies. For example, Trung said that many universities in Vietnam inadvertently supported plagiarism by not giving clear rules or guidelines. According to Victor, because teachers encouraged students not to plagiarise but had no clear policies to support this, it was then hard to handle plagiarism.

\section{Plagiarism results from educational gaps}

Another factor that exacerbated plagiarism according to many participants was the lack of education both about plagiarism and how to avoid it. Paddy noted that most high schools did not teach students about these issues but allowed copying and pasting from Wikipedia:

Because they haven't been necessarily taught that it's not the best practice. Their way of constructing an assignment learnt through high school may have been to copy and paste and then reword something from Wikipedia. (Paddy, Int2)

Hoa and Trung highlighted that the length of time students at university was less important than whether they had been taught about plagiarism. Hoa said:

When plagiarism education is not emphasised, it doesn't matter if they have studied for a long time or have just started. If they study at a top tier university, where people say right from the beginning that plagiarism is not okay, they won't do it. (Hoa, Int2)

Linh, who completed her master's overseas, insisted that student attitudes and behaviours were impacted by surrounding environments. Specifically, if people were not taught about plagiarism, or accepted it silently, they would produce students who would silently and calmly 
steal someone else's work. She thought educators should create a learning environment where students developed their understanding and appreciation of academic integrity:

A child who just started school was unaware of plagiarism. If they're in an environment where adults allow and tolerate copying, then they find it acceptable. Teachers need to create an environment where students realise that the action is unacceptable. (Linh, Int4)

Sunny thought sometimes academics were negligent in their provision of plagiarism training:

There's a lack of training on that issue. No one shows them what plagiarism is. Not many students understand it well, except for those majoring in Linguistics or Humanities. Those majoring in like technology may have fewer opportunities to learn. (Sunny, Int2)

The idea of equity in education was raised by Ally and Trung, who considered universities as being responsible not only for teaching but also for making sure that all students had the same level of understanding.

The university is responsible for making students all have the same knowledge and level of understanding. They can't say that students can learn by themselves. If it's possible, Western universities don't have to embed it in orientations or course outlines. (Trung, Int2)

Trung said that apart from transferring subject content knowledge teachers should show students what was right or wrong. They should also have clear instructions and rules.

\section{Plagiarism results from a lack of support}

The university was believed to be responsible for providing students with general support to maximise their learning experience. However, the participants believed that some students struggled both within and outside academic settings which might affect their well-being and academic performance, and not many made good use of support services. Frank considered that students might encounter difficulties navigating university lives and could not keep personal circumstances out of academic life:

Someone is struggling outside of universities. There should be some types of professionals that they can see in order to get help. Because there's no doubt that these types of things impact someone's work. (Frank, Int3) 
In Interview 4, Frank emphasised that students might plagiarise due to lack of support from their current university or lack of confidence in seeking additional help. Similarly, Paddy thought students should be provided with appropriate skills to avoid plagiarism:

They need to give them the tools to be able to go about it. I think sometimes people plagiarise, for example, they're just quoting something. Maybe they don't have the tools to interpret it and use it much. (Paddy, Int2)

The participants pointed out that teaching staff should give students accessible resources. For Ally, teachers should inform their students about what would or would not be counted as plagiarism, why they should not plagiarise, and the consequences.

\subsubsection{Participants' Views of Academic Impacts of Plagiarism}

At an organisational level, most participants believed that plagiarism was contrary to the core purposes of tertiary education. Some thought plagiarism lowered the meaning of a degree which subsequently affected the prestige of the academic institutions. Many participants considered it a hindrance to students' ability to produce good scholarships.

Plagiarism diminishes the value of education

Most students viewed plagiarism as opposed to the general objectives of tertiary education. They said that students should show a certain level of capability to be awarded a degree:

Whatever industry as I'm assuming, you need people if they finish, say a master's or doctoral level, part of their degree means to say that they're capable of taking new information, understanding it, working with it, and arguing for some conclusions. (Paddy, Int3)

The participants maintained that the sole objective of assignments and marking was to assess student abilities. Therefore, if they plagiarise, they should not pass the course. They believed that the quality of a university was dependent on the validity of the assessment process:

If many students plagiarise, the quality of education at that university will surely decrease dramatically. It shows that the university doesn't care about evaluating students' work but just lets them copy freely. (Linh, Int3)

Several participants (Ally, Darshana, Emma, Paddy, Solace, Trung) confirmed that plagiarising students failed to engage in intellectual activities. They thought the primary aim of assignments 
was to get students to learn and expand their capacity to critique and write in their own words. Therefore, plagiarism would diminish the values and outcomes of higher education.

\section{Plagiarism lessens the degree's meaning}

Many interview participants believed that plagiarism would reduce the degree value. This result was consistent with the quantitative finding where most respondents agreed that plagiarism damaged the degree's meaning. For them, a degree acted as a marker of student products and plagiarism meant that students had not invested time and efforts as expected:

If you're really generating the ideas yourself, that makes the degree more meaningful, because the degree just means to be the marker of the work you've done. So, if you're plagiarising, it requires less work, so the degree is less meaningful. (Paddy, Int2)

Solace said that plagiarism would lessen the magnitude of the degree because students could not complete the work if not plagiarising. Similarly, Trung viewed a degree as a measure of student competence; when an unqualified student got a degree, he considered it as invalid:

When students graduate with a degree, it means they have acquired a certain level of knowledge and reached a certain level of thinking. If they graduate by plagiarising, the degree is invalid because students are not at that level. (Trung, Int3)

Linh thought the degree should correctly reflect student knowledge, skills, and experiences. Sunny viewed it as a certification for their progress. When a plagiarising student was awarded a degree, she found it meaningless because it represented nothing.

\section{Plagiarism threatens university's reputation}

Darshana, Frank, Huynh, and Linh thought plagiarism would damage university's prestige. They reasoned that an institution needed to ensure that they produced competent students. They thought serious plagiarism incidents might be reported by the media and created bad impressions about the university:

If it's something that serious enough to get out into the media, then it's going to reflect badly on the university in a much wider sense. So, I think that's why they try to ensure their scholarly quality and also public image. (Frank, Int3) 
Some thought plagiarism created poor images of students at that university and academics who let students pass easily. They believed that the situation got worse if multiple student plagiarists were discovered being awarded doctoral degrees from the university.

\section{Plagiarism damages good scholarship}

While supporting the idea of knowledge and quality loss, several students affirmed that a university that was strict on plagiarism would produce better scholars and staff members in terms of competencies, proficiency, skills, and work ethics:

If you're not hard on plagiarising, then you have people who are going into the workforce that haven't thought critically, haven't considered the ramifications of what they're doing, or haven't worked hard. Whereas if the universities, teachers, and institutions are hard on plagiarising, they produce better researchers and employees. (Emma, Int2)

For the students, plagiarism would prevent students from contributing to quality academic work. They considered plagiarism or reproduction as opposed to the scientific domain where people were supposed to contribute knowledge to their field. One said, for example:

Science means creating something new, so later studies must expand the earlier ones. If an educational system is based on reproduction, it doesn't have anything new. (Linh, Int3)

Darshana remarked that while the university wanted to produce graduates who were able to do rigorous research and knew the correct way to write, plagiarism impaired student competencies and skills. For Frank, plagiarism countered good scholarship and contradicted fundamental aspects of academia, research, and production knowledge. He thought writing with integrity would help to generate ground-breaking ideas:

There's a degree of integrity or being honest about your work. Hopefully, ideally, it would lead to the generation of new innovative ideas. If you take plagiarism seriously, you're potentially gonna be compelled to come up with your own original ideas. (Frank, Int4)

Beyond that, the participants thought not plagiarising required students a lot more time and energy which made their work worthier. That value would be undercut if they plagiarised:

Not plagiarising, you have to generate the work yourself and that requires as much more depth of processing. You have to genuinely grapple with the ideas and then squeeze them out piece by piece to the paper. That process is what makes academic writing hard and valuable in the abstract. (Paddy, Int3) 


\section{Plagiarism offends fairness}

Most VN- and NZ-educated believed that plagiarism at all levels led to unfairness. At the undergraduate levels, they thought plagiarising students invested less time and energy compared to those who completed the assignment on their own. At the postgraduate levels, many asserted that original authors were denied the credits, authority, and respect they deserved. Solace considered appropriating other people effort and credit as a "travesty":

If somebody has put a lot of effort into something, then someone else comes along, takes it, and gets the credit the original person deserves, I think that's a travesty. (Solace, Int4)

Most students thought unfairness was reflected in the evaluation and recognition of student effort. Therefore, student plagiarists gained advantages they did not earn or deserve because of not spending time and energy.

People, for example, get a job based on the fact they got a degree and they're getting it over someone who doesn't have a degree then it becomes kind of unfair if they sort of cheated through their way. (Ally, Int3)

Several students indicated that in short term, plagiarising students got the grade and passed. They passed university requirements, which technically meant that they were academically good when they were not. The participants thought when college graduates entered the job market, plagiarising students did not possess the same skillset and competence as nonplagiarists although their degrees might be seen as equal.

\subsubsection{Participants' Suggestions on How to Prevent Student Plagiarism}

While considering plagiarism as part of the learning process, many participants believed that interventions needed to be early; if not, students at higher levels would not realise the seriousness of plagiarism. Most students thought universities should not overestimate student understanding, especially at the beginning, because they came from various backgrounds. They believed that apart from providing students with basic knowledge about plagiarism, giving them skill sets to not plagiarise, and imposing harsh penalties, the university needed to catch plagiarism as it arose. Ally considered integrating plagiarism materials into tutorials and talks as more efficient than including them in handbooks and policies: 
The policy is boring. It's just a bit of information on some papers. It's not engaging at all. It would be much more engaging if it was taught by a tutor or a lecture, or even a student adviser, like just a human rather than just a thick thing of policy and guidelines. (Ally, Int3)

Ally emphasised that education was more efficient than punishment in the case of plagiarism:

You can teach students by showing them how to do it right and explaining thoroughly how to reference and why plagiarism is unfair. If you just threaten them with the punishment of what happened in the past, they're not going to learn anything. (Ally, Int3)

Frank thought students needed professional help and advice on personal matters because their well-being impacted their academic performance. Paddy suggested what he called a strengthbased approach - teachings about plagiarism and benefits of correct practices:

Explains not just that it's the rule and why you shouldn't plagiarise, but why you should actively seek to not plagiarise, why you should actively seek to cite and reference. Because it helps structure your work, it helps recognise your sources, and that is actually a really useful thing that makes your writing better. (Paddy, Int3)

Hoa, Linh, Trung, and Sunny asserted that plagiarism education should be offered the start of the degree programme. They suggested including real-life situations to facilitate learning:

We can give them real situations or scenarios and ask them if they think it's plagiarism and how they would do in the situation. There should be more training because the theory is vague and abstract. (Sunny, Int3)

Two VN-educated students (Victor and Trung) focused on the implementation of policy and detection procedures. They thought there should be clear plagiarism policies before punishing students and highlighted that plagiarism education needed to be consistently enforced.

\subsubsection{Conclusion}

Overall, more VN-educated than NZ-educated participants considered plagiarism as an institutional issue. However, NZ-educated participants talked about plagiarism as hindering valuable academic work and original ideas more than their VN-educated counterparts. While NZ-educated students discussed the issue broadly, the VN-educated students illustrated gaps in assessment processes, lack of detection, and limitations of plagiarism policy in their homeland universities. Both groups believed that education played a major role in improving 
students' ethical awareness. They thought plagiarism would impair the value of education, threatened the university's reputation, and offered plagiarists benefits they did not deserve.

\subsection{Chapter Summary}

This chapter has described interview participants' views and understanding of plagiarism. While all NZ-educated students obtained explicit plagiarism education previously, most VN-educated students indicated that teaching about the issue was little emphasised in Vietnam. The VNeducated students who pursued master's degrees in Western countries learnt about plagiarism from their overseas institutions. While most VN-educated students considered plagiarism as an institutional issue, the NZ-educated students found plagiarism a scholarly offence.

The next chapter explores how students developed their perceptions through describing pastestablished influences, current and on-going influences, and influences of future aspirations. 


\section{Chapter 8 | Influences on Student Perceptions of Plagiarism}

\subsection{Introduction}

Chapters 6 and 7 present interview participants' views and understanding of plagiarism. This chapter discusses how their perceptions were shaped and developed, drawing on Bourdieu's (1977) cultural capital theory, Bandura's (1991) social cognitive theory of moral thought and action, and Marginson's (2014) self-formation theory as appropriate to specific participants. Although findings that aligned with each theory are presented separately, there is a degree of overlap among different factors. Section 8.2 describes influences on individual participant's perceptions. Section 8.3 presents influences on student perceptions from a cultural capital perspective, focusing on parental strategic interaction, educational backgrounds, and personal experiences with plagiarism. Section 8.4 focuses on environmental factors highlighted by social cognitive theory of moral thought and action, featuring how professional roles and experiences, disciplinary practices, and doctoral environments affected student perceptions. Section 8.5 describes influences on student perceptions that are aligned with student self-formation theory. Section 8.6 concludes the chapter and introduces the next chapter.

\subsection{Influences on Individual Participants' Perception}

This section summarises key personal perspective features that best illustrate how influences on perceptions of individual student were consistent with each of these theories: Bourdieu's (1977) cultural capital theory, Bandura's (1991) social cognitive theory of moral thought and action, and Marginson's (2014) student self-formation theory. Full information about interview participants' profiles and perceptions is presented in Chapter Six: Individual stories.

\subsubsection{NZ-educated students}

Influences on Ally's perception resonated with social cognitive theory of moral thought and action. Her tutoring in tertiary education, which exposed her to undergraduates' limited knowledge of referencing conventions, led to her deep understanding and lenient attitudes towards their plagiarism. She insisted that plagiarism was not "the worst thing in the world" because mostly it would not actually "harm anyone". However, she made a clear distinction between plagiarism at different academic levels, saying that it was impossible to "put it black 
and white". She considered plagiarism of academics as unacceptable because she thought people "should be given credit" for their time and efforts.

Darshana's perception was strongly impacted by familial upbringing. The source of cultural capital that she possessed was parental strategic interaction, which is consistent with Lareau's conceptualisation of cultural capital theory. Darshana's harsh view of plagiarism resulted from her parents" "being quite strict about academic performance", their focus on "following the rules", and their emphasis on "strong work ethics". Her perception was also influenced by her tutoring and lecturing experiences, which gave her better insight into undergraduate plagiarism and reasons for its occurrence. However, understanding that there were different sources of academic support within the university, she insisted that plagiarism was mostly student fault because they should seek help rather than plagiarising. This view was related to what Darshana learnt from her parents about working hard and studying with integrity.

Influences on Frank resonated with Marginson's theory because he was the best illustration for associations between academic identity and plagiarism perceptions. He started his doctoral studies because of his passion for research and desire to develop his capacities. Frank wished to become an academic to cultivate critical and reflective thinking in students. He emphasised knowledge production within academia and viewed plagiarism as countering good scholarship, key to his emerging academic identity. He said that plagiarism would make him question plagiarists' scholarship and the quality of their academic work. Frank's perception of plagiarism was partly influenced by his professional roles, aligned with Bandura's social cognitive theory of moral thought and action. As an experienced tutor, he sympathised with undergraduate plagiarism, understanding that they went to school for learning and not all mastered citations and referencing techniques. He insisted that plagiarists were not necessarily bad because multiple factors could lead to plagiarism.

Influences on Emma's perceptions of plagiarism resonated with social cognitive theory of moral thought and action and partly with cultural capital theory. Having experienced the publication process, she emphasised academic contexts within which academic work existed and how plagiarism impacted original writers. As a tutor, she found plagiarism unacceptable because plagiarising students did not work with information or critically think about it. She believed that students should develop their abilities to think analytically, write critically, and synthesise the 
literature. As a victim of plagiarism, she felt strongly about it, saying that it was insulting because it meant "taking someone else's hard work and saying that it's yours".

Paddy's perception was impacted by his academic identity construction, a key aspect of Marginson's theory of student self-formation. As a PhD student and an experienced academic writer, he made a lot of effort to produce good academic work and contribute to his field. He viewed plagiarism at research levels as dishonest and reasonably grievous. He thought plagiarising students should not "be rewarded for other people's work". Influences on his perception were also consistent with social cognitive theory of moral thought and action. As an experienced tutor, Paddy considered student plagiarism as undesirable. He thought plagiarising students did not work with materials as much as if they did not plagiarise and their processing level was much shallower. He was concerned that many students poorly understood plagiarism as well as citation conventions. Drawing from a course he attended in his discipline, he promoted a strength-based approach to plagiarism which involved teaching students the positive and giving them some tools off. He believed that when students understood why they needed to cite; they could not only avoid plagiarism but also become better writers.

Solace primarily developed his perceptions through disciplinary and professional contexts, as conceptualised by social cognitive theory of moral thought and action. Majoring in computer science, where the notion of plagiarism was interpreted quite differently from other disciplines, Solace repeatedly emphasised that plagiarism was a morally grey area. Because borrowing and reusing code was acceptable and happened frequently in his discipline, he believed that looking at other people's work was "a fundamental concept in how people learn". As an experienced tutor, he thought poor understanding of citation and referencing might lead to inadvertent plagiarism. Having encountered several plagiarism instances by his students, he emphasised the role of universities and lecturers in managing and preventing student plagiarism. As a doctoral student, he considered academics' plagiarism as unethical because it meant "taking attribution away from original creators".

\subsubsection{VN-educated students}

Linh demonstrated a strong sense of student agency, a central concept of Marginson's (2014) self-formation theory. She started her PhD because of her passion for research and her aspirational identity as a researcher. Through her PhD, she was committed to developing her capabilities and worked hard to achieve her aims. Linh considered plagiarism by doctoral 
students as "a calculated moral behaviour of an intellectual person" which was unacceptable in academia. As an emerging researcher, she thought plagiarism would affect not only original authors but also plagiarists. Influences on her perceptions were also aligned with Bandura's social cognitive theory of moral thought and action. Lecturing helped her understand reasons for unintentional plagiarism. She believed that education would enhance student awareness because few students could deal with the complexity of writing conventions.

Influences on Trung's perceptions were mainly consistent with Marginson's self-formation theory. As a doctoral student, Trung understood his position in the academic community and worked hard to be part of it. Trung viewed plagiarism as contrary to an original contribution, which he considered fundamental in academia. He thought academic integrity would increase the value of a degree and plagiarism would negatively affect the quality of teaching and learning. He actively advanced his academic knowledge and skills to be able to attain his aspirational academic goals. He paid attention to find his writing voice and style. Among the VN-educated participants, Trung showed the greatest perception shift and most significant awareness increase during doctoral enrollment. His perception of plagiarism was also impacted by his lecturing experiences, aligned with Bandura's social cognitive theory of moral thought and action. He understood reasons that led to undergraduate plagiarism which made him hesitant to judge them as immoral. Lecturing showed him that many students were unaware of plagiarism and its forms and that many plagiarised due to gaps in education, unclear assessment design, and limitations in plagiarism policies. Therefore, he hoped to help them improve their understanding of academic conventions to become better learners and writers.

Influences on plagiarism perceptions of Hoa, Huynh, Sunny, and Victor were in line with Bandura's (1991) theory. Their perceptions primarily resulted from their lecturing roles and disciplinary practices. Among these four students, Sunny reflected more about her lecturing career, and how it led to her view on plagiarism. Despite having fewer teaching experiences, Hoa's perception was partly influenced by her lecturing career. Huynh and Victor's experiences of completing their previous postgraduate degree overseas helped them understand differences in the way different educational institutions enforced plagiarism policies.

\subsubsection{Conclusion}

While Bourdieu's (1977) cultural capital theory and Marginson's (2014) student self-formation theory each could explain experiences and attitudes of some students, influences on 
perceptions of most students were consistent with Bandura's (1991) social cognitive theory of moral thought and action. Also, Bandura's theory and Marginson's theory were more applicable than Bourdieu's theory to explain experiences of VN-educated students. However, Bourdieu's theory was useful in explaining differences in perceptions of VN- and NZ-educated students in several aspects such as the level of complexity with which they viewed plagiarism and their understanding of institutional factors for student plagiarism, which will be discussed in the following sections.

\subsection{Influences on Student Perceptions from a Cultural Capital Perspective}

According to Bourdieu's (1977) theory, cultural capital comprises resources and advantages which derive from and provide continued access to higher social status. People coming from privileged social groups would be more academically successful and have more opportunities for educational attainment than those from lower socioeconomic backgrounds.

Over nearly four decades of its existence, Bourdieu's signature concept has been expanded and elaborated. Research that employed Bourdieu's theory split into three streams: DiMaggio's high culture, Lareau's strategic interaction, and Collins' ritual interaction and cultural capital branches (See Chapter Three: Theoretical framework). Recent scholars in the field of plagiarism consider knowledge about plagiarism, academic skills, understanding of citation conventions, and the abilities to discuss the complexity of plagiarism as part of individuals' cultural capital (Howard, 2011; Kang \& Glassman, 2010; Riazantseva, 2012; Strangfeld, 2019).

This section describes types of cultural capital identified from the analysis and discusses their influences on student perceptions of plagiarism. These types of cultural capital are categorised to ascertain which conceptualisation of cultural capital they aligned with. All these factors were brought to student doctoral studies from their past experiences and were stable in nature.

While Bourdieu (1986) proposed three forms of cultural capital: embodied, objectified, and institutionalised, cultural capital that emerged from the data was mainly embodied. I used the term "cultural capital" to refer to knowledge and skills developed through parental concerted cultivation, educational histories, and individual experiences with plagiarism, and existing moral values and standards, which were established through cognitive development and experiences. Such knowledge and skills served as resources that contributed to student capacity and confidence to deal with the complexity of the issue of plagiarism. They also helped students to 
provide deep and broad explanations for plagiarism by other people. Therefore, students with higher levels of cultural capital were confident in dealing with the complexity of plagiarism, not just its basic moral features; each student cohort possessed distinct cultural capital.

However, because the three theories are not mutually exclusive and boundaries between them overlap, although the influences discussed above are framed primarily using the ontology of Bourdieu, they have aspects that relate to the other two theories.

\subsubsection{Parental Strategic Interaction}

The interview data indicated influences from academic backgrounds, a form of cultural capital, and the agency of parents on student understanding of plagiarism. There were two students (Darshana and Linh) whose parents not only placed high academic expectations on them but were also actively involved in their academic and moral development. Specifically, these parents deliberately oriented their children's academic paths and set moral standards for them to follow, attempting to align their home practice with the requirements of their children's schools and universities. Through the interviews, it appeared that these two students gained clear moral standards and perspectives early in life.

The strongest evidence was in the case of Darshana, an NZ-educated student, whose tertiaryeducated parents were focused on her academic success since her childhood. They engaged in Darshana's academic life by collaboratively deciding on her academic courses when she was in secondary school. They expected her to study hard and with integrity. They had a plan for her career after her undergraduate studies. In the first meeting, Darshana credited her academic success to the way she was parented and her parent's expectations for her. Their strictness about following the rules and academic success helped her develop an awareness of plagiarism early. It also played a crucial role in the formation of her harsh view of plagiarism:

It's possibly because of my parents' academic backgrounds and being quite strict about academic performance and studying hard. I just never even thought about that and made sure that I followed rules about referencing because the focus on getting good grades and doing well means following the rules. (Darshana, Int1)

Darshana's parents' academic backgrounds, involvement, and the expectations they placed on her provided her opportunities to gain moral standards relevant to plagiarism. The pressure she experienced as a child for high academic achievement helped Darshana understand that 
other students could be under constant pressure from their family for them to achieve good results, which she believed might lead them to plagiarism. While Darshana thought parental expectations might lead to behaviours which could be inconsistent with their values and detrimental to their aims, she highlighted that her parents promoted good work ethics. While expecting her to perform well at school, they emphasised the values of working hard and with integrity. From them, Darshana learnt that achievement should be obtained by endeavour:

From my family, it's like pressure to do well, but also good work ethics. Working hard is always promoted, work hard to do well, work hard to get what you want, don't cheat to get what you want, you have to put in a lot of effort and time. (Darshana, Int4)

Another less significant but related example of cultural capital influences was Linh, a VNeducated student, whose parents' involvement and support for her education significantly impacted her academic path. Her father, who possessed a tertiary degree in the English language, taught her English when she was a child. Linh's parents directed her towards becoming a teacher of English and pursuing postgraduate studies:

My parents wanted me to do a degree in the English language. My father taught me English when I was a little girl. They expected me to become a teacher of English [...]. They also want me to have a stable position in my career, so they supported me to pursue a master's program. (Linh, Int1)

Also, in Linh's family, there were rules that she had followed since childhood:

From my parents, I learnt to be disciplined, neat, and tidy. I was not allowed to come home late. And there are certain times that everyone in the family must be at home. [...] I was also expected to study hard and with integrity. (Linh, Int2)

While the rules she mentioned were not necessarily about plagiarism or other forms of academic dishonesty, her familial values about the importance of integrity partly influenced Linh's view in that since secondary school she considered plagiarism an unacceptable practice.

\subsubsection{Educational Background}

In this study, student educational history was treated within the ontology of Bourdieu because past educational experiences are stable in nature and assist in explaining their perceptions of complex moral issues. Knowledge and skills students gained through their academic histories gave them the confidence to discuss the complexity of plagiarism. 
This form of cultural capital was found to impact students' perspectives of plagiarism in multiple ways. Plagiarism knowledge gained from previous academic institutions decided the level of complexity at which students understood plagiarism. The educational institutions that they had attended helped them understand constraints in plagiarism management in their home universities. Also, student educational experiences showed them disparities in how institutions in different countries dealt with the issue.

\section{Prior plagiarism education}

As presented in Chapter Seven, VN- and NZ-educated students brought diverse cultural capital to doctoral studies, including prior knowledge about plagiarism and educational experiences at secondary and tertiary levels. Interview participants reported receiving diverse levels of plagiarism education before their studies at VUW. While NZ-educated students and the VNeducated students who studied overseas reported being taught explicitly about plagiarism, solely VN-educated students said that their previous universities did not emphasise plagiarism education. Learning opportunities offered by Western institutions, especially NZ universities, could be viewed as advantages compared to those provided by Vietnamese educational systems. At the start of their PhD, NZ- or VN-educated students with overseas study experiences were more familiar with and aware of university standards and expectations regarding plagiarism and academic integrity.

Variations in plagiarism education led to differences in attitudes towards the issue. While most VN-educated students showed basic understanding of the concept, all NZ-educated students were aware of its underlying complexity. Also, in the survey, several forms of plagiarism were rated less seriously by VN- than NZ-educated students. (See Section 5.5.1)

The findings revealed that VN- and NZ-educated students experienced different educational systems and brought with them diverse individual experiences as learners. Darshana's education at school and tertiary levels, which focused on critical thinking and creativity, shaped her view towards direct copying:

The way I was brought up academically through school and uni was not about rote learning but learning the ideas and being able to apply them. So, memorisation wouldn't really help. Like, big ideas you remember, and the rest you have to do on your own. (Darshana, Int2) 
In contrast, several VN-educated students (Hoa, Huynh, Linh, Trung) said that rote learning was not an issue in high schools in Vietnam, although they believed that this way of learning differed from copying from books without permission. For example, Linh stated:

In high school, we memorised details from books for exams. That form of education has been existing since the time of Confucius. He asked his students to read books and recite. That's why we have the term "rote learning". It's a culture where memorisation is accepted. It's different from copying someone else's work and presenting it as your own. (Linh, Int2)

Different educational experiences led to differences in how the two student cohorts thought about impacts of plagiarism. NZ-educated students, because they had experienced various levels of education in which people emphasised creativity, critical thinking, and knowledge contribution, understood that plagiarism was undesirable in academia. VN-educated students, conversely, focused more on how plagiarism affected plagiarising students and were more sympathetic to student mistakes because they understood factors for unintentional plagiarism.

\section{Educational experiences}

Experiences of being educated in two different educational systems helped some VN-educated students realise differences in ways that different universities taught and enforced plagiarism policies. During her master's degree, Hoa learnt about how seriously her overseas institution viewed and informed students about plagiarism. Victor noticed that universities in Vietnam did not have clear plagiarism policies while universities in other countries did. Trung understood how and why perceptions of students from these educational systems were different:

In Vietnam, plagiarism is less frequently mentioned, resulting in student limited awareness of it. At VUW, conversely, the educational system is well-structured, and students have clearer perceptions. (Trung, Int4)

Having experienced different educational systems, Linh realised that learning environments influenced student perceptions. She thought if the community were strict on plagiarism, students would understand that plagiarism was wrong; students in contexts where people allowed copying would grow up viewing copying as acceptable. She noticed the difference in the way her home and host country managed plagiarism and how it impacted her perception: 
In my master's overseas, I first knew about Turnitin and why to use it. I already knew that I had to quote when using other sources. But the use of Turnitin made me feel like I had to be more careful in my citations. Few universities in Vietnam use it. (Linh, Int4)

The evidence suggested that VN-educated students brought from their home country distinct knowledge about plagiarism. They understood constraints and limitations of plagiarism policies at their home country universities. While their NZ-educated counterparts talked more about individuals' responsibility, these students focused more on the roles of academic institutions in plagiarism management. They were aware of the level of awareness and understanding of plagiarism among students at various academic levels in Vietnam.

\subsubsection{Personal Experiences with Plagiarism}

Students' experiences either of being plagiarised or encountering plagiarism created many perceptions and emotions about the practice. These experiences sometimes made students respond more strongly to plagiarism and reflect more about its reasons and impacts. For example, Emma, who had been a victim of plagiarism, possessed a very strong view of it. She insisted that plagiarism was insulting and against her values. As a tutor, she had seen other tutors or lecturers being lenient with student plagiarism, inaction that she did not support:

I've seen more cases of plagiarising coming through. And they're not punishing or penalising the students that plagiarised. It may very well mean that our students know that they're plagiarising, but they're also aware that they can get away with it, which I don't agree with. (Emma, Int4)

Having seen her friend caught plagiarising when doing her undergraduate thesis, Linh thought more about how plagiarism would damage the reputation of the university:

I attended my friend's oral defense in Vietnam years ago. She invited her friends and family to the event. But the day did not go well. The examiner pointed out that part of the thesis was plagiarised. And my friend was asked to revise and resubmit her thesis. (Linh, Int4)

Linh said that not only her friend suffered from the incident, but the supervisor was criticised for it as well. Linh believed that plagiarism was not good for the university's image because an academic institution must prove that their students were academically competent, possessed real abilities, and showed strong work ethics. She thought no university wanted to be famous for plagiarism or wanted their students to reproduce theses. 
Experiencing misattribution or incorrect citations made some students reflect on writers and their work. Solace had many problems with others' research; he was frustrated by the time it took to identify sources because of improper citations by previous authors. He thought only when people dug deeper, they would realise these flaws:

If it was correctly attributed to the original source, I would have a much easier time trying to get this method, this algorithm to work, because I would have been able to identify the original source and understand the idea more clearly. But because it wasn't attributed in such a way, it did make it much more difficult for me. (Solace, Int4)

Emma's academic journey enhanced her insight into duplication in her field. She distinguished between people who copied someone else's work without effort and who genuinely searched:

I study [topic], so you'll find consistently across all articles that talk about [topic], they cite the same people, talk about the same articles, and they're not really doing their own research. They're just taking what previous articles have said about [topic], how many people are diagnosed, and what the symptoms are. And I don't always see that people are investing a lot of effort into their articles. They're just replicating. (Emma, Int3)

For several students, identifying student plagiarism through their professional roles made them think more about the issue. Having encountered student plagiarism, Solace understood more about its seriousness. Similarly, Frank's experiences of student potential plagiarism showed him inadequate understanding of citation and referencing of many undergraduates he tutored:

Because I've been marking other people's work. So, it's just gaining that actual practical experience of picking up on [...] even if it's not actually plagiarism, just being able to consider potential plagiarism along the way. (Frank, Int3)

As lecturers, some Vietnamese students experienced plagiarism in their students' writings, showing that Vietnamese undergraduate students' awareness and understanding of plagiarism were limited. For example, Trung said:

I encountered plagiarism by my students. Mostly, they paraphrased without acknowledging the sources, gave incorrect citations, or referenced insufficiently. I mean, these reflected a lack of understanding rather than an attempt to cheat. (Trung, Int1)

Sunny emphasised lack of education as a reason for student plagiarism, asserting that students need someone who told them what they were doing wrong and taught them correct practices. 
This empathetic stance was impacted by her experience of lecturing and marking undergraduate assignments:

When I asked them if they wrote it, they said that they didn't. It meant they knew that they copied someone else's work. When I asked them about the reason for not citing, they said that they didn't know they had to do so. That was what they told me. They did not know that they needed to cite. I mean, few students know that. (Sunny, Int2)

Similarly, Sunny's experience of plagiarism by her students showed her that relationships between lecturers and students did not get worse if students plagiarised unintentionally. She treated these students the way she normally did, telling them why they were wrong, and educating them which she thought made their relationship even better.

Several students related their general learning experiences, which they thought would clarify challenges students would face. For example, difficulties Frank encountered, which were not necessarily about plagiarism, made him sympathise with those experienced by undergraduates. He considered that sometimes there was confusion around expectations and students were not confident enough to ask for help, which led to unintended plagiarism:

So perhaps, my own experiences, even though it has nothing to do with plagiarism, but just trying to navigate people within the university, I can see that difficulty. So, an undergraduate student might also be unsure of what to ask, who to ask, or whether they're gonna feel stupid in asking or something like that. (Frank, Int4)

Similarly, Trung understood that many students were confused about what was required and struggled not only to avoid plagiarism but also to navigate university life. He believed that not all students made good use of the support services offered by universities.

\subsubsection{Conclusion}

Through the lens of cultural capital theory, the study found that VN- and NZ-educated postgraduate students possessed divergent embodied cultural capital which affected their perceptions and engagement with plagiarism. The theory allowed an exploration of various aspects of student knowledge and skills that impacted how they viewed and understood plagiarism. From a cultural capital perspective, the study indicated influences of familial involvement, educational history, and individual experiences on student perceptions. 


\subsection{Influences on Student Perceptions from a Social Cognitive Perspective}

\subsubsection{Environmental Factors}

According to Bandura (1991), people's moral thoughts and actions are affected by their parents and other adults around them. They adopt new moral standards appropriate to social realities and their social roles (Bandura, 1991).

Student perceptions of plagiarism were influenced by social relations and environments they occupied. They adopted moral principles through multiple disciplinary, professional, and scholarly platforms and their moral reasoning changed from being concrete to more abstract. These influences are framed by the ontology of Bandura because they were strongly aligned with Bandura's (1991) theory which hypothesised that individuals develop moral standards and judgments through interactions within social communities and contexts, and that these were ongoing and dynamic rather than historical influences.

\section{Disciplinary norms and ideologies}

Findings from interviews indicated that disciplinary training partly influenced how students viewed plagiarism, explaining survey results that indicated differences in perceptions across disciplinary contexts. Solace, who majored in computer science, thought judgement on plagiarism should depend on specific situations regarding whether borrowing was allowed, insisting that plagiarism was a grey area. He believed that people could copy if their copying contributed to their own work. He thought in certain cases, copy and pasting did not mean stealing or taking away attribution from the original creators:

We copy a lot of codes. In those cases, it's about using these tools, or knowledge that other people have given us, or not given us, to improve something else. It's not necessarily stealing somebody else's thing or taking attribution away from them. (Solace, Int4)

Solace added that programming was mostly about reusing code. He thought instead of doing the same thing again, students should use that time for something else. He considered recycling one's own assignment as understandable and acceptable, emphasising that sometimes people should work "smart" rather than work "hard". One of his students wrote a programme and later used the code for that programme in another course, which he found unproblematic. 
In the last interview, Solace drew on copyright, which was a fundamental concept in computer science, and explained how it was related to plagiarism:

Copyright was specifically designed to ensure that when somebody puts in some effort, towards creating something, that they will be awarded for that effort [...] So, I think that plays a big part in plagiarism in general. In some cases, you can take away the credit that they rightly deserve for the effort they put in, as opposed to you. (Solace, Int4)

Paddy applied his psychology knowledge to teaching about plagiarism; he explained why telling students the benefits of not plagiarising worked better than just teaching them why plagiarism was wrong. He thought if students understood profits of correct practice or why they needed to cite, they would be less likely to plagiarise, produce much better writings, and present arguments rather than copying from other materials:

From behavioural learning, we know that reward and positive is sort of a much more straightforward approach to learning than telling them not to do this. [...] If they understand the positive benefits for their own writing, the spillover effects, it doesn't just discourage plagiarism, but makes them better writers as well. (Paddy, Int4)

For Darshana, coming from a science background might partly explain her strong disagreement with plagiarism. In her field, when people did experiments and studies, they had to pay attention to reliability and validity; they had to rationalise their decisions.

We need to have evidence for things, and everything is like research based. [...] We must have good reasons for why we do things. We have to conduct things in a reliable way. We can't lie about results or something. (Darshana, Int4)

Huynh, Linh, Sunny, and Trung - experienced lecturers in Vietnam - believed that education was the key to development, emphasising lack of education as a reason for student plagiarism. For them, ethics and morality needed to be taught and teachers were responsible for that. For example, Linh believed that rules and standards needed to be enforced and students needed to be given the tools to exercise the right:

If someone tells them, and people around them don't do that, they wouldn't do that. For example, I sort rubbish and recycle here [New Zealand]. Because firstly, everyone here does it. Secondly, I will be punished if not doing so. And thirdly, I'm given the tools: different types of bags and bins. In Vietnam, I never separate rubbish and recycle. (Linh, Int4) 


\section{Professional environments and roles}

Some participants were influenced by their professional roles and experiences. Although they were aware of plagiarism and related aspects before starting their careers, direct engagement with plagiarism gave them greater insights into undergraduate plagiarism. They hoped to improve their students' understanding of plagiarism and academic integrity which could help them become better learners and writers.

\section{Lecturing roles}

As lecturers, VN-educated students talked about plagiarism more from a perspective of an educator than a student; they drew on their lecturing experience to exemplify their points. When talking about institutional factors for student plagiarism, Trung said that many of his colleagues only checked papers that they suspected of plagiarism. In that respect, they might miss other serious plagiarism instances. Trung referred to the unavailability of plagiarism detection tools in his home country, saying that as far as he knew, at many Vietnamese universities, plagiarism detection was carried out individually and inconsistently:

At universities where I studied or taught, there were no plagiarism detection tools. When lecturers suspected some papers, they copy and pasted them into Google to check. I don't think it's a good measure because it's time-consuming and unfair. (Trung, Int2)

Trung noticed that awareness of plagiarism varied among Vietnamese tertiary students, which he believed resulted from inconsistent practices among classes and universities. He noted that the tertiary curriculum in Vietnam focused on many fundamental courses with various forms of assessments. These observations made him thoughtful when dealing with student plagiarism and he tried to investigate reasons for plagiarism rather than being accusative:

If one or two students in a class don't know about it, we can blame them. But if all of them are unaware of this issue. Obviously, we cannot blame them. We must reconsider what the problem is and how they were previously taught. (Trung, Int4)

Similarly, Linh indicated limitations in plagiarism management in her Vietnamese university. She said that due to a lack of detection software, many lecturers used Google or manual checking, which she believed to be difficult, time-consuming, and inefficient. Also, teaching about plagiarism-related aspects was given little emphasis in Vietnam. Although at the university where she taught, orientations for students included a section about plagiarism, 
citing, and referencing, the section was only for thesis students. Therefore, many other students were uninformed about these issues.

Lecturing experience helped Linh understand various aspects of student plagiarism including how they perceived plagiarism, what sorts of mistakes they usually made, and their tricks to plagiarise. She also got an insight into student proficiency levels:

In the first year, they learn to write paragraphs and 500-word essays. It was until their second year that they learned about academic writing, how to write a small research paper of about 1500 to 2000 words. It was then that they learnt about citation. (Linh, Int2)

Other participants stated that as lecturers, they understood why many Vietnamese students possessed limited knowledge about plagiarism and its related aspects. As discussed in Chapter Seven, most VN-educated students expressed their views on how education impacted student understanding, noting constraints in plagiarism education at their home country universities. Trung said that although universities in Vietnam organised orientations at the start of the academic year, the purposes of the orientations differed from those in Western countries:

There's an orientation at my university at the start of every academic year. They introduce the university, facilities, and student support services. They also inform students about the university regulations but don't talk about plagiarism as in other countries. (Trung, Int2)

As lecturers, most VN-educated students were aware of faculty members' responsibility in managing plagiarism. For example, Linh thought the roles of an educator were both delivering content knowledge and building student moral character. She asserted that lecturers should have clear regulations and show students what was right or wrong. Hoa highlighted the responsibility of lecturers in checking student writing for plagiarism. Hoa, Huynh, Sunny, and Trung emphasised that lecturers needed to give clear guidelines when giving assignments.

Although NZ-educated participants had less lecturing experience compared to their VNeducated counterparts, they showed deep understanding of undergraduate situations related to plagiarism. For example, being an educator, Paddy was more compassionate with students. He tried not to blame them but figured out what he could do to help them avoid mistakes and improve their understanding, although this was hard:

I would be more compassionate in an undergraduate, because they may not know how to reference appropriately. (Paddy, Int4) 
When you get to see somebody plagiarises or writes badly, you get grumpy or angry. It's so easy to do that. But it's much harder to take a passionate stance and say maybe they're not responsible, there may be a way we can train them to be better. (Paddy, Int4)

Darshana, through lecturing and having direct contact with students, gained better insights into problems they faced. In the same vein, Ally's exposure and engagement in an Asian teaching context helped her understand various sources of pressure on Asian students. This made her more lenient with plagiarism by international undergraduates.

\section{Tutoring roles}

Tutoring experiences at VUW made most NZ-educated students better aware of student plagiarism and reasons for its occurrence. For example, as a tutor, Ally saw poor writings which shocked her because she thought first-year students should possess better academic skills. Her experience helped her understand undergraduates' levels of competence:

I tutored a 100-level course. About halfway through the course, there was a module on referencing and lots of the people didn't know about it [how to cite properly]. (Ally, Int2)

As a senior tutor at VUW, Solace noticed that when students felt interested in the assignment, they were far more involved in the work and less likely to plagiarise. He understands that students went to university to learn and teachers should not expect them to be perfect:

We're at university, where we're trying to teach students. And you know, these students aren't in the real world yet. I think it's the responsibility of teachers to accept the fact that none of the students are going to be perfect, and that you're never going to have a perfect class of perfect $A$ students. (Solace, Int4)

Similarly, while Frank viewed plagiarism as a concerning issue, he understood that students came to the university for learning and improvement. He did not expect anyone to be perfect. This stance made him empathetic towards unintentional plagiarism by undergraduates:

I consider plagiarism a serious thing, but at the same time, I don't hold anyone to be perfect. So, I think purposeful plagiarism is definitely unacceptable but I'm a bit more lenient if I was marking an undergraduate essay or something like that. (Frank, Int4)

Frank would not assume that people who plagiarised were bad but would consider reasons behind their behaviour: 
I think there are always multiple causal aspects. So, you can't just tie it to one thing. Because education is kind of a relational thing. There are always teachers and students, and neither of them is gonna be doing a perfect job. (Frank, Int4)

When tutoring, the participants saw more impacts of plagiarism on the university and student learning. For example, Emma worried about incompetent people entering academia. She emphasised the need to equip students with knowledge about and skills to avoid plagiarism. She asserted that, as an instructor, she had to help her students develop a skill set and understand appropriate referencing and citation practices because she could not know if other tutors would do the same:

I worry about what their [students'] thought processes are, and where they want to go. Because I don't want academics or people going further into academia if they don't know the appropriate processes or how to cite properly. (Emma, Int4)

Frank, through tutoring, considered that there were different types of students. While some might be very good at writing, others found it hard to convey their ideas. And he had experienced all these strengths and weaknesses through marking their papers:

As soon as you tutor or something, you realise the spectrum of people you're working with or tutoring. They all have different strengths and weaknesses. As soon as you have experience marking essays, I think you'll get a sense of what types of academic weaknesses of people. It becomes apparent in their work. (Frank, Int4)

Darshana said that most first-year students did not know much about plagiarism-related issues unless lecturers told them. She pointed out impacts of negligence in plagiarism education:

If you don't tell them then, they keep doing it in the second and third year. And you don't want people at a postgraduate level who don't know about plagiarism, so that's why it's important. (Darshana, Int1)

Linh, who tutored a group of international students at VUW, commented on the awareness of citation and referencing among those students with whom she worked:

They know little about referencing and citations. When they were asked to make a presentation on a specific issue with proper citation, they asked me why they had to source. Although I was shocked, it's understandable. They're not academics and have never done such things. (Linh, Int4) 
It took Linh a lot of time to show these students how to cite and explain to them why it was necessary. Although they eventually gained a basic understanding of the issue, Linh thought the university should provide extra instructions for students like this cohort.

\section{Doctoral environments}

This section describes how students developed their plagiarism perceptions during doctoral studies. There might be some overlap between this section and Section 8.5. However, while this section focuses on perception changes because of enculturation, Section 8.5 highlights student development as an agentic process of identity construction.

\section{Learning about Plagiarism and Writing Conventions at VUW}

Most VN- and NZ-educated students said that they learnt about plagiarism during the VUW doctoral orientation. This included academic integrity, different forms of plagiarism, why they should avoid it, and the benefits of not plagiarising. They considered the workshop as useful for them. A typical response was:

The introductory workshop for PhD students. [...] I think it's useful. I was amazed that the range of what counts as plagiarism, what people consider plagiarism across different domains. There was an exercise that we did with sort of different numbers and you had to consider what counts as plagiarism. Then we sort of lined ourselves up across the room. It was quite interesting and there were people at every number, I believe. (Paddy, Int3)

VN-educated students found the orientation especially useful to understand the university's expectations with regard to plagiarism and academic integrity. They said that their home universities put less emphasis on the issue.

During the orientation, they talked about academic integrity, plagiarism, and its various forms. It was useful for me as an international student, you know, to understand the university's expectations regarding academic integrity and plagiarism. Such information was not provided in orientations in my home country universities. (Trung, Int3)

Some VN-educated students said that they learnt a lot from their supervisors, not only about plagiarism but academic writing and finding their own voices. Said Trung, for example:

My supervisors told me about developing my own voice and writing style. She said that ones' writing expresses their thoughts or perspectives, and sometimes their cultures. (Trung, Int4) 
Other VN-educated students said that their supervisors help them improve academic writing skills by giving feedback, which they found useful for them as an international student whose English was a foreign language:

My supervisors understand that English is my foreign language [...]. They gave me a lot of feedback about word choices, writing styles, and how to structure my writing. It helps me improve my academic skills. (Sunny, Int2)

While the students found that student learning service was useful for improving their writing, they did not use it early in their doctoral studies. One typical example was:

I used student learning services a few times. Just recently, when I needed feedback for a piece of writing. I wished I had used it in the early stages. You know, when I started to write. Now that I'm writing up the thesis, I find it hard to seek detailed feedback for long pieces of writing like thesis chapters from them. (Trung, Int4)

The evidence suggests that during doctoral studies, students mainly learnt about plagiarism and writing conventions through orientation workshops and their supervisors. Most found these learning opportunities useful for them as research students. These various forms of enculturation were active influences of their perceptions of plagiarism. Apart from these, most relied on self-directed learning (See Section 8.5.1: Agency and Perceptions of Plagiarism).

Variations in students' perceptions of plagiarism and stages of study

Interview data revealed greater awareness of plagiarism among those who were writing up their thesis (Darshana, Emma, Paddy, Solace, Linh, Trung, Sunny) compared to those who were early in their degree (Hoa, Huynh, Victor). Students at a later stage of their study were more aware of the complexity of plagiarism. Exceptions were found with those who had a strong sense of agency (Frank) or were early in their studies but possessed scholarly experience such as writing for publication (Ally, Frank).

\section{Shifts in student perception of plagiarism during doctoral enrolment}

In this study, shifts in awareness or expansion in consciousness about plagiarism and relevant issues were illustrated better in VN-educated participants, those who reported receiving less plagiarism education prior to VUW, than in their NZ-educated counterparts. For example, since starting his doctoral studies, Trung had more access to information about plagiarism, which made him think more deeply about it and related issues: 
I didn't think much about this before. Since starting my PhD, I had more opportunities to learn about it, like the orientation, the course I took, my supervisors, or participating in this study. I feel like my understanding becomes deeper. (Trung, Int4)

Similarly, while Linh always viewed plagiarism as unacceptable, her awareness of the issue became more profound since engaging in her doctoral studies:

I've had the same stance that it's unacceptable, especially at high levels like the doctoral level. But it has become more profound because I read and was exposed to academic conventions more than ever. Sometimes, I'm at the fine line between plagiarism and not plagiarism. I must decide how to cite to not depend on or copy from others. (Linh, Int4)

Attitudes towards plagiarism among most NZ-educated participants remained unchanged since starting their PhD. However, they understood more about its severity and academic impacts. While Darshana always viewed plagiarism as immoral and unacceptable, her doctoral studies helped her understand the issue better:

For a long time, I have had the same stance. I would never do it or feel okay doing it. It probably hasn't impacted so much because of my doctoral studies. But it definitely made me more aware. Because you read so much and are more involved in academic literature, you understand a bit more. (Darshana, Int4)

While Solace's view on plagiarism did not change, he better understood impacts of plagiarism. Similarly, producing a theoretical thesis made Paddy recognise how good citing and referencing contributed to the success of academic work:

There's less concern about is this the kind of thing that needs citing and referencing. Just more naturally integrated into the process of constructing an argument and writing it. (Paddy, Int3)

The fourth interview was conducted around six months later when many participants had begun writing up their thesis. The thesis writing process helped some (Ally, Emma, Paddy, Solace, Linh, Trung) better understand and feel more strongly about impacts of plagiarism on original creators. For example, Solace said:

Putting more effort into my writing and whatnot makes me appreciate the fact that people are upset when other people plagiarise their work. But it hasn't really changed my opinion on plagiarism. (Solace, Int4) 
Trung knew more forms of plagiarism, whereas previously he thought plagiarism was simply taking someone else's words or ideas and turning them into one's own. As a PhD student, he thought more about causes of plagiarism and how to avoid it. Similarly, Linh's writing process helped her understand and appreciate the energy that each scholar devoted to creating work that many other people knew and recognised:

Previously, sometimes I read a lot but didn't understand much. There were authors who I thought were cumbersome and presented things in a very confusing way. Now I read more and understand why that person was praised so much. Compared with my paper, I can see how much effort they put into their work. It's a long process. I appreciate their effort more and realise how useful their papers are. (Linh, Int4)

In the last interview, Darshana talked about plagiarism in more detail than she did in the first three interviews. Discussions in interviews for this study helped her think more about different forms of plagiarism and student reasons for committing it:

From the interviews, I thought more about forms of plagiarism, it's not just copying without citations, it's also using your previous work, stuff like that. So, I just thought about it more and about what examples could constitute plagiarism. (Darshana, Int4)

The interviews themselves gave her a chance to think more deeply about the practice:

If you think about it for the first time, you think of specific examples. Like if I did this specific thing, and I got found out, it would be plagiarism. But the more we talk about it, like me coming to the interviews. You, kind of like, join it all together and you see the general theme of stealing or just lying about whose work it is. (Darshana, Int4)

These observations suggest that doctoral engagement enhanced students' perceptions of plagiarism and writing conventions. Those who were in later stages of their study were better aware of the complexity, severity, and academic impacts of plagiarism.

\subsubsection{Moral Agency, Self-regulation, and Perceptions of Plagiarism}

According to Bandura $(1991,2002,2006)$, individuals exercise agency through monitoring and regulating their moral behavior. They behave in ways that bring them respect from others within their environment and refrain from violating moral standards because of social criticism or consequences. Moral conduct is regulated through continuous use of self-reactive influence. 
In this study, participants' views of doctoral studies and academic work seemed to determine their ideas about moral behaviours related to plagiarism. Their agency was reflected in their refraining from violating rules related to academic integrity set by the university. Most understood that plagiarism was undesirable for them as research students.

Academia emphasises knowledge and respect for others' contributions. So, plagiarism is unacceptable, especially when we study at a high level like a doctoral level. (Linh, Int4)

At this [PhD] level, the expectations from the university and others for us are much higher. Also, we're all instructed about it. We cannot say that we don't know the rules. (Hoa, Int3)

Some said that having the identity of an emerging researcher prevented them from plagiarising. For example, Frank considered doctoral education as a self-cultivation process. He took his studies seriously and emphasised capacity advancement. As a person of integrity, he would never think of plagiarising in any circumstances:

Because I have a strong conscience, being dishonest is never an option. And I take scholarship seriously and that type of thing. Like I'm here to develop my own capacity to have ideas, so even under pressure, there's no reason for me to plagiarise. (Frank, Int4)

Similarly, Hoa recognised the value of "learning by doing" in her own work.

I have to write and do my research myself. It's helpful for my development. I have never thought about copying from someone else. (Hoa, Int4)

Students' views of citing and referencing as an integral part of good scholarship also helped them guide their behaviours. For example, Frank was meticulous in reading and taking notes, which he thought guarded him against accidental plagiarism:

I take a very meticulous approach to reading and note-taking. I'm always very clear in my notes, where the quotes come from. When I write, there's an aesthetic element to writing and using references. I'm always really sure what I'm doing. (Frank, Int4)

VN-educated participants' educator identity played a crucial role in governing their moral behavior and their educational work ethics influenced their perceptions. Most understood that they must create standards and be role models for their students. They believed that if they made mistakes, it would be hard for them to teach students.

What is more important is that if you do it yourself, you cannot teach others. (Linh, Int4) 
If you want to teach students, you have to do it right first. Lecturers have to set a good example for students. If you plagiarise, how will your students look at you. (Trung, Int4)

These remarks suggested that participants monitored and regulated their moral behaviours based on their moral standards and work ethics. As emerging researchers, most understood that plagiarism was undesirable in academia which was significant because it demonstrated their strong discipline and sense of responsibility. They were also aware that their main goal for doctoral studies was to develop their capacity and competence for the academic work environment. VN-educated students actively refrained from violating principles of academic integrity because consequences would be severe for them as lecturers and they were worried about how other people would look at them as plagiarists.

\subsubsection{Conclusion}

Social cognitive theory of moral thought and action enabled an exploration of ongoing external factors affecting student perceptions of plagiarism. Application of the theory showed that student moral perspectives were not solely impacted by embodied cultural capital but continuously developed through different environments that students interacted within. It helped to explain how they acquired moral standards that were suitable for their professional roles, disciplinary areas, and doctoral engagement. The students who were involved as lecturers or tutors sought to influence others in the environment or to help their students become better learners and writers. The theory was also useful in illuminating how students exercised agency to refrain from immoral behaviours related to plagiarism.

\subsection{Influences on Student Perceptions from a Self-formation Perspective}

Marginson (2014) considered international students to be engaged in a self-formation process, in which they are strong agents navigating their trajectories. This involves dramatic changes in knowledge, skills, and identity that are deliberate and self-driven. While affirming that domestic students also engage in agentic self-formation, Marginson (2014) maintained that it is more apparent and significant for international students.

The degree of student agency theorised by Marginson is higher than that of Bandura's theory. While Bandura emphasised student development as a response to new environments, Marginson focused on individuals as self-directed learners, highlighting their aspirations, objectives, and abilities to enact agency. In this study, students' exercising agency for self- 
formation was reflected in their active engagement in the self-formation process, strategic choices in response to challenges, deliberate development of their own voice in writing, and increased understanding of academic conventions as a result of self-directed learning.

This section describes the development of student perceptions of plagiarism as indicators of the agentic self-formation and identity construction processes proposed by Marginson (2014).

\subsubsection{Agency and Perceptions of Plagiarism}

In this study, both VN- and NZ-educated students displayed high levels of agency. VN-educated students' agency was reflected not only in their responses to challenges but their capacity to take charge of their own learning. Most deliberately set out their aims and achieved them by strategic new learning. While facing problems at the beginning, most managed to take control of their situations and became more confident and autonomous learners, leading to their greater understanding not only of plagiarism but academic conventions and academic integrity. NZ-educated students' agency was illustrated by the deliberate development of their own voice in writing, and their deepening understanding of writing with integrity.

\section{VN-educated students}

VN-educated students encountered several difficulties in academic settings during the first stages of their degree regarding mismatches between what they previously learnt in their home country universities and knowledge and skills required to complete their doctoral studies. Their agency was shown through the way they confronted and dealt with challenges. Most considered their PhD as a learning process where they continuously updated their knowledge to be able to attain their aspirational identities as a scholar and an academic. Trung, who was passionate about research and sought to contribute to the knowledge base, was the strongest evidence of student agency among VN-educated students.

Because you came from a different academic context [...]. For example, I studied research methods in my country already. But during the research methods in education course here, I realised that what I studied previously seemed insufficient. It was difficult regarding the amount of reading that I had to do and the time I need to invest in my work. Anyway, it was a learning opportunity and I worked hard to gain the best result that I could. (Trung, Int4)

As a PhD student, Trung devoted most of his time to advance his knowledge, academic skills, and capabilities. He spent considerable time reading - not only around his topic but widely - to 
increase his knowledge and improve his writing and critical thinking skills. He actively engaged in various academic activities at VUW, seeing them as learning opportunities:

I attended a lot of seminars and workshops at VUW. Many of them are about academic writing such as How to be a Narrative Ninja, Thesis Writing, or Managing the Writing Process. These workshops help me improve my academic writing, critical thinking, and also my synthesising skills. (Trung, Int4)

Another thing that Trung found significantly changed in the process of becoming a researcher was his awareness of constructing his voice and finding his writing style:

I focus on finding my own writing voice and style. I emphasise clarity and conciseness in writing. Before I write, I think a lot about what I really want to communicate. Then I write it in a way that makes it easy for the readers to understand - write concisely but convey ideas clearly. (Trung, Int4)

In the final interview, Trung brought up the idea of writing with integrity. Through his doctoral studies, he better understood the importance of citation and referencing. He gradually saw it as a tool to support his writing whereas he previously thought about it as a requirement:

I pay special attention to credit original authors. That part of acknowledgement is essential in academic work. Previously, I thought citation was just to let people know whose research it is. Now I see its role in describing the history of the problem, relating my research to others', showing the gap it addresses. It also shows my respect for them. (Trung, Int4)

Other relevant but less explicit examples of student agency are Hoa, Linh, and Sunny, who experienced similar problems in their studies. Their agency was reflected in how they dealt with the situations and the time and effort they put into their research.

There are disparities between what I studied in my home country and the expectations of my host country. I mean, it's a constant learning process. I do my research, learn new things, and apply them at the same time. I constantly update my knowledge. (Sunny, Int4)

I learned that I have to read as much as I can. I tried to read research articles related to my field, to learn the language that people used. (Hoa, Int3)

I had to use new software for my research but there were no instructions on how to use it in our uni. I had to learn and do it myself. Then, I realised that I had drawn a wrong conclusion from the results. My supervisors asked me to do it again. Until recently, I completed the analysis. It took me a long time for that process. (Linh, Int4) 
As academic writers, these students paid special attention to finding their voices. They invested substantial time and effort to produce high-quality work. Most wanted to help readers understand their writing easily.

I want to write in a logical and understandable way. The responsibility of a writer is to help readers understand your writing easily but not to make them feel vague. (Sunny, Int4)

I want to write easy-to-understand but not lengthy and ambiguous sentences. In Vietnamese, we usually add words like however and therefore. Actually, I don't think we need to use such words much in English. (Hoa, Int3)

My arguments must be clear and convincing. I think my writing must have a logical and straightforward structure and the sentences must be clear. I also pay special attention to the format, reference, and citation. (Linh, Int4)

The evidence suggests that VN-educated students showed a significant degree of agency. They were strong agents navigating their own trajectories, not deficit learners. They were able to direct their learning and respond to challenges leading to development in academic literacy and increased awareness of academic integrity.

\section{NZ-educated students}

NZ-educated students' agency was apparent in the deliberate development of their own voice in writing and growing awareness of academic integrity. For example, Frank, who emphasised knowledge production and good scholarship, believed that conscientiousness was essential in scholarly work. He also highlighted the importance of clarity in academic writing. He had clear ideas about the sort of academic writer he was working on becoming and a sense of agency:

It's to convey ideas clearly. To account for the potential complexity of a piece of research data or something but convey it in a way that doesn't water it down, but also doesn't become convoluted for the sake of being convoluted. I mean, so much academic stuff is so densely written that it becomes counterproductive for someone to read it. (Frank, Int4)

Paddy wanted to make his writing clear, fun, and engaging. For him, academic writers should write in a way that people outside of their area could understand easily.

I don't want my writing to be dry. I want it to be engageable and occasionally I try to get a little bit of humour or something [...] I try to bring the relevance and the purpose, and make sure the argument is clear throughout. I guess I'm trying to say that I want it to be serious, but that needs 
to be fun and engageable and should be able to be read by any educated person, or any intelligent person outside of my particular field. (Paddy, Int4)

Many students, as they progressed through their $\mathrm{PhD}$, started to view referencing and citing as a tool to support their writing as opposed to a rule they had to follow. Paddy's PhD thesis was theoretical in nature, which meant that he had to refer to others' work. Therefore, he was aware of how citing and referencing could assist him to construct his own writing:

I'm doing a theoretical thesis, pulling together other people's ideas, combining them, and generating some novel ideas. Part of the process is to use citation and referencing. I noticed how helpful it is in drafting my writing. So, the process of doing my PhD made me reflect on how good citation and referencing is just good writing skills. (Paddy, Int4)

Paddy expressed his understanding of the importance of acknowledging other people, which he saw more as a benefit than as a requirement. This demonstrates self-formation rather than just learning to be in their academic environment.

It's to keep track of your sources. It gives you justifications for your claims, sometimes it allows the readers to go back and check to see if they believe the claim you're relying on. (Paddy, Int2)

In the same vein, Ally understood that, as a researcher, she needed to place her work in the context of established literature. For her, writing with integrity not only helped her recognise the contributions of original authors but to provide a foundation for her own research:

It's to show that you've engaged with and understand the literature that came before your research. You can strengthen your own case. And then it kind of helps support your research and shows why your research is important. Also, it's to recognise the contribution of previous scholars in your field. (Ally, Int1)

These examples indicated that NZ-educated students took the initiatives to develop their capacity, consistent with the self-formation process suggested by Margindon. While not facing academic challenges leading to self-formation as their VN-educated counterparts, these students showed profound understanding of their positions as emerging researchers and academic writers. They deliberately developed their voices and were aware of academic integrity principles. going beyond simply following the rules of plagiarism. This demonstrates self-formation rather than compliance with the environment. 


\subsubsection{Identity Construction and Perceptions of Plagiarism}

Beyond the exercise of agency, there was a process of identity construction that students went through. Many students, both VN-and NZ-educated started to see themselves as emerging researchers and their discussion of plagiarism reflected that identity. They developed greater awareness of their responsibilities as researchers and academic writers, showing deepening understanding and concern about impacts of plagiarism within academia.

\section{NZ-educated students}

Frank was the best illustration of the deliberate construction of academic identity by NZeducated students. He was doing his PhD partly because of his desire to become an academic and to produce original knowledge. He wanted opportunities to get beneath the surface of ideas and engage multiple ideas and perspectives on every topic he investigated. As a PhD student, he understood his responsibility to produce quality and genuine scholarship. He was committed to and put in a lot of time and energy to complete his PhD. During his PhD, Frank worked as a research assistant to gain more research experiences and he co-authored a paper while doing this job. These suggested that Frank continuously exercised agency to attain his aspirational identity, the key concept of Marginson's theory.

From the first interview, Frank showed extensive knowledge and profound thinking about plagiarism. While he was more lenient with plagiarism by undergraduate students, he felt more strongly about academics' plagiarism. He emphasised the production of original knowledge and viewed plagiarism as a concerning offence. He considered that plagiarism countered good scholarship, the basis of academic work; his views were consistent with his ideas about what it means to have an academic identity:

Part of academic work, for me, involves a high level of reflexivity. So, to engage in plagiarism demonstrates a non-reflective approach to things. It, kind of, goes against the grain of the central element of academic work. (Frank, Int2)

Frank believed that students who understood the process of creating academic work developed a strong opposition to plagiarism; this was for him a key part of that identity:

Appreciating the work that goes into academic work makes me oppose even a higher level of integrity. Yeah, the more you understand what's going into it, I guess the less desirable that you're plagiarising someone's ideas. (Frank, Int4) 
Similarly, Emma pursued a doctoral programme to go depth into research and contribute to her field. She was a persevering and disciplined student who was committed to developing her identity as an academic writer and researcher through her PhD. Emma had several publications, both from her PhD research and previous postgraduate project. She worked with several academics outside her faculty to write a book chapter. The academic writing that Emma had done both for her thesis and publication made her more serious about plagiarism and its severity. Through the publication process, Emma understood the contexts of academic work and emphasised that credit was what scholars received. Apart from that, she knew that they received little financial benefits for their published work:

Because it's recognising somebody's work. [...] There's no financial benefit for publishing particularly research papers or experimental practice, we get credit; we get the authority and we get respect for our work and when people take that and cite that as their own it diminishes our own research. (Emma, Int3)

As a PhD student, Paddy was interested in what he was doing and put in a lot of effort to be good at it. He considered being a PhD student was a new role because it involved contributing to the knowledge base. Therefore, he made great efforts to accumulate academic and research skills and produce publications. Similarly, Ally was aware that she had to contribute to the knowledge base and show respect to scholars in their field, which she found contrary to plagiarism. She understood and valued the energy people put into their work because he could imagine how it felt when somebody else came along and took credit away from them. She hoped that these academics, as well as herself, would be given the credit they earned:

At this level, PhD level, I wouldn't do it because [...] I have more appreciation and respect for people in my field and I wouldn't want to, you know, discredit them. (Ally, Int3)

I know how it feels [...] put the time and effort in. So, I wouldn't like if somebody else put their name on my time and effort. (Ally, Int4)

The findings evidenced self-formation among NZ-educated students rather than compliance with the environments. Gradually, they better understood their positions within academic communities, making them commit to producing quality scholarship as opposed to plagiarism. 


\section{VN-educated students}

VN-educated students became more aware of the ideas of originality and knowledge contribution within academia they progressed through their doctoral journey. The selfformation was greater for Linh and Trung, who started doctoral studies because of their passion for research. As a PhD student, Linh wanted to contribute to her field and produce quality work. During her doctoral studies, she presented at various conferences in and outside New Zealand and completed a publishable paper from her PhD research. She worked as a research assistant to gain more skills and experience. Linh's perception of plagiarism developed in the process of becoming a researcher. She spent the first two years of her PhD grappling with the idea of not knowing what her study would contribute to scholarship in her field. It was in her third year that she recognised her contribution.

It's hard to find something new. I've been to many conferences and seminars and asked people how to make a mark while so much has been done about the topic. They told me to keep working and I will soon know what my contribution is. (Linh, Int2)

Linh's process of constructing her academic identity and becoming part of the academic community created her sense of responsibility and commitment to ensure rigor in her work which she found different from how she was as an undergraduate student:

I know how difficult it is to complete a study. I also see myself now differently from when I was an undergrad student. Now I'm an independent researcher, I need to have my own opinion, I must have what is called the honour of a researcher. If I plagiarise, it will impact others, my career, and my name. (Linh, Int3)

Linh described differences between herself during the first year of enrolment and at the stage of writing up her thesis, saying that she gradually saw herself as a researcher:

During the proposal stage, I saw myself as an apprentice. I read whatever I found and didn't care about my identity. I didn't plagiarise, but my writing wasn't deep or critical. I just cited what people said. Now, I understand things better and see myself as a researcher. I read and cite others, compare this person with that person. My analysing and critical thinking skills have improved. (Linh, Int3)

Each time I conducted a new study, I learnt new software, or a new method to analyze the data. Through that, I used all my knowledge to look at a test as a whole, I don't evaluate everything subjectively as I used to. (Linh, Int3) 
Linh's take-up of her new identity as an academic researcher and how that influenced her perceptions of plagiarism was emphasized again in the last interview, when she brought up the concept of "authorship". Linh commented that she thought about the issue more recently because she would be an author soon and she wanted to protect her intellectual products.

Similarly, Trung was committed and tried his best to produce a quality thesis. He wanted to gain scholarly experiences by presenting at several conferences in NZ and overseas and publishing one paper from his PhD project. As an emerging academic, he considered originality and knowledge contribution as fundamental.

In academia, creating something new, or contributing to new knowledge is very important. I think plagiarists do not create anything new, but simply replicate what people have done. (Trung, Int4)

Other VN-educated students, while not giving detailed descriptions, showed increased awareness of their responsibilities as PhD students concerning citing and using sources. Hoa found plagiarism unacceptable for research students because she considered that they were responsible for their projects. As a doctoral student, Sunny understood the importance of acknowledging people's academic products as a sign of respect for them. Sunny found that the higher she studied, especially abroad, she had to follow standards. If someone asked her about plagiarism or how to avoid it, she felt like she had to know:

PhD students, especially in Western institutions, must know about it [plagiarism]. It's part of the university policies. Of course, whatever we read; we see people citing. We know that we have to be aware of what is ours and what belongs to someone else. (Sunny, Int4)

The findings indicated students' construction of academic identities. Some of them better grasped the importance of originality and knowledge contribution for their researcher and academic identities as they progressed through their doctoral studies. They also showed greater respect for scholars in their field and deepening understanding of academic integrity.

\subsubsection{Conclusion}

Marginson's (2014) student self-formation theory allowed an exploration of relationships between students' agency, their academic identity and engagement, and their perceptions of plagiarism. Both VN- and NZ-educated students demonstrated high levels of agency through their active engagement in the self-formation process. Most were committed to developing their capabilities, proactively responded to challenges, and became more confident and 
autonomous as progressing through doctoral studies. They became more aware of their responsibilities as researchers and better understood impacts of plagiarism. However, the selfformation was greater and more apparent for participants who started their PhD because of a passion than those who wanted to fulfill a requirement. The participants took on multiple identities (as students, educators, and researchers) when talking about plagiarism. The section includes the students whose self-formation was more significant to their plagiarism perceptions which does not mean that those who were not mentioned did not involve in self-formation.

\subsection{Chapter Summary}

The findings revealed multiple influences on plagiarism perceptions, including cultural capital, environmental factors, and personal agency. The first source of influence was related to familial involvement, individual experiences with plagiarism, and educational histories. Professional roles offered insights into student plagiarism. Therefore, they sought to influence others in the environment by helping their students gain academic skills and thus become better learners and writers. Disciplinary contexts equipped students with specific knowledge and skills and had a huge influence on their thinking. Also, doctoral studies led to positive changes in student perception, especially with VN-educated students. The students monitored and regulated their moral behaviours and reported that they consciously refrained from violating moral rules and standards. Student agency was reflected in their responses to challenges, their development of their own voice in writing, and their increased awareness of plagiarism and academic integrity. Student perceptions developed through their path of becoming a researcher, reflected by how they perceived themselves within the academic community and their commitment to being part of it. The findings indicate the relevance and usefulness of the three theories in illuminating influences on student perceptions of plagiarism, suggesting the importance to consider the extent to which university practices could be effective considering the range of influences on students' ideas about plagiarism. This will be discussed in Section 9.5.1. 


\section{Chapter 9 | Discussion and Conclusions}

\subsection{Introduction}

The main purpose of this study was to contribute better understanding of VN- and NZ-educated postgraduate student perceptions of plagiarism and influences on their perceptions, by examining these through the lenses of cultural capital theory (Bourdieu, 1977), social cognitive theory of moral thought and action (Bandura, 1991), and student self-formation theory (Marginson, 2014). This chapter briefly recaps and discusses key findings presented in Chapters $5,6,7$, and 8 . It is structured in relation to the research questions and is divided into five sections, including this introduction. The next section focuses on student understanding and attitudes towards plagiarism, answering the first research question. The two sections following discuss inter-group and intra-group differences in VN- and NZ-educated students' perceptions, providing evidence that speaks to the two sub-research questions. Also included is a discussion of influences on student perceptions from the theoretical perspectives, explaining differences in their perceptions and addressing the second research question. Section 9.5 concludes the chapter by noting implications of the study, its limitations, suggestions for future scholarship, and contributions of this research.

\subsection{Student Perceptions of Plagiarism}

The first research question examined plagiarism perceptions among VN- and NZ-educated postgraduate students: How do VN- and NZ-educated postgraduate students perceive plagiarism? This section describes student understanding and attitudes towards plagiarism. Differences between and within groups will be presented in Section 9.3.

\subsubsection{Student Understanding of Plagiarism}

In response to the first research question regarding VN- and NZ-educated postgraduate student perceptions of plagiarism, this study found that most students held substantial understanding of plagiarism, both in terms of the concept's meaning and what is required to correctly apply this understanding. Through the online survey, most students could distinguish between plagiarism behaviours and acceptable practices. During the interviews, they referred to a variety of plagiarism behaviours and could explain how each was different. Most were aware of the seriousness of plagiarism, understanding why it was undesirable in various academic 
contexts. They showed proper understanding of VUW's expectations regarding plagiarism and academic integrity. Most students could provide a definition of plagiarism consistent with the definition used by the university and were aware of reasons why plagiarism was prohibited at VUW. The findings are aligned with published research showing conceptual understanding of plagiarism among postgraduate students (Selemani et al., 2018) and corroborate previous findings indicating that most students considered plagiarism as a serious academic offence (Fish \& Hura, 2013; Gullifer \& Tyson, 2010; Selemani et al., 2018). These results do not support those revealing student superficial understanding of plagiarism (e.g., Amiri \& Razmjoo, 2016; Babaii \& Nejadghanbar, 2017; Du, 2020; Rathore et al., 2018; Rezanejad \& Rezaei, 2013; Stappenbelt, 2012), their confusions about its various forms (e.g., Amiri \& Razmjoo, 2016; Ehrich et al., 2016; Hu \& Lei, 2012), and unaware of their university expectations concerning plagiarism (Amiri \& Razmjoo, 2016; Ramzan et al., 2012; Stappenbelt, 2012). However, while the literature is limited to undergraduate and first-year engagement (e.g., Hu \& Lei, 2015; Stappenbelt, 2012) and postgraduate students in Asian contexts (e.g., Du, 2020; Rathore et al., 2018; Rezanejad \& Rezaei, 2013), the current study emphasises the importance of studying the postgraduate students' experiences in an international setting and not assuming that findings from other studies are relevant to that cohort.

\subsubsection{Student Attitudes towards Plagiarism}

The students perceived plagiarism as both an individual and organisational matter. On an individual level, most believed that (1) plagiarism was plagiarists' responsibility because it was related to personal ethical values; (2) stemmed from individual decisions and (3) negatively affected the people who plagiarised. On an organisational level, they considered (1) plagiarism as the responsibility of the academic institutions, emphasising that (2) plagiarism arose from flaws in the assessment process, policy enforcement, instructional practices, and support systems, and (3) it would result in various institutional impacts.

\section{Student attitudes towards plagiarism on a personal level}

Survey and interview participants considered intentional plagiarism as a moral concern because plagiarising students deceived themselves, the teaching staff, and original authors. Many students regarded plagiarism as serious as other types of larceny. Previous studies similarly reported that students viewed plagiarism as deceitful and stealing (Adam et al., 2016; Dawson \& Overfield, 2006; Gunnarsson et al., 2014; Shang, 2019). However, several interviewees did 
not consider plagiarism by undergraduates as immoral, contesting the link between plagiarism and personal moral values. They said that people could plagiarise for various reasons and plagiarism was more linked to plagiarism education, and policies. The findings support considerations of intentionality factors when dealing with student plagiarism (Adam, 2015a; Howard, 1993; Pecorari \& Petric, 2014) and corroborate the ideas of Grossberg (2009) and Senders (2009), who argued that student plagiarism should not be treated as literary theft.

Many survey and interview participants believed that students deliberately plagiarised mostly because of unearned benefits they could gain, confirming previous findings suggesting that plagiarism resulted from a desire to obtain high grades (Curtis \& Popal, 2011; Eret \& Ok, 2014). The students indicated various types of academic pressure that may contribute to student plagiarism. Those results are consistent with published studies which revealed that students might plagiarise due to time constraints (Adam et al., 2016; Hu \& Lei, 2015) and heavy workload pressure (Selemani et al., 2018; Sousa-Silva, 2014). Several VN-educated students mentioned challenges of transitioning to a new educational system as a reason for student plagiarism. An explanation for this may be that VN-educated participants better understood the challenges that NESB international students may encounter regarding plagiarism and academic integrity because they were studying in NZ, an unfamiliar cultural and educational environment from that of their home country. They were also aware of how insufficient academic skills would impact student academic writing abilities and performances.

Some interview participants considered inadvertent plagiarism as part of the learning process, a transition in the path to becoming a writer, or a means of knowledge acquisition. Many students thought accidental plagiarism should be treated differently from plagiarism with an attempt to cheat. The findings are aligned with a growing recognition of plagiarism as a learning and development issue (Blum, 2009; Gu \& Brooks, 2008; Howard, 2016) and further supporting consideration of patch-writing as a way to acquire content knowledge (Introna \& Hayes, 2008; Neville, 2007) and language (Howard, 1993; Pecorari \& Petric, 2014).

Many participants said that limited understanding of plagiarism, academic writing, referencing and citation conventions, and the university's expectations concerning plagiarism might result in unintentional plagiarism. The finding matches earlier findings showing that students plagiarised due to poor academic writing skills (Curtis \& Popal, 2011; Donnelly, 2013), and inadequate understanding of plagiarism, referencing conventions, and the university's 
expectation regarding plagiarism (Amiri \& Razmjoo, 2016; Devlin \& Gray, 2007; Song-Turner, 2008). One possible explanation for the results is that experiences as lecturers or tutors helped the participants understand the spectrum of student plagiarism and reasons for its occurrence. They were aware of the roles of academic institutions and faculty in managing student plagiarism and supporting their learning.

In the survey, both VN- and NZ-educated students held negative attitudes towards plagiarism. Many interview participants thought plagiarism would result in tremendous personal impacts such as immediate penalties if caught or losing trust from readers and wider communities. Some thought plagiarising students would lose learning opportunities because they did not critically engage with materials to the same degree as the non-plagiarisng students. The finding agrees with earlier findings showing that plagiarism would threaten student learning (Adam et al., 2016; Babaii \& Nejadghanbar, 2017).

\section{Student attitudes towards plagiarism on an organisational level}

In the online survey and interviews, many VN- and NZ-educated students viewed plagiarism as a breach of university obligations. They believed that most plagiarising students were aware of their behaviours but deliberately broke the rules. This finding agrees with previous findings showing that many students considered plagiarism as a violation of university rules (Adam et al., 2016; Gullifer \& Tyson, 2010; Selemani et al., 2018). This result may be explained by the fact that the participants were not only learners but also educators. In these roles, they considered not plagiarism as complying with the institutional requirements.

The participants pointed out several institutional factors that contributed to student plagiarism such as gaps in the assessment process, limited plagiarism policies, and lack of detection. The finding supports previous studies showing that many students plagiarised because of poor assessment design (Amsberry, 2009; Comas-Forgas \& Sureda-Negre, 2010; Walker \& White, 2014), limited plagiarism policies (Babaii \& Nejadghanbar, 2017; Walker \& White, 2014), and lack of detection (Devlin \& Gray, 2007; Sutherland-Smith, 2008). Many believed that plagiarism education would positively affect student ethical awareness which is aligned with previous findings that students might plagiarise because of limited education about the issue (Halupa \& Bolliger, 2015; Khathayut et al., 2020). The results seem to be due to participants' professional experiences. As lecturers and tutors, they understood the importance of education and were aware of what the institutions and lecturers could do to prevent plagiarism. 
Most VN-educated participants and two NZ-educated participants considered plagiarism as a scholarly offence because of attribution taken from the original writers. They thought plagiarism was against knowledge contribution. While no previous studies reported that postgraduate students hold this view, the findings support arguments of researchers who suggest that plagiarism was contrary to knowledge contribution (Balve, 2014; Bruton, 2014; Martin, 2016; Power, 2009; Vardi, 2012; Vehviläinen et al., 2018). The findings may be due to students' increased awareness of plagiarism and academic integrity as they progressed through their doctoral studies. More explanations for these findings will be given in Section 9.4.3 Influences of future aspirations.

Many interview participants were concerned about severe academic impacts of plagiarism. Several believed that plagiarism would threaten the meaning of the degree, consistent with previous studies where students believed that plagiarism threatened the intrinsic value of higher education (Dawson \& Overfield, 2006; Ehrich et al., 2015; Gunnarsson et al., 2014). The participants mentioned negative impacts of misattribution or incorrect citations on readers. They thought plagiarism countered good scholarship and offended fairness because of unearned benefits plagiarists received. Students in previous studies also thought plagiarism was unfair to original writers (e.g., Adam et al., 2016; Martin, 2016; Shang, 2019).

\subsection{Variations in Student Perceptions}

This section answers the two research sub-questions which explored variations in perceptions of students from diverse educational backgrounds, disciplines, and stages of study.

\subsubsection{Variations between Groups}

The first research sub-question sought to determine if there were differences in perceptions of plagiarism between VN- and NZ-educated cohorts: How do VN- and NZ-educated postgraduate students' attitudes and understanding of plagiarism differ between these groups? The online survey identified that VN-educated students' responses to three out of five subscales were significantly different from those of their NZ-educated counterparts. Interview data revealed differences in perceptions of the two groups in terms of focuses, level of concern, and degree of complexity in their discussions. These results echo previous studies suggesting a strong link between educational backgrounds and plagiarism perceptions (e.g., Marshall \& Garry, 2006; Perkins \& Roe, 2020; Sutton et al., 2014). The findings will be further discussed in Section 9.4.1. 
The most significant difference between the two groups was their perceived seriousness of the issue. In the survey, NZ-educated students perceived several forms of plagiarism more seriously than VN-educated students. NZ-educated students viewed direct copying and self-plagiarism more seriously than their VN-educated counterparts. The findings further support previous findings that international students viewed several types of plagiarism less seriously than local students (Ehrich et al., 2016; Hayes \& Introna, 2005; Marshall \& Garry, 2006; Sutton et al., 2014). The divergence can be explained by different levels of plagiarism instruction the two groups experienced prior to postgraduate studies. While VN-educated students received limited learning opportunities in their home country, NZ-educated students reported learning about plagiarism through multiple channels and platforms early in their undergraduate studies. (see Section 7.3: Prior learning about plagiarism)

Another noticeable difference was that NZ-educated students were more aware of the complexity of plagiarism than their VN-educated counterparts. While most Vietnam-educated talked about plagiarism as a moral and regulatory issue, NZ-educated students discussed more of its underlying academic impacts. More NZ-educated students considered plagiarism as a scholarly issue, emphasising that plagiarism prohibited the production of valuable academic work. One possible explanation for these results was differences in cultural capital regarding plagiarism possessed by the two groups (Howard, 2011; Kang \& Glassman, 2010; Riazantseva, 2012; Strangfeld, 2019). The difference can also be explained by differing educational approaches. While NZ higher education focuses on critical reading and thinking, memorisation and rote learning are common learning strategies in Vietnam. Researchers have speculated that academic experiences impacted how students viewed plagiarism (e.g., Hu \& Lei, 2015; SongTurner, 2008; Stappenbelt, 2012).

The survey findings suggest that VN-educated students were more likely than NZ-educated students to perceive that plagiarism resulted from academic factors. VN-educated interview participants were more sympathetic with student plagiarism, showing their understanding of reasons why students plagiarised. These findings might be due to dissimilar experiences in academic writing (Bloch, 2012; Marshall \& Garry, 2006; Pecorari, 2008) and professional experiences (Leonard et al., 2015). Also, all VN-educated students were full-time lecturers in Vietnam, and most were experienced lecturers. Their professional status may give them more insight into students' knowledge and skills which might affect their plagiarism perceptions. 
VN-educated survey participants were more likely than their NZ-educated counterparts to agree that plagiarism resulted from assessment factors. Similarly, interview data suggest that VN-educated students were more concerned about impacts of assessment practices on student plagiarism. These findings might be related to different assessment practices that the two groups experienced prior to postgraduate studies. Assessment methods focusing on textbook content are common in Vietnamese educational systems. Also, Vietnamese students had limited exposure to coursework before starting their studies in NZ.

Another important difference is that while NZ-educated participants talked about plagiarism broadly, VN-educated students illustrated constraints in plagiarism management at their home country universities. Students in the two groups also hold different beliefs about where the responsibility that plagiarism laid. While NZ-educated participants emphasised individuals' responsibility, their VN-educated counterparts underlined the responsibilities of institutions. These differences may relate to the fact that the two groups have different professional experiences. While all VN-educated participants were full-time lecturers in Vietnam, the NZeducated participants had been employed as tutors at VUW. The difference could also be attributed to many other factors that are discussed in Section 9.4: Theoretical perspectives on influences on student perceptions.

Finally, while NZ-educated students thought plagiarism would make them lose trust in plagiarists and their future work, most VN-educated students were concerned about the reactions of the wider communities. Differences between individualistic-collectivist cultural values (Chien, 2017; Sutton et al., 2014) provide a possible explanation because Chien (2017) suggests social relationships are more important in collective-oriented societies.

\subsubsection{Variations within Groups}

The second research sub-question focused on variations in student perceptions: How do VNand NZ-educated postgraduate students' attitudes and understanding of plagiarism differ within these groups? This study found connections between student perceptions and demographics: gender, age, level of study, stages of study, discipline, and teaching experience.

Findings from the survey indicated that female students possessed more negative attitudes towards plagiarism than males, confirming associations between gender and plagiarism perceptions in the literature (Bokosmaty et al., 2019; Gullifer \& Tyson, 2014; Jereb et al., 2018; 
Smith et al., 2007; Yeo, 2007). Bokosmaty et al. (2019), however, found that male students were more tolerant of plagiarism than their female counterparts. Jereb et al. (2018) revealed that male students possessed more positive attitudes towards plagiarism than females.

The online survey indicated differences in perceptions of plagiarism between younger and older students. Students who were older than 44 perceived plagiarism more seriously than those who were younger than 24 . The result is likely a consequence of variations in writing experience and length of exposure to academic environments (Hu \& Lei, 2015; Stappenbelt, 2012; Sutton et al., 2014). Another possible explanation is that older students would have longer exposure to professional environments which might impact their perceptions. (See Section 9.4.2)

The survey findings revealed that PhD students viewed plagiarism more seriously than master's students, confirming the relationship between academic level and understanding of plagiarism suggested in previous studies (Rinnert \& Kobayashi, 2005; Sutton et al., 2014). The findings could be explained by students' length of exposure to academic environments. While PhD students are committed to their research within three to four years, master's students complete their studies within a shorter timeframe. The more students progress through the academic path, the more they understand the seriousness of plagiarism. Master's and PhD students differed in their perceptions about the relationship between features of assessment and plagiarism which is perhaps the result of distinctive assessment activities that students at different levels have experienced. While master's programmes in NZ could be by either coursework or thesis, doctoral students are required to conduct research and produce theses.

Interview data revealed different levels of awareness and perceived seriousness of plagiarism among students at different stages of studies. Students who were writing up their theses were more aware of the complexity of plagiarism than those who were early in their studies. Senior students were more aware of their position and responsibility as academic writers. These results match previous findings showing that experienced writers were more aware of writing conventions and their responsibility as academic writers than those with less experience (e.g., Abasi et al., 2006; Hu \& Lei, 2015; Song-Turner, 2008). The findings may be due to differences in their length of exposure to academic writing and academic conventions. Another explanation for the results may be related to influences of environmental factors as suggested by Bandura's (1991) social cognitive theory of moral thought and action. 
Variations were found among students from different disciplines. In the online survey, students majoring in science possessed more negative attitudes towards plagiarism than education students. The interview students from different disciplines expressed distinctive moral values representing their disciplinary practices. The findings further support results from previous studies that student perceptions are associated with disciplinary norms (Hu \& Lei, 2015; Rinnert \& Kobayashi, 2005; Sutton et al., 2014). Sutton et al. (2014) reported a similar finding that plagiarism was viewed less seriously by business students than those from other faculties. Rinnert and Kobayashi (2005) found that the awareness of plagiarism among students majoring in liberal arts was higher than those coming from science. The findings support Bandura's (1991) social cognitive theory of moral thought and action which hypothesises that individuals adopt new moral standards through various platforms.

The analysis indicated a relationship between teaching experience and student perceptions. In the survey, students with earlier employment as a teacher or tutor agreed more strongly than those without teaching experience on impacts of academic factors on student plagiarism. Interview participants with more teaching experiences better understood factors for student plagiarism and were more sympathetic to student limitations as they experienced similar situations with their students. This is consistent with findings reported by Leonard et al. (2015) who showed that perceptions and understanding of plagiarism of students with professional experiences differed from those without experiences. Discussions about relationships between teaching experience and perceptions of plagiarism are presented in Section 9.4.2.

\subsection{Theoretical Perspectives of Influences on Student Perceptions}

The second research question addressed possible influences on student perceptions: What are the influences on VN- and NZ-educated postgraduate students' perceptions of plagiarism?

Student perceptions varied between and within the two groups of VN- and NZ-educated postgraduate students which could be attributed to variations in embodied cultural capital (parental strategic interaction, educational backgrounds, and personal experiences with plagiarism), environmental factors (disciplinary practices, professional contexts, and doctoral environments), and self-formation experiences. When discussing plagiarism, the students not only used their existing knowledge but drew on various experiences and observations from their educational and professional contexts. 


\subsubsection{Past Established Influences}

Drawing on Bourdieu's (1977) theory of cultural capital, the study identified various forms of cultural capital that might impact participants' views and understanding of plagiarism.

Interview participants received different levels of plagiarism instruction before commencing their doctoral studies. While the VN-educated students, who obtained their master's degree overseas reported learning about plagiarism in their overseas institutions, solely VN-educated students reported having fewer learning opportunities. Also, all NZ-educated students were instructed about plagiarism and related aspects during their tertiary education. The results confirm variations in plagiarism instruction among domestic and international in previous studies (Nguyen \& Buckingham, 2019; Stappenbelt, 2012; Sutherland-Smith, 2005b).

Varying plagiarism education opportunities between the two groups led to differences in their plagiarism perceptions. Compared to their VN-educated counterparts, NZ-educated students showed greater awareness of academic impacts of plagiarism and gave in-depth explanations for its complexity. This finding affirms Strangfeld's (2019) finding that student understanding of academic conventions resulted from their educational histories, which he considered a form of cultural capital, rather than immediate circumstances. Similarly, Kang and Glassman (2010) indicated moral thought developed through both cognitive development and experience as a type of cultural capital that assists in explaining complex moral issues.

Students experienced different educational approaches prior to postgraduate studies. While NZ-educated students emphasised critical thinking and creativity, VN-educated students said that Vietnamese educational system focused more on memorisation. VN- and NZ-educated students possessed diverse attitudes about assessment factors. Many scholars indicated different assessment practices among different educational systems (Amsberry, 2009; SongTurner, 2008). Leask (2006) similarly, pointed out differences in assessment and evaluation in different educational approaches.

The next cultural asset that influenced some students' perceptions of plagiarism was parental strategic interaction or parents' agency. Those whose parents were deliberately involved in their children's moral development held clear moral perspectives early in life. The result supports Strangfeld's (2019) finding that students' understanding of academic conventions was partly influenced by their parents' involvement and support. 
Past experiences as a victim of plagiarism or encountering plagiarism made the students respond more strongly to the practice. They also helped them be more aware of reasons for its occurrence and its impact. However, because such observations have not been reported in the literature and given the small sample size, these results need to be interpreted with caution.

\subsubsection{Current and On-going Influences}

In line with Bandura's (1991) social cognitive theory of moral thought and action, students developed new moral standards related to plagiarism appropriate to their recent and/or ongoing social realities and social roles. Environmental factors associated with their perceptions included disciplinary practices, professional norms, and doctoral environments.

The ways students viewed and addressed plagiarism partly reflected their disciplinary training and orientations. Interviewed students from different faculties held unique perspectives featuring their disciplinary norms and practices. Several drew on the knowledge they obtained in their disciplinary training when discussing plagiarism, showing the relationship between their disciplinary identity and perceptions. The findings confirm associations between disciplinary norms and perceptions of plagiarism in previous studies (Hu \& Lei, 2015; Pecorari, 2006; Rinnert \& Kobayashi, 2005; Sutton et al., 2014). The findings support Bandura's (1991) social cognitive theory of moral thought and action which hypothesises that individuals adopt new moral standards through various platforms to suit their social roles.

The survey indicated differences in perceptions and areas of concern among students with and without teaching experiences. As lecturers, VN-educated students were aware of the issue of plagiarism in their Vietnamese tertiary contexts, both on personal and organisational levels. NZ-educated students, who were experienced tutors, conveyed deep understanding of student plagiarism at VUW, the prevalence and reasons for its occurrence. The findings are consistent with those of previous research showing that professional experiences impacted students' perceptions and understanding of plagiarism (Leonard et al., 2015). Lecturing experiences exposed students to situations where they were directly involved with plagiarism, giving them a greater insight into why students committed plagiarism (see Chapter Eight: Influences on student perceptions). Those who had been employed as a teacher or tutor had more experience of working with students and dealing with their inappropriate behaviours. They also understood university's procedures and in managing plagiarism. Therefore, most hope to help 
their students improve their understanding of plagiarism and academic integrity and made them better learners and writers.

Section 9.3.1 described differences in perceptions of students at different stages of studies, indicating their increased awareness and understanding over time. The finding is consistent with previous studies showing associations between academic exposure and understanding improvement (Hu \& Lei, 2015; Song-Turner, 2008; Stappenbelt, 2012) and the effectiveness of university initiatives on student awareness (Divan et al., 2013; Du, 2020; Newton et al., 2014; Perkins \& Roe, 2020; Rathore et al., 2018). The findings can be explained by drawing on Bandura's (1991) theory which hypothesises that individuals improve their moral awareness in different educational environments.

In this study, VN-educated participants, who reported receiving less plagiarism education prior to VUW, demonstrated a greater shift in awareness about plagiarism than their NZ-educated counterparts. VN-educated students reported increased awareness of their responsibilities as doctoral students regarding plagiarism and appropriate source use. NZ-educated participants, however, affirmed that their attitudes towards plagiarism remained unchanged since they started their doctoral studies although they understood more about its severity and impacts on the academic community. The findings match those observed in an earlier study where international students showed greater improvement in understanding and skills than domestic students after a writing development programme (Divan et al., 2013).

The findings support the applicability for the study of influences on plagiarism of Bandura's (1991) social cognitive theory of moral thought and action which hypothesises that individuals enact agency through monitoring and regulating their own moral conduct, drawing on their moral standards. As emerging researchers, postgraduate students gradually developed their understanding of academic conventions which guarded them against plagiarism. VN-educated students, who were full-time lecturers in Vietnam, disengaged from plagiarism because they were aware of their responsibilities to set an example for their students. They also understood that the consequences would be severe for them as lecturers.

\subsubsection{Influences of Future Aspirations}

Most interview participants were found to actively engage in the self-formation process because they set out their goals from the beginning of their PhD and worked hard to achieve 
them. They significantly transformed through doctoral studies, either in disciplinary knowledge or knowledge of plagiarism. While previous studies reported expansion of knowledge due to academic exposure (Sutton et al., 2014) and university initiatives (Brown \& Howell, 2001; Newton et al., 2014; Sutton et al., 2014), in this study, the advancements in knowledge of plagiarism experienced by all the postgraduate participants, and VN-educated students' shifting perceptions of plagiarism were not merely developmental changes but influenced by future aspirations and purposeful decision making.

While most students showed a high level of agency, the self-formation processes were more significant and apparent for international than domestic students. The findings support Marginson's (2014) argument that domestic students' self-formation was less compelling compared to those of their international counterparts because of fewer obvious cultural challenges. He believes that self-formation of international students, which involves selfcultivation and self-improvement in a brief period of time is more substantial. In this study, agency of $\mathrm{VN}$-educated students was reflected in the way they responded to challenges, how they deliberately improved their knowledge and academic skills, and their efforts to develop their own voice and styles in writing. NZ-educated students also enacted agency to obtain their intellectual objectives. They strived to find their own voice in writing and write with integrity.

As they progressed through doctoral studies, both VN- and NZ-educated students started to see themselves as researchers and were committed to their studies. The findings confirm Marginson's (2014) ideas that students actively construct new identities in new academic contexts. The participants understood their responsibilities as research students and emerging researchers in making novel contributions to their field. The thesis writing process helped several participants understand and feel more strongly about impacts of plagiarism on original creators. Those who had been through the publication process showed deeper understanding and greater concern about academic impacts of plagiarism.

The study found that for both groups, level of agency was associated with motivations for doctoral studies. Accordingly, those who started their PhD because of a passion showed greater growth in their awareness of plagiarism than those who viewed their studies as a requirement to fulfill. However, because such observations have not been reported elsewhere and given the small size of the current study, these results need to be interpreted cautiously. 


\subsection{Conclusions}

\subsubsection{Implications of Findings}

While advancing understanding of postgraduate student perceptions of plagiarism, the findings suggest practical implications for lecturers, institutions, and postgraduate students to support good writing and referencing practices.

\section{Implications for lecturers}

This thesis points to practical implications which could help the university faculty engage with postgraduate students' needs and expectations in ways that respect their diverse social and educational backgrounds, and generate meaningful and productive outcomes across student groups, thus enhancing equity.

The findings highlight that VN- and NZ-educated postgraduate students are diverse in terms of demographics, educational experiences, motivations, and expectations. These variations need to be recognised and addressed without treating them as deficiencies. Lecturers and supervisors, especially those who work with international students from other academic contexts, should focus on acknowledging their differing starting points and providing them with support that is needs-based, to enhance and maximise their learning experience.

The students received different levels of plagiarism education prior to doctoral studies which impacted how they perceived plagiarism. While NZ-educated students were informed as undergraduates about plagiarism and related issues through various channels, VN-educated students received limited instructions about plagiarism in their undergraduate degrees. This suggests that academic staff should communicate information about plagiarism at the start of every course rather than making assumptions about student understanding (e.g., how plagiarism is defined by the university, what would be considered plagiarism, what students could do to avoid it, and consequences if they are found to have committed plagiarism). If lecturers suggested learning resources for students, it would enhance their study efficiency and contribute to their academic development.

The results of this study suggest that students from different disciplines might possess diverse perceptions of plagiarism, which potentially result from variations in disciplinary norms and ideologies, and citation and referencing requirements in specific disciplines. It is recommended 
that lecturers who work with students from different disciplines should take into consideration students' existing disciplinary knowledge and practice to better facilitate their learning. These diversities should also be acknowledged when addressing and dealing with student plagiarism. Students' professional experiences and roles affected their perceptions of plagiarism. Those with lecturing and tutoring experiences showed greater understanding of plagiarism in university contexts, its academic impacts, and reasons for its occurrence. This suggests that lecturers could benefit from becoming aware of student backgrounds that might lead to differences in their perceptions. They could also actively encourage or facilitate teaching roles as part of PhD study to help students develop deeper understanding of plagiarism.

Because all interview participants were doctoral students, there are also implications for supervisors. Not all interview participants shared the same level of understanding about plagiarism although all were doctoral students. Students who have been through the publication process better understood the complexity of plagiarism, especially its academic impacts. Therefore, lecturers who supervise doctoral students should prioritise discussions at the beginning of their PhD to learn about their prior experiences and/or current understanding of plagiarism, so they may identify and provide them with appropriate support. Such a needsbased approach might include directing them to specific resources which will be most suitable to support their knowledge development and relevant for their disciplinary context. Supervisors could also encourage different forms of writing beyond thesis writing (e.g., conference papers, journal articles) and have students engage in academic writing as early as possible to help them develop a wide continuum of academic skills.

\section{Implications for academic institutions}

Several practical implications for academic institutions are evident, especially universities with diverse groups of international students. Consistent with observations in the literature (e.g., Fatemi \& Saito, 2020; Franken, 2013; Schmitt, 2005; Tobbell \& O’Donnell, 2013), the scholarly journey was tougher and more challenging for $\mathrm{VN}$-educated students who came from different academic, language, and cultural backgrounds. Results from this study support moving beyond merely policing policy to focusing on supporting student learning, taking into consideration their diverse backgrounds and needs. I recommend integrating communication of plagiarism policy with teaching skills to engage with sources. 
The findings of the study imply that there is no generic remedy for plagiarism. A deep understanding of student contexts may avoid problems arising from institutional staff making incorrect assumptions about students' perceptions and help to develop more comprehensive support resources. Students are diverse, and their needs and expectations are dynamic with different academic contexts embedded in different cultures.

Next, the finding that not all VN-educated postgraduate students were concerned about academic impacts of plagiarism suggests the need for institutions to create a more effective environment that prepares students to enter academia or to become scholars, especially those from other academic cultures. Enhancing students' awareness of knowledge contribution and values of correct practices would hopefully promote a culture of academic integrity.

The study evidenced that VN-educated students' purposes of international doctoral education included improving oneself, bettering their lecturing career, and contributing to their home country and institution after finishing their studies. The finding suggests the importance of focusing not only on students' awareness of plagiarism when they were in host countries but also implications for plagiarism education that they could use in their later careers.

The findings suggest that student understanding of plagiarism increased significantly during the supervision and doctoral processes. Although most students believed that VUW had effectively informed them about plagiarism, the university practice could be enhanced. I recommend that the university creates more learning opportunities and accessible information. Some opportunities could include tutorials, course outlines, online learning platforms, workshops, seminars, and orientations. Frequent emphasis on these materials throughout students' programmes will help to increase their awareness significantly. Because student needs and current knowledge are diverse, the university could consider providing a raft of resources with which students can engage as needed.

Finally, the doctoral students in this study encountered various challenges both within and outside academic environments, and not all of them made good use of support services. These influence their wellbeing, mental health, and academic performance. Therefore, institutions should investigate barriers that students experience related to accessing support services. Developing this knowledge will help institutions to make these services more accessible, which could help students either to settle into academic life or to maximise their learning experiences. 


\section{Implications for students}

There are several recommendations for students on how to navigate university life and avoid accusations of plagiarism, which might be disseminated to students through institutions or lecturers who work with international and domestic tertiary students. Within the current neoliberal model, this is consistent with the responsibilities of a provider towards their consumers.

Firstly, understanding the university's rules and expectations is fundamental to acceptance in the academic community and successful navigation of university study. To comply with their university's requirements related to plagiarism, students should actively learn about plagiarism policies at their current university (e.g., how plagiarism is defined by the university, what constitutes plagiarism, and how they could avoid it). Apart from possessing basic knowledge about plagiarism and academic integrity, students need to develop good citing and referencing skills. They should understand not only the value of correct academic practice but how referencing can enhance their writing and position their work. Also, students need to know differences in teaching and assessment standards between their previous and current universities to formulate appropriate learning strategies. They should also learn about available support services at the university (e.g., student learning, international student support, student counselling, and financial support and advice) where they can get advice, guidance, and support not only for everyday but also academic issues.

\subsubsection{Limitations and Suggestions for Further Research}

There are several limitations of the study that other researchers need to consider when interpreting the findings. Based on these limitations, several suggestions for future research are provided.

Firstly, this study was limited to VN- and NZ-educated postgraduate students, so results need to be interpreted with caution when applied to other student populations. More research is needed to validate these findings. Future research may include international students from other countries to explore and understand how perceptions of each student cohort are different, and the nature of influences on their perceptions.

The second limitation is related to participant selection strategies for the qualitative phase. Because the duration of the master's degree programme at VUW is from one and a half to two years, I considered that the intensity of the programme did not make it manageable for 
master's students to participate in a set of four interviews; therefore, all selected interviewees were PhD students. Also, there were more students from the Faculty of Education, Science, and Humanities and Social Sciences than the other two faculties. No students were from the Faculty of Health, Law, and Architecture and Design. Therefore, the sample might not fully represent the VN- and NZ-educated postgraduate student population at VUW.

As a qualitative dominant mixed methods study, the quantitative phase did not require a large sample. However, future studies may be undertaken with larger sample sizes so that the findings could be generalised across New Zealand universities. Large-scale studies also enable an examination of possible interactions between different variables.

The final limitation is related to the validity and reliability of the survey instrument. Although the instrument has been through various validation processes (pretesting, piloting, and exploratory factor analysis) for exploratory purposes, further validation (confirmatory factor analysis) might be added before using the tool. Also, because factor loadings for some items were relatively low, future researchers could consider excluding these marginal items. They could include larger sample sizes to obtain more stable pattern structures. Next, although the overall alpha for the Plagiarism Perception Scale with 29 items was .73, well within the expected range for a reliable instrument, the alpha value for Subscale 4 with three items was relatively low (.59). Future researchers could consider adding more related items to the subscale to improve its alpha value.

\subsubsection{Contributions of the Study}

This section highlights the contributions of the study to the literature on plagiarism, its methodological contributions, and theoretical contributions.

\section{Empirical contributions}

The main contribution of this study lies in evidence regarding doctoral student perceptions of plagiarism, especially Vietnamese and New Zealand students. While numerous studies have explored how international students in Australia, the UK, and the USA perceive plagiarism, only two address student perception of plagiarism in New Zealand contexts (Adam et al., 2016; Marshall \& Garry, 2006), and both studies included undergraduate students. Five studies on plagiarism in Vietnamese contexts (Do et al., 2016; Nguyen \& Buckingham, 2019; Perkins et al., 2018; Perkins \& Roe, 2020; Tran et al., 2018) focused on the prevalence of and reasons for 
student plagiarism but not their perceptions. Only two studies focused on perceptions of Vietnamese international students, both in Australian contexts (Doan, 2012; Tran, 2012). However, Doan (2012) did not state the participants' academic levels; Tran (2012) included Vietnamese students as a sub-group of international students. No previous studies have examined doctoral students' perceptions in international education settings.

The findings suggest that as PhD students, VN- and NZ-educated postgraduate students were aware of plagiarism and fundamental principles of academic integrity. Most students were concerned about how plagiarism would break trust and offend fairness. They understood their responsibility to contribute to the knowledge base, emphasised the importance of honesty on the part of academic writers and showed their respect for academics in their field.

The study provides comprehensive understanding of similarities and differences in perceptions of VN- and NZ-educated students that speak to the broader domestic/international dichotomy. Although VN-educated students viewed plagiarism less seriously than their NZ-educated counterparts, they possessed substantial understanding of plagiarism because they could identify various forms of plagiarism and were aware of its various impacts. NZ-educated students understood the complexity of plagiarism better than their VN-educated counterparts.

This study goes beyond the rule-based understanding of plagiarism by focusing on an in-depth explanation of influences on student perceptions, knowledge of which would allow universities and academics to take an holistic stance on the problem. Greater knowledge of students could assist in avoiding any stereotypes of international students and potentially provide a more effective response to the issue. The finding that student knowledge and perceptions of plagiarism improved during doctoral studies is useful for developing interventions to help students increase their understanding and awareness.

This study provides new insights into multiple factors influencing plagiarism perceptions, explaining differences in perceptions of students from diverse familial, educational, disciplinary, and professional backgrounds. The data further supports the idea that plagiarism was not merely a cultural issue but rooted in educational histories and wider environmental and developmental factors. While complementing previous research, the findings provide broader contextual information for managing and dealing with student plagiarism. The findings may assist in developing interventions that align with the needs of different groups of students. 
Next, the study demonstrates the value of the three theoretical lenses (cultural capital theory, social cognitive theory of moral thought and action, and student self-formation theory) for exploring student perceptions which potentially illuminates influences on their perceptions. Findings from this study provide a platform for further investigations of the research problem.

\section{Methodological contributions}

Methodologically, most studies exploring student perceptions have been quantitative, using self-report questionnaires (e.g., Bamford \& Sergiou, 2005; Bokosmaty et al., 2019; Egan, 2008; Ehrich et al., 2016; Hayes \& Introna, 2005; Maxwell et al., 2008; Stappenbelt, 2012) and scenarios (e.g., Marshall \& Garry, 2006; Maxwell et al., 2008; Sutton et al., 2014). There has been little qualitative analysis to support deeper and more complete understanding of the subject (e.g., Adam, 2015b; Adam et al., 2016; Gullifer \& Tyson, 2010).

Therefore, this mixed-method analysis allowed a broad and in-depth exploration of students which could not be achieved using purely quantitative or qualitative research. Using a mixedmethod research design, this study contributes both an overview of student perceptions and deeper understanding of sources of their perceptions. The study provides not only information about VN- and NZ-educated student perceptions of plagiarism but also an in-depth exploration of their shifting perceptions over a period of time.

\section{Theoretical contributions}

This study has several theoretical contributions. Because few studies in this field have described theories underpinning their scholarship, this study offered an exploration of theoretical perspectives on factors influencing student perceptions. It illuminates an additional perspective for interpreting cultural capital in the context of plagiarism.

The study found that each of the three theories has its own strength and made unique contributions to the investigation of student perceptions of plagiarism. While cultural capital theory illuminated influences that were rooted in parental and educational histories, social cognitive theory of moral thought and action helped to identify possible environmental influences, highlighting bidirectional relationships among environments, students' moral thinking, and their moral behaviours. Self-formation theory explained relationships between doctoral engagement and perceptions of plagiarism and helped to illuminate differences in 
perceptions between self-motivated students who were aware of developing their capacity to be part of the academic community and those who started their PhD to fulfill a job requirement. The study indicated how the theories may apply to each student cohort. Bandura's (1991) social cognitive theory of moral thought and action and Marginson's (2014) student self-formation better explained influences on VN-educated students' perceptions of plagiarism than Bourdieu's cultural capital theory. The findings suggested that while Bandura's theory might illuminate experiences of students from collectivist cultures, Bourdieu's (1977) theory was more applicable for students from individualist societies. Marginson's (2014) theory, however, may apply to both domestic and international students.

An application of a theoretical framework means that this research offers a contrasting perspective to deficit models of plagiarism applied to international students. In this way, the study contributes to efforts to achieve socially just and equitable education for culturally diverse students, especially those who undertake university study beyond their home country. 


\section{References}

Abasi, A. R., Akbari, N., \& Graves, B. (2006). Discourse appropriation, construction of identities, and the complex issue of plagiarism: ESL students writing in graduate school. Journal of Second Language Writing, 15(2), 102-117.

https://doi.org/10.1016/j.jslw.2006.05.001

Abasi, A. R., \& Graves, B. (2008). Academic literacy and plagiarism: Conversations with international graduate students and disciplinary professors. Journal of English for Academic Purposes, 7(4), 221-233. https://doi.org/10.1016/j.jeap.2008.10.010

Adam, L. (2015a). Student perspectives on plagiarism. In T. Bretag (Ed.), Handbook of academic integrity (pp. 519-536). Springer. https://doi.org/10.1007/978-981-287-0797 67-1

Adam, L. (2015b). Troubling plagiarism: University students' understandings of plagiarism [Unpublished doctoral thesis, University of Otago]. Dunedin, New Zealand. http://hdl.handle.net/10523/5712

Adam, L., Anderson, V., \& Spronken-Smith, R. (2016). 'It's not fair': Policy discourses and students' understandings of plagiarism in a New Zealand university. Higher Education, 74(1), 1-16. https://doi.org/10.1007/s10734-016-0025-9

Adhikari, S. (2018). Beyond culture: Helping international students avoid plagiarism. Journal of International Students, 8(1), 375-388. https://doi.org/10.5281/zenodo.1134315

Ahmad, U. K., Mansourizadeh, K., \& Ai, G. K. M. (2012). Non-native university students' perception of plagiarism. Advances in Language and Literary Studies, 3(1), 39-48. https://doi.org/10.7575/aiac.alls.v.3n.1p.39

Ali, H. I. H., \& Alhassan, A. (2021). Fighting contract cheating and ghostwriting in Higher Education: Moving towards a multidimensional approach. Cogent Education, 8(1), 1-18. https://doi.org/10.1080/2331186X.2021.1885837

Amiri, F., \& Razmjoo, S. A. (2016). On Iranian EFL undergraduate students' perceptions of plagiarism. Journal of Academic Ethics, 14(2), 115-131.

https://doi.org/10.1007/s10805-015-9245-3

Amsberry, D. (2009). Deconstructing plagiarism: International students and textual borrowing practices. The Reference Librarian, 51(1), 31-44.

https://doi.org/10.1080/02763870903362183

Anderson, M. S., \& Steneck, N. H. (2011). The problem of plagiarism. Urologic Oncology: Seminars and Original Investigations, 29(1), 90-94.

https://doi.org/10.1016/j.urolonc.2010.09.013

Babaii, E., \& Nejadghanbar, H. (2017). Plagiarism among Iranian graduate students of language studies: Perspectives and causes. Ethics \& Behavior, 27(3), 240-258. https://doi.org/10.1080/10508422.2016.1138864 
Babbie, E. R. (2017). The basics of social research (7th ed.). Cengage Learning.

Badke, W. (2007). Give plagiarism the weight it deserves. Online, 31(5), 58-60.

Balve, J. (2014). Authorship, plagiarism and cooperation in higher education: Conclusions from experiences with Asian cultures and learning environments. Journal of Asian Pacific Communication, 24(1), 81-93. https://doi.org/10.1075/japc.24.1.05bal

Bamford, J., \& Sergiou, K. (2005). International students and plagiarism: An analysis of the reasons for plagiarism among international foundation students. Investigations in University Teaching and Learning, 2(2), 17-22.

Bandura, A. (1986). Social foundations of thought and action: A social cognitive theory. Prentice Hall.

Bandura, A. (1991). Social cognitive theory of moral thought and action. In W. M. Krytines \& J. L. Gewirtz (Eds.), Handbook of moral behavior and development (Vol. 1, pp. 45-103). Lawrence Erlbaum Associates Publishers.

Bandura, A. (2002). Selective moral disengagement in the exercise of moral agency. Journal of Moral Education, 31(2), 101-119. https://doi.org/10.1080/0305724022014322

Bandura, A. (2006). Toward a psychology of human agency. Perspectives on Psychological Science, 1(2), 164-180. https://doi.org/10.1111/j.1745-6916.2006.00011.x

Bandura, A., Barbaranelli, C., Caprara, G. V., \& Pastorelli, C. (1996). Mechanisms of moral disengagement in the exercise of moral agency. Journal of Personality and Social Psychology, 71(2), 364-374. https://doi.org/10.1037/0022-3514.71.2.364

Barnacle, R. (2005). Research education ontologies: Exploring doctoral becoming. Higher Education Research \& Development, 24(2), 179-188. https://doi.org/10.1080/07294360500062995

Becker, S., Johnson, D., \& Britton, P. (2019). Mapping the challenges in making the transition to taught postgraduate study in psychology. Psychology Teaching Review, 25(1), 12-21.

Belter, R. W., \& Du Pré, A. (2009). A strategy to reduce plagiarism in an undergraduate course. Teaching of Psychology, 36(4), 257-261. https://doi.org/10.1080/00986280903173165

Bennett, R. (2005). Factors associated with student plagiarism in a post-1992 university. Assessment \& Evaluation in Higher Education, 30(2), 137-162. https://doi.org/10.1080/0260293042000264244

Bird, S. (2002). Self-plagiarism and dual and redundant publications: What is the problem? Science and Engineering Ethics, 8(4), 543-544. https://doi.org/10.1007/s11948-002$\underline{0007-4}$

Bloch, J. (2012). Plagiarism, intellectual property and the teaching of L2 writing. Multilingual Matters. http://site.ebrary.com/lib/vuw/Doc?id=10582799 
Blum, S. D. (2009). Academic integrity and student plagiarism: A question of education, not ethics. The Chronicle of Higher Education, 55(24), 1-5.

Bokosmaty, S., Ehrich, J., Eady, M. J., \& Bell, K. (2019). Canadian university students' gendered attitudes toward plagiarism. Journal of Further and Higher Education, 43(2), 276-290. https://doi.org/10.1080/0309877X.2017.1359505

Borg, E. (2009). Local plagiarisms. Assessment \& Evaluation in Higher Education, 34(4), 415426. https://doi.org/10.1080/02602930802075115

Born, A. D. (2003). How to reduce plagiarism. Journal of Information Systems Education, 14(3), 223-224. http://www.jise.org/Volume14/14-3/Pdf/14(3)-223.pdf

Bourdieu, P. (1973). Cultural reproduction and social reproduction. In R. Brown (Ed.), Knowledge, education, and cultural change (pp. 7-84). Tavistock Publications.

Bourdieu, P. (1977). Cultural reproduction and social reproduction. In J. K. A. H. Halsey (Ed.), Power and ideology in education (pp. 487-511). Oxford University Press.

Bourdieu, P. (1986). The forms of capital. In J. G. Richardson (Ed.), Handbook of theory and research for the sociology of education (pp. 241-258). Macmillan.

Bouville, M. (2008). Plagiarism: Words and ideas. Science and Engineering Ethics, 14(3), $311-$ 322. https://doi.org/10.1007/s11948-008-9057-6

Braun, V., \& Clarke, V. (2006). Using thematic analysis in psychology. Qualitative Research in Psychology, 3(2), 77-101. https://doi.org/10.1191/1478088706qp063oa

Bretag, T. (2013). Challenges in addressing plagiarism in education. PLoS Medicine, 10(12), e1001574. https://doi.org/10.1371/journal.pmed.1001574

Bretag, T., \& Mahmud, S. (2009). Self-plagiarism or appropriate textual re-use? Journal of Academic Ethics, 7(3), 193-205. https://doi.org/10.1007/s10805-009-9092-1

Briggs, R. (2009). Shameless! Reconceiving the problem of student plagiarism. Angelaki: Journal of the Theoretical Humanities, 14(1), 65-75. https://doi.org/10.1080/09697250903006476

Brown, T. A. (2015). Confirmatory factor analysis for applied research (2nd ed.). Guilford Press.

Brown, V., \& Howell, M. (2001). The efficacy of policy statements on plagiarism: Do they change students' views? Research in Higher Education, 42(1), 103-118.

https://doi.org/10.1023/A:1018720728840

Bruton, S. V. (2014). Self- plagiarism and textual recycling: Legitimate forms of research misconduct. Accountability in Research, 21(3), 176-197.

https://doi.org/10.1080/08989621.2014.848071 
Burnett, A. J., Smith, T. M. E., \& Wessel, M. T. (2016). Use of the social cognitive theory to frame university students' perceptions of cheating. Journal of Academic Ethics, 14(1), 49-69. https://doi.org/10.1007/s10805-015-9252-4

Camara, S., Eng-Ziskin, S., Wimberley, L., Dabbour, K. S., \& Lee, C. M. (2017). Predicting students' intention to plagiarize: An ethical theoretical framework. Journal of Academic Ethics, 15(1), 1-16. https://doi.org/10.1007/s10805-016-9269-3

Carroll, J. (2008). Assessment issues for international students and for teachers of international students. The Higher Education Academy, 1-13.

http://www.hear.ac.uk/assets/documents/rc import/carroll.pdf

Carroll, J. (2009). Plagiarism as a threat to learning: An educational response. In G. Joughin (Ed.), Assessment, learning and judgement in higher education (pp. 115-131). Springer.

Carroll, J. (2016). Making decisions on management of plagiarism cases where there is a deliberate attempt to cheat. In T. Bretag (Ed.), Handbook of academic integrity (pp. 199-219). Springer.

Carroll, J., \& Zetterling, C. (2009). Guiding students away from plagiarism. KTH Learning Lab and the authors.

Chandrasoma, R., Thompson, C., \& Pennycook, A. (2004). Beyond plagiarism: Transgressive and nontransgressive intertextuality. Journal of Language, Identity \& Education, 3(3), 171-193. https://doi.org/10.1207/s15327701jlie0303 1

Cheah, J. K. S. (2016). Perspectives on academic plagiarism in Malaysia. In T. Bretag (Ed.), Handbook of academic integrity (pp. 87-91). Springer.

Chen, Y., \& Chou, C. (2016). Are we on the same page? College students' and faculty's perception of student plagiarism in Taiwan. Ethics \& Behavior, 27(1), 53-73. https://doi.org/10.1080/10508422.2015.1123630

Chen, Y. H., \& Van Ullen, M. K. (2011). Helping international students succeed academically through research process and plagiarism workshops. College \& Research Libraries, 72(3), 209-235. https://doi.org/10.5860/crl-117rl

Chien, S. (2017). Taiwanese college students' perceptions of plagiarism: Cultural and educational considerations. Ethics \& Behavior, 27(2), 118-139. https://doi.org/10.1080/10508422.2015.1136219

Cohen, L., Manion, L., \& Morrison, K. (2011). Research methods in education. Routledge.

Collier, P., \& Morgan, D. (2008). "Is that paper really due today?": Differences in firstgeneration and traditional college students' understandings of faculty expectations. Higher Education, 55(4), 425-446. https://doi.org/10.1007/s10734-007-9065-5

Collins, R. (2014). Interaction ritual chains (2nd ed.). Princeton University Press. https://doi.org/10.2307/j.ctt13x0rs3 
Comas-Forgas, R., \& Sureda-Negre, J. (2010). Academic plagiarism: Explanatory factors from students' perspective. Journal of Academic Ethics, 8(3), 217-232.

https://doi.org/10.1007/s10805-010-9121-0

Creswell, J. W. (2008). Educational research: Planning, conducting, and evaluating quantitative and qualitative research. Prentice Hall Upper Saddle River.

Creswell, J. W. (2014). Research design: Qualitative, quantitative, and mixed methods approaches. Sage.

Creswell, J. W. (2015). A concise introduction to mixed methods research. Sage.

Creswell, J. W. (2018). Qualitative inquiry \& research design: Choosing among five approaches (4th ed.). Sage.

Creswell, J. W., \& Clark, V. L. P. (2018). Designing and conducting mixed methods research (3rd ed.). Sage.

Culwin, F. (2006). An active introduction to academic misconduct and the measured demographics of misconduct. Assessment \& Evaluation in Higher Education, 31(2), 167-182. https://doi.org/10.1080/02602930500262478

Curtis, G. J., \& Popal, R. (2011). An examination of factors related to plagiarism and a five-year follow-up at an Australian university. International Journal for Educational Integrity, 7(1), 30-42. https://doi.org/10.21913/IJEI.v7i1.742

Curtis, G. J., \& Tremayne, K. (2019). Is plagiarism really on the rise? Results from four 5-yearly surveys. Studies in Higher Education, 1-11.

https://doi.org/10.1080/03075079.2019.1707792

Curtis, G. J., \& Vardanega, L. (2016). Is plagiarism changing over time? A 10-year time-lag study with three points of measurement. Higher Education Research \& Development, 35(6), 1-13. https://doi.org/10.1080/07294360.2016.1161602

Davies, S., \& Rizk, J. (2018). The three generations of cultural capital research: A narrative review. Review of Educational Research, 88(3), 331-365. https://doi.org/10.3102/0034654317748423

Davis, M., Davis, K. J., \& Dunagan, M. (2012). Scientific papers and presentations (3rd ed.). Elsevier Science.

Dawson, M. M., \& Overfield, J. A. (2006). Plagiarism: Do students know what it is? Bioscience Education, 8(1), 1-15. https://doi.org/10.3108/beej.8.1

de Jager, K., \& Brown, C. (2010). The tangled web: Investigating academics' views of plagiarism at the University of Cape Town. Studies in Higher Education, 35(5), 513-528. https://doi.org/10.1080/03075070903222641

DeVellis, R. F. (2017). Scale development: Theory and applications (4th ed.). Sage. 
Devlin, M., \& Gray, K. (2007). In their own words: A qualitative study of the reasons Australian university students plagiarize. Higher Education Research \& Development, 26(2), 181198. https://doi.org/10.1080/07294360701310805

Dimaggio, P. (1982). Cultural capital and school success: The impact of status culture participation on the grades of U.S. high school students. American Sociological Review, 47(2), 189-201.

Divan, A., Bowman, M., \& Seabourne, A. (2013). Reducing unintentional plagiarism amongst international students in the biological sciences: An embedded academic writing development programme. Journal of Further and Higher Education, 39(3), 1-21. https://doi.org/10.1080/0309877X.2013.858674

Do, B. K., Do, B. K., Lam, Q. D., Le, D. T. B. A., Nguyen, P. L., Nguyen, P. Q., \& Pham, Q. L. (2016). Student plagiarism in higher education in Vietnam: An empirical study. Higher Education Research \& Development, 36(5), 934-946.

https://doi.org/10.1080/07294360.2016.1263829

Doan, T. (2012). Vietnamese students' view on plagiarism in the Australian context. The Internet Journal of Language, Culture and Society(34), 26-32.

Donnelly, M. (2013). Critical conversations about plagiarism. Parlor Press. http://ebookcentral.proquest.com/lib/vuw/detail.action?doclD=3440290

Doss, D. A., Henley, R., Gokaraju, B., McElreath, D., Lackey, H., Hong, Q., \& Miller, L. (2016). Assessing domestic vs. international student perceptions and attitudes of plagiarism. Journal of International Students, 6(2), 542-565. https://doi.org/10.32674/jis.v6i2.370

Dougherty, M. V. (2020). Disguised academic plagiarism: A typology and case studies for researchers and editors (1st ed. 2020. ed.). Springer International Publishing. https://doi.org/10.1007/978-3-030-46711-1

Drinan, P. M., \& Gallant, T. B. (2008). Plagiarism and academic integrity systems. Journal of Library Administration, 47(3-4), 125-140. https://doi.org/10.1080/01930820802186472

Du, Y. (2020). Evaluation of intervention on Chinese graduate students' understanding of textual plagiarism and skills at source referencing. Assessment \& Evaluation in Higher Education, 45(1), 14-29. https://doi.org/10.1080/02602938.2019.1601680

Duff, A. H., Rogers, D. P., \& Harris, M. B. (2006). International engineering students: Avoiding plagiarism through understanding the Western academic context of scholarship. European Journal of Engineering Education, 31(6), 673-681. https://doi.org/10.1080/03043790600911753

Dumais, S. A. (2002). Cultural capital, gender, and school success: The role of habitus. Sociology of Education, 75(1), 44-68. https://doi.org/10.2307/3090253

Dumais, S. A., \& Ward, A. (2010). Cultural capital and first-generation college success. Poetics, 38(3), 245-265. https://doi.org/10.1016/j.poetic.2009.11.011 
East, J. (2010). Judging plagiarism: A problem of morality and convention. Higher Education, 59(1), 69-83. https://doi.org/10.1007/s10734-009-9234-9

Egan, V. (2008). A cross-cultural and cross-gender comparison of attitudes to plagiarism: The case of Malaysian and Australian business students. AFBE Journal, 1(1), 19-33.

Ehrich, J., Howard, S., Tognolini, J., \& Bokosmaty, S. (2015). Measuring attitudes toward plagiarism: Issues and psychometric solutions. Journal of Applied Research in Higher Education, 7(2), 243-257. https://doi.org/10.1108/JARHE-02-2014-0013

Ehrich, J., Howard, S. J., Mu, C., \& Bokosmaty, S. (2016). A comparison of Chinese and Australian university students' attitudes towards plagiarism. Studies in Higher Education, 41(2), 231-246. https://doi.org/10.1080/03075079.2014.927850

Ellery, K. (2008). Undergraduate plagiarism: A pedagogical perspective. Assessment \& Evaluation in Higher Education, 33(5), 507-516. https://doi.org/10.1080/02602930701698918

Eret, E., \& Ok, A. (2014). Internet plagiarism in higher education: Tendencies, triggering factors and reasons among teacher candidates. Assessment \& Evaluation in Higher Education, 39(8), 1002-1016. https://doi.org/10.1080/02602938.2014.880776

Evering, L. C., \& Moorman, G. (2012). Rethinking plagiarism in the digital age. Journal of Adolescent and Adult Literacy, 56(1), 35-44. https://doi.org/10.1002/JAAL.00100

Fabrigar, L. R., \& Wegener, D. T. (2012). Exploratory factor analysis. Oxford University Press.

Farahian, M., Avarzamani, F., \& Rezaee, M. (2021). Plagiarism in higher education across nations: A case of language students. Journal of Applied Research in Higher Education. https://doi.org/10.1108/JARHE-09-2020-0309

Fatemi, G., \& Saito, E. (2020). Unintentional plagiarism and academic integrity: The challenges and needs of postgraduate international students in Australia. Journal of Further and Higher Education, 44(10), 1-15. https://doi.org/10.1080/0309877X.2019.1683521

Field, A. P. (2009). Discovering statistics using SPSS (3rd ed.). Sage.

Fish, R., \& Hura, G. (2013). Students' perceptions of plagiarism. Journal of the Scholarship of Teaching and Learning, 13(5), 33-45. https://scholarworks.iu.edu/journals/index.php/josotl/article/view/3654/3865

Foltýnek, T., Rybička, J., \& Demoliou, C. (2014). Do students think what teachers think about plagiarism? International Journal for Educational Integrity, 10(1), 21-30. https://doi.org/10.21913/IJEl.v10i1.931

Franken, M. (2012). Re-situation challenges for international students 'becoming'researchers. Higher Education, 64(6), 845-859. https://doi.org/10.1007/s10734-012-9532-5 
Franken, M. (2013). Significant knowledge transitions and resituation challenges in becoming a researcher: International scholarship students' perspectives. International Journal for Researcher Development, 4(2), 86-102. https://doi.org/10.1108/IJRD-04-2013-0006

Geraldi, J. (2021). Self-plagiarism in project studies: A call for action and reflection. Project Management Journal, 1-8. https://doi.org/10.1177/8756972820982445

Gipp, B. (2014). Citation-based plagiarism detection detecting disguised and cross-language plagiarism using citation pattern analysis. Springer.

Gourlay, L., \& Deane, J. (2012). Loss, responsibility, blame? Staff discourses of student plagiarism. Innovations in Education and Teaching International, 49(1), 19-29. https://doi.org/10.1080/14703297.2012.647780

Graff, G., \& Birkenstein, C. (2006). They say, I say. W. W. Norton Company.

Green, M. M., Williams, M., \& Van Kessel, G. (2006). How well do postgraduate students identify plagiarism? Focus on Health Professional Education: A Multi-disciplinary Journal, 7(3), 48-61.

Grossberg, M. (2009). History and the disciplining of plagiarism. In C. Eisner \& M. Vicinus (Eds.), Originality, imitation, and plagiarism: Teaching writing in the digital age (pp. 159-183). University of Michigan Press.

Gu, Q., \& Brooks, J. (2008). Beyond the accusation of plagiarism. System, 36(3), 337-352. https://doi.org/10.1016/j.system.2008.01.004

Gullifer, J., \& Tyson, G. A. (2010). Exploring university students' perceptions of plagiarism: A focus group study. Studies in Higher Education, 35(4), 363-381. https://doi.org/10.1080/03075070903096508

Gullifer, J., \& Tyson, G. A. (2014). Who has read the policy on plagiarism? Unpacking students' understanding of plagiarism. Studies in Higher Education, 39(7), 1202-1218. https://doi.org/10.1080/03075079.2013.777412

Gunnarsson, J., Kulesza, W. J., \& Pettersson, A. (2014). Teaching international students how to avoid plagiarism: Librarians and faculty in collaboration. The Journal of Academic Librarianship, 40(3-4), 413-417. https://doi.org/10.1016/j.acalib.2014.04.006

Halupa, C., \& Bolliger, D. (2013). Faculty perceptions of student self plagiarism: An exploratory multi-university study. Journal of Academic Ethics, 11(4), 297-310. https://doi.org/10.1007/s10805-013-9195-6

Halupa, C., \& Bolliger, D. U. (2015). Student perceptions of self-plagiarism: A multi-university exploratory study. Journal of Academic Ethics, 13(1), 91-105.

https://doi.org/10.1007/s10805-015-9228-4

Halupa, C., Breitenbach, E., \& Anast, A. (2016). A Self-plagiarism intervention for doctoral students: A qualitative pilot study. Journal of Academic Ethics, 14(3), 175-189. https://doi.org/10.1007/s10805-016-9262-x 
Halupa, C. M. (2014). Exploring student self-plagiarism. International Journal of Higher Education, 3(1), 121-126. https://doi.org/10.5430/ijhe.v3n1p121

Hayes, N., \& Introna, L. D. (2005). Cultural values, plagiarism, and fairness: When plagiarism gets in the way of learning. Ethics \& Behavior, 15(3), 213-231.

https://doi.org/10.1207/s15327019eb1503 2

Heitman, E., \& Litewka, S. (2011). International perspectives on plagiarism and considerations for teaching international trainees. Urologic Oncology: Seminars and Original Investigations, 29(1), 104-108. https://doi.org/10.1016/j.urolonc.2010.09.014

Hesse-Biber, S. N. (2010). Mixed methods research: Merging theory with practice. Guilford Press.

Houston, D. (2015). Quality in postgraduate research. Quality in Higher Education, 21(1), 1-6. https://doi.org/10.1080/13538322.2015.1049440

Howard, R. M. (1993). A plagiarism pentimento. Journal of Teaching Writing, 11(2), 233-245. http://journals.iupui.edu/index.php/teachingwriting/article/viewFile/1116/1088

Howard, R. M. (1995). Plagiarisms, authorships, and the academic death penalty. College English, 57(7), 788-806. https://doi.org/10.2307/378403

Howard, R. M. (2002). Don't police plagiarism: Just teach! The Education Digest, 67(5), 46-49.

Howard, R. M. (2007). Understanding internet plagiarism. Computers and Composition, 24(1), 3-15. https://doi.org/10.1016/j.compcom.2006.12.005

Howard, R. M. (2011). Postpedagogical reflections on plagiarism and capital. In S. Dobrin, J. A. Rice, \& M. Vastola (Eds.), Beyond Postprocess (pp. 219-231). Utah State University Press.

Howard, R. M. (2016). Plagiarism in higher education: An academic literacies issue? Introduction. In T. Bretag (Ed.), Handbook of academic integrity (pp. 499-501). Springer.

Hu, G., \& Lei, J. (2012). Investigating Chinese university students' knowledge of and attitudes toward plagiarism from an integrated perspective. Language Learning, 62(3), 813-850. https://doi.org/10.1111/j.1467-9922.2011.00650.x

Hu, G., \& Lei, J. (2015). Chinese university students' perceptions of plagiarism. Ethics \& Behavior, 25(3), 233-255. https://doi.org/10.1080/10508422.2014.923313

Hyland, F. (2011). Dealing with plagiarism when giving feedback. ELT Journal, 55(4), 375-381. https://doi.org/10.1093/elt/55.4.375

Institute of International Education. (2020). Project Atlas - New Zealand. https://www.iie.org/Research-and-Insights/Project-Atlas/Explore-Data/New-Zealand

International Center for Academic Integrity. (2017). Fundamental values of academic integrity. https://www.academicintegrity.org/fundamental-values/ 
Introna, L., \& Hayes, N. (2008). International students and plagiarism detection systems. In T. S. Roberts (Ed.), Student plagiarism in an online world: Problems and solutions (pp. 108-123). Information Science Reference. https://doi.org/10.4018/978-1-59904-8017.ch008

Javaeed, A., Khan, A. S., Khan, S. H., \& Ghauri, S. K. (2019). Perceptions of plagiarism among undergraduate medical students in Rawalpindi, Pakistan. Pakistan Journal of Medical Sciences, 35(2), 532-536. https://doi.org/10.12669/pjms.35.2.33

Jereb, E., Urh, M., Jerebic, J., \& Šprajc, P. (2018). Gender differences and the awareness of plagiarism in higher education. Social Psychology of Education, 21(2), 409-426. https://doi.org/10.1007/s11218-017-9421-y

Johnson, B., \& Christensen, L. (2014). Educational research: Quantitative, qualitative, and mixed approaches (5th ed.). Sage.

Johnson, R. B., Onwuegbuzie, A. J., \& Turner, L. A. (2007). Toward a definition of mixed methods research. Journal of Mixed Methods Research, 1(2), 112-133.

https://doi.org/10.1177/1558689806298224

Jones, L. R. (2011). Academic integrity \& academic dishonesty: A handbook about cheating \& plagiarism. Florida Institute of Technology.

Kang, M. J., \& Glassman, M. (2010). Moral action as social capital, moral thought as cultural capital. Journal of Moral Education, 39(1), 21-36.

https://doi.org/10.1080/03057240903528592

Khathayut, P., Walker-Gleaves, C., \& Humble, S. (2020). Using the theory of planned behaviour to understand Thai students' conceptions of plagiarism within their undergraduate programmes in higher education. Studies in Higher Education, 1-18. https://doi.org/10.1080/03075079.2020.1750584

Kokkinaki, A. I., Demoliou, C., \& lakovidou, M. (2015). Students' perceptions of plagiarism and relevant policies in Cyprus. International Journal for Educational Integrity, 11(1), 1-11. https://doi.org/10.1007/s40979-015-0001-7

Kumar, R. (2008). Research methodology: A step-by-step guide for beginners. Sage.

Kura, K. M., Shamsudin, F., \& Chauhan, A. (2014). Effects of honor codes and classroom justice on students' deviant behavior. Procedia-Social and Behavioral Sciences, 112(C), 77-86. https://doi.org/10.1016/j.sbspro.2014.01.1141

Kwong, T., Ng, H.-M., Mark, K.-P., \& Wong, E. (2010). Students' and faculty's perception of academic integrity in Hong Kong. Campus-Wide Information Systems, 27(5), 341-355. https://doi.org/10.1108/10650741011087766

Lareau, A. (2000). Home advantage: Social class and parental intervention in elementary education (2nd ed.). Rowman \& Littlefield Publishers, Inc. 
Lareau, A. (2002). Unequal childhoods: Class, race, and family life (2nd ed.). University of California Press.

Lareau, A., \& Weininger, E. (2003). Cultural capital in educational research: A critical assessment. Theory and Society, 32(5), 567-606. https://doi.org/10.1023/B:RYSO.0000004951.04408.b0

Leask, B. (2006). Plagiarism, cultural diversity and metaphor: Implications for academic staff development. Assessment \& Evaluation in Higher Education, 31(2), 183-199. https://doi.org/10.1080/02602930500262486

Leonard, M., Schwieder, D., Buhler, A., Bennett, D. B., \& Royster, M. (2015). Perceptions of plagiarism by STEM graduate students: A case study. Science and Engineering Ethics, 21(6), 1587-1608. https://doi.org/10.1007/s11948-014-9604-2

Liu, D. (2005). Plagiarism in ESOL students: Is cultural conditioning truly the major culprit? ELT Journal, 59(3), 234-241. https://doi.org/10.1093/elt/cci043

Ma, H. J., Wan, G., \& Lu, E. Y. (2008). Digital cheating and plagiarism in schools. Theory Into Practice, 47(3), 197-203. https://doi.org/10.1080/00405840802153809

Macdonald, R., \& Carroll, J. (2006). Plagiarism: A complex issue requiring a holistic institutional approach. Assessment \& Evaluation in Higher Education, 31(2), 233-245. https://doi.org/10.1080/02602930500262536

Maio, C., Dixon, K., \& Yeo, S. (2020). Responding to student plagiarism in Western Australian universities: The disconnect between policy and academic staff. Journal of Higher Education Policy and Management, 42(1), 102-116. https://doi.org/10.1080/1360080X.2019.1662927

Marginson, S. (2014). Student self-formation in international education. Journal of Studies in International Education, 18(1), 6-22. https://doi.org/10.1177/1028315313513036

Marshall, S., \& Garry, M. (2005). How well do students really understand plagiarism. 22nd Annual Conference of the Australasian Society for Computers in Learning in Tertiary Education, Brisbane, Australia.

Marshall, S., \& Garry, M. (2006). NESB and ESB students' attitudes and perceptions of plagiarism. International Journal for Educational Integrity, 2(1), 26-37. https://doi.org/10.21913/IJEl.v2i1.25

Martin, B. (2016). Plagiarism, misrepresentation, and exploitation by established professionals: Power and tactics. In T. Bretag (Ed.), Handbook of academic integrity (pp. 913-927). Springer.

Martin, D. E. (2012). Culture and unethical conduct: Understanding the impact of individualism and collectivism on actual plagiarism. Management Learning, 43(3), 261273. https://doi.org/10.1177/1350507611428119 
Maxwell, A., Curtis, G. J., \& Vardanega, L. (2006). Plagiarism among local and Asian students in Australia. Guidance \& Counselling, 21, 210-215.

Maxwell, A., Curtis, G. J., \& Vardanega, L. (2008). Does culture influence understanding and perceived seriousness of plagiarism? International Journal for Educational Integrity, 4(2), 25-40. https://doi.org/10.21913/IJEl.v4i2.412

McCabe, D. L., \& Stephens, J. M. (2006). Epidemic" as opportunity: Internet plagiarism as a lever for cultural change. https://www.tcrecord.org/content.asp?contentid=12860

Menzies, J. L., \& Baron, R. (2014). International postgraduate student transition experiences: The importance of student societies and friends. Innovations in Education and Teaching International, 51(1), 84-94. https://doi.org/10.1080/14703297.2013.771972

Mundfrom, D. J., Shaw, D. G., \& Ke, T. L. (2005). Minimum sample size recommendations for conducting factor analyses. International Journal of Testing, 5(2), 159-168. https://doi.org/10.1207/s15327574ijt0502 4

Neville, C. (2007). The complete guide to referencing and avoiding plagiarism. Open University Press.

New Zealand Education. (2019). Study for a PhD in New Zealand. https://www.studyinnewzealand.govt.nz/study-options/phd-package/

Newton, F. J., Wright, J. D., \& Newton, J. D. (2014). Skills training to avoid inadvertent plagiarism: Results from a randomised control study. Higher Education Research \& Development, 33(6), 1-14. https://doi.org/10.1080/07294360.2014.911257

Nguyen, Q., \& Buckingham, L. (2019). Source-use expectations in assignments: The perceptions and practices of Vietnamese Master's students. English for Specific Purposes, 53, 90-103. https://doi.org/10.1016/j.esp.2018.10.001

Noble, J., \& Davies, P. (2009). Cultural capital as an explanation of variation in participation in higher education. British Journal of Sociology of Education, 30(5), 591-605. https://doi.org/10.1080/01425690903101098

O'Donnell, V. L., Tobbell, J., Lawthom, R., \& Zammit, M. (2009). Transition to postgraduate study: Practice, participation and the widening participation agenda. Active Learning in Higher Education, 10(1), 26-40. https://doi.org/10.1177/1469787408100193

Palmer, A., Pegrum, M., \& Oakley, G. (2019). A wake-up call? Issues with plagiarism in transnational higher education. Ethics \& Behavior, 29(1), 23-50. https://doi.org/10.1080/10508422.2018.1466301

Pàmies, M. D. M., Valverde, M., \& Cross, C. (2020). Organising research on university student plagiarism: A process approach. Assessment \& Evaluation in Higher Education, 45(3), 401-418. https://doi.org/10.1080/02602938.2019.1658714 
Park, C. (2003). In other (people's) words: Plagiarism by university students-literature and lessons. Assessment \& Evaluation in Higher Education, 28(5), 471-488.

https://doi.org/10.1080/02602930301677

Pecorari, D. (2003). Good and original: Plagiarism and patchwriting in academic secondlanguage writing. Journal of Second Language Writing, 12(4), 317-345. https://doi.org/10.1016/j.jslw.2003.08.004

Pecorari, D. (2006). Visible and occluded citation features in postgraduate second-language writing. English for Specific Purposes, 25(1), 4-29.

https://doi.org/10.1016/j.esp.2005.04.004

Pecorari, D. (2008). Academic writing and plagiarism: A linguistics analysis. A\&C Black.

Pecorari, D. (2013). Teaching to avoid plagiarism: How to promote good source use. McGrawHill Education.

Pecorari, D. (2015). Plagiarism in second language writing: Is it time to close the case? Journal of Second Language Writing, 30, 94-99. https://doi.org/10.1016/i.js/w.2015.08.003

Pecorari, D. (2016). Plagiarism, international students, and the second-language writer. In T. Bretag (Ed.), Handbook of academic integrity (pp. 537-550). Springer.

Pecorari, D., \& Petric, B. (2014). Plagiarism in second-language writing. Language Teaching, 47(3), 269-302. https://doi.org/10.1017/S0261444814000056

Perkins, M., Gezgin, U. B., \& Roe, J. (2018). Understanding the relationship between language ability and plagiarism in non-native English speaking business students. Journal of Academic Ethics, 16(4), 317-328. https://doi.org/10.1007/s10805-018-9311-8

Perkins, M., \& Roe, J. (2020). Reducing plagiarism through academic misconduct education. International Journal for Educational Integrity, 16(1), 1-15.

https://doi.org/10.1007/s40979-020-00052-8

Phan, L. H. (2006). Plagiarism and overseas students: Stereotypes again? ELT Journal, 60(1), 76-78. https://doi.org/10.1093/elt/cci085

Power, L. G. (2009). University students' perceptions of plagiarism. The Journal of Higher Education, 80(6), 643-662. https://doi.org/10.1353/jhe.0.0073

Prochaska, E. (2001). Western rhetoric and plagiarism: Gatekeeping for an English-only international academia. Writing on the Edge, 12(2), 65-79.

http://www.jstor.org/stable/pdf/43157168.pdf

Puengpipattrakul, W. (2016). Investigating academic plagiarism in a Thai context. Electronic Journal of Foreign Language Teaching, 13(2), 203-228.

Ramzan, M., Munir, M. A., Siddique, N., \& Asif, M. (2012). Awareness about plagiarism amongst university students in Pakistan. Higher Education, 64(1), 73-84.

https://doi.org/10.1007/s10734-011-9481-4 
Rathore, F., Fatima, N., \& Mansoor, S. (2018). Combating scientific misconduct: The role of focused workshops in changing attitudes towards plagiarism. Cureus, 10(5), e2698. https://doi.org/10.7759/cureus.2698

Resurreccion, P. F. (2012). The impact of faculty, peers and integrity culture in the academe on academic misconduct among Filipino students: An empirical study based on social cognitive theory. International Journal of Academic Research in Business and Social Sciences, 2(12), 33-50.

Rezanejad, A., \& Rezaei, S. (2013). Academic dishonesty at universities: The case of plagiarism among Iranian language students. Journal of Academic Ethics, 11(4), 275-295. https://doi.org/10.1007/s10805-013-9193-8

Riazantseva, A. (2012). "I ain't changing anything": A case-study of successful generation 1.5 immigrant college students' writing. Journal of English for Academic Purposes, 11(3), 184-193. https://doi.org/10.1016/j.jeap.2012.04.007

Rinnert, C., \& Kobayashi, H. (2005). Borrowing words and ideas: Insights from Japanese L1 writers. Journal of Asian Pacific Communication, 15(1), 31-56.

https://doi.org/10.1075/japc.15.1.04sut

Robertson, M., Line, M., Jones, S., \& Thomas, S. (2000). International students, learning environments and perceptions: A case study using the Delphi technique. Higher Education Research \& Development, 19(1), 89-102. https://doi.org/10.1080/07294360050020499

Roig, M. (2016). Recycling our own work in the digital age. In T. Bretag (Ed.), Handbook of academic integrity (pp. 655-669). Springer.

Ryan, G., Bonanno, H., Krass, I., Scouller, K., \& Smith, L. (2009). Undergraduate and postgraduate pharmacy students' perceptions of plagiarism and academic honesty. American Journal of Pharmaceutical Education, 73(6), 1-8. https://doi.org/10.5688/aj7306105

Sawir, E., Marginson, S., Forbes-Mewett, H., Nyland, C., \& Ramia, G. (2012). International student security and English language proficiency. Journal of Studies in International Education, 16(5), 434-454. https://doi.org/10.1177/1028315311435418

Schirato, T. (2018). Bourdieu: A critical introduction. Allen and Unwin.

Schmitt, D. (2005). Writing in the international classroom. In J. Carroll \& J. Ryan (Eds.), Teaching international students: Improving learning for all (pp. 63-74). Routledge.

Selemani, A., Chawinga, W., \& Dube, G. (2018). Why do postgraduate students commit plagiarism? An empirical study. International Journal for Educational Integrity, 14(1), 115. https://doi.org/10.1007/s40979-018-0029-6

Senders, S. (2009). Academic plagiarism and the limits of theft. In M. Vicinus \& C. Eisner (Eds.), Originality, imitation, and plagiarism: Teaching writing in the digital age (pp. 195-207). University of Michigan Press. 
Shang, H.-F. (2019). An investigation of plagiarism software use and awareness training on English as a foreign language (EFL) students. Journal of Computing In Higher Education, 31(1), 105-120. https://doi.org/10.1007/s12528-018-9193-1

Shi, L. (2004). Textual borrowing in second-language writing. Written Communication, 21(2), 171-200. https://doi.org/10.1177/0741088303262846

Shi, L. (2006). Cultural backgrounds and textual appropriation. Language Awareness, 15(4), 264-282. https://doi.org/10.2167/la406.0

Singh, S., \& Remenyi, D. (2016). Plagiarism and ghostwriting: The rise in academic misconduct. South African Journal of Science, 112(5-6), 36-42.

https://doi.org/10.17159/sajs.2016/20150300

Smith, M., Ghazali, N., \& Minhad, F. S. N. (2007). Attitudes towards plagiarism among undergraduate accounting students: Malaysian evidence. Asian Review of Accounting, 15(2), 122-146. https://doi.org/10.1108/13217340710823350

Song-Turner, H. (2008). Plagiarism: Academic dishonesty or 'blind spot' of multicultural education? The Australian Universities' Review, 50(2), 39-50.

Soong, H., Tran, L., \& Pham, H. (2015). Being and becoming an intercultural doctoral student: Reflective autobiographical narratives. Reflective Practice, 16(4), 435-448.

https://doi.org/10.1080/14623943.2015.1023276

Sousa-Silva, R. (2014). Investigating academic plagiarism: A forensic linguistics approach to plagiarism detection. International Journal for Educational Integrity, 10(1), 31-41. https://doi.org/10.21913/IJEl.v10i1.932

Sousa-Silva, R. (2020). Plagiarism across languages and cultures: A (forensic) linguistic analysis. In R. K. Stanley D. Brunn (Ed.), Handbook of the changing world language map (pp. 2325-2345). Springer Nature

Sowden, C. (2005). Plagiarism and the culture of multilingual students in higher education abroad. ELT Journal, 59(3), 226-233. https://doi.org/0.1093/elt/cci042

Stappenbelt, B. (2012). Plagiarism in mechanical engineering education: A comparative study of international and domestic students. International Journal of Mechanical Engineering Education, 40(1), 24-41. https://doi.org/10.7227/IJMEE.40.1.6

Stephens, J. M., Young, M. F., \& Calabrese, T. (2007). Does moral judgment go offline when students are online? A comparative analysis of undergraduates' beliefs and behaviors related to conventional and digital cheating. Ethics \& Behavior, 17(3), 233-254. https://doi.org/10.1080/10508420701519197

Strangfeld, J. A. (2019). I just don't want to be judged: Cultural capital's impact on student plagiarism. Sage Open, 9(1), 1-14. https://doi.org/10.1177/2158244018822382

Sue, V. M., \& Ritter, L. A. (2011). Conducting online surveys. Sage. 
Sullivan, A. (2001). Cultural capital and educational attainment. Sociology, 35(4), 893-912. https://doi.org/10.1017/S0038038501008938

Sutherland-Smith, W. (2005a). Pandora's box: Academic perceptions of student plagiarism in writing. Journal of English for Academic Purposes, 4(1), 83-95.

https://doi.org/10.1016/j.jeap.2004.07.007

Sutherland-Smith, W. (2005b). The tangled web: Internet plagiarism and international students' academic writing. Journal of Asian Pacific Communication, 15(1), 15-29. https://doi.org/10.1075/japc.15.1.04sut

Sutherland-Smith, W. (2008). Students' perceptions of plagiarism. In W. Sutherland-Smith (Ed.), Plagiarism: The internet and student learning (pp. 154-180). Taylor \& Francis.

Sutherland-Smith, W. (2010). Retribution, deterrence and reform: The dilemmas of plagiarism management in universities. Journal of Higher Education Policy and Management, 32(1), 5-16. https://doi.org/10.1080/13600800903440519

Sutherland-Smith, W. (2014). Legality, quality assurance and learning: Competing discourses of plagiarism management in higher education. Journal of Higher Education Policy and Management, 36(1), 29-42. https://doi.org/10.1080/1360080X.2013.844666

Sutton, A., Taylor, D., \& Johnston, C. (2014). A model for exploring student understandings of plagiarism. Journal of Further and Higher Education, 38(1), 129-146. https://doi.org/10.1080/0309877X.2012.706807

Swartz, D. (2012). Culture and power: The sociology of Pierre Bourdieu. University of Chicago Press.

Tholen, G. (2015). What can research into graduate employability tell us about agency and structure? British Journal of Sociology of Education, 36(5), 766-784. https://doi.org/10.1080/01425692.2013.847782

Thompson, B. (2004). Exploratory and confirmatory factor analysis: Understanding concepts and applications (1st ed.). American Psychological Association.

http://helicon.vuw.ac.nz/login?url=http://search.proquest.com/psycbooks/publication/ $\underline{177021}$

Tobbell, J., \& O’Donnell, V. L. (2013). Transition to postgraduate study: Postgraduate ecological systems and identity. Cambridge Journal of Education, 43(1), 123-138. https://doi.org/10.1080/0305764X.2012.749215

Tran, L. T. (2013). International student adaptation to academic writing in higher education. Cambridge Scholars Publishing.

Tran, L. T. (2016). Mobility as "becoming": A Bourdieuian analysis of the factors shaping international student mobility. British Journal of Sociology of Education, 37(8), 12681289. https://doi.org/10.1080/01425692.2015.1044070 
Tran, T. T. J. (2012). The perceptions and attitudes of international students towards plagiarism. The ACPET Journal for Private Higher Education, 1(2), 13-21.

Tran, U., Huynh, T., \& Nguyen, H. (2018). Academic integrity in higher education: The case of plagiarism of graduation reports by undergraduate seniors in Vietnam. Journal of Academic Ethics, 16(1), 61-69. https://doi.org/10.1007/s10805-017-9279-9

Valentine, K. (2006). Plagiarism as literacy practice: Recognizing and rethinking ethical binaries. College Composition and Communication, 58(1), 89-109.

Vardi, I. (2012). Developing students' referencing skills: A matter of plagiarism, punishment and morality or of learning to write critically? Higher Education Research \& Development, 31(6), 921-930. https://doi.org/10.1080/07294360.2012.673120

Vehviläinen, S., Löfström, E., \& Nevgi, A. (2018). Dealing with plagiarism in the academic community: Emotional engagement and moral distress. Higher Education, 75(1), 1-18. https://doi.org/10.1007/s10734-017-0112-6

Victoria University of Wellington. (2020a). Plagiarism.

https://www.wgtn.ac.nz/students/support/student-interest-and-conflictresolution/academic-integrity/plagiarism

Victoria University of Wellington. (2020b). Research performance and rankings. https://www.wgtn.ac.nz/research/strengths/performance-and-rankings

Walker, B. (2009). New twists on an old problem: Preventing plagiarism and enforcing academic integrity in an art and design school. Art Documentation, 28(1), 48-51.

Walker, C., \& White, M. (2014). Police, design, plan and manage: Developing a framework for integrating staff roles and institutional policies into a plagiarism prevention strategy. Journal of Higher Education Policy and Management, 36(6), 674-687. https://doi.org/10.1080/1360080X.2014.957895

Walker, J. (1998). Student plagiarism in universities: What are we doing about it? Higher Education Research \& Development, 17(1), 89-106. https://doi.org/10.1080/0729436980170105

Walker, J. (2010). Measuring plagiarism: Researching what students do, not what they say they do. Studies in Higher Education, 35(1), 41-59. https://doi.org/10.1080/03075070902912994

Weber-Wulff, D. (2014). False feathers: A perspective on academic plagiarism. Springer Science \& Business.

Whitley Jr, B. E., \& Keith-Spiegel, P. (2012). Academic dishonesty: An educator's guide. Psychology Press.

William, B. T. (2007). Trust, betrayal, and authorship: Plagiarism and how we perceive students. Journal of Adolescent and Adult Literacy, 51(4), 350-354.

https://doi.org/10.1598/JAAL.51.4.6 
Williams, J. B. (2003). Plagiarism: Deterrence, detection, and prevention. In J. Houston \& D. Whigham (Eds.), The handbook for economics lecturers (pp. 1-20). University of Bristol.

Yeo, S. (2007). First-year university science and engineering students' understanding of plagiarism. Higher Education Research \& Development, 26(2), 199-216. https://doi.org/10.1080/07294360701310813

Yeo, S., \& Chien, R. (2007). Evaluation of a process and proforma for making consistent decisions about the seriousness of plagiarism incidents. Quality in Higher Education, 13(2), 187-204. https://doi.org/10.1080/13538320701629202

Yong, A. G., \& Pearce, S. (2013). A beginner's guide to factor analysis: Focusing on exploratory factor analysis. Tutorials in Quantitative Methods for Psychology, 9(2), 79-94. https://doi.org/10.20982/tamp.09.2.p079

Yosso, T. J. (2005). Whose culture has capital? A critical race theory discussion of community cultural wealth. Race Ethnicity and Education, 8(1), 69-91. https://doi.org/10.1080/1361332052000341006

Zafarghandi, A. M., Khoshroo, F., \& Barkat, B. (2012). An investigation of Iranian EFL Masters students' perceptions of plagiarism. International Journal for Educational Integrity, 8(2), 69-85. http://www.ojs.unisa.edu.au/index.php/IJEl/article/view/811

Zhang, Y. H. (2016). Against plagiarism: A guide for editors and authors. Springer International Publishing. https://doi.org/10.1007/978-3-319-24160-9

Zimerman, M. (2012). Plagiarism and international students in academic libraries. New Library World, 113(5/6), 290-299. https://doi.org/10.1108/03074801211226373

Zimitat, C. (2008). A student perspective of plagiarism. In T. S. Roberts (Ed.), Student plagiarism in an online world: Problems and solutions (pp. 10-22). Idea Group Publishing. https://doi.org/10.4018/978-1-59904-801-7.ch002

Zobel, J., \& Hamilton, M. (2002). Managing student plagiarism in large academic departments. Australian Universities Reviews, 45(2), 23-30. 


\section{Appendices}




\section{Appendix A: Questionnaire}

\section{Questionnaire Version 1-Expert Reviewing}

\section{Student Perceptions of Plagiarism - A Study of Vietnam- and New Zealand- Educated Postgraduate Students}

\section{Section 1: Demographic Information}

1. How old were you on your last birthday?

2. What is your gender?

3. What is your nationality?

4. Have you ever been employed as a teacher/tutor? Yes (Please specify) ... No ...

\section{Section 2: Educational Backgrounds}

1. Where did you go to secondary/high school? (e.g., Wellington High School, NZ).

2. Please list all the tertiary qualifications that you have. For each one, write down the type of degree, major, name of institutions, and year awarded (e.g., BA, Finance, Victoria University of Wellington, 2008).

3. Please tell us about your current study: type of degree, major, start year, and enrollment status (e.g., MA, Education, 7/2017, full time).

\section{Section 3: Plagiarism Attitudes Scale}

\section{Perspectives of plagiarism}

1. Plagiarism is a dishonest act.

2. Plagiarism is deceitful.

3. Plagiarism is a form of cheating.

4. Plagiarism is stealing.

5. Plagiarism weakens academic integrity.

6. Plagiarism impairs assessment processes.

7. Plagiarism threatens the reputation of the university

8. Plagiarism makes the degree less meaningful.

9. Plagiarism lessens students' learning experiences.

10. Plagiarism breaks teachers' trust.

11. Students plagiarise suffer the consequences.

\section{Perceived seriousness of plagiarism}

1. It is no big deal if you submit exactly copied or slightly modified work as your own without appropriate attribution. 
2. It is not a serious problem if you hire a writer to produce a text that is subsequently submitted as your own work.

3. There is no need to worry if you change a copied text by deleting some words, alter grammatical structures, or substitute synonyms for an assignment.

4. It is not a serious problem if you insufficiently acknowledge original sources.

5. It is not a serious problem if you heavily depend on an original source for ideas without citation while using few or no words from that source.

6. It is not a serious problem if you translate an original work in another language by another author and claim it as your own work.

7. It is not a serious problem if you submit the same assignment to more than one class.

8. It is not a serious problem if you copy a passage from a book with a quotation mark.

9. It is not a serious problem if you write an essay about a popular novel.

10. It is not a serious problem if you have an assignment with poor grammar.

\section{Reasons for student plagiarism}

1. Plagiarism helps people do well in later life.

2. Plagiarism is common with novice writers.

3. Plagiarism is a problem caused by the process of learning to write.

4. Students plagiarise due to desires to gain high grades.

5. Good students don't plagiarise.

6. Students plagiarise due to poor understanding of citing and referencing.

7. Students plagiarise because of poor time management skills.

8. Students plagiarise due to poor understanding of how to write academically.

9. Students plagiarise due to language difficulties.

10. Students plagiarise because of the assessment methods focusing on textbook content.

11. Students are more likely to plagiarise in written assignments.

12. Students plagiarise due to lack of supporting information and services.

13. The Internet makes it easy for students to plagiarise.

14. Students plagiarise because of the high course workloads.

15. When there are low chances of being caught students are more likely to plagiarise.

16. Students plagiarise because the Western concept of plagiarism is different from the one in their home country.

17. When lectures set the same assignments year after year, students are more likely to plagiarise.

18. When lectures set boring assignments, students are more likely to plagiarise. 


\section{Questionnaire Version 2-Questionnaire Pretesting}

\section{Student Perceptions of Plagiarism}

\section{Section 1: Demographic Information}

1. How old were you on your last birthday?

2. What is your gender?

3. What is your nationality?

4. Have you ever been employed as a teacher/tutor? Yes (Please specify) ... No ...

\section{Section 2: Educational Backgrounds}

1. Where did you go to secondary/high school? (e.g., Wellington High School, NZ).

2. Please list all the tertiary qualifications that you have. For each one, write down the type of degree, major, name of institutions, and year awarded (e.g., BA, Finance, Victoria University of Wellington, 2008).

3. Please tell us about your current study: type of degree, major, start year, and enrollment status (e.g., MA, Education, 7/2017, full time).

\section{Section 3: Plagiarism Attitudes Scale}

Please indicate your level of agreement or disagreement with each of the following statements
1. Strongly agree
2. Somewhat agree
3. Neither agree nor disagree

\section{Somewhat disagree $\quad$ 5. Strongly disagree}

1. It is fine to put in an assignment a copied text in which you delete some words,

(1) (2) (3) (4) alter grammatical structures, or substitute synonyms.
2. Students are more likely to plagiarise written assignments than presentations.
(1) (2) (3) (5)
3. Plagiarism compromises teacher-student relationships.
(1) (2) (3) (4) (5)
4. Plagiarism happens when students are learning to write.
(1) (2) (3) (4) (5)
5. Students who are very fluent in their use of language don't plagiarise.
(1) (2) (3) (4) (5)
6. You can include in your own work passages from books without quotation
(1) (2) (3) (5) marks.
7. Students plagiarise when lecturers set the same assignments year after year.
(1) (2) (3) (4) (5)
8. Plagiarism is common in the work of novice writers.
(1) (2) (3) (4) (5)
9. Good students don't plagiarise.
(1) (2) (3) (4) (5)
10. Heavily depending on an original source for ideas without citation is no big deal
(1) (2) (3) (4) (5) if you use few or no words from that source.
11. Students don't plagiarise when assignments are personalised.
(1) (2) (3) (4) (5)
12. Plagiarism damages the meaning of a degree.
(1) (2) (3) (4) (5)
13. Students plagiarise because they want high grades.

(1) (2) (3) (4) (5)
14. Students plagiarise because they are confused about plagiarism.
(1) (2) (3) (4) (5) 
15. Plagiarism is dishonest.

16. It is fine to submit the same assignment to more than one class.

17. Students don't plagiarise when there is a high chance of being caught.

18. It is not a serious problem if you hire a writer to produce a text that you subsequently submit as your own work.

19. Students plagiarise when assessments focus on textbook content.

20. Students who plagiarise are penalised by the university.

21. Students plagiarise because of the pressure from their family.

\section{Plagiarism is deceitful.}

23. Plagiarism helps students do well in later life.

\section{Students plagiarise when assigned too much work.}

25. It is not a serious problem if you mention an author in the reference list while not including an in-text citation.

\begin{tabular}{|c|c|}
\hline 26. Students' poor understanding of how to write academically causes plagiarism. & (1) (2) (3) (4) (5) \\
\hline 27. Plagiarism threatens the reputation of the university. & (1) (2) (3) (4) (5) \\
\hline 28. The Internet makes it easy for students to plagiarise. & (1) (2) (3) (4) \\
\hline $\begin{array}{l}\text { 29. It is not a serious problem if you copy information from the internet and use it } \\
\text { as your own work. }\end{array}$ & (1) (2) (3) (4) (5) \\
\hline
\end{tabular}

(1) (2) (3) (4) (5)

(1) (2) (3) (4) (5)

(1) (2) (3) (4) (5)

(1) (2) (3) (4) (5)

(1) (2) (3) (4) (5)

(1) (2) (3) (4) (5)

(1) (2) (3) (4) (5)

(1) (2) (3) (4) (5)

(1) (2) (3) (4) (5)

(1) (2) (3) (4) (5)
(1) (2) (3) (4) (5)

30. Plagiarism is a form of academic cheating.

(1) (2) (3) (4) (5)

31. Students' poor understanding of citing and referencing leads them to plagiarise.

32. Plagiarism lessens students' learning experiences.
33. Time constraints have no influence on student plagiarism.

34. There is nothing wrong if your friends let you copy their assignments.

(1) (2) (3) (4) (5)

35. Students don't plagiarise when the assignments are interesting.

(1) (2) (3) (4) (5)

36. Plagiarism helps students pass courses.

(1) (2) (3) (4) (5)

37. It is no big deal if you submit exactly copied work as your own without (1) (2) (3) (4) (5) acknowledgement.

\begin{tabular}{llll}
\hline 38. Plagiarism is stealing. & (1) (2) (4) (5) \\
39. Students plagiarise when there are no policies about plagiarism. & (1) (2) (3) (4) (5)
\end{tabular}

\section{Interview Participation}

The study involves a series of four in-depth interviews aiming to learn more about your perceptions of plagiarism. You will not be asked to disclose information about specific examples of plagiarism you or other students have undertaken. If you are interested to be confidentially interviewed, please give your contact information.

Email:

Phone:

Name: 


\section{Questionnaire Version 3- Pilot Questionnaire}

\section{Student Perceptions of Plagiarism - A Pilot Survey}

\section{Researcher}

My name is Tran Ngoc Minh and I am a PhD student in the Faculty of Education, Victoria University of Wellington. I am conducting an online survey as part of a study on students' perceptions of plagiarism. The purpose of this survey is to explore your attitudes towards and understandings of plagiarism.

\section{Participation}

It is your choice whether or not to participate in this survey.

\section{Anonymity}

The survey is completely anonymous. It means that no one can tell which answers you have given in the survey.

\section{How the data will be stored and used?}

All printed material will be stored in a locked file; all electronic information will be passwordprotected, access restricted to the research team. The data will be used for my PhD thesis, conference presentations, and publications. Data will be destroyed within seven years after the project is completed.

\section{Prize draw}

As a thank you for completing this survey, you can enter a draw for one \$20 New World voucher. There are 2 vouchers to be won.

\section{Consent}

By submitting the completed questionnaire, you are consenting to participate in the survey and for the information you have given to be used for research purposes.

\section{Contact}

If you have any questions, either now or in the future, please feel free to contact:

$\begin{array}{lll}\text { PhD student } & \text { Primary supervisor } & \text { Secondary supervisor } \\ \text { Tran Ngoc Minh } & \text { AProf Stephen Marshall } & \text { Dr Linda Hogg } \\ \text { Email: } & \text { Email: } & \text { Email: } \\ \text { Phone: } & \text { Phone: } & \text { Phone: }\end{array}$

The research has been approved by Victoria University Human Ethics Committee. If you have any ethical concerns about the research, you may contact Dr Judith Loveridge. Email or telephone 
The survey should take about 15 minutes to complete. If you consent, click the "Next" button to get started.

\section{Please indicate your level of agreement or disagreement with each of the following statements}

\section{$\begin{array}{lll}\text { 1. Strongly agree } & \text { 2. Somewhat agree } & \text { 3. Neither agree nor disagree }\end{array}$ \\ 4. Somewhat disagree $\quad$ 5. Strongly disagree}

1. It is fine to put in an assignment a copied text in which you delete some words,

(1) (2) (3) (4) (5) alter grammatical structures, or substitute synonyms.

2. Plagiarism happens when students are learning to write.

(1) (2) (3) (4) (5)

3. Students are more likely to plagiarise written assignments than presentations.

(1) (2) (3) (4) (5)

4. Plagiarism compromises teacher-student relationships.

(1) (2) (3) (4) (5)

5. Students who are very fluent in their use of language don't plagiarise.

(1) (2) (3) (4) (5)

6. You can include in your own work passages from books without quotation marks.

(1) (2) (3) (4) (5)

7. Students plagiarise when lecturers set the same assignments year after year.

(1) (2) (3) (4) (5)

8. Plagiarism is common in the work of novice writers.

(1) (2) (3) (4) (5)

9. Good students don't plagiarise.

(1) (2) (3) (4) (5)

10. Heavily depending on an original source for ideas without citation is no big deal if you use few or no words from that source.

(1) (2) (3) (4) (5)

11. Students don't plagiarise when assignments are personalised.

(1) (2) (3) (4) (5)

12. Plagiarism damages the meaning of a degree.

(1) (2) (3) (4) (5)

13. Students plagiarise because they want high grades.

(1) (2) (3) (4) (5)

14. Students plagiarise because they are confused about plagiarism.

(1) (2) (3) (4) (5)

15. Plagiarism is dishonest.

(1) (2) (3) (4) (5)

16. It is fine to submit the same assignment to more than one class.

17. Students don't plagiarise when there is a high chance of being caught.

(1) (2) (3) (4) (5)

18. It is not a serious problem if you hire a writer to produce a text that you

(1) (2) (3) (4) (5) subsequently submit as your own work.

19. Students plagiarise when assessments focus on textbook content.

(1) (2) (3) (4) (5)

20. Students who plagiarise are penalised by the university.

21. Students plagiarise because of the pressure from their family.

(1) (2) (3) (4) (5)

22. Plagiarism is deceitful.

(1) (2) (3) (4) (5)

23. Plagiarism helps students do well in later life.

(1) (2) (3) (4) (5)

24. Students plagiarise when assigned too much work.

(1) (2) (3) (4) (5)

25. It is not a serious problem if you mention an author in the reference list while not

(1)

(2) (3)

(4) (5) including an in-text citation.

26. Students' poor understanding of how to write academically causes plagiarism.

(1) (2) (3) (4) (5) 
28. Students plagiarise when they have easy access to electronic materials.

29. It is not a serious problem if you copy information from the internet and use it as

(1) (2) (3) (4) (5) your own work.

30. Plagiarism is a form of academic cheating.

31. Students' poor understanding of citing and referencing leads them to plagiarise.

(1) (2) (3) (4) (5)

32. Students who plagiarise learn less.

(1) (2) (3) (4) (5)

33. Time constraint have no influence on student plagiarism.

(1) (2) (3) (4) (5)

34. There is nothing wrong if your friends let you copy their assignments.

35. Students don't plagiarise when the assignments are interesting.

(1) (2) (3) (4) (5)

36. Plagiarism helps students pass courses.

37. It is no big deal if you submit exactly copied work as your own without

(1) (2) (3) (4) (5) acknowledgement.

\begin{tabular}{lll}
\hline 38. Plagiarism is stealing. & (1) (2) (3) (4) (5) \\
39. Students plagiarise when there are no policies about plagiarism. & (1) (2) (3) (4) (5)
\end{tabular}

Thank you very much for completing the survey. 


\section{Questionnaire Modification}

Original: 4. Plagiarism compromises teacher-student relationships.

Revised: 30. Plagiarism worsens teacher-student relationships.

Original: 8. Plagiarism is common in the work of novice writers.

Revised: 5. Plagiarism is more common in the work of beginner writers.

Original: 9. Good students don't plagiarise.

Revised: 27. Academically weak students are more likely to plagiarise.

20. A good person doesn't plagiarise.

Original: 30. Plagiarism is a form of academic cheating.

Revised: 32. Plagiarism is academically wrong.

Original: 25. It is not a serious problem if you mention an author in the reference list while not including an in-text citation.

Revised: 34. It is not a serious problem if you acknowledge the original sources insufficiently.

Original: 29. It is not a serious problem if you copy information from the internet and use it as your own work.

Revised: 2. It is no big deal if you submit slightly modified work as your own without proper citation.

Original: 1. It is fine to put in an assignment a copied text in which you delete some words, alter grammatical structures, or substitute synonyms.

Revised: 13. In an assignment, it is fine to include some texts if you delete some words, alter grammatical structures, or substitute synonyms.

Original: 37. It is no big deal if you submit exactly copied work as your own without acknowledgement.

Revised: 26. Submitting exactly copied work as your own without appropriate acknowledgement is not a serious problem.

Original: 21 . Students plagiarise because of pressure from their family.

Revised: 9. Students plagiarise because of pressure to succeed.

Original: 24. Students plagiarise when assigned too much work.

Revised: 36 . Students plagiarise when they are under academic workload pressure.

Original: 36. Plagiarism helps students pass courses.

Revised: 29. Students plagiarise because they want to pass courses.

Original: 14. Students plagiarise because they are confused about plagiarism.

Revised: 14. Students plagiarise because they can't tell what is or isn't plagiarism.

Original: 26. Students' poor understanding of how to write academically causes plagiarism. 
Revised: 18 . Students' poor understanding of how to write academically leads to plagiarism.

Original: 31 . Students' poor understanding of citing and referencing leads them to plagiarise.

Revised: 3. Students' poor understanding of citation and referencing conventions leads them to plagiarise.

Original: 19. Students plagiarise when assessments focus on textbook content.

Revised: 35. Students plagiarise when assessments test understandings of textbook materials.

\section{Deleted items:}

18. You can include in your own work passages from books without quotation marks.

29. It is not a serious problem if you hire a writer to produce a text that you subsequently submit as your own work.

34. There is nothing wrong if your friends let you copy their assignments. 


\section{Questionnaire Version 4-Final Questionnaire}

\section{Student Perceptions of Plagiarism - A study of Vietnam- and New Zealand-educated Postgraduate Students}

You are invited to take part in this research. Please read this information before deciding whether or not to take part. If you decide to participate, thank you. If you decide not to participate, thank you for considering this request.

\section{Researcher}

My name is Tran Ngoc Minh and I am a PhD student in the Faculty of Education, Victoria University of Wellington. This research project is work towards my thesis.

\section{The aim of the project}

The purpose of this survey is to explore your attitudes towards and understandings of plagiarism. This research has been approved by the Victoria University of Wellington Human Ethics Committee (reference number: 0000025145).

\section{How can you help?}

If you agree to take part, you will complete a survey about your background and perceptions of plagiarism. It will take you about 10 minutes to complete.

\section{What will happen to the information you give?}

This research is confidential. This means that the researchers named below will be aware of your identity, but the research data will be combined, and your identity will not be revealed in any reports, presentations, or public documentation. Information that can be used to identify a particular student will be altered or generalised. By answering the survey questions, you are giving consent for us to use your responses in this research.

\section{What will the project produce?}

Information collected from this research will be used in my PhD thesis, academic publications, and conference presentations. Identifiable information will be deleted by $01 / 02 / 2023$. All other data will be destroyed within seven years after the project is completed.

\section{Prize draw}

As a thank you, we have ten $\$ 20$ New World vouchers to be won. At the end of the survey questions, you will be redirected to a separate survey where you can enter the draw and provide contact details.

\section{Interviews}

At the end of the survey, you will be asked to consider participating in a series of four interviews over a 6-month period to give more information about your perceptions of plagiarism. A small number of participants will be selected for these interviews. Further information will be given after you complete this survey. 


\section{If you have any questions or problems, who can you contact?}

If you have any questions, either now or in the future, please feel free to contact either:

\section{PhD student \\ Tran Ngoc Minh}

Email:

Phone:
Primary supervisor

AProf Stephen Marshall

Email:

Phone:
Secondary supervisor Dr Linda Hogg

Email:

Phone:

\section{Human ethics committee information}

The research has been approved by Victoria University Human Ethics Committee. If you have any ethical concerns about the research, you may contact Dr Judith Loveridge: Email

phone

If you consent, click the "Next" button to get started.

\section{Section 1: Demographic Information}

1. How old were you on your last birthday?

2. What is your gender?

3. What is your nationality?

4. Have you ever been employed as a teacher/tutor? Yes (Please specify) ... No ...

\section{Section 2: Educational backgrounds}

1. Where did you go to high school/secondary school? For each school, please write down the school name and the location/country (e.g., Wellington High School, NZ).

2. Please list all the tertiary qualifications that you have. For each one, write down the type of degree, major, name of institutions, and year awarded (e.g., BA, Finance, Victoria University of Wellington, 2008).

3. Please tell us about your current study: the type of degree, major, start year, and enrollment status (e.g., MA, Finance, 7/2017, full time).

\section{Section 3: Plagiarism attitudes}

Please indicate your level of agreement or disagreement with each of the following statements.
1. Strongly agree
2. Agree
3. Slightly agree
4. Slightly disagree
5. Disagree
6. Strongly disagree

1. Plagiarism damages the meaning of a degree.

(1) (2) (3) (4) (5) (6)

2. It is no big deal if you submit slightly modified work as your own without proper citation.

(1) (2) (3) (4) (5) (6)

3. Students' poor understanding of citing and referencing leads them to

(1) (2) (3) (4) (5) (6) plagiarise.

4. More students plagiarise when lecturers set the same assignments year (1) (2) (3) (4) (5) (6) after year. 
5. Plagiarism is more common in the work of beginner writers.

6. Students who plagiarise learn less.

7. Heavily depending on an original source for ideas without citation is no big deal if you use few or no words from that source.

\begin{tabular}{|c|c|c|c|c|}
\hline Plagiarism is unethical. & & & & \\
\hline Students plagiarise because of pressure to succeed. & & & & \\
\hline gagarise when assigmments are interessting. & & & & \\
\hline 1. Plabarisis threaten sthe reputation of the unviversity. & (1) (2) & (3) & (4) (5) & \\
\hline 12. Sutuents plagarisise because they want high grades. & & & & \\
\hline 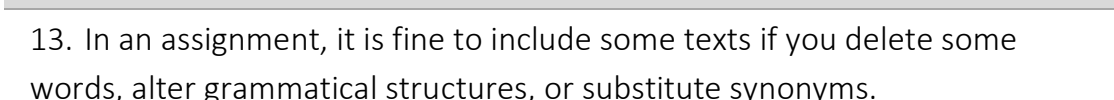 & & & & \\
\hline 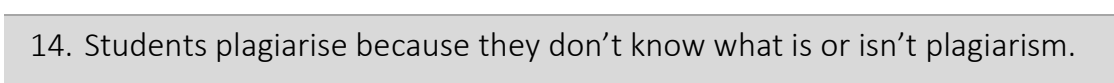 & & & & \\
\hline 15. Students don't plagiarise when there is a high chance of being caught. & & & & \\
\hline 16. Students are more likely to plagiaririse written assignments than & & (3) & & \\
\hline 17. Plagiarissm i d deceetitul. & & & & \\
\hline 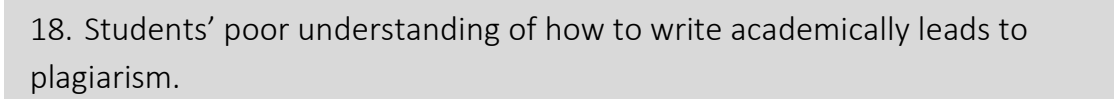 & & (3) & & \\
\hline 9. It is fin to submit the same assignment to orer than one class. & & & & \\
\hline 20. A good person doesn't plagiarise. & (1) (2) & (3) & (4) (5) & (๑) \\
\hline 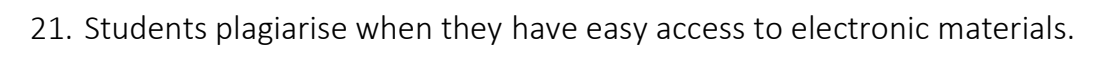 & & (3) & & \\
\hline 2. Plagararsm i s stealing. & & & & \\
\hline 233. Plagirisism happens when students are learning to write. & & (3) & (4) (5) & \\
\hline 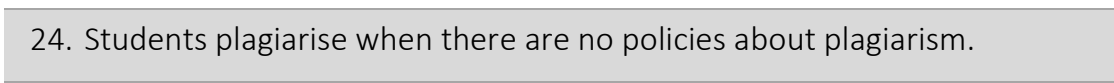 & & (3) & (4) (5) & \\
\hline 25. Time constraints have no iffluence on student plagiairsm. & & & & \\
\hline 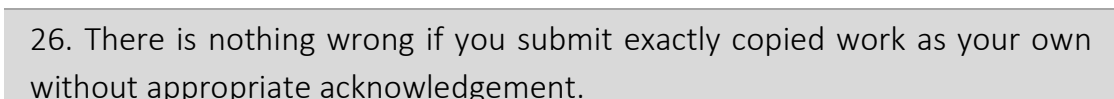 & & & & \\
\hline 27. Acadernically weak sutuents are more likey to plazärise. & & (3) & (4) (5) & \\
\hline 28. Students don't plagiarise when assignments are personalised. & (1) (2) & (3) & & \\
\hline 29. Students plagiarise because they want to pass courses. & & & & \\
\hline 30. Pagajarism worsens teachers.sudent relationships. & & (3) & (4) (5) & \\
\hline ause it helps them do well in later Ilife. & (1) (2) & (3) & (4) (5) & \\
\hline sm is sacademically wrong. & & (3) & & \\
\hline who & & & & \\
\hline & & & & \\
\hline
\end{tabular}

(1) (2) (3) (4) (5) (6)

(1) (2) (3) (4) (5) (6)

(1) (2) (3) (4) (5) (6)

(1) (2) (3) (4) (5) (6)

(1) (2) (3) (4) (5) (6)

(1) (2) (3) (4) (5) (6)

(1) (2) (3) (4) (5) (3)

8. Plagiarism is unethical$$
\text { 年 }
$$
. 年 
35. Students plagiarise when assessments tests understandings of textbook materials.
(1) (2) (3) (4) (5) (6)

36. Students plagiarise when they are under academic workload pressure.

(1) (2) (3) (4) (5) (6)

37. Students who plagiarise are penalised by the university.

(1) (2) (3) (4) (5) (6)

\section{Interview Participation}

The study involves a series of four in-depth interviews aiming to learn more about your perceptions of plagiarism. You will not be asked to disclose information about specific examples of plagiarism you or other students have undertaken. In appreciation of your participation in these interviews, you will receive four New World vouchers with a total value of $\$ 80$. If you are interested to be confidentially interviewed, please give your contact information.

Name:

Email:

Phone:

We thank you for your time spent taking this survey. Your response has been recorded.

If you would like to be in the draw, please click here to enter your contact details. 


\section{Appendix B: Interview Participants' Survey Responses}

\section{New Zealand-educated Participants}

\section{Ally's responses}

\begin{tabular}{|c|c|c|c|c|c|c|}
\hline Statements & $\begin{array}{l}\text { Strongly } \\
\text { agree }\end{array}$ & Agree & $\begin{array}{c}\text { Slightly } \\
\text { agree }\end{array}$ & $\begin{array}{l}\text { Slightly } \\
\text { disagree }\end{array}$ & Disagree & $\begin{array}{l}\text { Strongly } \\
\text { disagree }\end{array}$ \\
\hline $\begin{array}{l}\text { 2. It is no big deal if you submit slightly modified work as your own } \\
\text { without proper citation. }\end{array}$ & (1) & (2) & (3) & (4) & (5) & \\
\hline 32. Plagiarism is academically wrong. & & (2) & (3) & (4) & (5) & (6) \\
\hline $\begin{array}{l}\text { 7. Heavily depending on an original source for ideas without citation is no } \\
\text { big deal if you use few or no words from that source. }\end{array}$ & (1) & (2) & (3) & (4) & (5) & \\
\hline 31. Plagiarism helps students do well in later life. & (1) & (2) & (3) & (4) & (5) & \\
\hline 19. It is fine to submit the same assignment to more than one class. & (1) & (2) & (3) & & (5) & (6) \\
\hline $\begin{array}{l}\text { 26. Submitting exactly copied work as your own without appropriate } \\
\text { acknowledgement is not a serious problem. }\end{array}$ & (1) & (2) & (3) & (4) & (5) & \\
\hline $\begin{array}{l}\text { 13. In an assignment, it is fine to include some texts if you delete some } \\
\text { words, alter grammatical structures, or substitute synonyms. }\end{array}$ & (1) & (2) & (3) & & (5) & (6) \\
\hline $\begin{array}{l}\text { 34. It is not a serious problem if you acknowledge the original sources } \\
\text { insufficiently. }\end{array}$ & (1) & (2) & (3) & (4) & & (6) \\
\hline 29. Students plagiarize because they want to pass courses. & (1) & & (3) & (4) & (5) & (6) \\
\hline 9. Students plagiarize because of pressure to succeed. & (1) & (2) & & (4) & (5) & (6) \\
\hline $\begin{array}{l}\text { 36. Students plagiarize when they are under academic workload } \\
\text { pressure. }\end{array}$ & (1) & (2) & & (4) & (5) & (6) \\
\hline 12. Students plagiarize because they want high grades. & (1) & & (3) & (4) & (5) & (6) \\
\hline 25. Time constraints have no influence on student plagiarism. & (1) & (2) & (3) & & (5) & (6) \\
\hline $\begin{array}{l}\text { Inderstanding of citation and referencing conventions } \\
\text { iarize. }\end{array}$ & (1) & 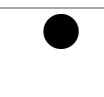 & (3) & (4) & (5) & (6) \\
\hline $\begin{array}{l}\text { 18. Students' poor understanding of how to write academically leads to } \\
\text { plagiarism. }\end{array}$ & (1) & (2) & & (4) & (5) & (6) \\
\hline 14. Students plagiarize because they can't tell what is or isn't plagiarism. & (1) & (2) & & (4) & (5) & (6) \\
\hline 5. Plagiarism is more common in the work of beginner writers. & (1) & (2) & & (4) & (5) & (6) \\
\hline 23. Plagiarism happens when students are learning to write. & (1) & (2) & (3) & (4) & & (6) \\
\hline 27. Academically we & (1) & (2) & (3) & & (5) & (6) \\
\hline 10. Students don't plagiarize when assignments are interesting. & (1) & (2) & (3) & $\Omega$ & (5) & (6) \\
\hline 28. Students don't plagiarize when assignments are personalized. & (1) & (2) & & (4) & (5) & (6) \\
\hline 15. Students don't plagiarize when there is a high chance of being caught. & (1) & & (3) & (4) & (5) & (6) \\
\hline 17. Plagiarism is deceitful. & (1) & & (3) & (4) & (5) & (6) \\
\hline 22. Plagiarism is st & (1) & (2) & & (4) & (5) & (6) \\
\hline 1. Plagiarism damages the meaning of a degree. & & (2) & (3) & (4) & (5) & (6) \\
\hline 20. A good person doesn't plagiarize. & (1) & (2) & (3) & & (5) & (6) \\
\hline 30. Plagiarism worsens teacher-student relationships. & (1) & (2) & & (4) & (5) & (6) \\
\hline 6. Students who plagiarize learn less. & (1) & & (3) & (4) & (5) & (6) \\
\hline 11. Plagiarism threatens the reputation of the university. & & (2) & (3) & (4) & (5) & (6) \\
\hline
\end{tabular}




\section{Darshana's responses}

\begin{tabular}{|c|c|c|c|c|c|c|}
\hline Statements & $\begin{array}{l}\text { Strongly } \\
\text { agree }\end{array}$ & Agree & $\begin{array}{c}\text { Slightly } \\
\text { agree }\end{array}$ & $\begin{array}{l}\text { Slightly } \\
\text { disagree }\end{array}$ & Disagree & $\begin{array}{l}\text { Strongly } \\
\text { disagree }\end{array}$ \\
\hline $\begin{array}{l}\text { 2. It is no big deal if you submit slightly modified work as your own } \\
\text { without proper citation. }\end{array}$ & (1) & (2) & (3) & (4) & (5) & \\
\hline 32. Plagiarism is academically wrong. & & (2) & (3) & (4) & (5) & (6) \\
\hline $\begin{array}{l}\text { 7. Heavily depending on an original source for ideas without citation is no } \\
\text { big deal if you use few or no words from that source. }\end{array}$ & (1) & (2) & (3) & (4) & (5) & \\
\hline 31. Plagiarism helps students do well in later life. & (1) & (2) & (3) & (4) & (5) & \\
\hline 19. It is fine to submit the same assignment to more than one class. & (1) & (2) & (3) & (4) & (5) & \\
\hline $\begin{array}{l}\text { 26. Submitting exactly copied work as your own without appropriate } \\
\text { acknowledgement is not a serious problem. }\end{array}$ & (1) & (2) & (3) & (4) & (5) & \\
\hline $\begin{array}{l}\text { 13. In an assignment, it is fine to include some texts if you delete some } \\
\text { words, alter grammatical structures, or substitute synonyms. }\end{array}$ & (1) & (2) & (3) & 0 & (5) & (6) \\
\hline $\begin{array}{l}\text { 34. It is not a serious problem if you acknowledge the original sources } \\
\text { insufficiently. }\end{array}$ & (1) & (2) & (3) & (4) & (5) & \\
\hline 29. Students plagiarize because they want to pass courses. & (1) & (2) & & (4) & (5) & (6) \\
\hline 9. Students plagiarize because of pressure to succeed. & (1) & (2) & (3) & (4) & & (6) \\
\hline $\begin{array}{l}\text { 36. Students plagiarize when they are under academic workload } \\
\text { pressure. }\end{array}$ & (1) & (2) & (3) & (4) & & (6) \\
\hline 12. Students plagiarize because they want high grades. & (1) & (2) & (3) & (4) & & (6) \\
\hline 25. Time constraints have no influence on student plagiarism. & (1) & & (3) & (4) & (5) & (6) \\
\hline $\begin{array}{l}\text { 3. Students' poor understanding of citation and referencing conventions } \\
\text { leads them to plagiarize. }\end{array}$ & (1) & (2) & & (4) & (5) & (6) \\
\hline $\begin{array}{l}\text { 18. Students' poor understanding of how to write academically leads to } \\
\text { plagiarism. }\end{array}$ & (1) & (2) & (3) & (4) & & (6) \\
\hline 14. Students plagiarize because they can't tell what is or isn't plagiarism. & (1) & (2) & (3) & (4) & & (6) \\
\hline 5. Plagiarism is more common in the work of beginner writers. & (1) & (2) & 0 & (4) & (5) & (6) \\
\hline 23. Plagiarism happens when students are learning to write. & (1) & (2) & (3) & (4) & & (6) \\
\hline 27. Academically weak students are more likely to plagiarize. & (1) & (2) & (3) & 0 & (5) & (6) \\
\hline 10. Students don't plagiarize when assignments are interesting. & (1) & (2) & (3) & (4) & & (6) \\
\hline 28. Students don't plagiarize when assignments are personalized. & (1) & (2) & (3) & (4) & & (6) \\
\hline 15. Students don't plagiarize when there is a high chance of being caught. & (1) & (2) & (3) & (4) & & (6) \\
\hline 17. Plagiarism is deceitful. & & (2) & (3) & (4) & (5) & (6) \\
\hline 22. Plagiarism is stealing. & & (2) & (3) & (4) & (5) & (6) \\
\hline 1. Plagiarism damages the meaning of a degree. & & (2) & (3) & (4) & (5) & (6) \\
\hline 20. A good person doesn't plagiarize. & (1) & & (3) & (4) & (5) & (6) \\
\hline 30. Plagiarism worsens teacher-student relationships. & (1) & (2) & & (4) & (5) & (6) \\
\hline 6. Students who plagiarize learn less. & (1) & & (3) & (4) & (5) & (6) \\
\hline 11. Plagiarism threatens the reputation of the university. & & (2) & (3) & (4) & (5) & (6) \\
\hline
\end{tabular}


Emma's responses

\begin{tabular}{|c|c|c|c|c|c|c|}
\hline Statements & $\begin{array}{l}\text { Strongly } \\
\text { agree }\end{array}$ & Agree & $\begin{array}{c}\text { Slightly } \\
\text { agree }\end{array}$ & $\begin{array}{l}\text { Slightly } \\
\text { disagree }\end{array}$ & Disagree & $\begin{array}{l}\text { Strongly } \\
\text { disagree }\end{array}$ \\
\hline $\begin{array}{l}\text { 2. It is no big deal if you submit slightly modified work as your own } \\
\text { without proper citation. }\end{array}$ & (1) & (2) & (3) & (4) & (5) & \\
\hline 32. Plagiarism is academically wrong. & & (2) & (3) & (4) & (5) & (6) \\
\hline $\begin{array}{l}\text { 7. Heavily depending on an original source for ideas without citation is no } \\
\text { big deal if you use few or no words from that source. }\end{array}$ & (1) & (2) & (3) & (4) & (5) & \\
\hline 31. Plagiarism helps students do well in later life. & (1) & (2) & (3) & (4) & (5) & \\
\hline 19. It is fine to submit the same assignment to more than one class. & (1) & (2) & (3) & (4) & (5) & \\
\hline $\begin{array}{l}\text { 26. Submitting exactly copied work as your own without appropriate } \\
\text { acknowledgement is not a serious problem. }\end{array}$ & (1) & (2) & (3) & (4) & (5) & \\
\hline $\begin{array}{l}\text { 13. In an assignment, it is fine to include some texts if you delete some } \\
\text { words, alter grammatical structures, or substitute synonyms. }\end{array}$ & (1) & (2) & (3) & (4) & & (6) \\
\hline $\begin{array}{l}\text { 34. It is not a serious problem if you acknowledge the original sources } \\
\text { insufficiently. }\end{array}$ & (1) & (2) & (3) & (4) & & (6) \\
\hline 29. Students plagiarize because they want to pass courses. & (1) & & (3) & (4) & (5) & (6) \\
\hline 9. Students plagiarize because of pressure to succeed. & (1) & (2) & (3) & (4) & (5) & \\
\hline $\begin{array}{l}\text { 36. Students plagiarize when they are under academic workload } \\
\text { pressure. }\end{array}$ & (1) & & (3) & (4) & (5) & (6) \\
\hline 12. Students plagiarize because they want high grades. & (1) & (2) & (3) & (4) & & (6) \\
\hline 25. Time constraints have no influence on student plagiarism. & (1) & (2) & (3) & (4) & & (6) \\
\hline $\begin{array}{l}\text { 3. Students' poor understanding of citation and referencing conventions } \\
\text { leads them to plagiarize. }\end{array}$ & & (2) & (3) & (4) & (5) & (6) \\
\hline $\begin{array}{l}\text { 18. Students' poor understanding of how to write academically leads to } \\
\text { plagiarism. }\end{array}$ & & (2) & (3) & (4) & (5) & (6) \\
\hline 14. Students plagiarize because they can't tell what is or isn't plagiarism. & (1) & (2) & & (4) & (5) & (6) \\
\hline 5. Plagiarism is more common in the work of beginner writers. & (1) & 8 & (3) & (4) & (5) & (6) \\
\hline 23. Plagiarism happens when students are learning to write. & (1) & (2) & & (4) & (5) & (6) \\
\hline 27. Academically weak students are more likely to plagiarize. & (1) & C & (3) & (4) & (5) & (6) \\
\hline 10. Students don't plagiarize when assignments are interesting. & (1) & (2) & (3) & (4) & O & (6) \\
\hline 28. Students don't plagiarize when assignments are personalized. & (1) & (2) & (3) & (4) & & (6) \\
\hline 15. Students don't plagiarize when there is a high chance of being caught. & & (2) & (3) & (4) & (5) & (6) \\
\hline 17. Plagiarism is deceitful. & & (2) & (3) & (4) & (5) & (6) \\
\hline 22. Plagiarism is stealing. & & (2) & (3) & (4) & (5) & (6) \\
\hline 1. Plagiarism damages the meaning of a degree. & & (2) & (3) & (4) & (5) & (6) \\
\hline 20. A good person doesn't plagiarize. & (1) & 0 & (3) & (4) & (5) & (6) \\
\hline 30. Plagiarism worsens teacher-student relationships. & (1) & & (3) & (4) & (5) & (6) \\
\hline 6. Students who plagiarize learn less. & & (2) & (3) & (4) & (5) & (6) \\
\hline 11. Plagiarism threatens the reputation of the university. & & (2) & (3) & (4) & (5) & (6) \\
\hline
\end{tabular}


Frank's responses

\begin{tabular}{|c|c|c|c|c|c|c|}
\hline Statements & $\begin{array}{l}\text { Strongly } \\
\text { agree }\end{array}$ & Agree & $\begin{array}{c}\text { Slightly } \\
\text { agree }\end{array}$ & $\begin{array}{l}\text { Slightly } \\
\text { disagree }\end{array}$ & Disagree & $\begin{array}{l}\text { Strongly } \\
\text { disagree }\end{array}$ \\
\hline $\begin{array}{l}\text { 2. It is no big deal if you submit slightly modified work as your own } \\
\text { without proper citation. }\end{array}$ & (1) & (2) & (3) & (4) & 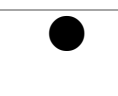 & (6) \\
\hline 32. Plagiarism is academically wrong. & 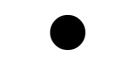 & (2) & (3) & (4) & (5) & (6) \\
\hline $\begin{array}{l}\text { 7. Heavily depending on an original source for ideas without citation is no } \\
\text { big deal if you use few or no words from that source. }\end{array}$ & (1) & (2) & & (4) & (5) & (6) \\
\hline 31. Plagiarism helps students do well in later life. & (1) & (2) & (3) & (4) & (5) & \\
\hline 19. It is fine to submit the same assignment to more than one class. & (1) & (2) & (3) & (4) & (5) & \\
\hline $\begin{array}{l}\text { 26. Submitting exactly copied work as your own without appropriate } \\
\text { acknowledgement is not a serious problem. }\end{array}$ & (1) & (2) & (3) & (4) & (5) & \\
\hline $\begin{array}{l}\text { 13. In an assignment, it is fine to include some texts if you delete some } \\
\text { words, alter grammatical structures, or substitute synonyms. }\end{array}$ & (1) & (2) & (3) & & (5) & (6) \\
\hline $\begin{array}{l}\text { 34. It is not a serious problem if you acknowledge the original sources } \\
\text { insufficiently. }\end{array}$ & (1) & (2) & (3) & (4) & & (6) \\
\hline 29. Students plagiarize because they want to pass courses. & (1) & O & (3) & (4) & (5) & (6) \\
\hline 9. Students plagiarize because of pressure to succeed. & (1) & (2) & (3) & (4) & & (6) \\
\hline $\begin{array}{l}\text { 36. Students plagiarize when they are under academic workload } \\
\text { pressure. }\end{array}$ & (1) & & (3) & (4) & (5) & (6) \\
\hline 12. Students plagiarize because they want high grades. & (1) & (2) & & (4) & (5) & (6) \\
\hline 25. Time constraints have no influence on student plagiarism. & (1) & (2) & (3) & 0 & (5) & (6) \\
\hline $\begin{array}{l}\text { 3. Students' poor understanding of citation and referencing conventions } \\
\text { leads them to plagiarize. }\end{array}$ & (1) & 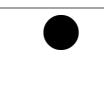 & (3) & (4) & (5) & (6) \\
\hline $\begin{array}{l}\text { 18. Students' poor understanding of how to write academically leads to } \\
\text { plagiarism. }\end{array}$ & (1) & (2) & & (4) & (5) & (6) \\
\hline 14. Students plagiarize because they can't tell what is or isn't plagiarism. & (1) & (2) & & (4) & (5) & (6) \\
\hline 5. Plagiarism is more common in the work of beginner writers. & (1) & (2) & & (4) & (5) & (6) \\
\hline 23. Plagiarism happens when students are learning to write. & (1) & (2) & (3) & O & (5) & (6) \\
\hline 27. Academically weak students are more likely to plagiarize. & (1) & (2) & & (4) & (5) & (6) \\
\hline 10. Students don't plagiarize when assignments are interesting. & (1) & (2) & (3) & & (5) & (6) \\
\hline 28. Students don't plagiarize when assignments are personalized. & (1) & (2) & & (4) & (5) & (6) \\
\hline 15. Students don't plagiarize when there is a high chance of being caught. & (1) & (2) & & (4) & (5) & (6) \\
\hline 17. Plagiarism is deceitful. & (1) & C & (3) & (4) & (5) & (6) \\
\hline 22. Plagiarism is stealing. & (1) & (2) & & (4) & (5) & (6) \\
\hline 1. Plagiarism damages the meaning of a degree. & & (2) & (3) & (4) & (5) & (6) \\
\hline 20. A good person doesn't plagiarize. & (1) & (2) & (3) & (4) & & (6) \\
\hline 30. Plagiarism worsens teacher-student relationships. & (1) & (2) & & (4) & (5) & (6) \\
\hline 6. Students who plagiarize learn less. & (1) & (2) & & (4) & (5) & (6) \\
\hline 11. Plagiarism threatens the reputation of the university. & (1) & (2) & & (4) & (5) & (6) \\
\hline
\end{tabular}




\section{Paddy's responses}

\begin{tabular}{|c|c|c|c|c|c|c|}
\hline Statements & $\begin{array}{l}\text { Strongly } \\
\text { agree }\end{array}$ & Agree & $\begin{array}{c}\text { Slightly } \\
\text { agree }\end{array}$ & $\begin{array}{l}\text { Slightly } \\
\text { disagree }\end{array}$ & Disagree & $\begin{array}{l}\text { Strongly } \\
\text { disagree }\end{array}$ \\
\hline $\begin{array}{l}\text { 2. It is no big deal if you submit slightly modified work as your own } \\
\text { without proper citation. }\end{array}$ & (1) & (2) & (3) & (4) & (5) & \\
\hline 32. Plagiarism is academically wrong. & & (2) & (3) & (4) & (5) & (6) \\
\hline $\begin{array}{l}\text { 7. Heavily depending on an original source for ideas without citation is no } \\
\text { big deal if you use few or no words from that source. }\end{array}$ & (1) & (2) & (3) & (4) & (5) & \\
\hline 31. Plagiarism helps students do well in later life. & (1) & (2) & (3) & (4) & (5) & \\
\hline 19. It is fine to submit the same assignment to more than one class. & (1) & (2) & & (4) & (5) & (6) \\
\hline $\begin{array}{l}\text { 26. Submitting exactly copied work as your own without appropriate } \\
\text { acknowledgement is not a serious problem. }\end{array}$ & (1) & (2) & (3) & (4) & (5) & \\
\hline $\begin{array}{l}\text { 13. In an assignment, it is fine to include some texts if you delete some } \\
\text { words, alter grammatical structures, or substitute synonyms. }\end{array}$ & (1) & (2) & (3) & (4) & & (6) \\
\hline $\begin{array}{l}\text { 34. It is not a serious problem if you acknowledge the original sources } \\
\text { insufficiently. }\end{array}$ & (1) & (2) & (3) & (4) & & (6) \\
\hline 29. Students plagiarize because they want to pass courses. & (1) & & (3) & (4) & (5) & (6) \\
\hline 9. Students plagiarize because of pressure to succeed. & (1) & (2) & & (4) & (5) & (6) \\
\hline $\begin{array}{l}\text { 36. Students plagiarize when they are under academic workload } \\
\text { pressure. }\end{array}$ & (1) & & (3) & (4) & (5) & (6) \\
\hline 12. Students plagiarize because they want high grades. & (1) & (2) & (3) & & (5) & (6) \\
\hline 25. Time constraints have no influence on student plagiarism. & (1) & (2) & (3) & 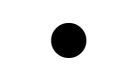 & (5) & (6) \\
\hline $\begin{array}{l}\text { 3. Students' poor understanding of citation and referencing conventions } \\
\text { leads them to plagiarize. }\end{array}$ & (1) & & (3) & (4) & (5) & (6) \\
\hline $\begin{array}{l}\text { 18. Students' poor understanding of how to write academically leads to } \\
\text { plagiarism. }\end{array}$ & (1) & ( & (3) & (4) & (5) & (6) \\
\hline 14. Students plagiarize because they can't tell what is or isn't plagiarism. & (1) & (2) & & (4) & (5) & (6) \\
\hline 5. Plagiarism is more common in the work of beginner writers. & (1) & (2) & 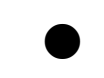 & (4) & (5) & (6) \\
\hline 23. Plagiarism happens when students are learning to write. & (1) & (2) & & (4) & (5) & (6) \\
\hline 27. Academically weak students are more likely to plagiarize. & (1) & (2) & 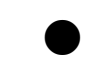 & (4) & (5) & (6) \\
\hline 10. Students don't plagiarize when assignments are interesting. & (1) & (2) & (3) & & (5) & (6) \\
\hline 28. Students don't plagiarize when assignments are personalized. & (1) & (2) & (3) & & (5) & (6) \\
\hline 15. Students don't plagiarize when there is a high chance of being caught. & (1) & (2) & & (4) & (5) & (6) \\
\hline 17. Plagiarism is deceitful. & & (2) & (3) & (4) & (5) & (6) \\
\hline 22. Plagiarism is stealing. & (1) & C & (3) & (4) & (5) & (6) \\
\hline 1. Plagiarism damages the meaning of a degree. & & (2) & (3) & (4) & (5) & (6) \\
\hline 20. A good person doesn't plagiarize. & (1) & (2) & (3) & & (5) & (6) \\
\hline 30. Plagiarism worsens teacher-student relationships. & (1) & & (3) & (4) & (5) & (6) \\
\hline 6. Students who plagiarize learn less. & & (2) & (3) & (4) & (5) & (6) \\
\hline 11. Plagiarism threatens the reputation of the university. & & (2) & (3) & (4) & (5) & (6) \\
\hline
\end{tabular}


Solace's responses

\begin{tabular}{|c|c|c|c|c|c|c|}
\hline Statements & $\begin{array}{c}\text { Strongly } \\
\text { agree }\end{array}$ & Agree & $\begin{array}{c}\text { Slightly } \\
\text { agree }\end{array}$ & $\begin{array}{l}\text { Slightly } \\
\text { disagree }\end{array}$ & Disagree & $\begin{array}{l}\text { Strongly } \\
\text { disagree }\end{array}$ \\
\hline $\begin{array}{l}\text { 2. It is no big deal if you submit slightly modified work as your own } \\
\text { without proper citation. }\end{array}$ & (1) & (2) & (3) & (4) & O & \\
\hline 32. Plagiarism is academically wrong. & (1) & & (3) & (4) & (5) & (6) \\
\hline $\begin{array}{l}\text { 7. Heavily depending on an original source for ideas without citation is no } \\
\text { big deal if you use few or no words from that source. }\end{array}$ & (1) & (2) & (3) & (4) & (5) & \\
\hline 31. Plagiarism helps students do well in later life. & (1) & (2) & & (4) & (5) & (6) \\
\hline 19. It is fine to submit the same assignment to more than one class. & & (2) & (3) & (4) & (5) & (6) \\
\hline $\begin{array}{l}\text { 26. Submitting exactly copied work as your own without appropriate } \\
\text { acknowledgement is not a serious problem. }\end{array}$ & (1) & (2) & (3) & (4) & (5) & \\
\hline $\begin{array}{l}\text { 13. In an assignment, it is fine to include some texts if you delete some } \\
\text { words, alter grammatical structures, or substitute synonyms. }\end{array}$ & (1) & (2) & (3) & (4) & & (6) \\
\hline $\begin{array}{l}\text { 34. It is not a serious problem if you acknowledge the original sources } \\
\text { insufficiently. }\end{array}$ & (1) & (2) & (3) & (4) & & (6) \\
\hline 29. Students plagiarize because they want to pass courses. & (1) & (2) & & (4) & (5) & (6) \\
\hline 9. Students plagiarize because of pressure to succeed. & (1) & (2) & & (4) & (5) & (6) \\
\hline $\begin{array}{l}\text { 36. Students plagiarize when they are under academic workload } \\
\text { pressure. }\end{array}$ & (1) & (2) & & (4) & (5) & (6) \\
\hline 12. Students plagiarize because they want high grades. & (1) & (2) & & (4) & (5) & (6) \\
\hline 25. Time constraints have no influence on student plagiarism. & (1) & (2) & (3) & 0 & (5) & (6) \\
\hline $\begin{array}{l}\text { 3. Students' poor understanding of citation and referencing conventions } \\
\text { leads them to plagiarize. }\end{array}$ & (1) & (2) & & (4) & (5) & (6) \\
\hline $\begin{array}{l}\text { 18. Students' poor understanding of how to write academically leads to } \\
\text { plagiarism. }\end{array}$ & (1) & & (3) & (4) & (5) & (6) \\
\hline 14. Students plagiarize because they can't tell what is or isn't plagiarism. & (1) & (2) & & (4) & (5) & (6) \\
\hline 5. Plagiarism is more common in the work of beginner writers. & (1) & 8 & (3) & (4) & (5) & (6) \\
\hline 23. Plagiarism happens when students are learning to write. & (1) & (2) & & (4) & (5) & (6) \\
\hline 27. Academically weak students are more likely to plagiarize. & (1) & (2) & & (4) & (5) & (6) \\
\hline 10. Students don't plagiarize when assignments are interesting. & (1) & & (3) & (4) & (5) & (6) \\
\hline 28. Students don't plagiarize when assignments are personalized. & (1) & (2) & (3) & (4) & & (6) \\
\hline 15. Students don't plagiarize when there is a high chance of being caught. & & (2) & (3) & (4) & (5) & (6) \\
\hline 17. Plagiarism is deceitful. & (1) & 8 & (3) & (4) & (5) & (6) \\
\hline 22. Plagiarism is stealing. & (1) & (2) & (3) & & (5) & (6) \\
\hline 1. Plagiarism damages the meaning of a degree. & (1) & & (3) & (4) & (5) & (6) \\
\hline 20. A good person doesn't plagiarize. & (1) & (2) & (3) & (4) & & (6) \\
\hline 30. Plagiarism worsens teacher-student relationships. & (1) & (2) & & (4) & (5) & (6) \\
\hline 6. Students who plagiarize learn less. & (1) & (2) & & (4) & (5) & (6) \\
\hline 11. Plagiarism threatens the reputation of the university. & & (2) & (3) & (4) & (5) & (6) \\
\hline
\end{tabular}




\section{Vietnam-educated Participants}

\section{Hoa's responses}

\begin{tabular}{|c|c|c|c|c|c|c|}
\hline Statements & $\begin{array}{l}\text { Strongly } \\
\text { agree }\end{array}$ & Agree & $\begin{array}{c}\text { Slightly } \\
\text { agree }\end{array}$ & $\begin{array}{l}\text { Slightly } \\
\text { disagree }\end{array}$ & Disagree & $\begin{array}{l}\text { Strongly } \\
\text { disagree }\end{array}$ \\
\hline $\begin{array}{l}\text { 2. It is no big deal if you submit slightly modified work as your own } \\
\text { without proper citation. }\end{array}$ & (1) & (2) & (3) & (4) & (5) & \\
\hline 32. Plagiarism is academically wrong. & (1) & (2) & & (4) & (5) & (6) \\
\hline $\begin{array}{l}\text { 7. Heavily depending on an original source for ideas without citation is no } \\
\text { big deal if you use few or no words from that source. }\end{array}$ & (1) & (2) & (3) & & (5) & (6) \\
\hline 31. Plagiarism helps students do well in later life. & (1) & (2) & & & (5) & (6) \\
\hline 19. It is fine to submit the same assignment to more than one class. & (1) & (2) & & & (5) & \\
\hline $\begin{array}{l}\text { 26. Submitting exactly copied work as your own without appropriate } \\
\text { acknowledgement is not a serious problem. }\end{array}$ & (1) & (2) & (3) & (4) & & (6) \\
\hline $\begin{array}{l}\text { 13. In an assignment, it is fine to include some texts if you delete some } \\
\text { words, alter grammatical structures, or substitute synonyms. }\end{array}$ & (1) & (2) & (3) & & (5) & (6) \\
\hline $\begin{array}{l}\text { 34. It is not a serious problem if you acknowledge the original sources } \\
\text { insufficiently. }\end{array}$ & (1) & (2) & (3) & & (5) & (6) \\
\hline 29. Students plagiarize because they want to pass courses. & (1) & (2) & & (4) & (5) & (6) \\
\hline 9. Students plagiarize because of pressure to succeed. & (1) & (2) & & O & (5) & (6) \\
\hline $\begin{array}{l}\text { 36. Students plagiarize when they are under academic workload } \\
\text { pressure. }\end{array}$ & (1) & (2) & & (4) & (5) & (6) \\
\hline 12. Students plagiarize because they want high grades. & (1) & (2) & (3) & & (5) & (6) \\
\hline 25. Time constraints have no influence on student plagiarism. & (1) & (2) & (3) & & (5) & (6) \\
\hline $\begin{array}{l}\text { 3. Students' poor understanding of citation and referencing conventions } \\
\text { leads them to plagiarize. }\end{array}$ & (1) & & (3) & (4) & (5) & (6) \\
\hline $\begin{array}{l}\text { 18. Students' poor understanding of how to write academically leads to } \\
\text { plagiarism. }\end{array}$ & (1) & (2) & & (4) & (5) & (6) \\
\hline 14. Students plagiarize because they can't tell what is or isn't plagiarism. & (1) & (2) & & (4) & (5) & (6) \\
\hline 5. Plagiarism is more common in the work of beginner writers. & (1) & (2) & & (4) & & (6) \\
\hline 23. Plagiarism happens when students are learning to write. & (1) & (2) & (3) & $\mathrm{C}$ & (5) & (6) \\
\hline 27. Academically weak students are more likely to plagiarize. & (1) & (2) & & (4) & (5) & (6) \\
\hline 10. Students don't plagiarize when assignments are interesting. & (1) & (2) & (3) & Q & (5) & (6) \\
\hline 28. Students don't plagiarize when assignments are personalized. & (1) & (2) & & (4) & (5) & (6) \\
\hline 15. Students don't plagiarize when there is a high chance of being caught. & (1) & (2) & & (4) & (5) & (6) \\
\hline 17. Plagiarism is deceitful. & (1) & 0 & (3) & (4) & (5) & (6) \\
\hline 22. Plagiarism is & (1) & (2) & & (4) & (5) & (6) \\
\hline 1. Plagiarism damages the meaning of a degree. & & (2) & 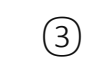 & (4) & (5) & (6) \\
\hline 20. A good person doesn't plagiarize. & (1) & (2) & & (4) & (5) & (6) \\
\hline 30. Plagiarism worsens teacher-student relationships. & (1) & (2) & & (4) & (5) & (6) \\
\hline & (1) & (2) & & (4) & (5) & (6) \\
\hline 11. Plagiarism threatens the reputation of the university. & (1) & (2) & & (4) & (5) & (6) \\
\hline
\end{tabular}


Huynh's responses

\begin{tabular}{|c|c|c|c|c|c|c|}
\hline Statements & $\begin{array}{l}\text { Strongly } \\
\text { agree }\end{array}$ & Agree & $\begin{array}{c}\text { Slightly } \\
\text { agree }\end{array}$ & $\begin{array}{l}\text { Slightly } \\
\text { disagree }\end{array}$ & Disagree & $\begin{array}{l}\text { Strongly } \\
\text { disagree }\end{array}$ \\
\hline $\begin{array}{l}\text { 2. It is no big deal if you submit slightly modified work as your own } \\
\text { without proper citation. }\end{array}$ & (1) & (2) & (3) & (4) & (5) & \\
\hline 32. Plagiarism is academically wrong. & & (2) & (3) & (4) & (5) & (6) \\
\hline $\begin{array}{l}\text { 7. Heavily depending on an original source for ideas without citation is no } \\
\text { big deal if you use few or no words from that source. }\end{array}$ & (1) & (2) & (3) & (4) & 0 & (6) \\
\hline 31. Plagiarism helps students do well in later life. & (1) & (2) & (3) & (4) & (5) & \\
\hline 19. It is fine to submit the same assignment to more than one class. & (1) & (2) & (3) & (4) & (5) & \\
\hline $\begin{array}{l}\text { 26. Submitting exactly copied work as your own without appropriate } \\
\text { acknowledgement is not a serious problem. }\end{array}$ & (1) & (2) & (3) & (4) & (5) & \\
\hline $\begin{array}{l}\text { 13. In an assignment, it is fine to include some texts if you delete some } \\
\text { words, alter grammatical structures, or substitute synonyms. }\end{array}$ & (1) & (2) & & (4) & (5) & (6) \\
\hline $\begin{array}{l}\text { 34. It is not a serious problem if you acknowledge the original sources } \\
\text { insufficiently. }\end{array}$ & (1) & (2) & (3) & (4) & & (6) \\
\hline 29. Students plagiarize because they want to pass courses. & (1) & (2) & & (4) & (5) & (6) \\
\hline 9. Students plagiarize because of pressure to succeed. & (1) & (2) & & (4) & (5) & (6) \\
\hline $\begin{array}{l}\text { 36. Students plagiarize when they are under academic workload } \\
\text { pressure. }\end{array}$ & (1) & (2) & & (4) & (5) & (6) \\
\hline 12. Students plagiarize because they want high grades. & (1) & (2) & & (4) & (5) & (6) \\
\hline 25. Time constraints have no influence on student plagiarism. & (1) & (2) & (3) & (4) & (5) & \\
\hline $\begin{array}{l}\text { 3. Students' poor understanding of citation and referencing conventions } \\
\text { leads them to plagiarize. }\end{array}$ & & (2) & (3) & (4) & (5) & (6) \\
\hline $\begin{array}{l}\text { 18. Students' poor understanding of how to write academically leads to } \\
\text { plagiarism. }\end{array}$ & & (2) & (3) & (4) & (5) & (6) \\
\hline 14. Students plagiarize because they can't tell what is or isn't plagiarism. & & (2) & (3) & (4) & (5) & (6) \\
\hline 5. Plagiarism is more common in the work of beginner writers. & (1) & (2) & 8 & (4) & (5) & (6) \\
\hline 23. Plagiarism happens when students are learning to write. & (1) & & (3) & (4) & (5) & (6) \\
\hline 27. Academically weak students are more likely to plagiarize. & (1) & 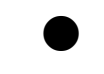 & (3) & (4) & (5) & (6) \\
\hline 10. Students don't plagiarize when assignments are interesting. & (1) & (2) & (3) & (4) & (5) & \\
\hline 28. Students don't plagiarize when assignments are personalized. & (1) & (2) & (3) & (4) & & (6) \\
\hline 15. Students don't plagiarize when there is a high chance of being caught. & (1) & (2) & (3) & (4) & & (6) \\
\hline 17. Plagiarism is deceitful. & & (2) & (3) & (4) & (5) & (6) \\
\hline 22. Plagiarism is stealing. & & (2) & (3) & (4) & (5) & (6) \\
\hline 1. Plagiarism damages the meaning of a degree. & (1) & & (3) & (4) & (5) & (6) \\
\hline 20. A good person doesn't plagiarize. & (1) & (2) & & (4) & (5) & (6) \\
\hline 30. Plagiarism worsens teacher-student relationships. & & (2) & (3) & (4) & (5) & (6) \\
\hline 6. Students who plagiarize learn less. & (1) & & (3) & (4) & (5) & (6) \\
\hline 11. Plagiarism threatens the reputation of the university. & & (2) & (3) & (4) & (5) & (6) \\
\hline
\end{tabular}




\section{Linh's responses}

\begin{tabular}{|c|c|c|c|c|c|c|}
\hline Statements & $\begin{array}{l}\text { Strongly } \\
\text { agree }\end{array}$ & Agree & $\begin{array}{c}\text { Slightly } \\
\text { agree }\end{array}$ & $\begin{array}{l}\text { Slightly } \\
\text { disagree }\end{array}$ & Disagree & $\begin{array}{l}\text { Strongly } \\
\text { agree }\end{array}$ \\
\hline $\begin{array}{l}\text { 2. It is no big deal if you submit slightly modified work as your own } \\
\text { without proper citation. }\end{array}$ & (1) & (2) & (3) & (4) & (5) & \\
\hline 32. Plagiarism is academically wrong. & & (2) & (3) & (4) & (5) & (6) \\
\hline $\begin{array}{l}\text { 7. Heavily depending on an original source for ideas without citation is no } \\
\text { big deal if you use few or no words from that source. }\end{array}$ & (1) & (2) & (3) & (4) & (5) & \\
\hline 31. Plagiarism helps students do well in later life. & (1) & (2) & (3) & (4) & & (6) \\
\hline 19. It is fine to submit the same assignment to more than one class. & (1) & (2) & (3) & (4) & & (6) \\
\hline $\begin{array}{l}\text { 26. Submitting exactly copied work as your own without appropriate } \\
\text { acknowledgement is not a serious problem. }\end{array}$ & (1) & (2) & (3) & (4) & (5) & \\
\hline $\begin{array}{l}\text { 13. In an assignment, it is fine to include some texts if you delete some } \\
\text { words, alter grammatical structures, or substitute synonyms. }\end{array}$ & (1) & (2) & (3) & (4) & & (6) \\
\hline $\begin{array}{l}\text { 34. It is not a serious problem if you acknowledge the original sources } \\
\text { insufficiently. }\end{array}$ & (1) & (2) & (3) & (4) & (5) & \\
\hline 29. Students plagiarize because they want to pass courses. & (1) & & (3) & (4) & (5) & (6) \\
\hline 9. Students plagiarize because of pressure to succeed. & (1) & & (3) & (4) & (5) & (6) \\
\hline $\begin{array}{l}\text { 36. Students plagiarize when they are under academic workload } \\
\text { pressure. }\end{array}$ & (1) & & (3) & (4) & (5) & (6) \\
\hline 12. Students plagiarize because they want high grades. & (1) & & (3) & (4) & (5) & (6) \\
\hline 25. Time constraints have no influence on student plagiarism. & (1) & (2) & (3) & (4) & & (6) \\
\hline $\begin{array}{l}\text { 3. Students' poor understanding of citation and referencing conventions } \\
\text { leads them to plagiarize. }\end{array}$ & (1) & (2) & O & (4) & (5) & (6) \\
\hline $\begin{array}{l}\text { 18. Students' poor understanding of how to write academically leads to } \\
\text { plagiarism. }\end{array}$ & (1) & (2) & O & (4) & (5) & (6) \\
\hline 14. Students plagiarize because they can't tell what is or isn't plagiarism. & (1) & (2) & & (4) & (5) & (6) \\
\hline 5. Plagiarism is more common in the work of beginner writers. & (1) & (2) & (3) & (4) & & (6) \\
\hline 23. Plagiarism happens when students are learning to write. & (1) & (2) & (3) & (4) & & (6) \\
\hline 27. Academically weak students are more likely to plagiarize. & (1) & (2) & (3) & (4) & & (6) \\
\hline 10. Students don't plagiarize when assignments are interesting. & (1) & (2) & (3) & (4) & & (6) \\
\hline 28. Students don't plagiarize when assignments are personalized. & (1) & (2) & 0 & (4) & (5) & (6) \\
\hline 15. Students don't plagiarize when there is a high chance of being caught. & (1) & ( & (3) & (4) & (5) & (6) \\
\hline 17. Plagiarism is deceitful. & & (2) & (3) & (4) & (5) & (6) \\
\hline 22. Plagiarism is stealing. & & (2) & (3) & (4) & (5) & (6) \\
\hline 1. Plagiarism damages the meaning of a degree. & & (2) & (3) & (4) & (5) & (6) \\
\hline 20. A good person doesn't plagiarize. & (1) & (2) & (3) & & (5) & (6) \\
\hline 30. Plagiarism worsens teacher-student relationships. & & (2) & (3) & (4) & (5) & (6) \\
\hline 6. Students who plagiarize learn less. & (1) & & (3) & (4) & (5) & (6) \\
\hline 11. Plagiarism threatens the reputation of the university. & & (2) & (3) & (4) & (5) & (6) \\
\hline
\end{tabular}




\section{Sunny's responses}

\begin{tabular}{|c|c|c|c|c|c|c|}
\hline Statements & $\begin{array}{l}\text { Strongly } \\
\text { agree }\end{array}$ & Agree & $\begin{array}{l}\text { Slightly } \\
\text { agree }\end{array}$ & $\begin{array}{l}\text { Slightly } \\
\text { disagree }\end{array}$ & Disagree & $\begin{array}{l}\text { Strongly } \\
\text { agree }\end{array}$ \\
\hline $\begin{array}{l}\text { 2. It is no big deal if you submit slightly modified work as your own } \\
\text { without proper citation. }\end{array}$ & (1) & & (3) & (4) & (5) & (6) \\
\hline 32. Plagiarism is academically wrong. & (1) & & (3) & (4) & (5) & (6) \\
\hline $\begin{array}{l}\text { 7. Heavily depending on an original source for ideas without citation is no } \\
\text { big deal if you use few or no words from that source. }\end{array}$ & (1) & (2) & (3) & & (5) & (6) \\
\hline 31. Plagiarism helps students do well in later life. & (1) & (2) & (3) & & (5) & (6) \\
\hline 19. It is fine to submit the same assignment to more than one class. & (1) & (2) & 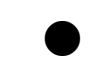 & (4) & (5) & (6) \\
\hline $\begin{array}{l}\text { 26. Submitting exactly copied work as your own without appropriate } \\
\text { acknowledgement is not a serious problem. }\end{array}$ & (1) & (2) & (3) & (4) & 8 & (6) \\
\hline $\begin{array}{l}\text { 13. In an assignment, it is fine to include some texts if you delete some } \\
\text { words, alter grammatical structures, or substitute synonyms. }\end{array}$ & (1) & (2) & (3) & (4) & & (6) \\
\hline $\begin{array}{l}\text { 34. It is not a serious problem if you acknowledge the original sources } \\
\text { insufficiently. }\end{array}$ & (1) & (2) & C & (4) & (5) & (6) \\
\hline 29. Students plagiarize because they want to pass courses. & (1) & (2) & ก & (4) & (5) & (6) \\
\hline 9. Students plagiarize because of pressure to succeed. & (1) & & (3) & (4) & (5) & (6) \\
\hline $\begin{array}{l}\text { 36. Students plagiarize when they are under academic workload } \\
\text { pressure. }\end{array}$ & (1) & (2) & 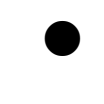 & (4) & (5) & (6) \\
\hline 12. Students plagiarize because they want high grades. & (1) & (2) & (3) & & (5) & (6) \\
\hline 25. Time constraints have no influence on student plagiarism. & (1) & (2) & (3) & & (5) & (6) \\
\hline $\begin{array}{l}\text { 3. Students' poor understanding of citation and referencing conventions } \\
\text { leads them to plagiarize. }\end{array}$ & (1) & & (3) & (4) & (5) & (6) \\
\hline $\begin{array}{l}\text { 18. Students' poor understanding of how to write academically leads to } \\
\text { plagiarism. }\end{array}$ & (1) & & (3) & (4) & (5) & (6) \\
\hline 14. Students plagiarize because they can't tell what is or isn't plagiarism. & (1) & & (3) & (4) & (5) & (6) \\
\hline 5. Plagiarism is more common in the work of beginner writers. & & (2) & (3) & (4) & (5) & (6) \\
\hline 23. Plagiarism happens when students are learning to write. & (1) & & (3) & (4) & (5) & (6) \\
\hline 27. Academically weak students are more likely to plagiarize. & (1) & & (3) & (4) & (5) & (6) \\
\hline 10. Students don't plagiarize when assignments are interesting. & (1) & (2) & (3) & & (5) & (6) \\
\hline 28. Students don't plagiarize when assignments are personalized. & (1) & & (3) & (4) & (5) & (6) \\
\hline 15. Students don't plagiarize when there is a high chance of being caught. & (1) & (2) & (3) & & (5) & (6) \\
\hline 17. Plagiarism is deceitful. & (1) & (2) & (3) & & (5) & (6) \\
\hline 22. Plagiarism is stealing. & (1) & & (3) & (4) & (5) & (6) \\
\hline 1. Plagiarism damages the meaning of a degree. & (1) & & (3) & (4) & (5) & (6) \\
\hline 20. A good person doesn't plagiarize. & (1) & (2) & (3) & & (5) & (6) \\
\hline 30. Plagiarism worsens teacher-student relationships. & (1) & (2) & (3) & (4) & & (6) \\
\hline 6. Students who plagiarize learn less. & (1) & (2) & (3) & (4) & & (6) \\
\hline 11. Plagiarism threatens the reputation of the university. & (1) & & (3) & (4) & (5) & (6) \\
\hline
\end{tabular}




\section{Trung's responses}

\begin{tabular}{|c|c|c|c|c|c|c|}
\hline Statements & $\begin{array}{l}\text { Strongly } \\
\text { agree }\end{array}$ & Agree & $\begin{array}{c}\text { Slightly } \\
\text { agree }\end{array}$ & $\begin{array}{l}\text { Slightly } \\
\text { disagree }\end{array}$ & Disagree & $\begin{array}{l}\text { Strongly } \\
\text { agree }\end{array}$ \\
\hline $\begin{array}{l}\text { 2. It is no big deal if you submit slightly modified work as your own } \\
\text { without proper citation. }\end{array}$ & (1) & (2) & (3) & (4) & (5) & \\
\hline 32. Plagiarism is academically wrong. & & (2) & (3) & (4) & (5) & (6) \\
\hline $\begin{array}{l}\text { 7. Heavily depending on an original source for ideas without citation is no } \\
\text { big deal if you use few or no words from that source. }\end{array}$ & & (2) & (3) & (4) & (5) & (6) \\
\hline 31. Plagiarism helps students do well in later life. & (1) & (2) & (3) & (4) & (5) & \\
\hline 19. It is fine to submit the same assignment to more than one class. & (1) & & (3) & (4) & (5) & (6) \\
\hline $\begin{array}{l}\text { 26. Submitting exactly copied work as your own without appropriate } \\
\text { acknowledgement is not a serious problem. }\end{array}$ & (1) & (2) & (3) & (4) & (5) & \\
\hline $\begin{array}{l}\text { 13. In an assignment, it is fine to include some texts if you delete some } \\
\text { words, alter grammatical structures, or substitute synonyms. }\end{array}$ & (1) & (2) & & (4) & (5) & (6) \\
\hline $\begin{array}{l}\text { 34. It is not a serious problem if you acknowledge the original sources } \\
\text { insufficiently. }\end{array}$ & (1) & (2) & (3) & (4) & & (6) \\
\hline 29. Students plagiarize because they want to pass courses. & & (2) & (3) & (4) & (5) & (6) \\
\hline 9. Students plagiarize because of pressure to succeed. & (1) & (2) & & (4) & (5) & (6) \\
\hline $\begin{array}{l}\text { 36. Students plagiarize when they are under academic workload } \\
\text { pressure. }\end{array}$ & & (2) & (3) & (4) & (5) & (6) \\
\hline 12. Students plagiarize because they want high grades. & (1) & & (3) & (4) & (5) & (6) \\
\hline 25. Time constraints have no influence on student plagiarism. & (1) & (2) & (3) & O & (5) & (6) \\
\hline $\begin{array}{l}\text { 3. Students' poor understanding of citation and referencing conventions } \\
\text { leads them to plagiarize. }\end{array}$ & (1) & & (3) & (4) & (5) & (6) \\
\hline $\begin{array}{l}\text { 18. Students' poor understanding of how to write academically leads to } \\
\text { plagiarism. }\end{array}$ & (1) & & (3) & (4) & (5) & (6) \\
\hline 14. Students plagiarize because they can't tell what is or isn't plagiarism. & & (2) & (3) & (4) & (5) & (6) \\
\hline 5. Plagiarism is more common in the work of beginner writers. & & (2) & (3) & (4) & (5) & (6) \\
\hline 23. Plagiarism happens when students are learning to write. & (1) & (2) & & (4) & (5) & (6) \\
\hline 27. Academically weak students are more likely to plagiarize. & (1) & (2) & a & (4) & (5) & (6) \\
\hline 10. Students don't plagiarize when assignments are interesting. & & (2) & (3) & (4) & (5) & (6) \\
\hline 28. Students don't plagiarize when assignments are personalized. & (1) & & (3) & (4) & (5) & (6) \\
\hline 15. Students don't plagiarize when there is a high chance of being caught. & & (2) & (3) & (4) & (5) & (6) \\
\hline 17. Plagiarism is deceitful. & (1) & & (3) & (4) & (5) & (6) \\
\hline 22. Plagiarism is stealing. & (1) & & (3) & (4) & (5) & (6) \\
\hline 1. Plagiarism damages the meaning of a degree. & (1) & & (3) & (4) & (5) & (6) \\
\hline 20. A good person doesn't plagiarize. & (1) & (2) & & (4) & (5) & (6) \\
\hline 30. Plagiarism worsens teacher-student relationships. & (1) & 8 & (3) & (4) & (5) & (6) \\
\hline 6. Students who plagiarize learn less. & (1) & (2) & 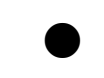 & (4) & (5) & (6) \\
\hline 11. Plagiarism threatens the reputation of the university. & & (2) & (3) & (4) & (5) & (6) \\
\hline
\end{tabular}




\section{Victor's responses}

\begin{tabular}{|c|c|c|c|c|c|c|}
\hline Statements & $\begin{array}{l}\text { Strongly } \\
\text { agree }\end{array}$ & Agree & $\begin{array}{c}\text { Slightly } \\
\text { agree }\end{array}$ & $\begin{array}{l}\text { Slightly } \\
\text { disagree }\end{array}$ & Disagree & $\begin{array}{l}\text { Strongly } \\
\text { disagree }\end{array}$ \\
\hline $\begin{array}{l}\text { 2. It is no big deal if you submit slightly modified work as your own } \\
\text { without proper citation. }\end{array}$ & (1) & (2) & (3) & (4) & (5) & \\
\hline 32. Plagiarism is academically wrong. & & (2) & (3) & (4) & (5) & (6) \\
\hline $\begin{array}{l}\text { 7. Heavily depending on an original source for ideas without citation is no } \\
\text { big deal if you use few or no words from that source. }\end{array}$ & (1) & (2) & (3) & (4) & (5) & \\
\hline 31. Plagiarism helps students do well in later life. & (1) & (2) & (3) & (4) & (5) & \\
\hline 19. It is fine to submit the same assignment to more than one class. & (1) & (2) & (3) & (4) & (5) & \\
\hline $\begin{array}{l}\text { 26. Submitting exactly copied work as your own without appropriate } \\
\text { acknowledgement is not a serious problem. }\end{array}$ & (1) & (2) & (3) & (4) & (5) & \\
\hline $\begin{array}{l}\text { 13. In an assignment, it is fine to include some texts if you delete some } \\
\text { words, alter grammatical structures, or substitute synonyms. }\end{array}$ & (1) & (2) & (3) & (4) & (5) & \\
\hline $\begin{array}{l}\text { 34. It is not a serious problem if you acknowledge the original sources } \\
\text { insufficiently. }\end{array}$ & (1) & (2) & (3) & (4) & (5) & \\
\hline 29. Students plagiarize because they want to pass courses. & (1) & (2) & (3) & O & (5) & \\
\hline 9. Students plagiarize because of pressure to succeed. & & (2) & (3) & (4) & (5) & \\
\hline $\begin{array}{l}\text { 36. Students plagiarize when they are under academic workload } \\
\text { pressure. }\end{array}$ & (1) & (2) & $=$ & (4) & (5) & \\
\hline 12. Students plagiarize because they want high grades. & (1) & (2) & (3) & (4) & (5) & \\
\hline 25. Time constraints have no influence on student plagiarism. & (1) & (2) & (3) & (4) & (5) & \\
\hline $\begin{array}{l}\text { 3. Students' poor understanding of citation and referencing conventions } \\
\text { leads them to plagiarize. }\end{array}$ & & (2) & (3) & (4) & (5) & \\
\hline $\begin{array}{l}\text { 18. Students' poor understanding of how to write academically leads to } \\
\text { plagiarism. }\end{array}$ & & (2) & (3) & (4) & (5) & (6) \\
\hline 14. Students plagiarize because they can't tell what is or isn't plagiarism. & (1) & (2) & (3) & (4) & (5) & \\
\hline 5. Plagiarism is more common in the work of beginner writers. & (1) & (2) & 0 & (4) & (5) & (6) \\
\hline 23. Plagiarism happens when students are learning to write. & (1) & (2) & ( & (4) & (5) & (6) \\
\hline 27. Academically weak students are more likely to plagiarize. & (1) & (2) & (3) & (4) & (5) & \\
\hline 10. Students don't plagiarize when assignments are interesting. & (1) & (2) & (3) & (4) & (5) & \\
\hline 28. Students don't plagiarize when assignments are personalized. & (1) & (2) & (3) & (4) & (5) & \\
\hline 15. Students don't plagiarize when there is a high chance of being caught. & (1) & (2) & (3) & (4) & (5) & \\
\hline 17. Plagiarism is deceitful. & & (2) & (3) & (4) & (5) & (6) \\
\hline 22. Plagiarism is stealing. & & (2) & (3) & (4) & (5) & (6) \\
\hline 1. Plagiarism damages the meaning of a degree. & & (2) & (3) & (4) & (5) & \\
\hline 20. A good person doesn't plagiarize. & (1) & (2) & (3) & 0 & (5) & (6) \\
\hline 30. Plagiarism worsens teacher-student relationships. & & (2) & (3) & (4) & (5) & \\
\hline 6. Students who plagiarize learn less. & (1) & (2) & 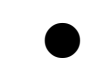 & (4) & (5) & (6) \\
\hline 11. Plagiarism threatens the reputation of the university. & & (2) & (3) & (4) & (5) & 6 \\
\hline
\end{tabular}




\section{Appendix C: Sample Interview Questions}

\section{The first Interview}

\section{English version}

\section{Educational background}

- Tell me about your tertiary education?

- What are you studying at VUW? Why did you choose this field of study/university?

\section{Personal information}

- Can you tell me about your family?

- How would you describe yourself?

- Tell me about your reading interests?

- What was your job before your doctoral studies?

\section{Academic writing and literature}

- How did you learn about academic writing?

- What do you think are the purposes of an academic literature?

\section{Scholarly experiences}

- Can you tell me about your research experiences?

- Can you tell me about your academic experiences?

\section{Prior learning about plagiarism}

- When did you first hear about plagiarism?

- How did you feel about plagiarism as an undergraduate? Why?

- How did your teachers or universities teach you about plagiarism?

\section{Vietnamese version}

\section{Nền tảng giáo dục}

- Hãy cho tôi biết về việc học đại học của bạn.

- Bạn đang học gì ở VUW? Tại sao bạn chọn ngành học/ trường học này?

\section{Thông tin cá nhân}

- Hãy cho tôi biết về gia đình bạn?

- Bạn tự mô tả mình như thế nào?

- Hãy cho tôi biết về sở thích đọc của bạn.

- Công việc của bạn trước khi học nghiên cứu sinh là gì?

Viết học thuật và phần lịch sử vấn đề

- Bạn đã học viết học thuật như thế nào?

- Bạn nghĩ mục đích phần lịch sử vấn đề là gì?

\section{Kinh nghiệm học thuật}

- Hãy cho tôi biết về kinh nghiệm nghiên cứu của bạn?

- Hãy tôi biết về kinh nghiệm học thuật của bạn?

\section{Việc học về đạo văn trước đây}

- Lần đầu bạn nghe về đạo văn là khi nào?

- Khi học đại học, bạn cảm thấy thế nào về đạo văn? Tại sao?

- Giáo viên hoặc trường của bạn dạy bạn về đạo văn như thế nào? 


\section{The second Interview}

\section{English version}

\section{Student academic identity?}

- What do you think about yourself as a - Bạn nghĩ thế nào về bản thân mình là postgraduate student?

- What is it about doctoral studies that attracts you? Has that changed since you started?

- What/who motivated you to pursue a - Điều gì đã thúc đẩy bạn theo đuổi doctoral program?

- What do you feel is the most exciting about your doctoral study?

\section{Scenarios}

- Have a look at this scenario. As you read it, could you tell me your thoughts?

- Do you think this student plagiarised? Why do you think so?

- What is important in the situation? Why is the student behaving this way?

\section{Perspectives and understanding of plagiarism}

- As a doctoral student, how do you define plagiarism?

- What specific behaviours do you think are plagiarism? Why?

- What do you think about plagiarism?

- How would you describe plagiarists?

- What do you think about the responsibility of plagiarising students?

- What do you think is the responsibility of lecturers or university for student plagiarism?

\section{Vietnamese version}

\section{Bản sắc học thuật của sinh viên?} một nghiên cứu sinh?

- Việc học tiến sĩ thu hút bạn như thế nào? Điều đó có thay đổi khi bạn bắt đầu học không? chương trình sau đại học?

- Bạn cảm thấy điều gì thú vị nhất về việc học nghiên cứu sinh?

\section{Câu hỏi tình huống}

- Hãy xem xét tình huống này và cho tôi biết suy nghĩ của bạn.

- Bạn có nghĩ rằng sinh viên này đạo văn không? Tại sao?

- Điều gì là quan trọng trong tình huống này? Tại sao sinh viên này cư xử như thế?

\section{Quan điểm và hiểu biết về đạo văn}

- Là một nghiên cứu sinh, bạn định nghĩa đạo văn thế nào?

- Bạn nghĩ hành vi cụ thể nào là đạo văn? Tại sao?

- Bạn nghĩ gì về đạo văn?

- Bạn mô tả người đạo văn như thế nào?

- Bạn nghĩ gì về trách nhiệm của sinh viên đối với đạo văn?

- Trách nhiệm của giảng viên/ trường học đối với đạo văn của sinh viên là gì? 


\section{The third Interview}

\section{English version}

\section{Doctoral studies and plagiarism perceptions}

- How your understanding of plagiarism has changed since starting your PhD?

\section{Scenarios}

- Have another look at this scenario and think about it from a different perspective.

- Do you think this student plagiarised? How serious is the case is?

- Do you think this student should be punished? Why?

- What do you think the university can do to prevent student plagiarism of this type?

- What do you think may contribute to student plagiarism?

- Can you tell me why you think people care about plagiarism?

\section{Understandings of VUW's plagiarism policy}

- Can you tell me what you know about VUW policies about plagiarism?

- Why do you think plagiarism is prohibited at VUW?

- How do your supervisors help you avoid plagiarism?

\section{Vietnamese version}

\section{Việc học tiến sĩ và hiểu biết về đạo văn}

- Nhận thức và hiểu biết về đạo văn của bạn có thay đổi từ khi bắt đầu học tiến sĩ không?

\section{Các câu hỏi tình huống}

- Hãy xem xét tình huống này một lần nữa và cho tôi biết suy nghĩ của bạn.

- Bạn nghĩ sinh viên này có đạo văn không? Trường hợp này nghiêm trọng thế nào?

- Bạn có nghĩ sinh viên này nên bị phạt? Tại sao?

- Bạn nghĩ trường có thể làm gì để ngăn chặn hình thức đạo văn này?

- Bạn nghĩ sinh viên đạo văn vì lí do gì?

- Theo bạn nghĩ thì tại sao mọi người quan tâm đến đạo văn?

\section{Hiểu về chính sách đạo văn của VUW}

- Bạn biết gì về chính sách của VUW về đạo văn?

- Theo bạn thì tại sao đạo văn lại bị cấm trường này?

- Giáo viên hướng dẫn đã giúp bạn tránh đạo v như thế nào? 


\section{The fourth Interview}

\section{English version}

\section{Academic identity}

- Can you tell me how you connect with academics in your field?

- What academic groups are you part of? How is that working for you?

- Can you tell me about your academic publications, conference presentations, and research activities?

\section{Self-formation}

- Have you become more confident as a doctoral student? Why do you think so?

- How are you making progress on the goals you set in the first interview?

- Have your goals/ plans changed since that meeting?

- Have you experienced any challenges in your doctoral studies?

\section{Perceptions of plagiarism}

- As a doctoral student, how do you define plagiarism?

- What specific behaviours do you think are plagiarism? Why?

- What do you think about plagiarism?

- Why do you think students plagiarise?

\section{Vietnamese version}

\section{Bản sắc học thuật}

- Bạn kết nối với các học giả trong lĩnh vực của bạn như thế nào?

- Bạn có tham gia nhóm học tập nào không? Bạn đánh giá về các nhóm này thế nào?

- Hãy cho tôi biết về việc đăng báo, trình bày ở hội thảo, hoặc tham gia các dự án nghiên cứu của bạn?

\section{Quá trình tự hoàn thiện}

- Là nghiên cứu sinh, bạn có tự tin hơn không? Tại sao?

- Bạn đã hoàn thành được các mục tiêu bạn đặt ra trong buổi phỏng vấn đầu tiên chưa?

- Bạn có thay đổi mục tiêu kể từ buổi phỏng vấn đó không?

- Bạn có gặp khó khăn gì trong quá trình học không?

\section{Quan điểm và hiểu biết về đạo văn}

- Là nghiên cứu sinh, bạn định nghĩa đạo văn thế nào?

- Theo bạn những hành vi cụ thể nào là đạo văn? Tại sao?

- Bạn nghĩ gì về đạo văn?

- Theo bạn thì tại sao sinh viên đạo văn? 


\section{Appendix D: Scenarios \\ Scenarios (English Version)}

Scenario 1: Jane is in her first year at Auckland University. She is the first person from her family to study at university. She feels so proud but it's quite overwhelming too. She needs to write an essay for her PSYC class, but she finds it hard to get ideas about what to write. Sometimes she feels a bit unsure about what university work should look like. She finds several articles on the web which discuss the same issue. These are perfect - they are right on topic. It seems pretty clear that they will be useful for her assignment. The papers help her get ideas about some main points for her assignment, and also provide valuable research evidence. She writes the essay, inserting some pieces of text from those papers, to make the work better. She is careful to put it into her own words, deletes some words, alters grammar structures, and substitutes some synonyms. She hands in the assignment without including the papers in her reference list.

Scenario 2: Mark is in his second year at Massey. He is struggling to meet the deadline for his EDUC assignment. As usual he has several assignments for different courses, and of course his part-time work. He realises that the assignment requirements are similar to the one he submitted for the previous course. He is so glad to realise that he has already done work for this topic. To prepare for his current assignment, he takes the final draft of the old assignment, paraphrases the introduction, changes some quotations, substitutes synonyms here and there, and adds a new conclusion. He is very happy when he turns in the assignment - because he had already done all that work earlier, it really eased his workload - normally assignment prep is much more stressful.

Scenario 3: Susan is in her final year of her undergraduate degree in Linguistics. She is working on an assignment which is worth $40 \%$ of the total marks for the LING course. She did not get good marks for the previous Stage Three assignments - it has become really hard this year - it seems that what the lecturers are looking for is so much more than before. Having lots of arguments with her boyfriend lately hasn't helped either. While searching online, she finds a paper on the web that is very similar to her topic. She decides that it has lots of good ideas, so she uses it to prepare her assignment - she is so relieved that she has found some helpful material. She puts ideas from the internet paper in her own words, citing the same theorists and research. She carefully includes in-text citations and copies the reference list correctly, so that she is referencing the sources. 


\section{Scenarios (Vietnamese Version)}

Tinh huống 1: Phương đang học năm nhất tại Đại học Khoa Học Xã Hội và Nhân Văn Thành Phố Hồ Chí Minh. Cô là người đầu tiên từ gia đình học đại học. Phương cảm thấy tự hào về điều đó, nhưng cũng khá áp lực. Cô cần phải viết một bài luận cho môn Tâm Lý, nhưng cảm thấy khó để có được ý tưởng để viết. Đôi khi cô không hiểu rõ yêu cầu của trường. Cô tìm thấy một số bài viết trên mạng về cùng vấn đề. Thật tuyệt - những bài này đúng về chủ đề, chắc chắn sẽ có ích cho bài tập của cô. Chúng giúp cô có ý tưởng cho bài tập của mình và cung cấp những dẫn chứng nghiên cứu có giá trị. Cô bắt đầu viết bài luận, chèn một số đoạn văn từ những bài báo đó để giúp bài làm của mình tốt hơn. Cô cẩn thận dùng từ ngữ của chính mình để diễn đạt: cô xóa một số từ, thay đổi cấu trúc ngữ pháp, và thay thế một số từ đồng nghĩa. Cô nộp bài luận mà không hề đề cập tới các bài báo trên trong danh sách tham khảo của mình.

Tinh huống 2: Nam đang học năm hai tại Đại học Sư phạm Đại học Hồ Chí Minh. Cậu đang cố gắng để hoàn thành bài tập Giáo Dục Học đúng hạn. Như mọi khi, Nam có nhiều bài tập cho các môn học khác, và tất nhiên là vẫn tiếp tục công việc bán thời gian. Nam nhận ra rằng các yêu cầu của bài tập này tương tự yêu cầu của một bài tập mà cậu đã nộp cho khóa học trước đó. Cậu rất mừng khi biết rằng mình đã từng viết về chủ đề này. Để chuẩn bị bài tập hiện tại, Nam lấy bản nháp sau cùng của bài tập trước, diễn giải lại phần giới thiệu, thay đổi một số trích dẫn, thay thế một số từ đồng nghĩa ở vài nơi, và thêm một kết luận mới. Nam rất vui khi nộp bài tập này - vì cậu đã làm tất cả mọi thứ trước đó, nó thực sự làm giảm khối lượng công việc của Nam - thường thì phần chuẩn bị bài tập căng thẳng hơn nhiều.

Tinh huống 3: Trang đang học năm cuối đại học ngành Ngôn ngữ học. Cô đang làm một bài tập chiếm 40\% tổng số điểm cho khóa học này. Cô đã không được điểm tốt cho học kì trước - năm nay đã trở nên thực sự khó khăn - có vẻ như yêu cầu của giảng viên cao hơn trước rất nhiều. Cô cũng đang có nhiều cuộc cãi vã với bạn trai, làm cho mọi việc trở nên tồi tệ hơn. Trong khi tìm kiếm tài liệu trên mạng, cô tìm được một bài báo giống chủ đề của mình. Tin rằng bài này có nhiều ý tưởng hay, Trang sử dụng nó để chuẩn bị bài tập của mình - cô cảm thấy nhẹ nhõm vì tìm được tài liệu hữu ích. Cô viết lại ý tưởng từ bài báo bằng lời lẽ của mình, trích dẫn cùng một số lý thuyết và dẫn chứng. Cô cẩn thận thêm một đoạn trích dẫn trong bài và sao chép chính xác danh sách tài liệu tham khảo từ bài báo đó để không thiếu phần tài liệu tham khảo. 


\section{Appendix E: Ethics Approval Documents}

vicroan unversirt or

WELLINGTON

TE HERENGA WAKA

\begin{tabular}{l|l}
\hline TO & Minh Tran \\
\hline FROM & Associate Professor Judith Loveridge, Convenor, Human Ethics Committee \\
\hline
\end{tabular}

\begin{tabular}{l|l}
\hline DATE & 25 October 2017 \\
\hline PAGES & 1 \\
\hline
\end{tabular}

\begin{tabular}{l|l}
\hline SUBJECT & Ethics Approval \\
& Number: 25144 \\
& Title: Student perceptions of plagiarism - A pilot survey \\
\hline
\end{tabular}

Thank you for your application for ethical approval, which has now been considered by the Human Ethics Committee.

Your application has been approved from the above date and this approval is valid for three years. If your data collection is not completed by this date you should apply to the Human Ethics Committee for an extension to this approval.

Best wishes with the research.

Kind regards,

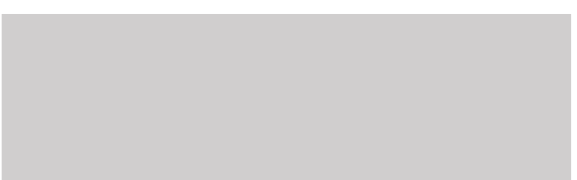

Judith Loveridge

Convenor, Victoria University of Wellington Human Ethics Committee 


\begin{tabular}{l|l}
\hline TO & Minh Tran \\
\hline FROM & Associate Professor Judith Loveridge, Convenor, Human Ethics Committee \\
\hline
\end{tabular}

\begin{tabular}{l|l}
\hline DATE & 16 March 2018 \\
\hline PAGES & 1 \\
\hline
\end{tabular}

\begin{tabular}{l|l}
\hline SUBJECT & Ethics Approval \\
& Number: 25145 \\
& Title: Student perceptions of plagiarism - A study of Vietnam-educated \\
& and New Zealand-educated postgraduate students - Quantitative phase \\
\hline
\end{tabular}

Thank you for your application to amend/extend your ethics approval, this has now been considered and the request granted.

In the case of an amendment, this approval is valid until the end date of your original ethics approval; in the case of an extension, this approval applies until the new end date that you have nominated. If your data collection is not completed by this date you should apply to the Human Ethics Committee for an extension to this approval.

Best wishes with the research.

Kind regards,

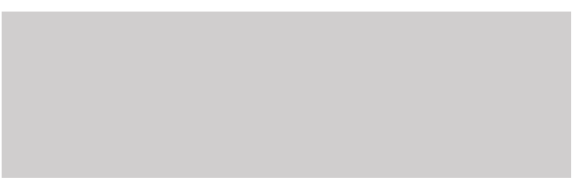

Judith Loveridge

Convenor, Victoria University of Wellington Human Ethics Committee 


\begin{tabular}{l|l}
\hline TO & Minh Tran \\
\hline FROM & Associate Professor Judith Loveridge, Convenor, Human Ethics Committee \\
\hline & \\
\hline DATE & 7 May 2019 \\
\hline PAGES & 1 \\
\hline
\end{tabular}

\begin{tabular}{l|l}
\hline SUBJECT & Ethics Approval \\
& Number: 25464
\end{tabular}

Title: Student perceptions of plagiarism - A study of Vietnam-educated and New Zealand-educated postgraduate students - Qualitative phase

Thank you for your application to amend/extend your ethics approval, this has now been considered and the request granted.

In the case of an amendment, this approval is valid until the end date of your original ethics approval; in the case of an extension, this approval applies until the new end date that you have nominated. If your data collection is not completed by this date you should apply to the Human Ethics Committee for an extension to this approval.

Best wishes with the research.

Kind regards,

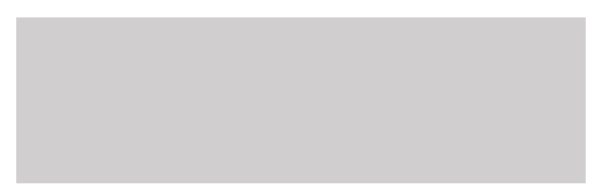

Judith Loveridge

Convenor, Victoria University of Wellington Human Ethics Committee 


\section{Appendix F: Information sheet \\ Information Sheet (English Version)}

TE WHARE WĀNANGA O TE ÜPOKO O TE IKA A MĀUI

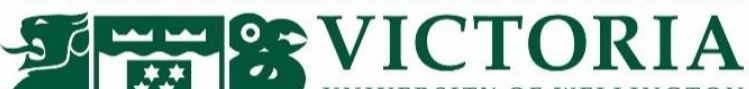

* * UNiversity of Wellington

\section{Student Perceptions of Plagiarism - A Study of Vietnam- and New Zealand-educated Postgraduate Students}

\section{INFORMATION SHEET FOR INTERVIEW PARTICIPANTS}

You are invited to take part in this research. Please read this information before deciding whether or not to take part. If you decide to participate, thank you. If you decide not to take part, thank you for considering my request.

\section{Who am I?}

I am Tran Ngoc Minh and I am a PhD student in the Faculty of Education at Victoria University of Wellington. This research project is work towards my thesis.

What is the aim of the project?

The primary aim of the study is to explore your perceptions of plagiarism. This research has been approved by the Victoria University of Wellington Human Ethics Committee (reference number: 0000025464).

\section{How can you help?}

If you agree to take part, I will interview you four times over a six-month period. The interviews will be at the time and place that is convenient for you.

Each interview will take about one hour. I will audio record the interviews with your permission and transcribe them later. You can choose to not answer any question or stop the interview at any time, without giving a reason. You can withdraw from the study by contacting me at any time. If you withdraw, the information you provided will be destroyed. Withdrawal will be possible up until a week after the final interview.

\section{What will happen to the information you give?}

This research is confidential. This means that the researchers named below will be aware of your identity, but the research data will be combined, and your identity will not be revealed in any reports, presentations, or public documentation. 
Only my supervisors and I will read the notes or transcripts of the interviews. The interview transcripts, summaries, and any recordings will be kept securely and destroyed seven years after the completion of the thesis.

\section{What will the project produce?}

The information from my research will be used in my PhD thesis, academic publications, or presented to conferences.

\section{If you accept this invitation, what are your rights as a research participant?}

You do not have to accept this invitation if you don't want to. If you do decide to participate, you have the right to:

- choose not to answer any question;

- ask for the recorder to be turned off at any time during the interviews;

- withdraw from the study at any time, and inform the researcher via email;

- ask any questions about the study at any time;

- receive a copy of your interview transcript;

- agree on another name for me to use rather than your real name;

- read over and comment on a written summary of your interviews;

- be able to read any reports of this research by emailing the researcher to request a copy.

\section{If you have any questions or problems, who can you contact?}

If you have any questions, either now or in the future, please feel free to contact either:

$\begin{array}{lll}\text { PhD Student } & \text { Primary supervisor } & \text { Secondary supervisor } \\ \text { Tran Ngoc Minh } & \text { AProf Stephen Marshall } & \text { Dr Linda Hogg } \\ \text { School of Education } & \text { Centre for Academic Development } & \text { School of Education } \\ \text { Email: } & \text { Email: } & \text { Email: } \\ \text { Phone: } & \text { Phone: } & \text { Phone: }\end{array}$

\section{Human Ethics Committee information}

The research has been approved by Victoria University Human Ethics Committee. If you have any ethical concerns about the research, you may contact Dr Judith Loveridge. Email or telephone 


\title{
Information Sheet (Vietnamese Version)
}

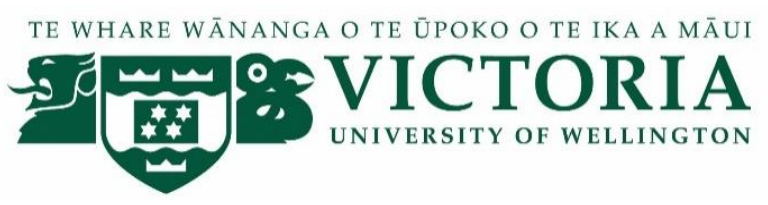

\begin{abstract}
Nhận thức của sinh viên về đạo văn - Một nghiên cứu với sinh viên sau đại học từng được đào tạo ở Việt Nam và sinh viên sau đại học từng được đào tạo ở New Zealand
\end{abstract}

\section{BẢN THÔNG TIN CHO NGƯỜI THAM GIA PHỎNG VẤN}

Bạn được mời tham gia vào nghiên cứu này. Vui lòng đọc thông tin này trước khi quyết định tham gia hay không. Nếu bạn quyết định tham gia, xin cảm ơn bạn. Nếu bạn quyết định không tham gia, cảm ơn bạn đã xem xét lời mời của tôi.

Tôi là ai?

Tôi là Trần Ngọc Minh, nghiên cứu sinh khoa Giáo dục Đại học Victoria, thành phố Wellington. Đây là nghiên cứu sẽ được sử dụng cho luận văn của tôi.

\section{Mục đích của nghiên cứu là gì?}

Mục tiêu chính của nghiên cứu là để khảo sát nhận thức của bạn về đạo văn. Nghiên cứu này đã được Hội đồng đạo đức trong nghiên cứu con người, Đại học Victoria, thành phố Wellington chấp nhận (số tham chiếu: 0000025464).

\section{Bạn có thể giúp như thế nào?}

Nếu bạn đồng ý tham gia, tôi sẽ phỏng vấn bạn bốn lần trong thời gian 6 tháng. Các buổi phỏng vấn sẽ được thực hiện vào thời gian và tại địa điểm thuận tiện cho bạn.

Mỗi buổi phỏng vấn sẽ kéo dài khoảng một giờ. Tôi sẽ thu âm các buổi phỏng vấn với sự cho phép của bạn và ghi chép lại sau. Bạn có thể không trả lời câu hỏi hoặc dừng buổi phỏng vấn bất cứ lúc nào, mà không cần lý do. Bạn có thể ngừng tham gia, tiếp tục tham gia, hoặc rút khỏi nghiên cứu bằng cách liên hệ với tôi. Nếu bạn rút khỏi nghiên cứu, thông tin bạn cung cấp sẽ bị hủy. Việc rút khỏi nghiên cứu có thể kéo dài một tuần sau buổi phỏng vấn cuối cùng.

\section{Thông tin bạn cung cấp sẽ được xử lý như thế nào?}

Nghiên cứu này mang tính bí mật. Nghĩa là những người nghiên cứu kể tên bên dưới sẽ biết thông tin nhận dạng của bạn nhưng dữ liệu nghiên cứu sẽ được tổng hợp và thông tin nhận dạng của bạn sẽ không được tiết lộ trong bất kỳ báo cáo hay tài liệu được công bố nào.

Chỉ có các giáo viên hướng dẫn của tôi và tôi đọc được các ghi chú hoặc bản ghi chép lại của các buổi phỏng vấn. Các bản chép ghi lại, bản tóm tắt, và bản thu âm sẽ được giữ an toàn và tiêu hủy bảy năm sau khi hoàn thành luận văn. 


\section{Nghiên cứu này sẽ tạo ra sản phẩm gì?}

Thông tin từ nghiên cứu này sẽ được sử dụng trong luận án tiến sĩ của tôi, các ấn bản học thuật, hoặc được trình bày ở các hội nghị.

Nếu bạn chấp nhận lời mời, quyền của bạn là gì?

Bạn không phải chấp nhận lời mời này nếu bạn không muốn. Nếu bạn quyết định tham gia, bạn có quyền:

- chọn không trả lời bất kỳ câu hỏi nào;

- đề nghị tắt thiết bị ghi âm bất kỳ lúc nào trong các buổi phỏng vấn;

- rút khỏi nghiên cứu bất kỳ lúc nào, và thông báo cho tôi qua email;

- hỏi bất kỳ câu hỏi nào về nghiên cứu bất kỳ lúc nào;

- nhận một bản ghi chép lại của bản thu âm các buổi phỏng vấn;

- sử dụng một tên gọi khác thay cho tên thật;

- đọc và nhận xét bản tóm tắt buổi phỏng vấn của bạn;

- có thể đọc bất kỳ báo cáo nào của nghiên cứu này bằng cách gửi email cho tôi.

Nếu bạn có thắc mắc, bạn có thể liên lạc với ai?

Nếu bạn có thắc mắc gì, bây giờ hoặc sau này, vui lòng liên hệ một trong các cá nhân sau:

$\begin{array}{lll}\text { Nghiên cứu sinh } & \text { Giáo viên hướng dẫn chính } & \text { Giáo viên hướng dẫn phụ } \\ \text { Trần Ngọc Minh } & \text { PGS Stephen Marshall } & \text { TS Linda Hogg } \\ \text { Trường Giáo Dục } & \text { Trung Tâm Phát Triển Học Thuật } & \text { Trường Giáo Dục } \\ \text { Email: } & \text { Email: } & \text { Email: } \\ \text { Điện thoại: } & \text { Điện thoại: } & \text { Điện thoại: }\end{array}$

\section{Thông tin về Hội đồng đạo đức trong nghiên cứu con người}

Nếu bạn bận tâm về các vấn đề đạo đức của nghiên cứu, bạn có thể liên hệ Chủ tịch Hội đồng đạo đức trong nghiên cứu con người của Đại học Victoria - Wellington: TS Judith Loveridge. Email hoặc điện thoại 


\section{Appendix G: Consent Form \\ Consent Form (English Version)}

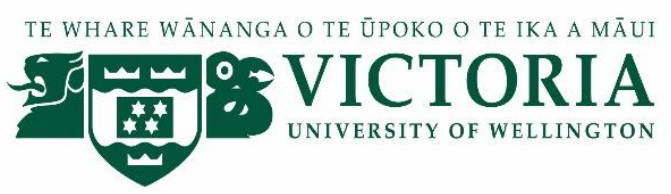

\section{Student Perceptions of Plagiarism - A Study of Vietnam- and New Zealand-Educated Postgraduate Students \\ CONSENT FOR INTERVIEW PARTICIPANTS}

This consent form will be held for seven years.

Researcher: Tran Ngoc Minh, Faculty of Education, Victoria University of Wellington.

I have read the Information Sheet and the project has been explained to me. My questions have been answered to my satisfaction. I understand that I can ask further questions at any time.

I understand that:

- I may choose not to answer any questions for any reasons.

- I may withdraw from this study at any point, and if I withdraw any information that I have provided will be destroyed. Withdrawal will be possible up until a week after the final interview.

- The identifiable information I have provided will be destroyed seven years after the thesis is completed.

- I understand that the results will be used for a PhD thesis, academic publications, and presented to conferences.

- My name and any information that would identify me will be kept confidential by the researcher and the supervisors.

I agree to take part in four audio recorded interviews over a six-month period.

I would like a copy of the transcript of my interviews: $\quad$ Yes $\square$ No

I would like to receive a copy of the thesis and have $\quad$ Yes $\square$ No added my email address below.

Signature of participant:

Name of participant:

Email:

Date: 


\section{Consent Form (Vietnamese Version)}

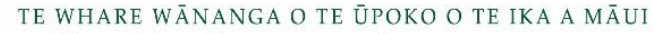 Sig \\ Nhận thức của sinh viên về đạo văn - Một nghiên cứu với sinh viên sau đại học từng được đào tạo ở Việt Nam và sinh viên sau đại học từng được đào tạo ở New Zealand ĐƠN ĐỒNG Ý THAM GIA PHỎNG VẤN}

Đơn đồng ý này sẽ được lưu trong bảy năm.

Người nghiên cứu: Trần Ngọc Minh, Khoa Giáo dục, Đại học Victoria, thành phố Wellington.

- Tôi đã đọc bản thông tin và đã được giải thích về nghiên cứu này. Các thắc mắc của tôi đã được giải đáp thỏa đáng. Tôi hiểu rằng tôi có thể đặt câu hỏi thêm vào bất kỳ lúc nào.

Tôi hiểu rằng:

- Tôi có thể chọn không trả lời bất kỳ câu hỏi nào;

- Tôi có thể rút khỏi nghiên cứu bất kỳ lúc nào, và nếu rút khỏi nghiên cứu, thông tin mà tôi cung cấp sẽ được hủy. Việc rút khỏi nghiên cứu sẽ có thể kéo dài một tuần sau buổi phỏng vấn cuối cùng.

- Những thông tin tôi cung cấp mà có thể nhận diện tôi sẽ bị hủy bảy năm sau khi luận văn hoàn thành.

- Tôi hiểu rằng kết quả sẽ được sử dụng cho một luận văn tiến sĩ, các ấn bản học thuật, hoặc được trình bày ở các hội nghị.

- Tên tôi, cũng như bất kỳ thông tin nào có thể nhận diện tôi sẽ được bảo mật bởi người nghiên cứu và các giáo viên hướng dẫn.

- Tôi đồng ý tham gia bốn buổi phỏng vấn được ghi âm trong khoảng thời gian 6 tháng.

Tôi muốn nhận bản ghi chép lại các buổi phỏng vấn của tôi:

Có $\square$ Không $\square$

Tôi muốn nhận bản báo cáo hoàn chỉnh và đã để lại địa chỉ email dưới đây. Có $\square$ Không

Chữ kí:

Tên:

Email:

Ngày:

\section{Appendix H: Interview Protocol}




\section{Student Perceptions of Plagiarism - A Study of Vietnam- and New Zealand-Educated Postgraduate Students INTERVIEW PROTOCOL}

Time of interview:

Date:

Place:

Interviewer:

Interviewee:

The interviews will be conducted in Vietnamese with Vietnamese participants and English with New Zealand participants.

Before the interview: Email topics and confirm the time and place of interview

\section{At the start of the interview:}

- Saying thank you for the interviewee's coming.

- Telling him/her about

(a) the purposes of the interview

(b) the sources of data being collected

(c) what will be done to protect the confidentiality of the interviewee

(d) how long the interview will take

(e) their rights during the interview

(f) they will be given the space to develop their ideas fully

(g) there are no right or wrong ideas

- Having the interviewee read and sign the consent form.

- Remind them not to disclose specific incidents of misconduct they have committed.

- Ask the interviewee to choose a pseudonym. 
After the interview: Thank the participants for their cooperation and participation. Give them the koha (a $\$ 20$ voucher). Assure them of the confidentiality of the responses and plan the next interviews.

\section{Interview plan}

The study involved a series of four interviews. Each interview included opening questions about students' current studies, scenario questions, and follow-up questions. Scenarios were used to contextualize follow-up questions about plagiarism. (See Appendices C and D). The first interview was to get to know students' personal and educational background, their writing process, and their views on academic literature. Students were also asked about their prior learning about plagiarism. This interview aimed at establishing mutual trust before moving to questions about student perceptions of plagiarism. In the second interview, students were inquired about their perspectives of plagiarism. In the third interview, they were asked to give more information about their perspectives of plagiarism and understanding of university policies about the issue. In the last interview, carried out six months after the third interview, issued discussed in the previous interviews were revisited to explore any changes in students' perceptions. This interview also focused on students' self-formation and their identity cóntruction to understand how these factors affected their plagiarism perceptions. 
Appendix I: Sample Codes and Definitions

\begin{tabular}{ll}
\hline Codes & Definitions \\
\hline Framing of P as PG stus & Student views of plagiarism as master's and honour students \\
\hline Framing of P as UG stus & Student views of plagiarism as undergraduates \\
\hline P-forms & Behaviours that might be considered plagiarism \\
\hline P-conceptualisation & How students define plagiarism as PhD students \\
\hline P-justifiable & Why students think plagiarism is justifiable \\
\hline P-not justifiable & Moral aspects of plagiarism e.g., stealing, dishonesty, deception \\
\hline P-punishments & Why students think plagiarism can't be justified \\
\hline P-reasons & Different forms of punishment for student plagiarism \\
\hline P-regulatory issue & Reasons for student plagiarism \\
\hline P-prior learning & Plagiarism is against the institution's regulations \\
\hline P-Vuw policy & Students learning about plagiarism before doctoral studies \\
\hline
\end{tabular}

